\title{
Representação de Construtores Semânticos em SIRIUS e Suporte através de um Editor de Esquemas
}

\section{Myrian Renata Barros Araujo}

\author{
Orientador \\ Prof. Dr. Caetano Traina Júnior
}

Dissertação apresentada ao Instituto de Ciências Matemáticas e de Computação - USP, como parte dos requisitos para a obtenção do título de mestre em ciências - Área: Ciências de Computação e Matemática Computacional 
"Por mais que na batalha se vença um ou mais inimigos, a vitória sobre si mesmo é a maior de todas as vitórias"

\author{
Buda
}




\section{vedicatória}

A Fábio com

muito amor 


\section{Agradecimentos}

Ao Prof. Dr. Caetano Traina Júnior, pela orientação sempre segura e principalmente pela amizade, dedicação e incentivo durante a execução deste trabalho, propiciando-me um grande crescimento pessoal e profissional

Ao meu querido, amigo e marido Fábio, pelo carinho, amor e compreensão que sempre me dedicou. Não medindo esforços para me apoiar em todos os momentos

À minha mãe Myrian, à titia Ismára e ao meu querido vovozinho Ismael, pelo incentivo e amor que sempre me deram. À amiga Gigi, pelos longos "papos" que me ajudaram a crescer muito

A todos os professores que contribuiram para a minha formação. Em especial as professoras Agma Juci Machado Traina e Solange Oliveira Rezende e o professor Mauro Biajiz

A todos os amigos do Grupo de Banco de Dados e Imagens, que de maneira direta ou indireta contribuiram para a realização deste trabalho

Às secretárias da Pós-Graduação, às funcionárias da Biblioteca e a Seção de Áudio e Vídeo pela forma prestativa e educada que semrpe me atenderam

Ao $\mathrm{CNPq}$, pelo apoio financeiro prestado 


\section{Sumário}

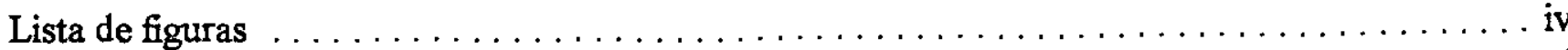

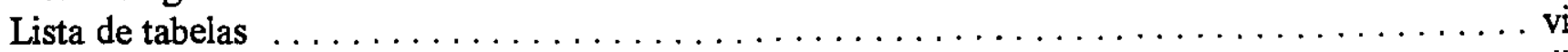

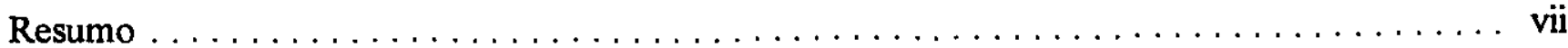

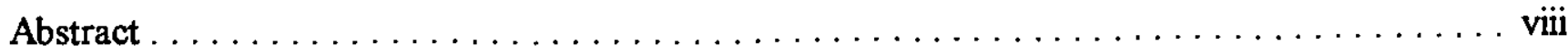

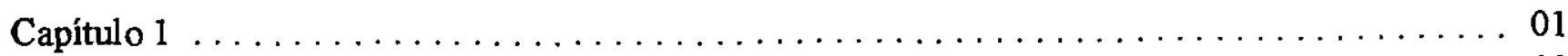

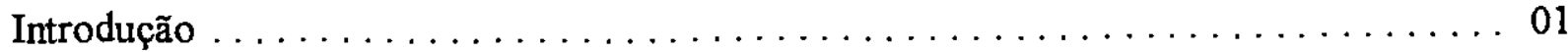

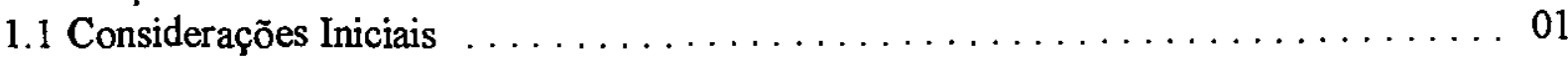

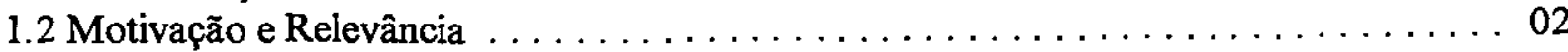

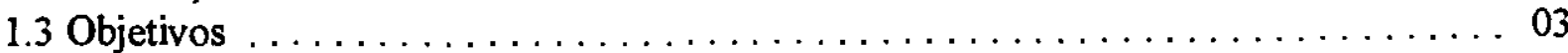

1.4 Organização da Dissertação . . . . . . . . . . . . . . . . . . . 04

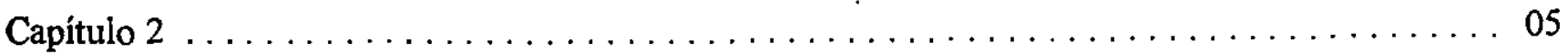

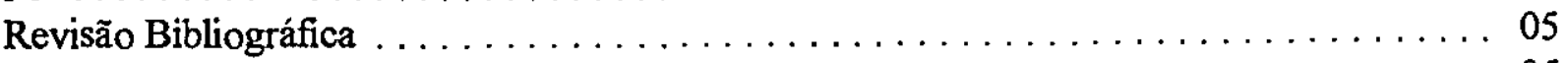

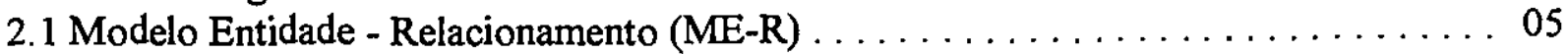

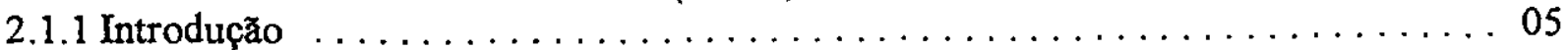

2.1.2 Descrição dos Principais Elementos do Modelo ................. 06

2.1.3 Resumo Notacional . . . . . . . . . . . . . . . . . . . . . . . . 08

2.1.4 Aplicação Prática ..................................... 09

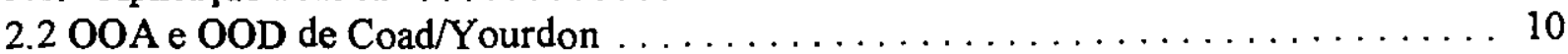

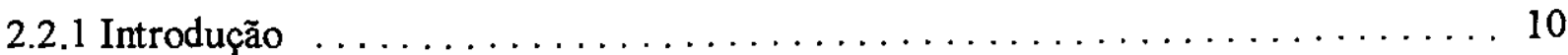

2.2 .2 Estrutura do Modelo . . . . . . . . . . . . . . . . . . . . . 11

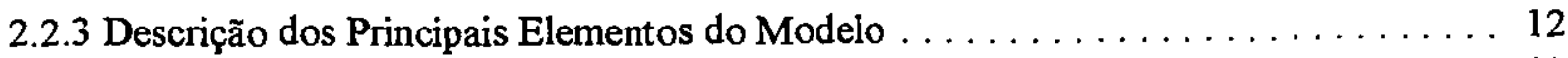

2.2.4 Resumo Notacional . . . . . . . . . . . . . . . . . . . . . . . . . . 13

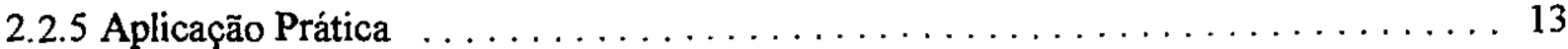

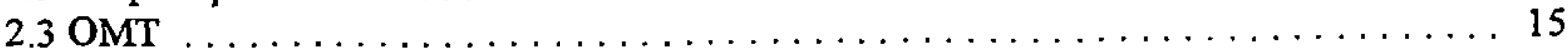

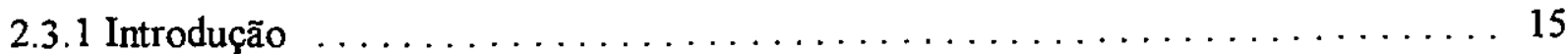

2.3.2 Estrutura do Modelo . . . . . . . . . . . . . . . . . . . . . 15

2.3.3 Descrição dos Principais Elementos do Modelo . . . . . . . . . . . . 16

2.3.4 Resumo Notacional . . . . . . . . . . . . . . . . . . . . . . . . . . . . . 19

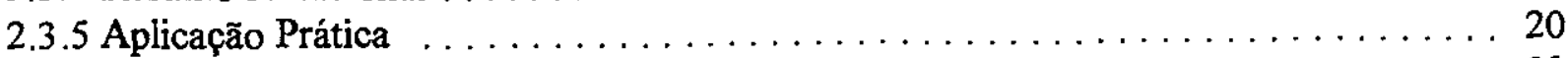

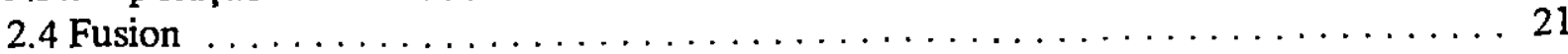

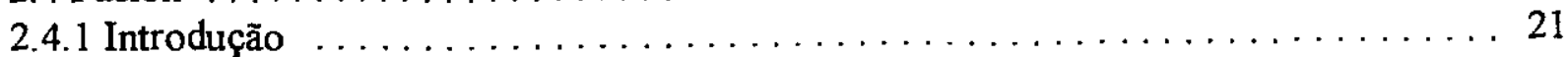

2.4.2 Estrutura do Modelo . . . . . . . . . . . . . . . . . . . . . 21,

2.4.3 Descrição dos Principais Elementos do Modelo . . . . . . . . . . . . 22 
2.4.4 Resumo Notacional . . . . . . . . . . . . . . . . . . . . . . . . . 24

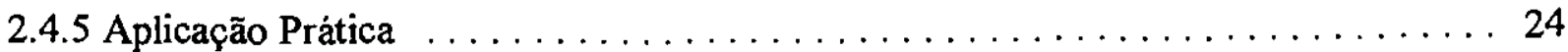

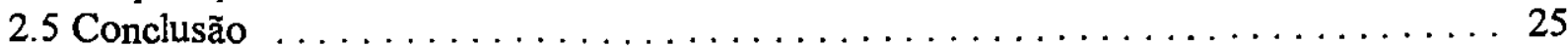

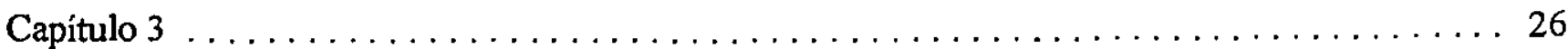

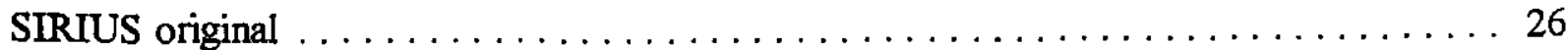

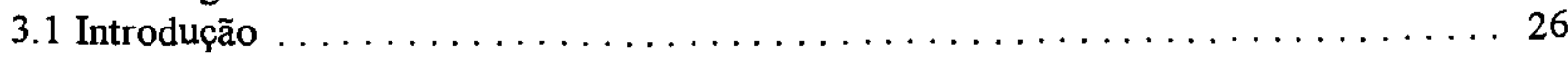

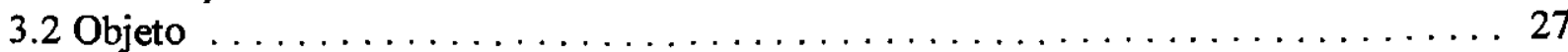

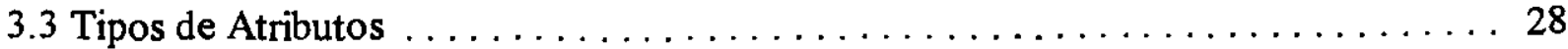

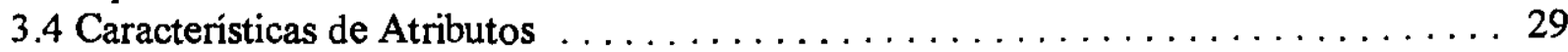

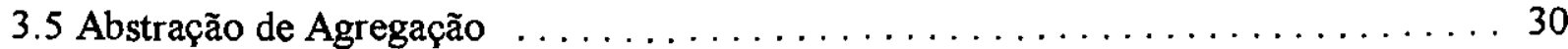

3.6 Abstração de Classificação . . . . . . . . . . . . . . . . . . . . . . . . 35

3.7 Abstração de Generalização . . . . . . . . . . . . . . . . . . . . . . . 39

3.8 Abstração de Composição . . . . . . . . . . . . . . . . . . . . . . 41

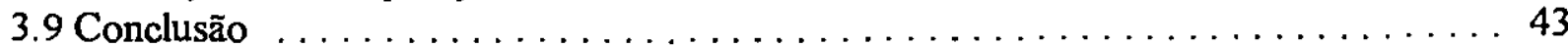

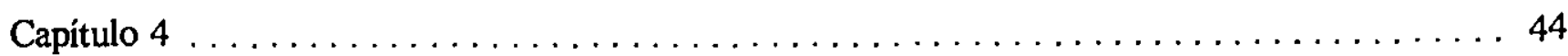

Comparação Entre os Elementos Básicos e Abstrações dos Modelos . . . . . . . . . . . 44

4.1 Introdução . . . . . . . . . . . . . . . . . . . . . . . . . . . . 44

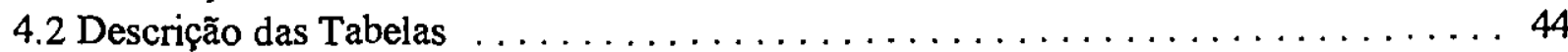

4.2.1 Entidade/Objeto e Conjunto/Classe . . . . . . . . . . . . . . . . . . 44

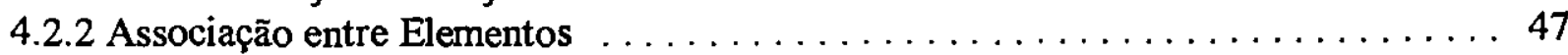

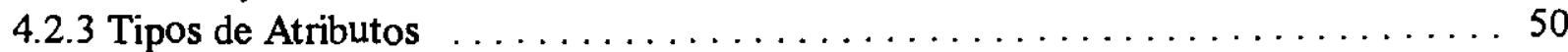

4.2.4 Cardinalidade/Multiplicidade . . . . . . . . . . . . . . . . . . . . 55

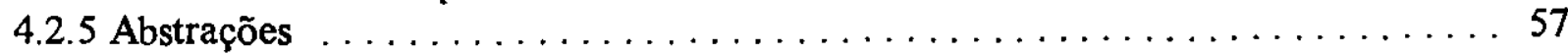

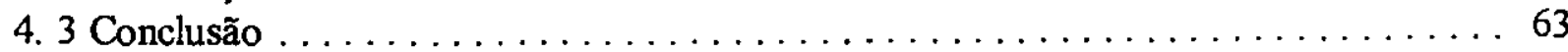

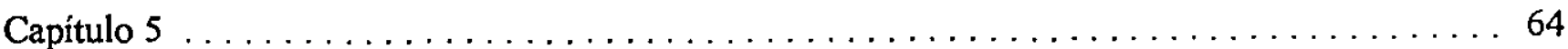

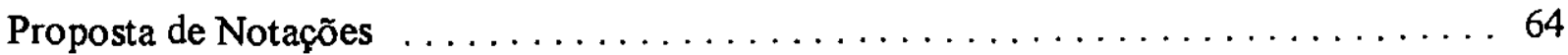

5.1 Representação de Atributos de Classificação e Atributos Inst . . . . . . . . . . 64

5.2 Características de Atributos . . . . . . . . . . . . . . . . . . . . . 72

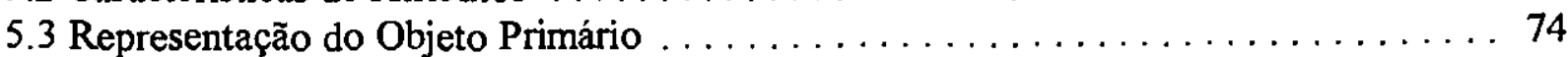

5.4 Representação dos Atributos Multivalorados .................... 75

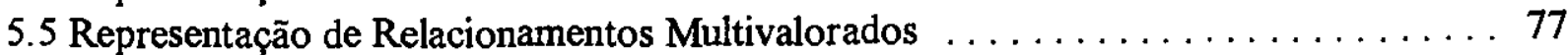

5.6 Representação da Abstração de Generalização . . . . . . . . . . . . . . . 81

5.7 Representação da Abstração de Composição . . . . . . . . . . . . . . . . 84

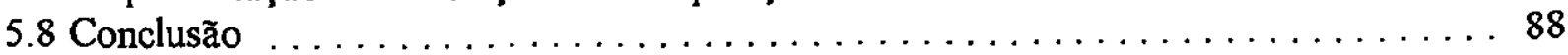

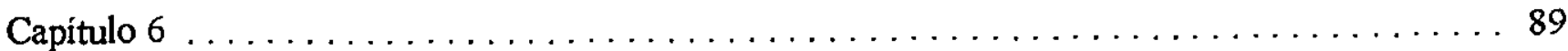

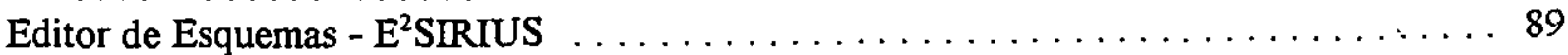

6.1 Descrição dos Principais Formulário $\ldots \ldots \ldots \ldots \ldots \ldots \ldots \ldots \ldots \ldots$

6.1 .1 Formulário Objeto . . . . . . . . . . . . . . . . . . . . . . . . . . . 90

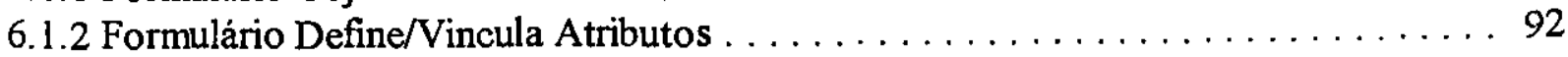


6.1.3 Remove Atributo . . . . . . . . . . . . . . . . . . . . . . . . . . . . 92

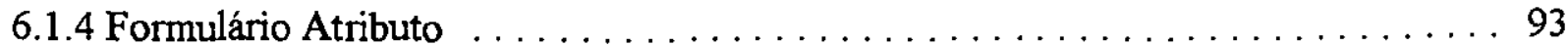

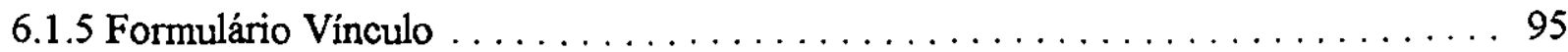

6.1.6 Formulários Editar e Definir Valor de Atributo . . . . . . . . . . . . . . 97

6.1.7 Formulário Generalização Ampla . . . . . . . . . . . . . . . . . . . . . . . 99

6.1.8 Formulário Especialização Restrita $\ldots \ldots \ldots \ldots \ldots \ldots \ldots \ldots \ldots \ldots \ldots$

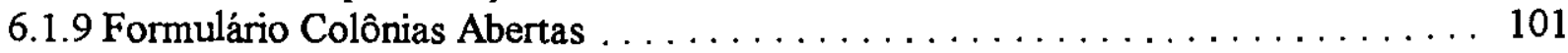

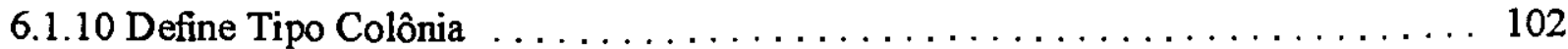

6.1 .11 Habita . . . . . . . . . . . . . . . . . . . . . . . . . . . . . 103

6.2 Navegação nas Abstrações Utilizando-se $E^{2}$ SIRIUS . . . . . . . . . . . . . . 103

6.3 Mapeamento para o Modelo Relacional . . . . . . . . . . . . . . . . . . 108

6.4 Implementação . . . . . . . . . . . . . . . . . . . . . . . . . 110

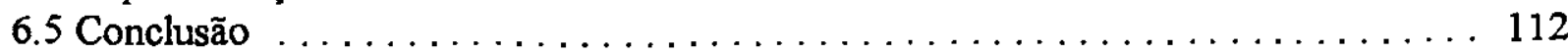

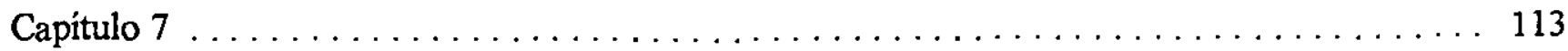

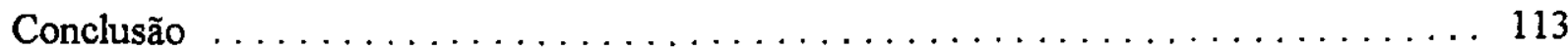

7.1 Decisões de Projeto . . . . . . . . . . . . . . . . . . . . . . . . . . . . 113

7.1.1 Por que Utilizar uma Base de Dados Relacional e não o GEO? . . . . . . . . . . 113

7.1 .2 Por que o $\mathrm{C}++$ Builder? . . . . . . . . . . . . . . . . . . . . . 114

7.1.3 Por que a Criação de um Editor de Esquemas e não um Editor $\ldots \ldots \ldots \ldots \ldots 115$

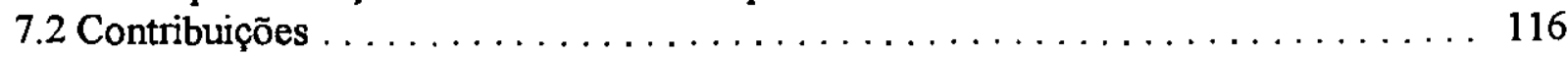

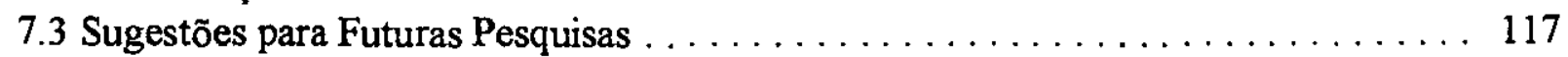

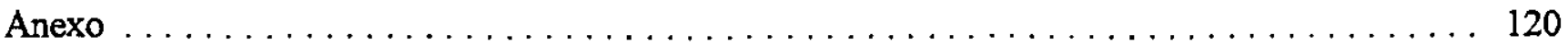

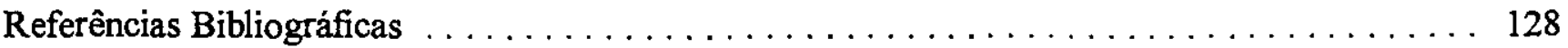

Referências Auxiliares . . . . . . . . . . . . . . . . . . . . . . . . . . . . . . . . . . . . 133 


\section{Lista de figuras}

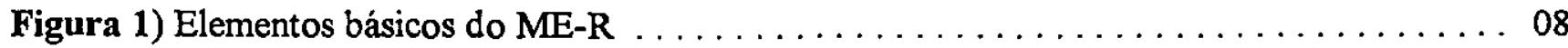

Figura 2) Abstração de Generalização e Agregação do ME-RX $\ldots \ldots \ldots \ldots \ldots \ldots \ldots \ldots$

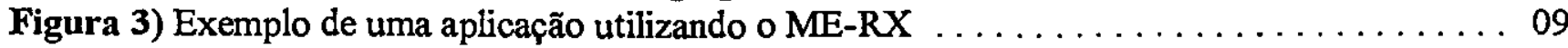

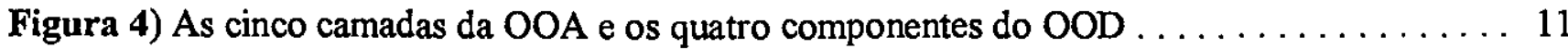

Figura 5) Notação dos elementos básicos da OOA ..................... 13

Figura 6) Exemplo de uma aplicação prática de parte de um Sistema de Transporte Aéreo, utilizando OOA ............................................ 14

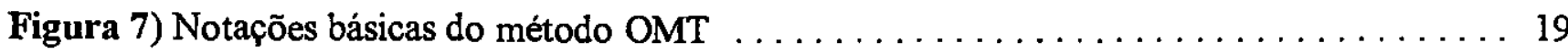

Figura 8) Exemplo de uma aplicação, Sistema de Gerenciamento de janelas em uma workstation,

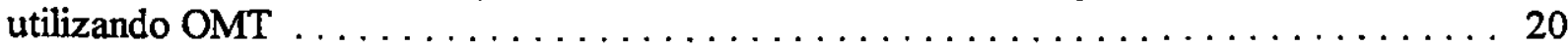

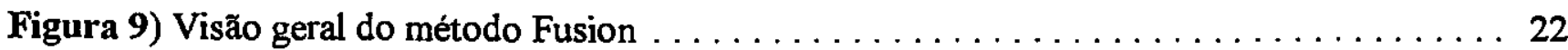

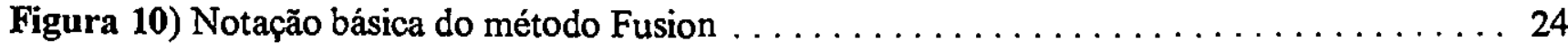

Figura 11) Sistema para Gerenciamento de Depósito de Cargas, exemplo da utilização notacional do

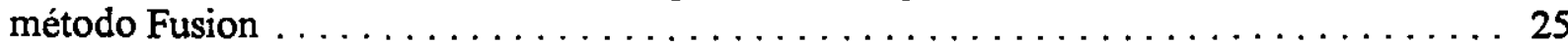

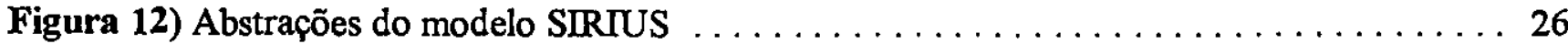

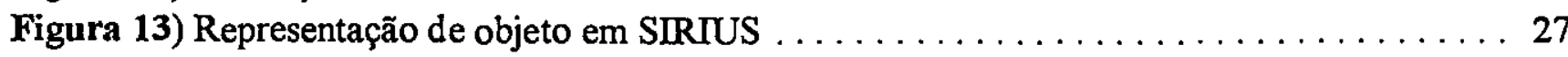

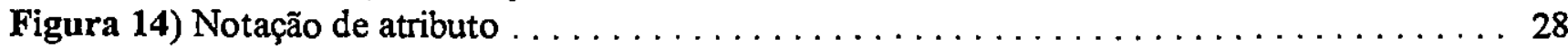

Figura 15) Símbolos utilizados para representar características de atributos e um exemplo . . . 29

Figura 16) Notação e exemplos da agregação de atributos $\ldots \ldots \ldots \ldots \ldots \ldots \ldots \ldots \ldots \ldots$

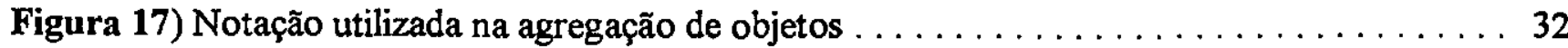

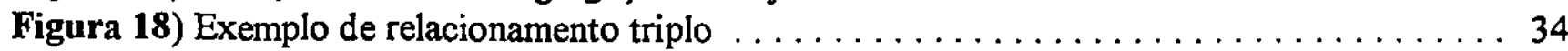

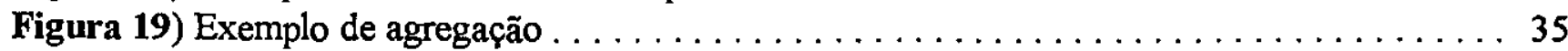

Figura 20) Representação gráfica de objetos e tipos de objetos $\ldots \ldots \ldots \ldots \ldots \ldots \ldots \ldots$

Figura 21) Exemplo de ocorrência de abstração de classificação $\ldots \ldots \ldots \ldots \ldots \ldots \ldots \ldots \ldots \ldots \ldots$

Figura 22) Exemplo de atributos multivalorados . . . . . . . . . . . . . . . . . . 38

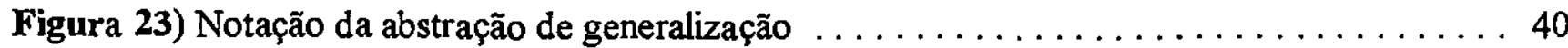

Figura 24) Exemplos de ocorrências da abstração de generalização . . . . . . . . . . . 40

Figura 25) Representação de composição (colônia de objetos) $\ldots \ldots \ldots \ldots \ldots \ldots \ldots \ldots$. 41

Figura 26) Exemplo de representação de colônias . . . . . . . . . . . . . . . . . 42

Figura 27) Representação alternativa para atributos $\ldots \ldots \ldots \ldots \ldots \ldots \ldots \ldots \ldots \ldots \ldots \ldots$

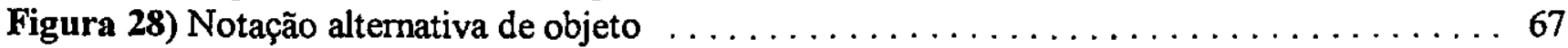

Figura 29) Notação alternativa de atributo com característica tupla . . . . . . . . . . 68

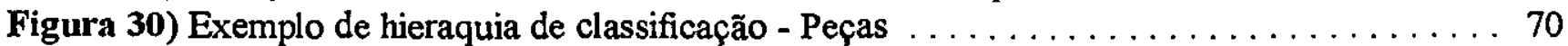

Figura 31) Exemplo de hieraquia de classificação - Peças (utilizando a notação de tipo coletivo - 71

Figura 32) Representação e exemplo de objeto primário $\ldots \ldots \ldots \ldots \ldots \ldots \ldots \ldots \ldots \ldots \ldots \ldots$

Figura 33) Representação de atributos multivalorados e exemplo da utilização destes . . . . . 76

Figura 34) Relacionamento multivalorado e uma instância deste . . . . . . . . . . . . 77 
Figura 35) Instâncias de relacionamento multivalorado $\ldots \ldots \ldots \ldots \ldots \ldots \ldots \ldots \ldots$

Figura 36) Instâncias de relacionamento multivalorado $\ldots \ldots \ldots \ldots \ldots \ldots \ldots \ldots \ldots$

Figura 37) Hieraquia de generalização - notação original $\ldots \ldots \ldots \ldots \ldots \ldots \ldots \ldots \ldots \ldots$

Figura 38) Representação da hierarquia de generalização e exemplos de objetos específicos que não estão vínculados diretamente na hierarquia de generalização $\ldots \ldots \ldots \ldots \ldots$

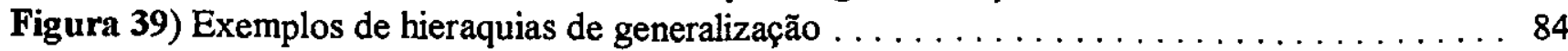

Figura 40) DHC - Diagrama Hierarquico de Colônia $\ldots \ldots \ldots \ldots \ldots \ldots \ldots \ldots$

Figura 41) DRI - Diagrama de Representação de Instâncias $\ldots \ldots \ldots \ldots \ldots \ldots \ldots \ldots$

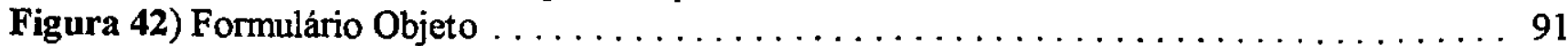

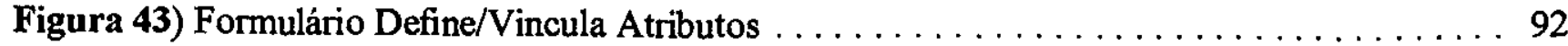

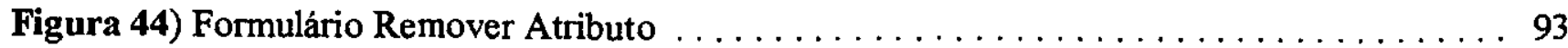

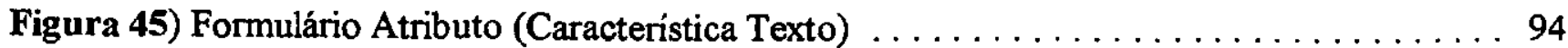

Figura 46) Formulário Atributo (Característica Tupla) . . . . . . . . . . . . . . . . . . 94

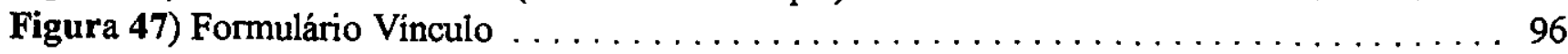

Figura 48) Formulário Editar Valor de Atributo (Objeto não instanciado) . . . . . . . . . . . 97

Figura 49) Formulário Editar Valor de Atributo (Objeto instanciado) . . . . . . . . . . . . 98

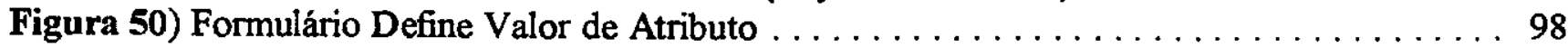

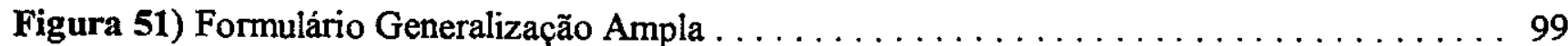

Figura 52) Formulário Especialização Restrita $\ldots \ldots \ldots \ldots \ldots \ldots \ldots \ldots \ldots \ldots \ldots$

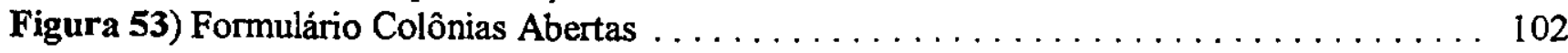

Figura 54) Formulário Define Tipo de Colônia . . . . . . . . . . . . . . . . . . . . 102

Figura 55) Formulário Habita $\ldots \ldots \ldots \ldots \ldots \ldots \ldots \ldots \ldots \ldots \ldots \ldots \ldots \ldots$

Figura 56) Navegação na abstração de classificação/instânciação . . . . . . . . . . . . . . . . 104

Figura 57) Navegação na abstração de agregação/separação . . . . . . . . . . . . . . . . 105

Figura 58) Navegação na abstração de generalização/especialização . . . . . . . . . . . . . 106

Figura 59) Navegação na abstração de composição $\ldots \ldots \ldots \ldots \ldots \ldots \ldots \ldots \ldots$

Figura 60) Tabelas relacionais para SIRIUS . . . . . . . . . . . . . . . . . . . . 109

Figura 61) Diagrama das tabelas relacionais $\ldots \ldots \ldots \ldots \ldots \ldots \ldots \ldots \ldots \ldots \ldots \ldots \ldots$

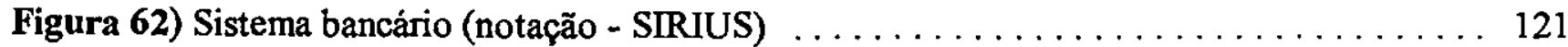

Figura 63) Sistema bancário (notação alternativa - SIRIUS) $\ldots \ldots \ldots \ldots \ldots \ldots \ldots \ldots$

Figura 64) Sistema de gerenciamento de depósito de cargas (notação - SIRIUS) . . . . . . . . 122

Figura 65) Sistema de gerenciamento de depósito de cargas (notação alternativa - SIRIUS) . . 123

Figura 66) Sistema de gerenciamento de fitas em uma locadora (notação - SIRIUS) . . . . . 123

Figura 67) Sistema de gerenciamento de fitas em uma locadora (notação alternativa - SIRIUS 124

Figura 68) Sistema empresas de aluguel (notação - SIRIUS) . . . . . . . . . . . . . . . 125

Figura 69) Sistema empresas de aluguel, primeiro nivel de instanciação (notação - SIRIUS) . . 125

Figura 70) Sistema empresas de aluguel, segundo nível de instanciação (notação - SIRIUS) . . 126

Figura .71) Abstrações de Classificação e Agregação . . . . . . . . . . . . . . . . . . . . 126

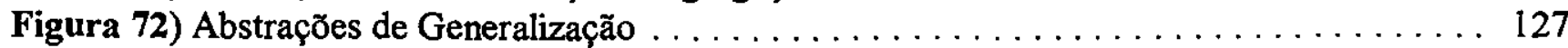

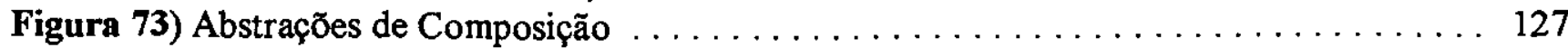




\section{Lista de tabelas}

Tabela 1) Elementos que representam "alguma coisa" ou um "conjunto de coisas" . . . . . . 46

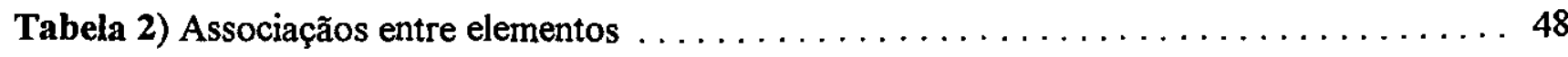

Tabela 3) Tipos de atributos existentes nos modelos estudados $\ldots \ldots \ldots \ldots \ldots \ldots \ldots \ldots 2$

Tabela 4) Representação de cardinalidade / multiplicidade $\ldots \ldots \ldots \ldots \ldots \ldots \ldots \ldots \ldots$

Tabela 5 ) Abstrações existentes nos modelos . . . . . . . . . . . . . . . . . 60 


\section{Resumo}

Esta dissertação visa analisar os construtores de Modelos de Dados Orientado a Objetos, para verificar sua usuabilidade nas situações de utilização real em projetos de aplicações centradas em Bases de Dados.

O trabalho aqui apresentado se fundamenta no modelo SIRIUS, um Modelo de Dados Orientado a Objetos, baseado em Abstrações de Dados. O desenvolvimento de SIRIUS utiliza como ponto de partida um metamodelo que permite representar, de maneira uniforme, os elementos essenciais de qualquer modelo de dados orientado a objetos. Seu desenvolvimento teve como objetivo atender às necessidades de suporte à construção de software para ambientes de projetos de engenharia.

A representação gráfica dos elementos construtivos de um modelo de dados é um dos principais recursos que permitem registrar o conhecimento representado por uma modelagem. Para que um usuário possa elaborar e/ou utilizar uma modelagem, é necessário que essa representação gráfica seja clara, limpa, concisa e efetiva. Por outro lado, deve permitir que os conceitos de modelagem do modelo em si também sejam claramente expressos. Logo, para que este modelo possa ser uma ferramenta adequada para ser utilizada por projetistas, analistas e programadores de gerenciadores de Bases de Dados, é necessário que a notação diagramática do modelo priorize a intuitividade e a clareza, e não só o compromisso com a teoria que embasa o modelo.

Para atender estas necessidades, este documento mostra uma nova representação, mais voltada para a modelagem de situações do mundo real, de fundamental importância para que um modelo possa ser aceito e realmente utilizado, e com isso incrementar sua utilidade prática. Conseqüentemente, alguns pontos do modelo foram validados e outros reformulados, acrescentando-se aspectos que não foram cobertos no modelo original. $O$ texto apresenta também o editor $E^{2}$ SIRIUS, criado com o objetivo de servir tanto para edição de esquemas quanto para auxiliar no treinamento de projetistas nos conceitos do modelo. 


\section{Abstract}

The work described herein consists of analyzing Object-Oriented Data Model constructors to verify their usability in real use situations for DataBase centered application projects.

The work presented here is based on the SIRIUS model, an Object-Oriented Data Model that is based on Data Abstractions. The development of SIRIUS uses, as a starting point, a metamodel that permits the uniform representation of the essential elements of any object-oriented data model. Its development aimed to fulfill the need for support for the construction of software for engineering project environments.

The graphic representation of a data model's construction elements is one of the main resources that permit the recording of knowledge represented through modeling. To enable the user to prepare and/or use a modeling, this graphic representation must be clear, clean, concise and effective. On the other hand, it must also allow for the model's modeling concepts themselves to be clearly expressed. Thus, for this model to constitute an adequate tool for use by Data Base management designers and programmers, it is necessary that the model's diagrammatic notation prioritize intuitiveness and clarity, rather than just its commitment to the theory on which the model is based.

To meet these needs, this document presents a new representation that focuses more strongly on the modeling of real world situations, a fundamentally important factor for a model to really become accepted and used, thus increasing its practical usefulness. Some of the model's points have, therefore, been reformulated with the addition of aspects that had not been covered in the original model. This paper also presents the $E^{2}$ SIRIUS editor, which was created to serve both for scheme editing and as a designer training aid of the model's concepts. 


\section{Capítulo 1}

Introdução

\subsection{Considerações Iniciais}

Atualmente, as aplicações comerciais caracterizam-se pela manipulação de dados que podem ser organizados em um conjunto relativamente pequeno de estruturas, mas por outro lado, com um grande volume de dados estruturalmente idênticos. No entanto, as aplicą̧ões não comerciais de sistemas de computação trabalham com dados que não apresentam esta mesma estrutura homogênea. Exemplo dessas aplicações são os sistemas CAD (Computer-Aided Design - Projeto Auxiliado por Computador) [Gupta_91][Ishikawa_93][Kempe_95], CAM (Computer-Aided Manufacturing - Manufatura Auxiliada por Computador), Sistema de Automação de Escritórios [Ruiz_94][Ruiz_95], entre outros. As aplicações não convencionais, em geral aproveitam os SGBDs ${ }^{1}$ já existentes, mesmo que estes não sejam adequados para estas aplicações. Esse aspecto faz que a falta de um núcleo comum de gerenciamento de dados traga problemas de compatibilidade entre os sistemas. Para sanar os problemas do emprego dos SGBDs disponíveis em aplicações não convencionais, muitas pesquisas estão sendo realizadas, para que novos modelos de dados possam dar o suporte necessário a uma ampla faixa de aplicações não convencionais. Estes modelos têm como objetivos suprir requisitos para a modelagem de sistemas não convencionais [Abieboul_87][Hsu_93][Hudson_89][Kim_89][Naja_95][Weiser_89].

Neste contexto, enquadra-se o SIRIUS, um Modelo de Dados Orientado a Objetos baseado em Abstrações de Dados, o qual está sendo desenvolvido pelo Grupo de Base de Dados e Imagens do ICMC $^{2}$. Seu desenvolvimento utiliza, como ponto de partida, um metamodelo [Biajiz_96], que permite

\footnotetext{
${ }^{1}$ SGBDs - Sistemas de Gerenciadores de Bases de Dados

${ }^{2}$ ICMC - Instituto de Ciências Matemáticas e de Computação
} 
representar, de maneira uniforme, os elementos essenciais de qualquer modelo de dados orientado a objetos, tendo como objetivo atender às necessidades de suporte à construção de software para ambientes de projetos de engenharia.

Uma característica do modelo é que ele presta-se bem à implementação de um Gerenciador de Objetos que o suporte, sendo que seu formalismo apresenta indicações de como essa implementação deve ser realizada, o que oferece uma indicação também formal de como uma modelagem feita em SIRIUS pode ser mapeada para implementação em um outro modelo. Uma implementação de um Gerenciador de Objetos que suporta SIRIUS, denominado SIRIUS/GO [Traina_96a], está sendo desenvolvida pelo Grupo de Base de Dados e Imagens do ICMC.

SIRIUS inclui, entre outros, os conceitos de: objetos, atributos, características de atributos, tipos de atributos e tipos de objetos. Tais conceitos são organizados semanticamente e sintaticamente, utilizando-se três abstrações fundamentais: abstração de classificação, abstração de associação e abstração de generalização, das quais a segunda ocorre especializada em duas outras que são: abstração de composição e abstração de agregação [Biajiz_96][Biajiz_96a].

Resumindo, SIRIUS é um modelo que permite a construção de sistemas que representam, de maneira uniforme, os elementos de qualquer modelo de dados orientado a objetos, e em particular, atende às necessidades de ambientes para apoio ao projeto de engenharia e aplicações científicas.

\subsection{Motivação e Relevância}

A representação gráfica dos elementos construtivos de um modelo de dados é um dos principais recursos que permitem transmitir (além de organizar) o conhecimento representado por uma modelagem. Para que um usuário possa elaborar e/ou utilizar uma modelagem, é necessário que essa representação gráfica seja clara, limpa, concisa e efetiva. Por outro lado, deve permitir que os conceitos de modelagem do modelo em si sejam também claramente expressos.

Este último objetivo foi atendido pela representação de SIRIUS proposta em seu documento original [Biajiz_96], que privilegiou a manutenção da representação explícita dos conceitos de modelagem nos diagramas que representam as modelagens do mundo real efetuadas com o modelo.

No entanto, em situações reais de modelagem, esse critério deve estar subordinado, em primeiro lugar, à clareza e efetividade da informação representada. Assim, para que este modelo possa ser uma ferramenta adequadamente utilizável por projetistas, analistas e programadores de gerenciadores de 
Bases de Dados, é necessário que a notação diagramática do modelo priorize a intuitividade e a clareza das modelagens efetivadas, e não apenas o compromisso com a teoria que embasa o modelo.

Uma nova representação, mais voltada para a modelagem de situações do mundo real, é assim de fundamental importância para que um modelo possa ser aceito e utilizado realmente. Este trabalho propõe justamente estender o SIRIUS neste aspecto, e com isso incrementar sua utilidade prática. Por outro lado, como SIRIUS integra diversos construtores semânticos, usualmente não disponiveis isoladamente, em toda sua abrangência, em outros modelos, a disponibilidade de tê-los integrados todos em um único modelo torna-o bastante poderoso e interessante para aplicação em tarefas de desenvolvimento de sistemas estruturalmente complexos, como é o caso de aplicações de ambientes de desenvolvimento em engenharia e aplicações científicas. No entanto, esse poder somente poderá ser explorado se a usabilidade e intuitividade de sua representação forem compatíveis.

\subsection{Objetivos}

Este trabalho tem por objetivo estudar a representação gráfica adotada no modelo SIRIUS, para desenvolver uma maneira adequada de representar os elementos do modelo que são estruturados segundo as abstrações que o modelo suporta.

Por ser um modelo novo, a notação gráfica do SIRIUS não foi validada através da utilização em aplicações práticas. A notação originalmente proposta teve como objetivo descrever as modelagens efetuadas, de maneira que ficasse bem claro o embasamento teórico que suporta SIRIUS. Esse objetivo não leva necessariamente a uma notação adequada para o uso coditiano em aplicações usuais de modelagem.

Num primeiro passo, para que esse novo modelo seja prático para aplicações reais, há a necessidade de que algumas notações sejam validadas, e que outras sejam,reformuladas para adequaremse melhor ao seu uso cotidiano, mantendo seu embasamento semântico. Isso é necessário para que a notação melhore a representação dos elementos de uma modelagem, gerando diagramas que sejam ao mesmo tempo intuitivos para a compreeensão da informação representada, (limpo) não apresente uma densidade demasiadamente elevada de informação em determinados locais e (efetivo) apresente toda a informação necessária ao entendimento do usuário. 
Nesta dissertação, também avalia-se a representação dos construtores semânticos adotada em diferentes modelos de dados semânticos, orientados a objetos descritos na literatura, buscando-se uma representação adequada para os conceitos de SIRIUS.

Este trabaho apresenta também o Editor de Esquemas [Araujo_98a], que foi elaborado com o objetivo de manipular de maneira clara e uniforme os elementos construtivos do modelo, gerando dados que poderão vir a ser utilizados na construção dos esquemas das aplicações para SIRIUS, quando o Gerenciador SIRIUS/GO estiver disponivel.

\subsection{Organização da Dissertação}

A dissertação é apresentada em 7 capitulos, os quais abordam os seguintes aspectos:

Capítulo 1: apresenta as idéias que motivam o desenvolvimento deste trabalho, incluindo as considerações iniciais, motivação e relevância, objetivos e a organização do trabalho;

Capítulo 2: mostra alguns modelos estudados na fase de revisão bibliográfica, que darão suporte para o desenvolvimento futuro da dissertação;

Capitulo 3: tem como principal objetivo apresentar os conceitos as notações propostas para o modelo SIRIUS, em sua versão original;

Capitulo 4: apresenta uma comparação entre os modelos estudados na revisão bibliográfica e o modelo SIRIUS;

Capitulo 5: contém a proposta de novas notações para o modelo SIRIUS, bem como novos conceitos que ampliam a capacidade de representação semântica do mesmo;

Capítulo 6: ilustra o Editor de Esquemas, uma interface gráfica para o modelo. Tal interface possibilita que os construtores semânticos do modelo sejam manipulados de maneira clara e uniforme, em outras palavras, permite a especificação, manipulação e visualização dos conceitos de SIRIUS, abrangendo assim todas as abstrações suportadas pelo modelo;

Capitulo 7: expõe as conclusões do trabalho.

Também faz parte do texto um anexo contendo alguns exemplos de modelagens em SIRIUS, utilizando as notações propostas no capítulo 5 . 


\section{Capítulo 2}

\section{Revisão Bibliográfica}

Neste capítulo são apresentados alguns modelos estudados. Para cada um faz-se uma breve introdução, mostra-se sua estrutura (exceto para o modelo ME-R), faz-se a descrição dos principais elementos, um resumo notacional destes elementos, e por fim, mostra-se o uso do modelo em uma aplicação prática, ou seja, um exemplo com o objetivo de esclarecer como os elementos e suas notações são utilizados em uma modelagem.

\subsection{Modelo Entidade - Relacionamento (ME-R)}

\subsubsection{Introdução}

Este modelo foi proposto, nos anos 70, por Peter Chen [Chen_76] com o objetivo de representar informações básicas, tanto sintaticamente como semanticamente, sobre uma realidade. Para que isto seja possível, este baseia-se na adoção de uma visão natural do mundo real, que pode ser descrita através de Conjuntos de Entidades e Conjuntos de Relacionamentos. Uma característica importante é que o ME-R [Elmasri_94][Loucopoulos_94] é intuitivo, o que é facilitado pela representação gráfica das informações modeladas.

O ME-R teve rápida e grande aceitação de uso e, desde o início, tem sido bastante explorado. No entanto, com as novas aplicações que foram sendo desenvolvidas, como bases de dados para projeto de engenharia (CAD/CAM) [Gupta_91][Ishikawa_93][Kempe_95], bases de dados para armazenar imagens e gráficos, aplicações de multimídia entre outras, novos elementos foram necessários para 
suportá-las. Assim, novos conceitos "semânticos" de modelagem foram adicionados ao ME-R, como: especialização, generalização, separação, agregação entre outros, ou seja, o ME-R foi estendido, sendo denominado ME-RX (Modelo Entidade - Relacionamento Estendido) [Elmasti_94] [Traina_96]. Muitas extensões para o modelo tem sido propostas por vários autores [Smith_77][Teorey_90][Gogolla_91].

\subsubsection{Descrição dos Principais Elementos do Modelo}

O ME-R original oferece quatro construtores para a representação semântica: Conjuntos de Entidades, Conjuntos de Relacionamentos, Atributos de Entidades e Atributos de Relacionamento.

Uma entidade é um elemento do mundo real que pode ser identificado; por exemplo, um carro, uma montadora, etc. As entidades que possuem os mesmos atributos são agrupadas em um Conjunto de Entidades, sendo representadas através de retângulos, como ilustra a Figura 1a).

Um relacionamento é uma associação entre entidades; por exemplo, Veículo_Pertence_Montadora é um relacionamento entre duas entidades: a entidade Carro e a entidade Montadora. Os relacionamentos que possuem os mesmos atributos são agrupados em um Conjunto de Relacionamentos, sendo representados através de losangos, como na Figura 1b). Na Figura 1c); temse um relacionamento $\mathrm{R}$ entre a entidade E_l e a entidade E_2. Cada Relacionamento é definido explicitamente com uma Cardinalidade $(1: 1,1: \mathrm{N}$ ou $\mathrm{N}: \mathrm{M}$, quando o relacionamento é binário, e N:M:P, quando for temário), ou seja, as quantidades de Entidades que podem estar associadas em cada Relacionamento. A notação utilizada é ilustrada na Figura 1d).

Conjuntos de Entidades e de Relacionamentos devem ser descritos através de valores de atributos, os quais expressam as propriedades das entidades e dos relacionamentos envolvidos. Assim, pode-se, por exemplo, atribuir a uma entidade Veículo o atributo Número_de_Pneus, cujo valor pode estar em torno de 2 a 20 (dependendo do veículo que estiver sendo considerado). Analogamente pode-se atribuir a um relacionamento, por exemplo, Veículo_Pertence_Montadora, o atributo Data_de_Montagem, cujo valor será o dia em que o veículo foi montado. Atributos de Entidades e de Relacionamento são representados através de elipses ligadas aos Conjuntos de Entidade e de Relacionamento respectivamente. A notação de atributo pode ser vista na Figura 1e). Na Figura 1f), tem-se atributos de entidades, que são Atributo_1 e Atributo_2, referentes à entidade E_1; os atributos Atributo_3 e Atributo_4 são referentes à entidade E_2 e o atributo do relacionamento Atributo_5. 
O ME-RX oferece os mesmos conceitos e notações já existentes no ME-R, incluindo também algumas abstrações, como por exemplo, a abstração de generalização ${ }^{3}$ [Elmasri_94][Traina_96] e a abstração de agregação [Traina_96]. Abstração de generalização corresponde à idéia de que os Conjuntos de Entidades representam o Tipo das Entidades, as quais podem ser especializadas em Subtipos de Entidades. A Figura 2a) apresenta uma abstração de generalização onde o Conjunto de Entidades Genérico (ou Entidades Abstrata) é um retângulo, que geralmente se situa no topo, e que é ligado a um hexágono que representa o Tipo das Entidades (ou Critério da Generalização). A este hexágono ligam-se os Subtipos de Entidades (ou Entidades Detalhe).

A Abstração de Agregação corresponde à idéia de que elementos de modelagem podem associar-se, formando outros objetos que representam essa associação, ou seja, associações entre entidades também correspondem a entidades (Entidade Agregada). Um poligono que envolve um Conjunto de Relacionamentos (Relacionamento Gerador da Agregação) e o(s) Conjunto(s) de Entidade(s) (Entidades Componentes) que estão associados ao Conjunto de Relacionamentos, representa a Abstração de Agregação, ilustrada na Figura 2b).

${ }^{3}$ A notação que será empregada para ilustrar esta abstração é extraída de [Traina_96], pois não existe uma notação padrão que represente esta abstração 


\subsubsection{Resumo Notacional}

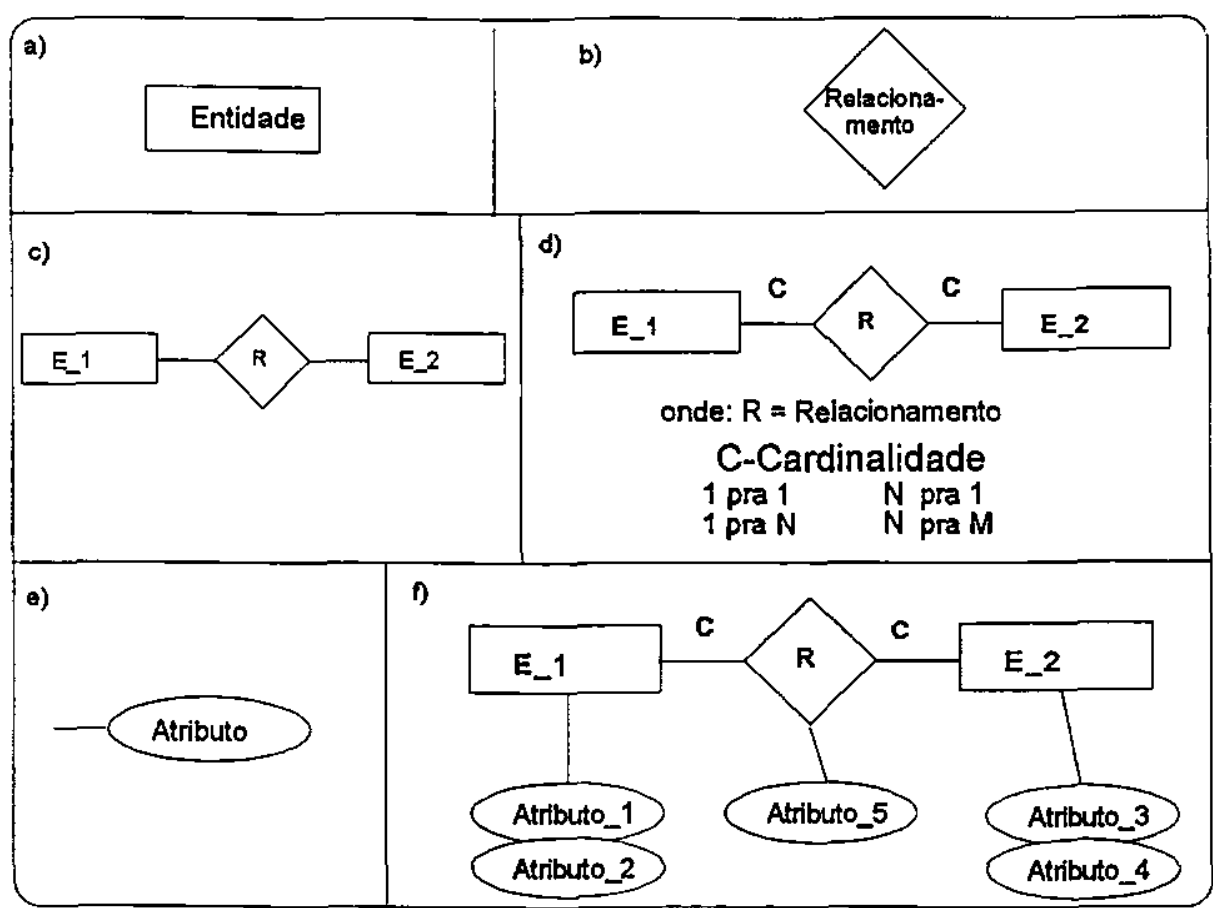

Figura 1) Elementos básicos do ME-R

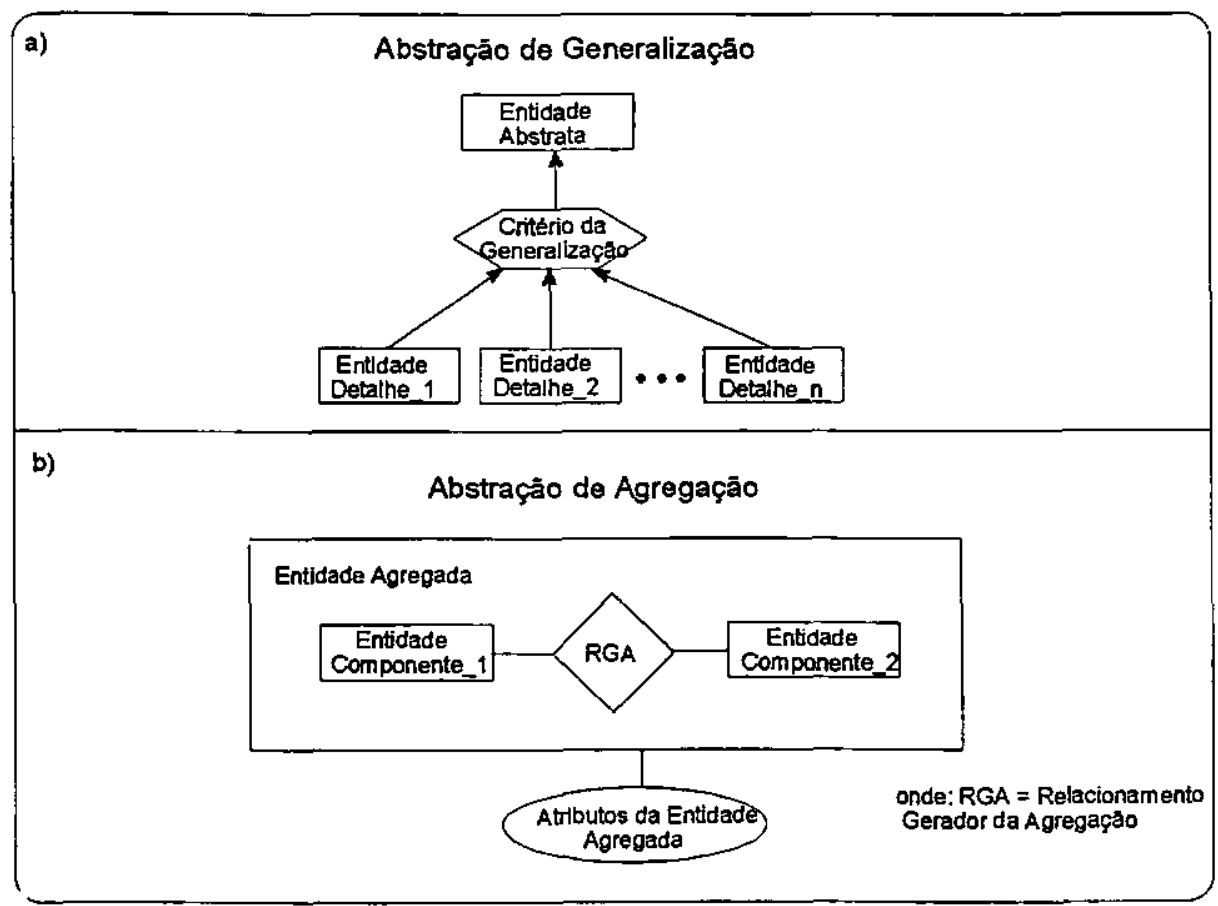

Figura 2) Abstração de Generalização e Agregação do ME-RX 


\subsubsection{Aplicação Prática}

Na Figura 3, Conta_Corrente é uma entidade agregada que possui Número e Saldo como atributos. As entidades Correntista (a qual possui os atributos Nome e CIC) e Banco (a qual possui os atributos Nome e Endereço) são entidades componentes que estão associadas através do relacionamento binário Tem_Conta, onde Agência é um atributo deste relacionamento, indicando qual agência de um banco está associada à conta corrente do correntista. Este relacionamento é um relacionamento $N: M$, ou seja, um correntista pode ter uma ou mais contas e um banco pode ter um ou mais correntistas. A entidade Conta_Corrente pode ser: do tipo Poupança (onde o correntista pode efetuar um ou mais depósitos e uma poupança pode ser de uma ou mais pessoas que efetuam depósitos, efetuados em uma data Data_Dep), do tipo Remunerada e pode também ser do tipo Empresarial (onde uma empresa pode efetuar vários depósitos em mais de uma Conta_Corrente, numa certa Data).

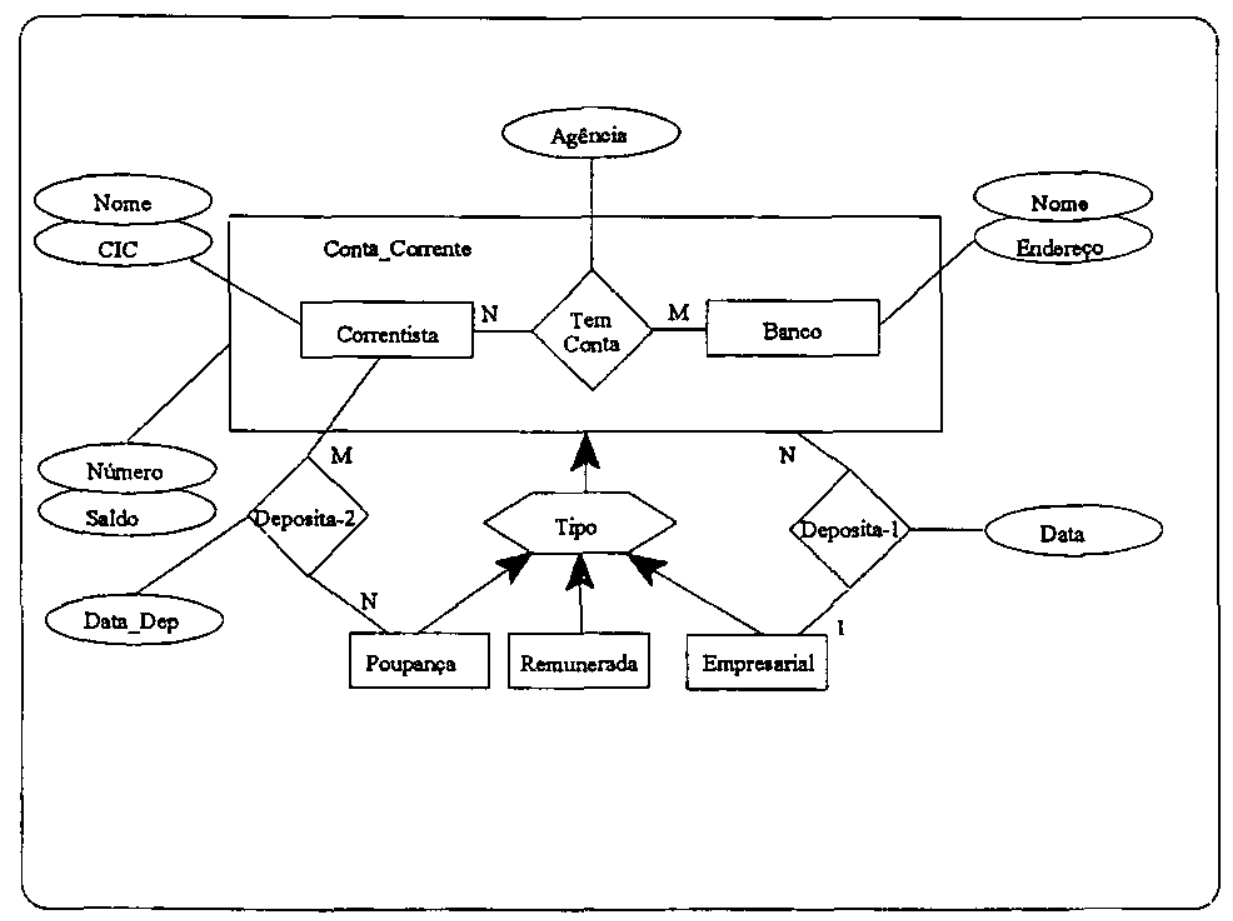

Figura 3) Exemplo de uma aplicação utilizando o ME-RX 


\subsection{OOA e OOD de Coad/Yourdon}

\subsubsection{Introdução}

A OOP (Object Oriented Programming - Programação Orientada a Objeto) baseada em objetos foi discutida pela primeira vez no final dos anos 70 , por pessoas que trabalhavam com a linguagem SIMULA [Dahl_70]. Nessa época, ela era uma parte importante da linguagem Smaltalk [Ingalls_78]desenvolvida na Xerox PARC. Enquanto isso, o resto do mundo usava linguagens tais como COBOL [ANSI_74][Sammet_69] e FORTRAN [ANSI_78] [Rosen_67] [Sammet_69], e métodos de decomposição funcional para o tratamento de problemas de projeto e implementação. Havia pouca discussão sobre OOD (Object Oriented Design - Projeto Oriendado a Objetos), e virtualmente nenhuma discussão sobre OOA (Object Oriented Analysis - Análise Orientada a Objetos).

Algumas alterações ocorreram na década passada, e são, nos anos noventa, fatores importantes: os conceitos básicos de um enfoque baseado em objetos tiveram uma década para amadurecimento, $\mathrm{e}$ a atenção mudou gradualmente de considerações sobre codificação, para considerações sobre projeto e análise. Note-se que era dificil pensar em codificação orientada a objetos quando as linguagens disponiveis eram COBOL, FORTRAN ou C [Kernighan_78], ficando essa tarefa mais fácil com as linguagens Smaltalk e Ada [Wegner_80]. Outro aspecto é que os sistemas interativos e on-line dedicam muito mais atenção à interface com o usuário do que os antigos sistemas de processamento batch, baseados em textos. Segundo Coad/Yourdon [Coad_93] [Coad_96], a experiência mostra que um enfoque baseado em tais sistemas, desde a análise até o projeto e a implementação, é uma forma mais natural de abordar sistemas voltados para usuários. Finalmente, a complexidade funcional é menos considerada agora do que antes; por outro lado, a modelagem de dados está sendo mais elaborada atualmente.

Os objetivos fundamentais da OOA são: a compreensão do domínio do problema, o desenvolvimento de uma comunicação interpessoal, e a evolução contínua e reutilização. Por outro lado, os objetivos fundamentais do OOD são: melhorar a produtividade, aumentar a qualidade, e elevar a manutenibilidade. 


\subsubsection{Estrutura do Modelo}

O modelo OOA consiste em cinco camadas: Assunto, Classe-\&-Objeto, Estrutura, Atributo e Serviço. Essas cinco camadas, ilustradas na Figura 4a), são colocadas umas sobre as outras apresentando gradualmente mais e mais detalhes. As camadas são cortes horizontais do modelo geral. Numa abordagem global, as cinco camadas correspondem às cinco atividades principais introduzidas na OOA: determinar Classes-\&-Objetos, identificar Estruturas, identificar Assuntos, definir Atributos e definir Serviços.

Essas camadas são atividades, não necessariamente passos seqüenciais. As atividades servem para guiar desde altos níveis de abstração (por exemplo, as Classes-\&-Objetos do domínio do problema) até níveis cada vez mais baixos de abstração (Estruturas, Atributos e Serviços). Além disso, a ordenação dessas cinco atividades representa a abordagem global mais comum.

$O$ modelo $O O D$, ilustrado na

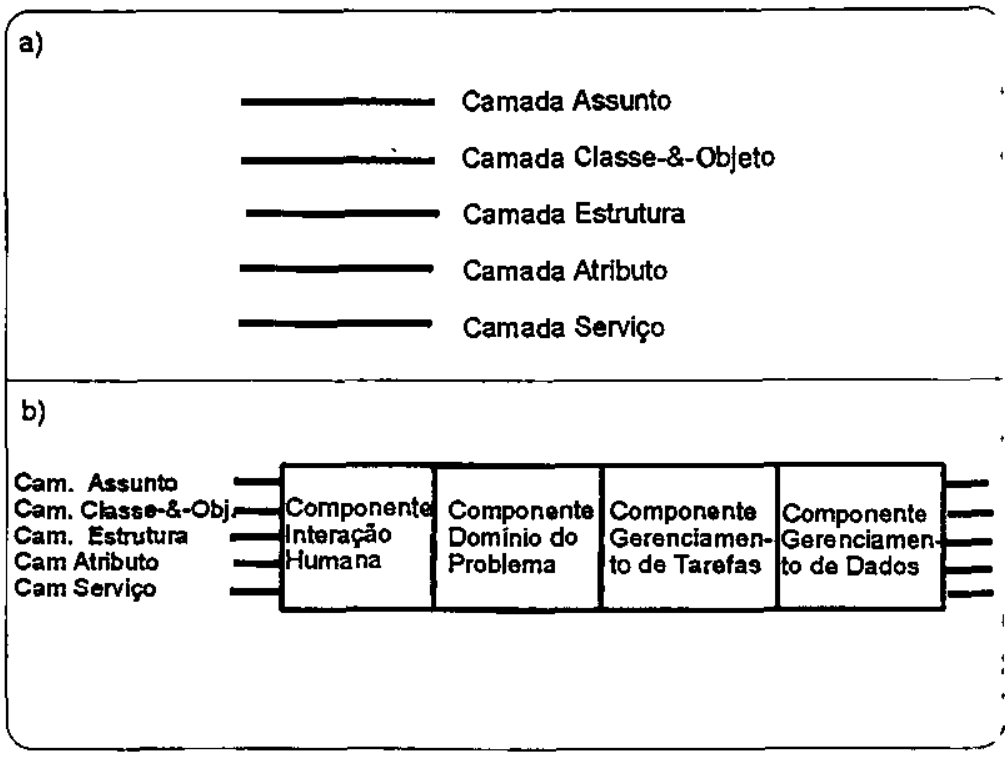

Figura 4) As cinco camadas da $\mathrm{OOA}$ e os quatro componentes do OOD

Figura 4b), consiste em quatro componentes: Domínio do Problema, Interação Humana, Gerenciamento de Tarefas e Gerenciamento de Dados. Os componentes são cortes verticais do modelo geral. Numa abordagem global, os quatro componentes correspondem às quatro atividades principais no OOD: Projetar o Componente Domínio do Problema, Projetar o Componente Interação Humana, Projetar o Componente Gerenciamento de Tarefas e Projetar o Componente Gerenciamento de Dados. Essas atividades, como ocorre em OOA, não são necessariamente passos seqüenciais [Coad_93] [Coad_96]. 


\subsubsection{Descrição dos Principais Elementos do Modelo}

Os principais elementos utilizados na modelagem são: Classe-\&-Objeto, Classe, Estrutura Gen-Espec (Estrutura de Generalização-Especialização), Estrutura Todo-Parte e Fluxo de Dados.

O termo Objeto é utilizado para expressar uma abstração de alguma coisa no domínio de um problema, refletindo a capacidade de um sistema manter informações sobre ela. Uma Classe, por sua vez, é uma descrição de um ou mais Objetos, que são representados através de um conjunto uniforme de Atributos e Serviços. Classe-\&-Objeto significa "uma Classe e os Objetos nessa Classe". A notação Classe é apresentada por um retângulo (com cantos arredondados) em negrito, dividido em três seções horizontais, como na Figura 5a). Os Objetos desta Classe são representados por um retângulo mais claro que "envolve" a representação da Classe, Figura 5b).

$O$ termo Estrutura é usado de maneira genérica, podendo ser empregado para descrever uma Estrutura de Gen-Espec e uma Estrutura Todo-Parte. Menos formalmente, uma Estrutura Gen-Espec é considerada como uma Estrutura "é um" ou "é um tipo de". Por exemplo, um veículo Caminhão é um (é um tipo de) Veículo. Por outro lado, a Estrutura Todo-Parte é considerada como uma Estrutura "tem um". Por exemplo, um veículo tem um Motor. As Estruturas Gen-Espec são mostradas como uma Classe de Generalização na parte superior e Classes de Especialização mais abaixo, com segmentos de retas para uni-las, onde um semicírculo representa esta Estrutura. A notação desta abstração é ilustrada na Figura 5d). Analogamente, as Estruturas Todo-Parte são mostradas como um Objeto Todo na parte superior e um ou mais Objeto(s) Parte mais abaixo, com segmentos de retas para uni-los, onde um triângulo representa esta Estrutura, Figura 5c).

Os Fluxos de Dados modelam a associação entre os Objetos, sendo mostrada com uma linha que une os objetos, a qual indica os mapeamentos entre os Objetos individuais. Cada Objeto tem indicadores de quantidade $(m)$ ou intervalo $(m, n)$ em cada uma dos seus Fluxos de Dados, refletindo seu relacionamento com os outros Objetos, ilustrado na Figura 5e). 


\subsubsection{Resumo Notacional}

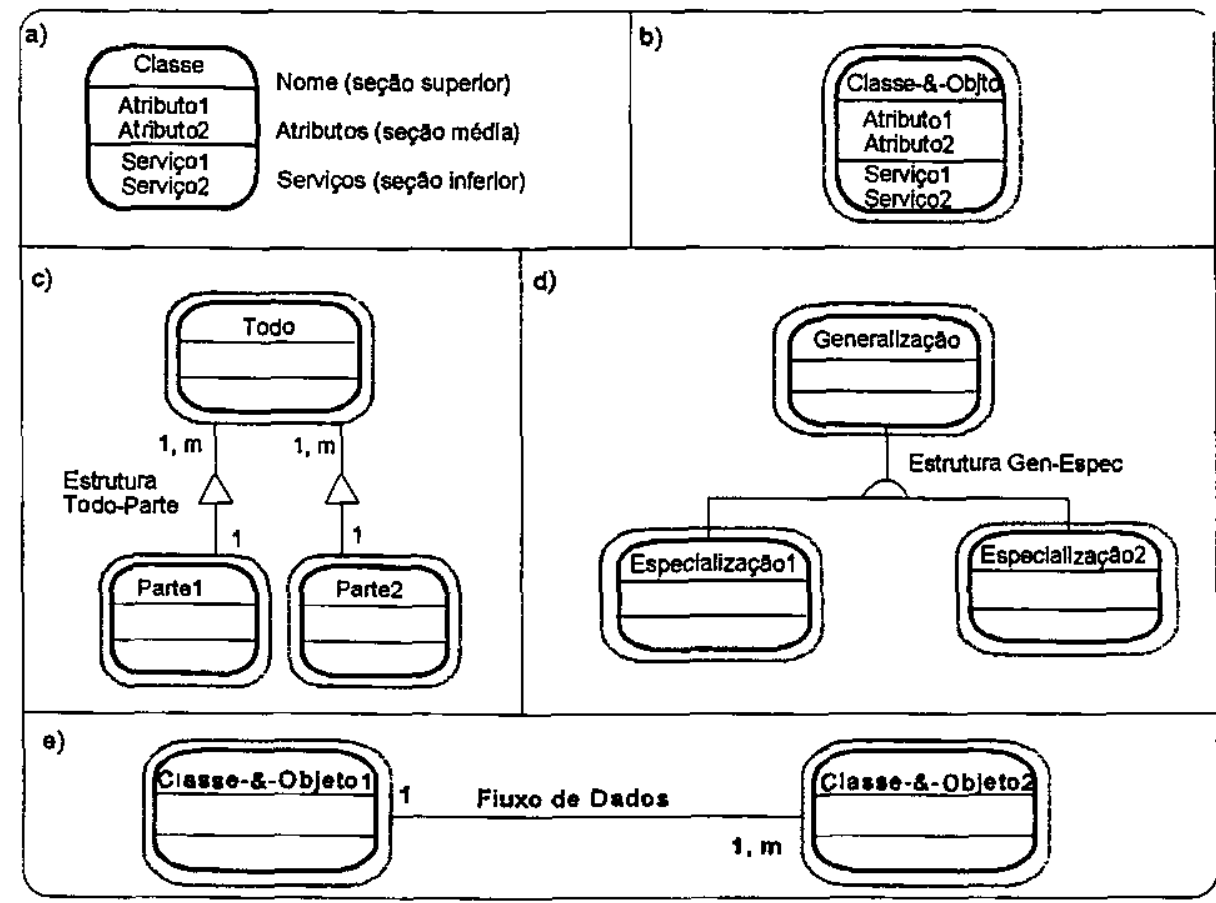

Figura 5) Notação dos elementos básicos da OOA

\subsubsection{Aplicação Prática}

O Sistema de Transporte Aéreo automatiza o planejamento de vôos e transporte de passageiros. Parte da modelagem deste sistema encontra-se na Figura 6). Os elementos que dizem respeito ao sistema são: Item_Embarcado, que inclui Passageiro (que possui um Nome e uma Posição como atributos) e Item_de_Carga (com atributos como: Peso, Dimensões e Descrição do item embarcado). 0 Segmento_de_Vôo (o qual possui os atributos Número, Origem e Destino) consiste de alguns números de Item_Embarcado. Um Vôo (com atributos Código, Número_Vôo e Descrição_Vôo) consiste de alguns números de Segmento_de_Vôo. O Avião que efetua os vôos possui, Número_de_Chamada, Status, Modelo, Capacidade e Posição em que o avião se encontra. Existe um fluxo de dados entre Avião e Segmento_de_Vôo que associa qual o avião irá efetuar um determinado segmento de vôo. Assim tem-se uma conexão entre Avião e Trajetória_do_Item_Aérotransportado (onde para cada item transportado é registrado o Nível_de_Confiança), pois através desta conexäo é possivel determinar qual a trajetória de um determinado item e qual avião transportou este item. Uma Trajetória_do_Item_Aérotransportado consiste de alguns números de Item_Aérotransportado 
(Data_Hora e Posição são atributos dos Itens Transportados), e há também uma conexão entre Falha_de_Avião (onde são registrados, Data_Hora, Descrição e Ação_Corretiva para uma determinada falha) e Avião.

Nesta aplicação tem-se dois tipos de estruturas. Uma Estrutura Gen-Espec (Item_Embarcado) e três Estruturas Todo-Parte. Uma Estrutura Todo-Parte é do tipo Recipiente Conteúdos, neste caso a abstração existe fisicamente (Avião-Item_Embarcado). As outras Estruturas Todo-Parte são do tipo Conjunto Membros, nas quais a abstração não existe fisicamente, pois abstrações deste tipo são "apenas um modelo mental". Este tipo de abstração pode ser útil para maior consideração dos limites do modelo. No exemplo, as Estruturas Todo-Parte conjunto-membro são:

TrajetóriaDoltemAéroTransportado-ItemAéroTransportado, Vôo-SegmentoDeVôo e

SegmentoDeVôo-ItemEmbarcado.

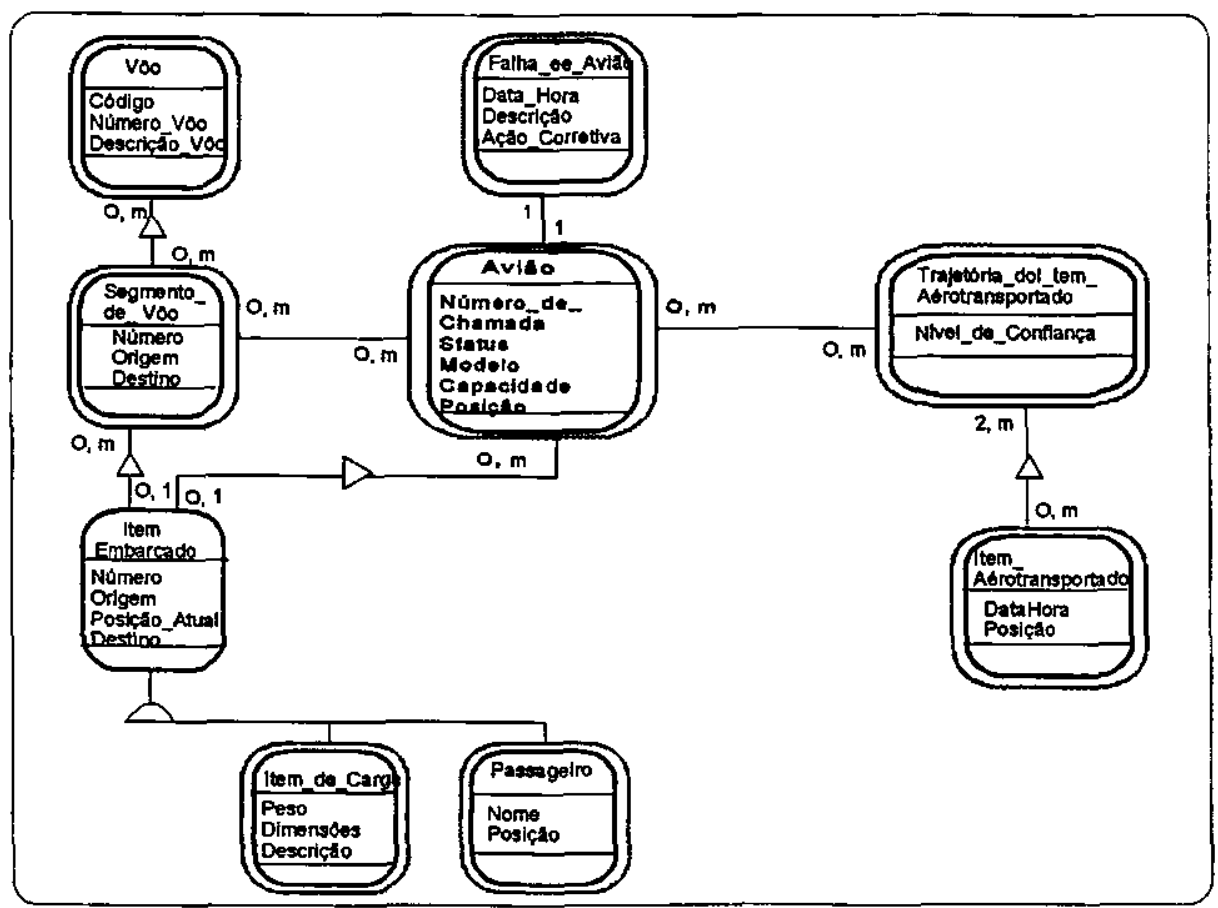

Figura 6) Exemplo de uma aplicação prática de parte de um Sistema de Transporte Aéreo, utilizando OOA 


\subsection{OMT}

\subsubsection{Introdução}

O método denominado OMT (Object Modeling Technique - Técnica de Modelagem de Objetos) foi criado por Rumbaugh [Rumbaugh_91] no início dos anos noventa, sendo um dos métodos mais completos desenvolvidos até então. Ele pode ser considerado como um divisor de águas, pois, a partir dele, houve uma evolução mais concreta dos modelos orientados a objetos. $\mathrm{O}$ método OMT estende desde a análise até o projeto e a implementação. Este método reuniu os conceitos importantes para uma modelagem orientada a objetos, introduzindo uma notação intuitiva, que é utilizada ao longo de todo o desenvolvimento do modelo, de modo que a informação adicionada em uma etapa do desenvolvimento não é necessariamente perdida na(s) etapa(s) seguinte(s). Este modelo serviu, também, de base para a criação de outros, como Fusion [Coleman_94], que será visto mais adiante.

\subsubsection{Estrutura do Modelo}

A metodologia empregada em OMT segue quatro estágios (Análise, Projeto do Sistema, Projeto de Objeto e Implementação).

- Análise enfoca-se o que o sistema deve fazer, e não como será feito, não existindo nenhuma decisão de implementação;

- Projeto do Sistema são tomadas decisões de alto-nivel sobre a arquitetura do sistema. $\mathrm{O}$ projetista deve decidir sobre as características de performance para otimizar o sistema, escolher as estratégias adequadas para a resolução do problema, tentar resolver problemas de alocação de memória;

- Projeto de Objeto escolhem-se as estruturas de dados e algoritmos necessários para a implementação de cada classe;

- Implementação, as classes e relacionamentos desenvolvidos durante a fase de projeto do objeto são finalmente implementadas. É uma etapa relativamente menor e mecânica no desenvolvimento do ciclo de vida, visto que todas as decisões importantes e dificeis de serem tomadas já ocorreram nas fases anteriores.

OMT combina três visões da modelagem de sistemas: 
- Modelo de Objeto, visão que descreve a estrutura estática dos objetos existentes em um sistema, isto é, seus relacionamentos com outros objetos, seus atributos, e suas operações, fornecendo também uma estrutura essencial para a aplicação do modelo dinâmico e funcional. Esta visão é representada graficamente com diagramas de objetos contendo classes de objetos, que podem estar relacionadas com outras classes, podendo ou não compartilhar estruturas e comportamento com outras classes;

- Modelo Dinâmico, visão que descreve os aspectos temporais e comportamentais de um sistema, isto é, a seqüência de eventos, estados e operações que ocorrem no interior de um sistema, ou seja, enfatiza o controle. O modelo dinâmico é representado graficamente através de diagramas de estados;

- Modelo Funcional que descreve os aspectos de um sistema concentrando-se nas transformações de valores, isto é, funções, mapeamentos, e dependências funcionais, enfatizando o que o sistema faz, sem considerar como, ou onde é feito. $\mathrm{O}$ modelo funcional é representado com um diagrama de fluxo de dados.

Note-se que cada modelo descreve um aspecto no sistema, sendo que cada um contém referências para os outros modelos. O Modelo Dinâmico e o Modelo Funcional atuam sobre a estrutura de dados representada no Modelo de Objetos. Os eventos do Modelo Dinâmico e as funções do Modelo Funcional têm correspondência com o Modelo de Objetos através das operações. A estrutura de controle de objetos é descrita no Modelo Dinâmico. As funçð̃es descritas no Modelo Funcional são chamadas pelas operações do Modelo de Objetos e pelas ações do Modelo Dinâmico. Essas funções operam sobre os valores de dados especificados pelo Modelo de Objetos. Logo, os três modelos interligados são partes ortogonais de um sistema completo, ou seja, os três são necessários para a modelagem do sistema.

\subsubsection{Descrição dos Principais Elementos do Modelo}

Alguns conceitos básicos da metodologia OMT são: classe, associações, qualificadores, generalização, agregação, atributos de ligação, objetos instâncias e multiplicidade de associações.

Uma Classe de Objetos (ou simplesmente uma Classe) descreve um grupo de objetos com propriedades semelhantes (atributos), o mesmo comportamento (operações), os mesmos relacionamentos com outros atributos, e a mesma semântica. Quando for necessário especificar 
exatamente a ocorrência de um elemento, em uma classe, será utilizado o termo instância de objeto, e o termo classe de objetos será utilizado para fazer referência a um grupo de coisas similares.

Uma classe é representada por um quadrado, que pode ter três regiões. Cada região contém, de cima para baixo: o nome da classe, escrito em negrito; uma lista de atributos; e uma lista de operações . Uma operação é uma função ou uma transformação, que pode ser aplicada a um objeto em uma classe. Cada nome de atributo é seguido por detalhes opcionais, tais como: tipo e valor default (o tipo é precedido por dois pontos e o valor default é precedido por um sinal de igual). Cada nome de operação pode também ser seguido por detalhes opcionais, tais como: uma lista de argumentos escrita entre parênteses depois do nome da operação, onde os argumentos são separados por vírgula (uma lista de argumentos vazia mostra explicitamente que não existem argumentos); e tipo de valores de retorno precedido por dois pontos (esse valor não deve ser omitido, porque é importante distinguir as operações que retornam valores das que não retornam). Atributo(s) e operação(ões) podem ou não serem mostrados, dependendo do nivel de detalhes que se pretende considerar. A notação de classe pode ser vista na Figura 7a).

O símbolo empregado para ilustrar uma instância de objetos é um retângulo com bordas arredondadas Figura $7 b$ ). O nome da classe fica entre parênteses no topo do retângulo, escrito em negrito. Nomes de objetos são escritos sem utilizar negrito.

As ligaçōes e associaçōes têm o mesmo significado para relacionamentos entre objetos e classes. Uma ligação é ưma conexão fisica ou conceitual entre objetos instâncias, e uma associação descreve um grupo de ligações com estruturas e semântica comuns. Em outras palavras, uma ligação é uma instância de uma associação, que é representada por uma linha entre classes ligando-as Figura 7c), e o termo ligação é representado através de uma linha entre objetos Figura 7d). O nome de uma associação é escrito em itálico, podendo ser omitido se um par de classes tem uma associação cujo significado é obvio.

O símbolo para representar uma associação ternária ou com grau maior que três, é um losango que conecta as classes que participam da associação Figura 7e). O nome de uma associação, se necessário, é escrito próximo ao losango.

A Multiplicidade, Figura 7f), especifica quantas instâncias de uma classe podem estar relacionadas com uma única instância de uma classe associada:

- uma bola cheia indica "muitos", significando zero ou muitos; 
- uma bola vazia indica zero ou um;

- uma linha sem símbolos de multiplicidade indica uma associação um para um; no caso geral, a multiplicidade é escrita próxima do final da linha de associação.

Atributo é uma propriedade de um objeto em uma classe; similarmente, um atributo de ligação é uma propriedade de uma ligação em uma associação, e é representado por um retângulo "dependurado" na linha, que representa a associação por um arco; um ou mais atributos de ligação podem ser representados na segunda parte do retângulo. Esta notação enfatiza a similaridade entre atributos de objetos e atributos de ligação e pode ser vista na Figura $7 \mathrm{~g}$ ).

Uma associação qualificada envolve duas classes e um qualificador. O qualificador é um atributo especial que reduz o efeito da multiplicidade de uma associação, e é representado graficamente como um quadrado no final de uma associą̧ão próximo à classe que será qualificada, Figura $7 \mathrm{~h}$ ).

Agregação e generalização são abstrações suportadas pelo OMT:

- agregação é a "parte do todo" ou "parte de" um relacionamento no qual os objetos representam componentes de alguma coisa associada com um objeto representando a totalidade (ou seja, o objeto inteiro). Esta abstração é desenhada como uma associação, em que um losango no final da conexão indica a existência de uma agregação Figura 7I);

generalização é uma conexão entre uma classe e uma ou mais versões refinadas ou especializadas desta. A classe que será refinada é chamada superclasse e cada versão de uma classe refinada é uma subclasse. A notação da generalização mostrada na Figura 7j), é um triângulo conectando uma superclasse nas suas subclasses. A superclasse é conectada por uma linha que parte do topo do triângulo. As subclasses são conectadas em uma linha horizontal que passa pela base do triângulo. Note-se que generalização e especialização são dois pontos de vista distintos de um mesmo relacionamento. Generalização refere-se ao fato de que superclasses generalizam a subclasse. Especialização refere-se ao fato de que superclasses são refinadas ou especializadas.

Observe-se que a notação gráfica é descrita para expressar o modelo e também para ajudar o desenvolvedor de software a visualizar um problema. As aplicações e os objetos podem ser modelados, projetados e implementados, usando-se os mesmos conceitos orientados a objetos e a mesma notação. O mesmo esquema notacional é usado na fase de análise, projeto e implementação; logo, as informações 
que são adicionadas ao longo do desenvolvimento não são perdidas e nem modificadas nos próximos estágios de desenvolvimento. Portanto, o desenvolvedor não precisa alterar a notação a cada estágio de desenvolvimento como acontece com muitas metodologias existentes.

É importante observar que ainda não existe uma notação gráfica para construtores orientados a objetos comumente aceita, e portanto, a notação aqui empregada foi desenvolvida para o OMT. Esta notação está sendo muito usada para a solução de problemas do mundo real, tendo sido empregada com sucesso por outros modelos orientados a objetos [Booch_94][Coleman_94], algumas vezes sofrendo pequenas adaptações.

\subsubsection{Resumo Notacional}

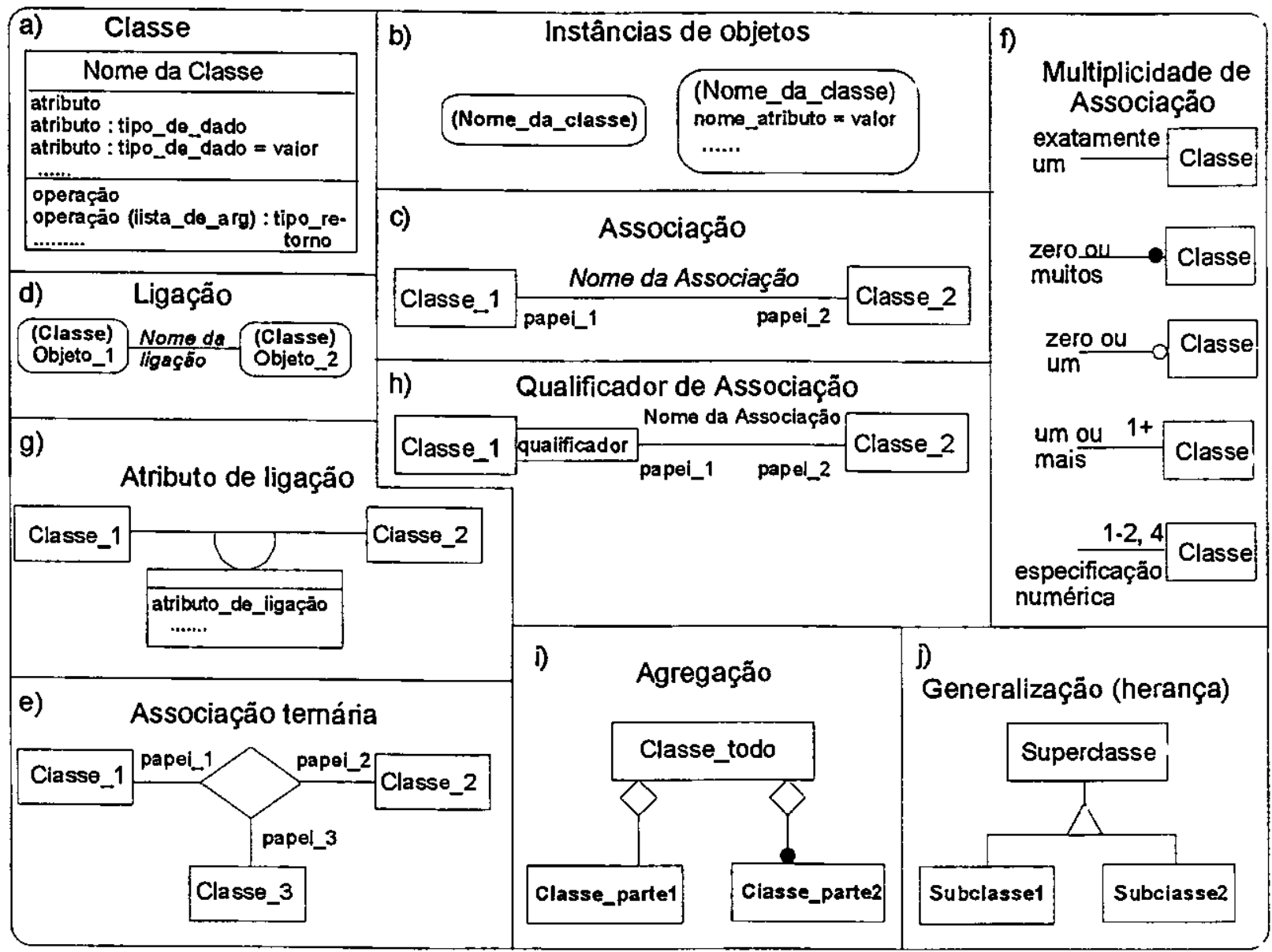

Figura 7) Notações básicas do método OMT 


\subsubsection{Aplicação Prática}

Na Figura 8), tem-se um exemplo simplificado de um Sistema de Gerenciamento de Janelas em uma workstation, tal como um sistema $X$-Window ou SunView.

A classe Window define as dimensões da janela (X1, Y1, X2 e Y2) e operações como: Exibe, Aumenta e Diminui. Tais definições são passadas para as suas subclasses, que são Scrolling_Window

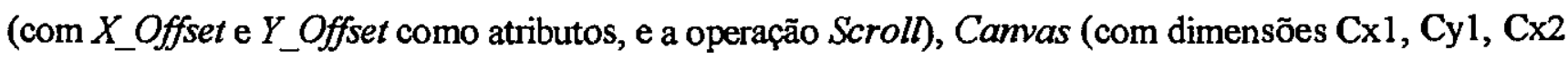
e Cy2 e as operações Adiciona_Elemento e Deleta_Elemento) e Panel. A classe Scrolling_Window tem, como subclasses, as classes Texto_Window (que têm String como atributo e as operações Insere e Deleta) e

Scrolling_Can vas. Esta última é subclasse também da classe Canvas. janela do tipo Canvas podem estar associadas muitas figuras, e estas fazem parte da classe Figura (que tem como atributos Cor e Linha). Tal classe tem

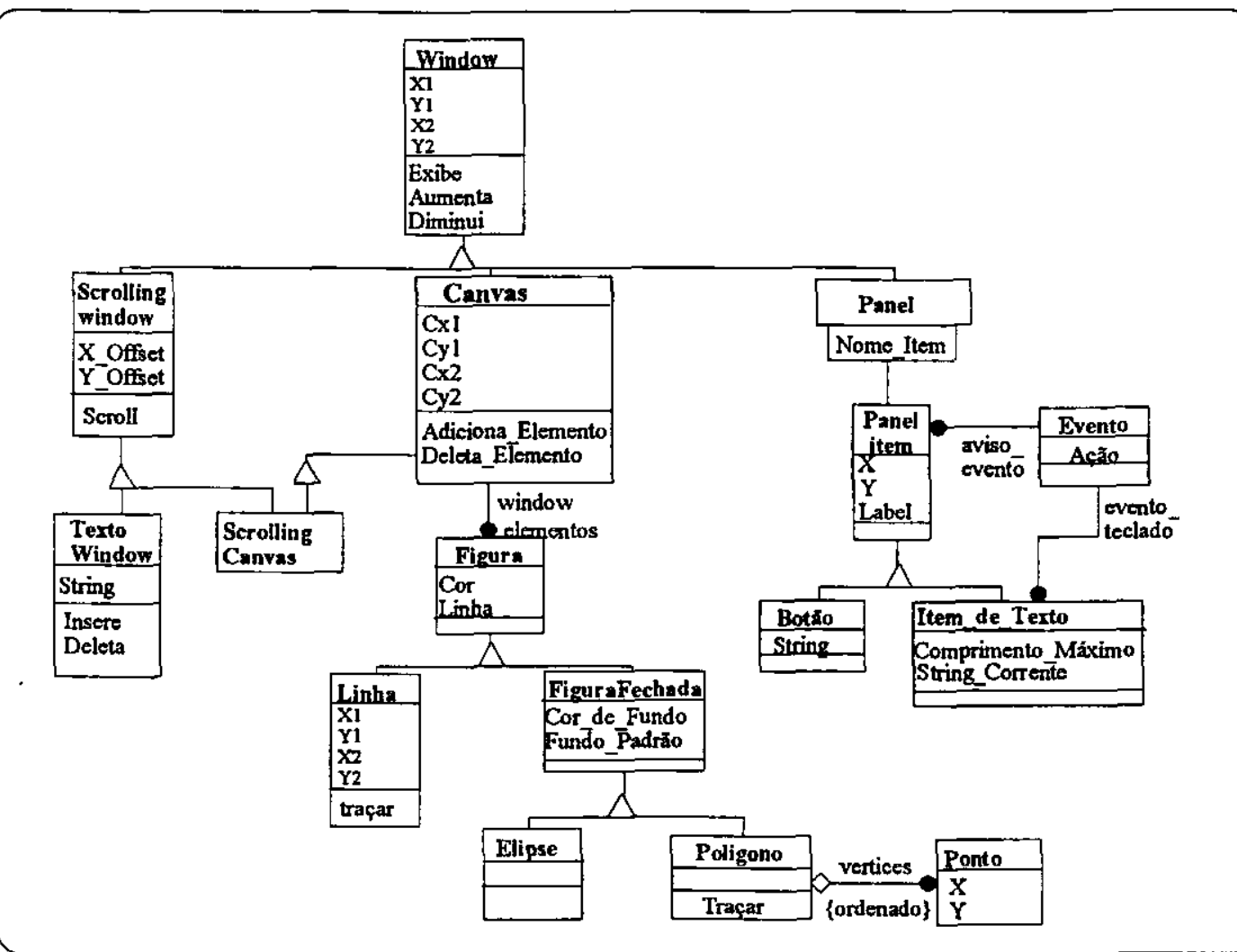

Figura 8) Exemplo de uma aplicação, Sistema de Gerenciamento de janelas em uma workstation, utilizando OMT

como subclasse as classes Linha (com dimensões $\mathrm{X} 1, \mathrm{Y} 1, \mathrm{X} 2$ e Y2 e a operação Traçar) e Figura_Fechada (Cor_de_Fundo e Fundo_Padrão são atributos desta classe). Esta última, por sua vez, tem como subclasse as classes Elipse e Polígono, onde cada polígono é composto por pontos. Isto é mostrado pela abstração de agregação entre as classes Poligono e Ponto. 
A classe Panel contém um conjunto de itens (objetos), e cada um é classificado unicamente por um Nome_Item. Isto é indicado pela associação qualificada entre as classes Panel e Panel_Item. Um Panel_Item pode ser do tipo Botão (com atributo String) ou Item_de_Texto (com atributos como Comprimento_Máximo e String_Corrente).

\subsection{Fusion}

\subsubsection{Introdução}

O método para análise e projeto orientado a objetos Fusion foi criado por Coleman e outros [Coleman_94] a fim de tentar reduzir ou eliminar algumas deficiências que os métodos orientados, a objetos publicados anteriormente, apresentavam, tais como os modelos, OMT [Rumbaugh_91] e Booch [Booch_94]. Muitos daqueles métodos surgiram a partir de métodos tradicionais de visão "funcional" e são considerados, segundo os autores, como a "primeira geração" dos métodos orientado a objetos. O desenvolvimento orientado a objetos tenta explorar os aspectos intuitivos durante as interações com o mundo real, uma vez que os objetos do software orientado a objetos estão ligados aos objetos do mundo fisico.

O método Fusion integra e estende abordagens existentes, oferecendo uma notação consistente de processo de desenvolvimento, que inicia no processo de análise e segue até à implementação, através de uma notação específica para cada um de seus diferentes modelos. O nome Fusion (em português significa: fusão) indica que o método foi criado como uma fusão a partir de notações e conceitos propostos por outros métodos[Chen_76][Rumbaugh_91][Booch_94], estendendo e integrando essas abordagens numa nova geração.

\subsubsection{Estrutura do Modelo}

As etapas que o método abrange são a análise, o projeto e a implementação de sistemas, tais como ilustrados na Figura 9). O método apresenta um processo de desenvolvimento de software nas três fases, indicando o que deve ser feito em cada uma, e quando se deve passar de uma fase para outra, de uma maneira bem definida. 
$\mathrm{Na}$ fase de análise, especifica-se o comportamento desejado do sistema através de modelos que captam as classes de objetos existentes no domínio do problema, e o relacionamento entre elas. Define-se também a interface do sistema com o ambiente através das operações que podem ser executadas. Nesta fase, não existe a associação de métodos às classes, como ocorre com outros métodos.

$\mathrm{Na}$ fase de projeto, especifica-se

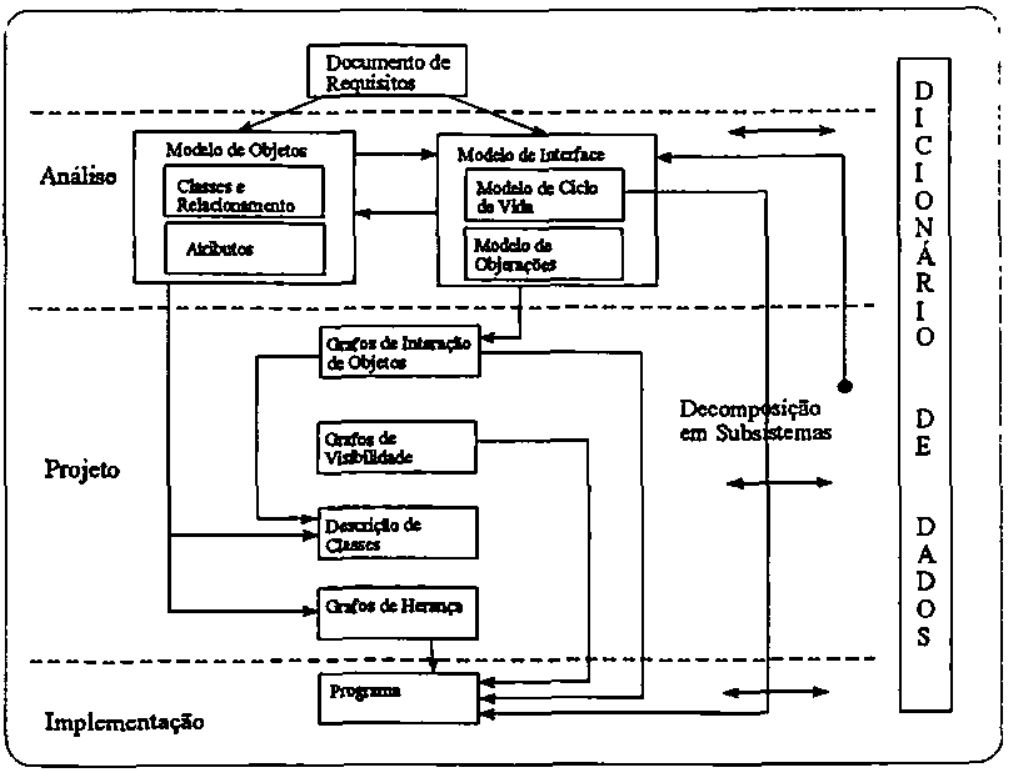

Figura 9) Visão geral do método Fusion como uma operação pode ser implementada através da interação de vários objetos que trocam mensagens entre si. Definem-se uma classe controladora da operação, um conjunto de classes colaboradoras e os métodos relevantes. Os métodos aparecem na troca de mensagens entre as classes para executar a operação, e são associados às classes que recebem as mensagens. Relações de herança e objetos de projeto não existentes no dominio da aplicação podem ser criados.

Na fase de implementação, Fusion oferece diretrizes para transformar o projeto em código. Em especial, oferece diretrizes de como implementar herança, referência e atributos como classes de linguagens de programação orientada a objetos, de como implementar interações entre objetos através de métodos, e de como implementar a interface do sistema.

\subsubsection{Descrição dos Principais Elementos do Modelo}

O Modelo de Objetos para o Domínio do Problema, que faz parte da fase de análise, tem como objetivo representar os conceitos existentes no domínio do problema e suas relações e portanto permite representar classes, atributos e relacionamentos entre classes, incluindo agregação e especialização/generalização. A notação foi baseada no Modelo de Objetos OMT [Rumbaugh_91], que por sua vez, teve sua notação baseada no Modelo Entidade-Relacionamento Estendido (ME-RX) [Smith_77][Teorey_90][Gogolla_91][Elmasri_94] [Traina_96]. 
Um objeto é uma "coisa" que pode ser identificada unicamente, devendo ter valores associados a si (os atributos). Classes são conjuntos de objetos, sendo a sua representação similar à representação no OMT, cuja notação é mostrada na Figura 10a). Relacionamentos são associações entre objetos existentes no mundo real, e expressam a possibilidade de um relacionamento entre os objetos das classes envolvidas. Eles são representados por um losango, que é dividido ao meio quando o relacionamento possui atributos de relacionamento Figura 10b). Neste caso, na parte superior do losango, indica-se o nome do relacionamento e, na parte inferior, o(s) atributo(s) do relacionamento. Podem ser utilizados também cardinalidade e papéis para aumentar a semântica de um relacionamento. A notação utilizada para expressar cardinalidade encontra-se na Figura 10c). Na Figura 10b), é possível ter uma noção de como cardinalidade e papéis são empregados em uma modelagem.

Há dois tipos especiais de relacionamento: a agregação e a especialização/generalização. Ambos são mecanismos de estruturação do modelo. A agregação é formada com as classes componentes contidas dentro da classe agregada, como mostra a Figura 10d). Neste caso, as classes componentes são: Classe_1 e Classe_2, onde a cardinalidade dos componentes é mostrada dentro da caixa que representa a classe agregada, ao lado da(s) classe(s) componente(s), sendo representada, neste caso, pela letra C. A generalização permite que um supertipo (ou superciasse) seja formado pelas propriedades comuns a várias classes denominadas subtipos (ou subclasses). A generalização de classes é representada por um triângulo conectando uma classe supertipo aos seus subtipos. Quando o triângulo é cheio, significa que as classes subtipos são disjuntas; caso contrário, significa que a(s) classe(s) subtipo(s) é (são) disjunta(s), caso contrário, significa que não é (são) disjunta(s). A notação para esta abstração pode ser vista na Figura 10e). Os objetos de um subtipo apenas estendem as propriedades do supertipo, sem jamais alterá-las. 


\subsubsection{Resumo Notacional}

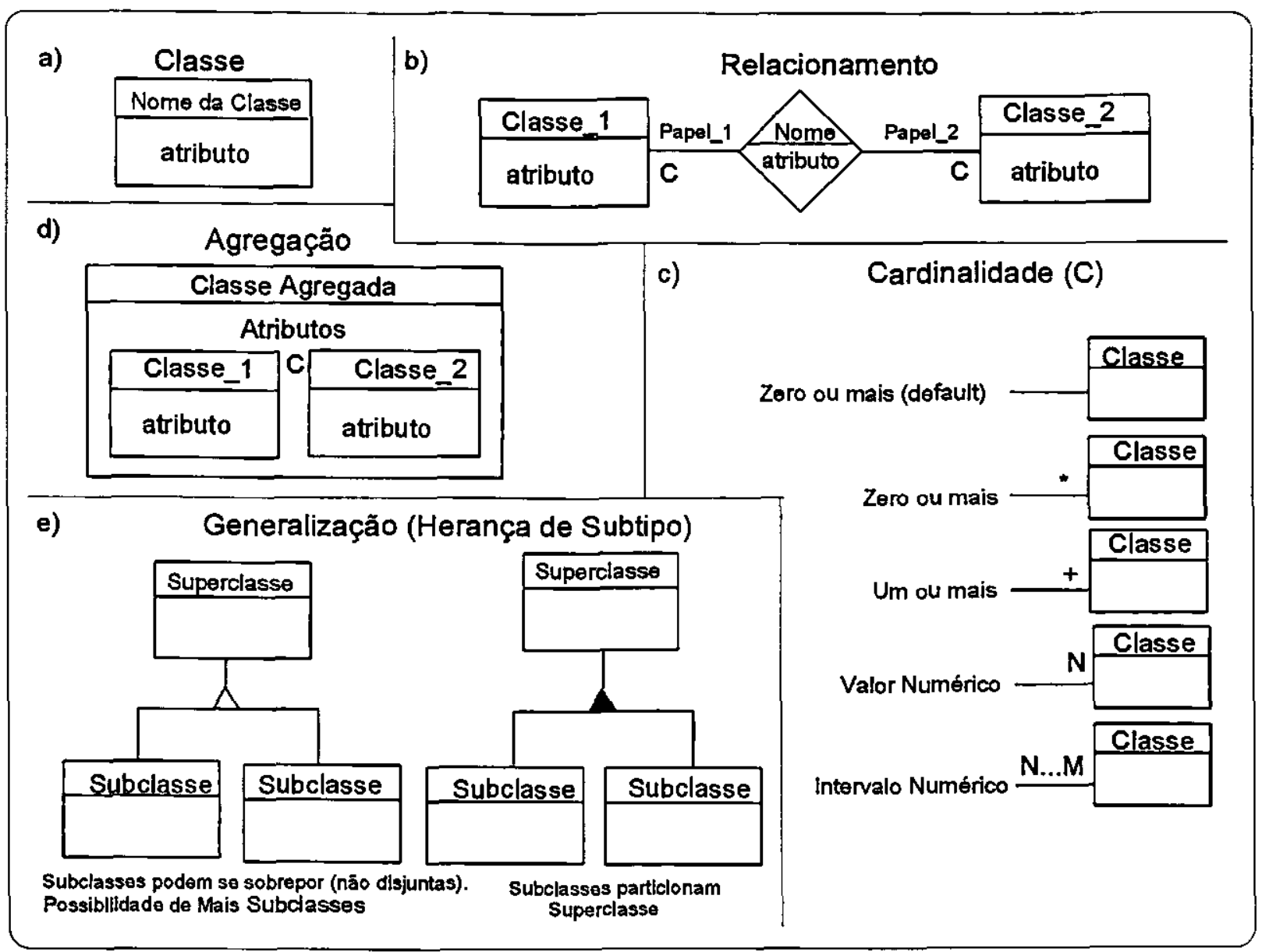

Figura 10) Notação básica do método Fusion

\subsubsection{Aplicação Prática}

No Sistema para Gerenciamento de Depósito de Cargas, indicado na Figura 11), tem-se a classe Edificio, onde os Tambores são armazenados. Estes edificios podem ser Edifício_Adm/Lab (Edifício Administrativo e Laboratório) ou Edifício_de_Armazenamento, que possui Capacidade_Máxima como atributo. Note-se que esta é uma generalização onde os subtipos Edifício_Adm/Lab e Edifício_de_Armazenamento são disjuntos.

Quando um caminhão de carga chega na Área_de_Carregamento (que possui um certo status) para uma entrega, é efetuada a documentação, produzindo um Manifesto que acompanha a carga. Os manifestos podem ser Manifesto_de_Entrega, que é um subtipo de Manifesto. 
O sistema produz uma Lista_de_Alocação do tipo tambor-para-edificio, que determina onde cada tambor deve ser armazenado. Esta lista é uma agregaçăo da classe Edificio_de_Armazenamento e Tambor, a qual tem como subtipo uma Lista_de_Status_de_Alocação e uma Lista_de_Alocação_de_Entrega.

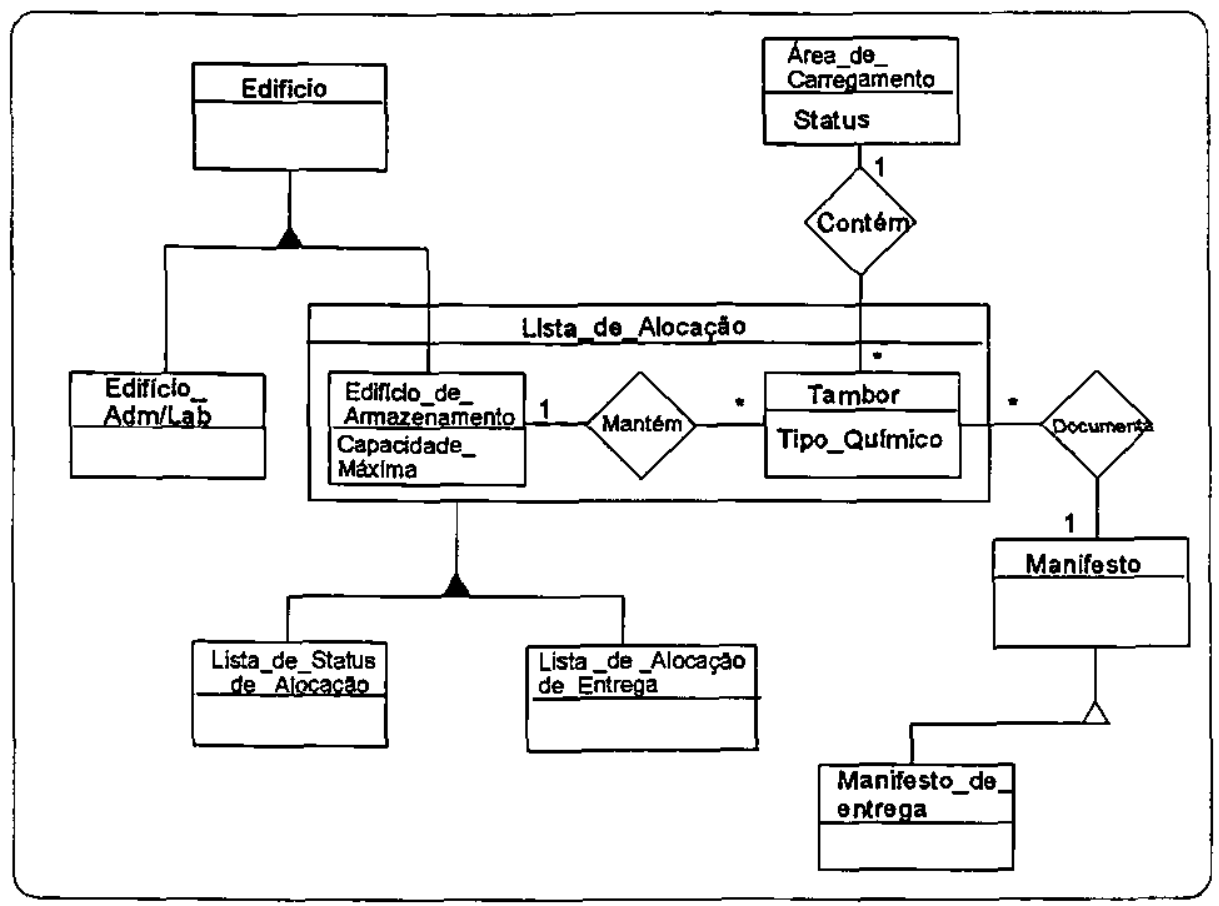

Figura 11) Sistema para Gerenciamento de Depósito de Cargas, exemplo da utilização notacional do método Fusion

\subsection{Conclusão}

Neste capítulo foi, efetuado um levantamento de algumas metodologias de análise e projeto de sistemas, avaliando-se a notação adotada em cada uma para representar seus conceitos. Pode-se notar que o conjunto de conceitos é, em geral, bastante parecido, embora a notação específica de cada metodologia difira bastante, obrigando a quem for interpretá-la, a conhecer os detalhes daquela metodologia em particular.

O próximo capitulo apresenta o modelo SIRIUS, no qual se baseia esta dissertação. Um dos objetivos do capitulo seguinte é apresentar o modelo com a finalidade de ilustrar os conceitos, bem como as notações empregadas neste. 


\section{Capítulo 3}

SIRIUS original

Este capitulo tem como principal objetivo apresentar os conceitos e a notação proposta para o modelo SIRIUS, em sua versão original.

\subsection{Introdução}

Os conceitos de objetos, atributos, característica de atributos, tipos de atributos e tipos de objetos constituem os elementos do modelo, sendo estes estruturados segundo as abstrações de: classificação, associação e generalização. Esta última ocorre especializada em duas outras: a abstração composição e de agregação, como mostra a Figura 12. Para ilustrar tais conceitos conforme Biajiz [Biajiz_96], houve a necessidade de representá-los de maneira a ressaltar o embasamento teórico do modelo, e é esta maneira de representação que será descrita a seguir.

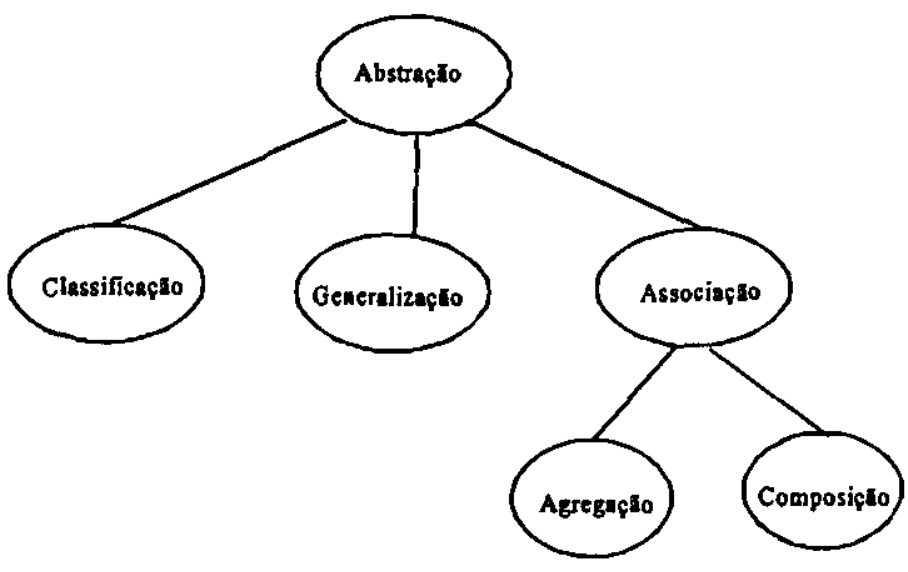

Figura 12) Abstrações do modelo SIRIUS 


\subsection{Objeto}

Em SIRIUS, apenas os objetos identificados pelo usuário como tal são chamados objetos ${ }^{4}$.

Notação: A representação gráfica de um objeto no modelo é feita por um retângulo dividido horizontalmente ao meio por uma reta, e cuja parte superior é dividida por uma reta vertical. $\mathrm{Na}$ parte superior, à esquerda, é colocado o nome do tipo deste objeto; a parte superior direita é utilizada para dados da Abstração de Composição, a qual será descrita na seção 3.8; e finalmente a parte inferior é reservada para o nome do próprio objeto. A representação gráfica de um objeto no modelo é mostrada na Figura 13a). Na Figura 13b) e Figura 13c), dois exemplos são dados pa-

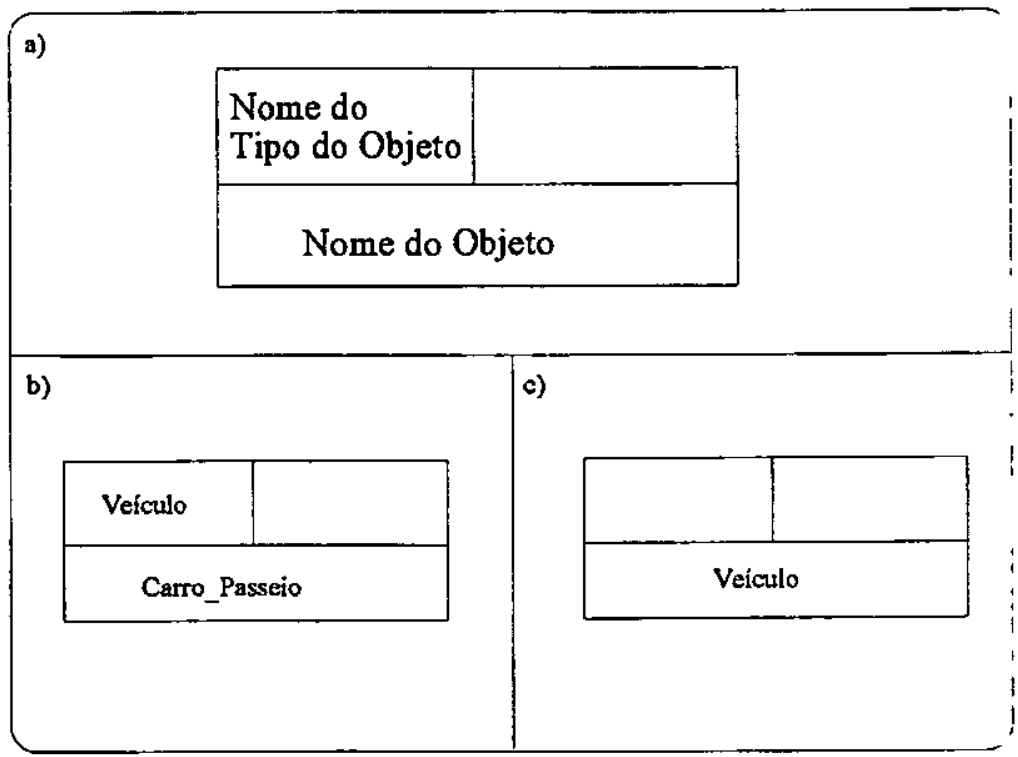

Figura 13) Representação de objeto em SIRIUS ra ilustrar a utilização desta notação.

Nos exemplos, a parte superior direita está em branco, pois seu uso ainda não foi explicado. No entanto numa modelagem, isto nunca deve ocorrer em objetos instanciaveis. Já o tipo de um objeto pode ficar em branco, quando seu tipo for o próprio metatipo tipo de objeto, que é reconhecido e controlado pelo sistema. Na Figura 13b), tem-se a representação de um objeto, cujo nome é Carro_Passeio, e o tipo é Veículo, e na Figura 13c) tem-se um objeto Veículo, onde o tipo de objeto é o metatipo tipo de objeto, que está omitido.

${ }^{4} \mathrm{O}$ modelo trata do termo objeto como sendo parte do objeto conceito (esse utilizado para referirse aos objetos identificados ou não pelo usuário). $\mathbf{O}$ termo objeto primário (que será visto adiante) também é uma parte do objeto conceito 


\subsection{Tipos de Atributos}

Existem dados no mundo real que estabelecem informações sobre os objetos e que, mesmo sendo também conceitos e, portanto, teoricamente objetos, não têm a propriedade de que cada uma de suas ocorrências no mundo real devam ser univocamente identificadas pelo usuário, a não ser por suas associações com outros objetos. Esses dados são modelados como valores de atributos e é através deles que se inserem a estrutura e o "comportamento" no objeto a que estão associados, caracterizando a sintaxe e a semântica do objeto na modelagem. No modelo, os tipos de atributos desempenham o papel de caracterizar objetos, podendo ser instanciados através de valores em atributos.

Notação: Na representação do modelo, os tipos de atributos são representados por setas, e estas são dispostas ortogonalmente a uma reta vertical que se origina no objeto ao qual estes atributos estão associados. As setas podem ser simples ou duplas. A seta simples indica o nome do tipo de atributo de um atributo monovalorado, e a seta dupla indica o nome do tipo de um atributo multivalorado. Esta representação pode ser vista

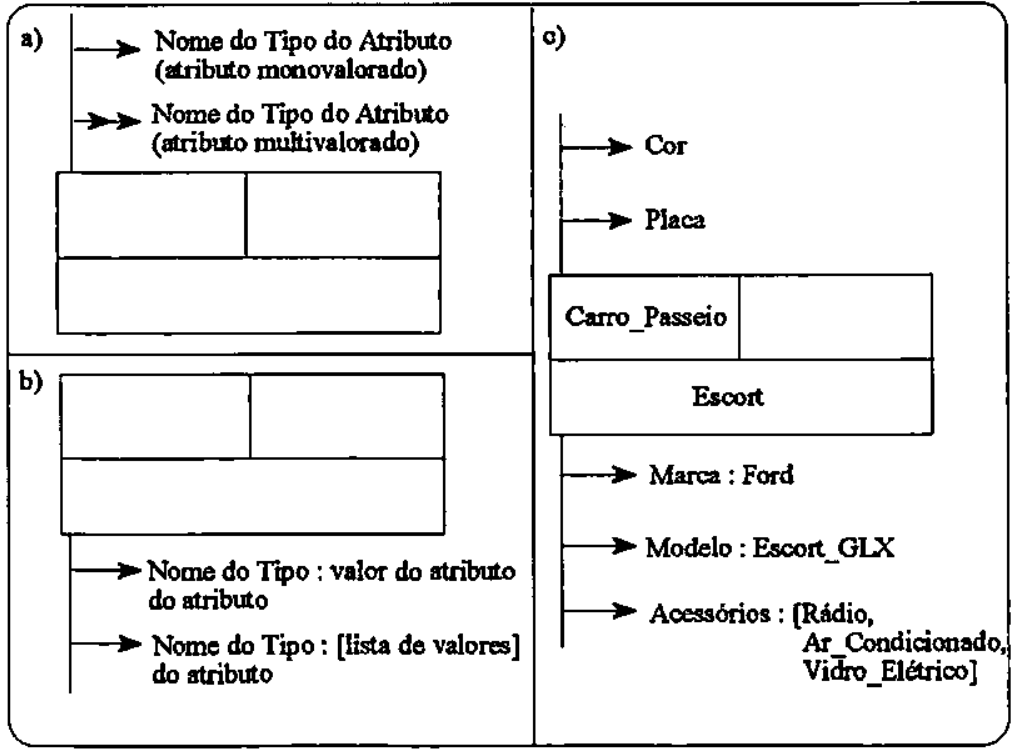

Figura 14) Notação de atributo na Figura 14. A informação de atributos instanciados e atributos não instanciados também é fornecida graficamente. Convencionou-se que os atributos situados acima do objeto são atributos não instanciados e os situados abaixo são atributos instanciados. Eles estão representados, respectivamente na Figura 14a) e na Figura 14b), onde o nome do tipo do atributo é seguido pelo símbolo de dois pontos, e este pelo valor do atributo. Observe-se que os atributos multivalorados, que são instanciados, são representados por setas simples. Para ilustrar esta representação na Figura 14c) é dado um exemplo, onde o objeto Escort do tipo Carro_Passeio, possui os tipos de atributo não instanciados Cor e Placa, situados acima do objeto. Na parte inferior do objeto, tem-se os atributos instanciados: Marca instanciada com o valor Ford, Modelo instanciado com o valor 
Escort_GLX, e o tipo de atributo multivalorado Acessórios instanciado com os valores Rádio, Ar_Condicionado e Vidro_Elétrico.

\subsection{Características de Atributos}

No modelo, considera-se que todo atributo possui um tipo e um conjunto de valores. A cada tipo de atributo estão associados uma característica e o tipo de dado que ele contém (um tipo de dado é dependente da característica). Por exemplo, para a característica número, pode ser um inteiro, real, byte, complexo, etc. A característica de um atributo de determinado tipo define o conjunto de operações que um Gerenciador de Dados pode efetuar sobre esse atributo (estabelecendo, portanto, o comportamento do objeto ao qual esse atributo está associado).

Em SIRIUS [Biajiz_96a], as características são divididas em: estáticas: comentário e propriedade; dinâmica: regra e procedimento; de interface: visualização, som, partitura [FigueiredoMB_97], imagem [Santos_97]e gráfico; e estruturais: estrutura de dados [Gazeta_97], tempo [FigueiredoLR_97], tupla, e relacionamento.

Notação: A notação utilizada para representar a característica de um atributo consiste em prefixar o nome do atributo no diagrama, como símbolo da sua característica precedendo-o. Os símbolos utilizados nas características estão indicados na Figura 15a), onde cada característica possui um símbolo que a indica (na maioria dos casos, são as iniciais da característica). O exemplo, mostrado na Figura 15b) e Figura 15c), ilustra como são utilizados os símbolos de característica. $\mathrm{Na}$

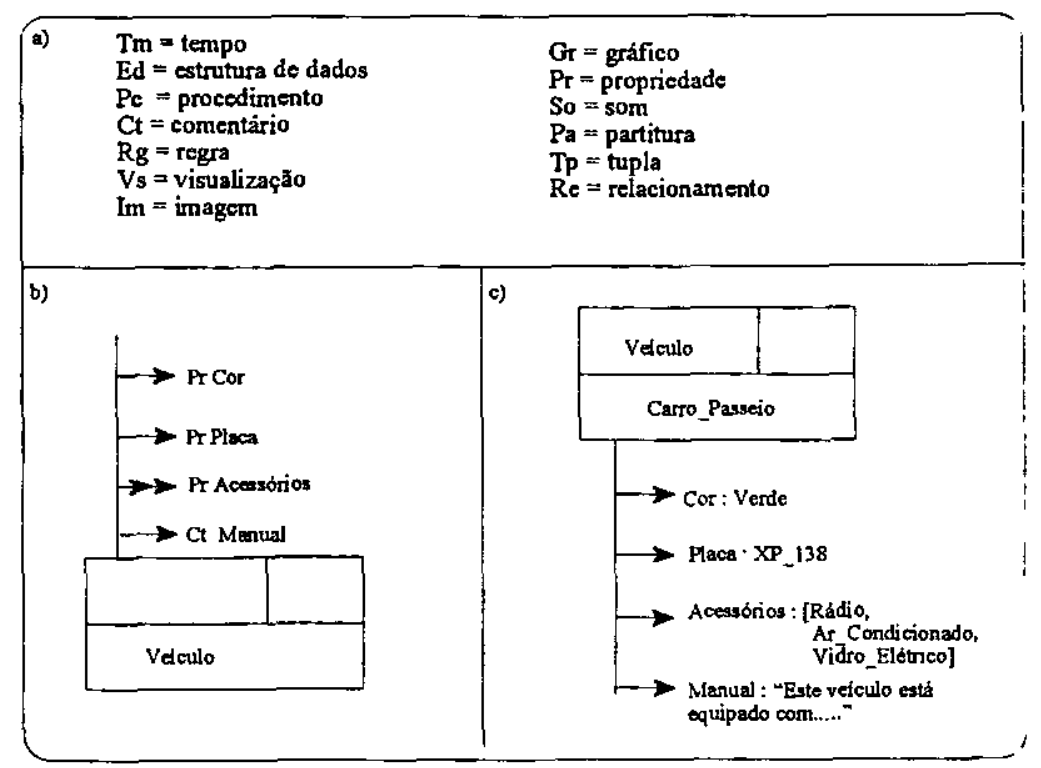

Figura 15) Símbolos utilizados para representar caracteristicas de atributos e um exemplo

Figura 15b), o objeto Veículo possui os atributos nāo instanciados Cor e Placa monovalorados, que possuem a caracteristica propriedade. $\mathrm{O}$ atributo Acessórios é multivalorado e sua caracteristica 
também é propriedade. $\mathrm{O}$ objeto Veículo possui também o atributo monovalorado Manual, cuja característica é comentário (pois este atributo corresponde a campos longos, ou seja, informações para o usuário tratadas apenas de forma textual). Na Figura 15c), os atributos do objeto Veículo são instanciados. Note-se que os símbolos das características de atributos não permanecem no objeto instanciado Carro_Passeio. Neste caso, o tipo do atributo do objeto (que agora é um atributo instanciado) é seguido de dois pontos e, finalmente, pelo valor do atributo.

\subsection{Abstração de Agregação}

Os atributos agregam-se para constituir o conjunto de dados que representam na modelagem os dados do objeto do mundo real, ou para constituir outros atributos. Atributos estabelecem também relacionamentos entre objetos, ou seja, dois ou mais objetos são agregados através de um objeto primário5. A agregação de atributos pode ocorrer através da associação de atributos, formando tuplas, e atributos de atributos. Netação: A notação utilizada na agregação de atributos está ilustrada na Figura 16. Nesta figura, não estão representados os símbolos de característica de atributos para não sobrecarregar a figura. $\mathrm{Na}$ Figura 16a), tem-se a notação da agregação de atributos monovalorados caracterizando informações sobre um objeto. Na Figura 16b) tem-se um exemplo de três atributos monovalorados, que são Motor, Marca, e Cor. A Figura 16c) ilustra a representação de uma lista, um conjunto e um vetor. Tais atributos permitem que se tenha mais de um valor associado a eles. A seta com duas pontas opostas representa uma lista; a seta com duas pontas na mesma direção indica um conjunto; e um colchete sobre uma seta representa um vetor. Um exemplo de atributos multivalorados é mostrado na Figura 16d). Nesta figura, está ilustrada uma lista, no caso o atributo Revisões representando uma seqüência de Revisões que um carro deve efetuar, o atributo Conj_pneus, que é um conjunto de pneus que o carro possui, e o atributo Troca_de_Óleo, um vetor que indica que três trocas de óleo devem ser efetuadas no máximo. Na Figura 16e) tem-se a notação de uma tupla formada pela agregação de mais do que um atributo. A representação é efetuada através de setas dispostas ortogonalmente a uma reta

${ }^{5} \mathrm{O}$ termo objeto primário é utilizado para repreferenciar os objetos que são manipulados pelo próprio sistema, pois estes apresentam uma caracteristica mais voltada à implementação 
vertical, aponta-

da por uma seta que indica a agregação, onde o nome de um atributo tupla é escrito sobre a seta que o representa. $\quad \mathrm{Na}$ Figura 16f) tem-se uma tupla Painel, composta pelos subatributos monovalorados Velocímetro,

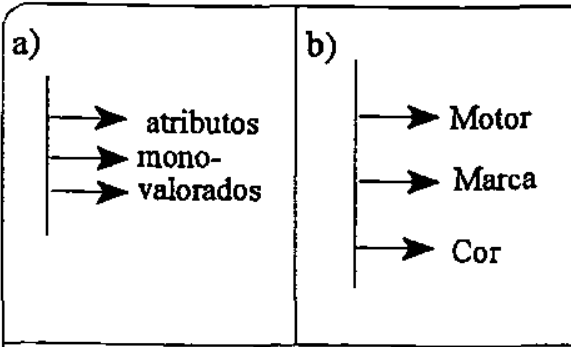

e)

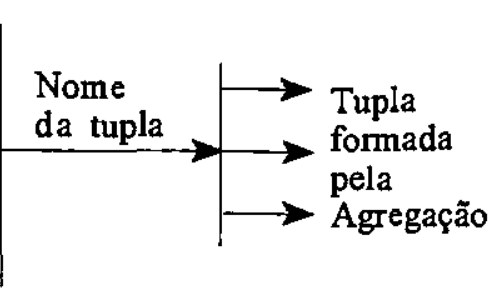

g)

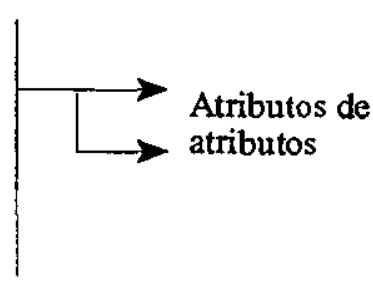

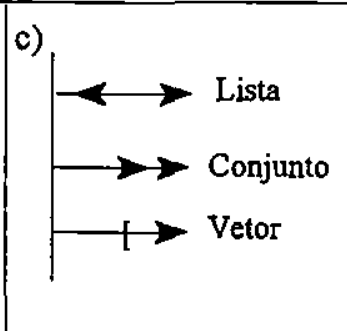

d)

f)

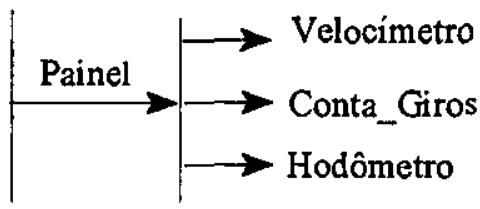

h)

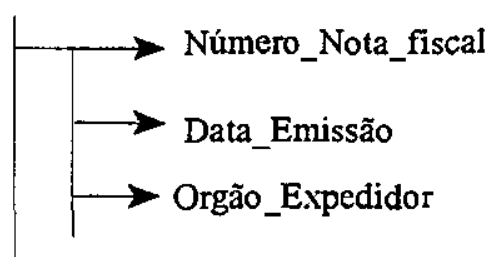

Conta_Giros e Hodômetro. A Figura 16g) ilustra um atributo denominado atributo de atributo. Este representa a associação de atributos (subatributos) a um atributo, o qual é denotado por setas que partem de uma reta ortogonal à seta do atributo que está associado ao objeto. A Figura 16h) exibe a representação de atributos de atributos. No exemplo, tem-se. o atributo de atributo chamado Número_Nota_Fiscal, e dois subatributos associados, que são: Data_Emissão e Orgão_Expedidor. Os atributos da Figura 16b), d), f) e h), podem, por exemplo, estarem associados a um objeto do tipo Veículo. No entanto, este objeto não está sendo representado para não sobrecarregar a figura desnecessariamente.

A notação utilizada na agregação de objetos através de relacionamentos está ilustrada na Figura 17. Os relacionamentos são caracterizados por atributos com característica de relacionamento nos objetos envolvidos. Na Figura 17a), está representado um relacionamento entre dois objetos. A notação do relacionamento é identificada através dos atributos, com característica de relacionamento. associados 


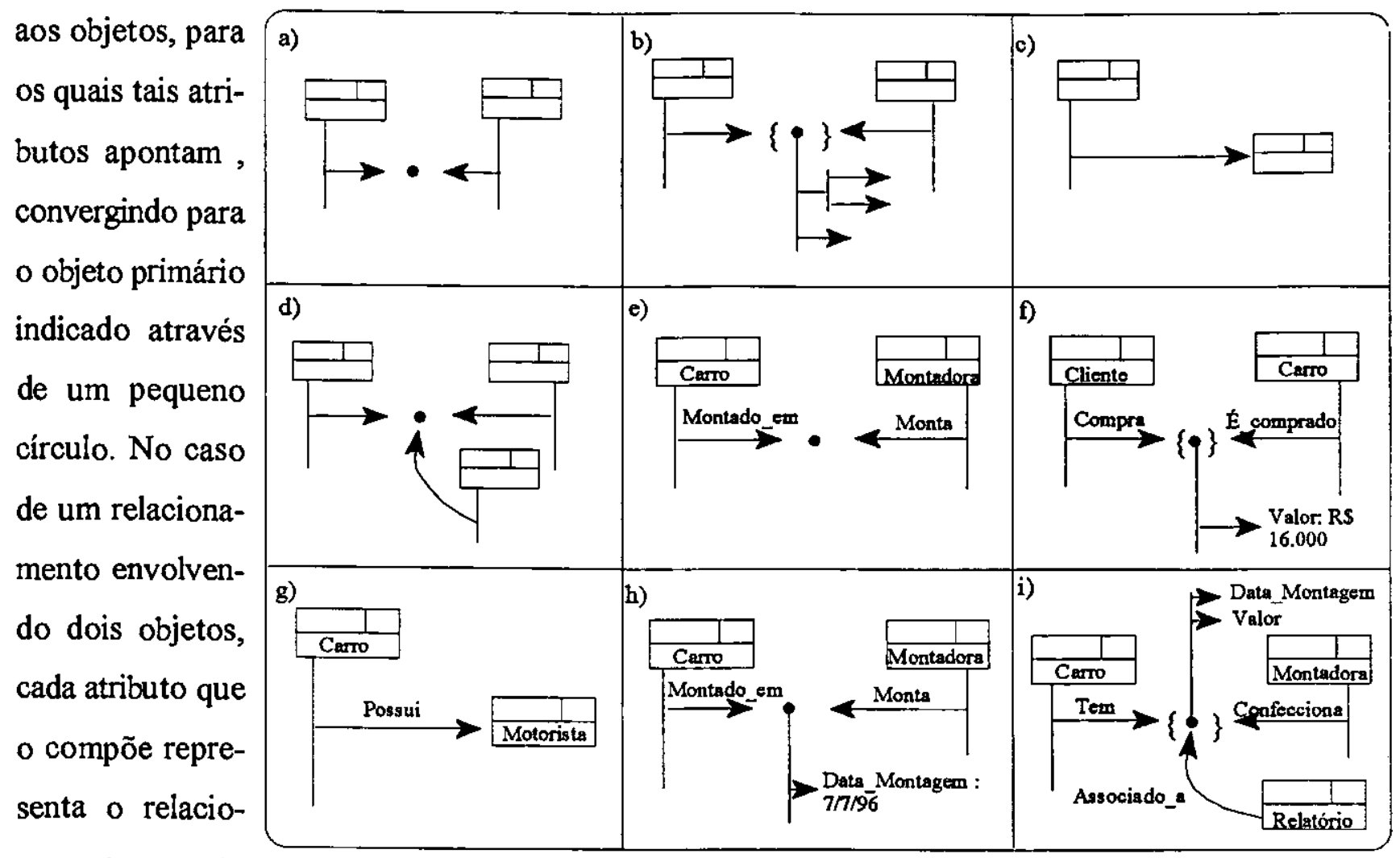

namento oposto Figura 17) Notação utilizada na agregação de objetos um ao outro. $\mathrm{Na}$

Figura 17b) pode-se ver a representação de atributos de relacionamento. A partir do objeto primário entre os dois atributos que caracterizam a agregação dos objetos, é traçada uma reta vertical, da qual partem os atributos desse relacionamento. Os atributos de relacionamento podem ser atributos simples, tuplas, listas, vetores, conjuntos, ou outros relacionamentos, como os de qualquer objeto. Quando são atribuídos valores a esse relacionamento, a representação da instância do relacionamento é similar ao ilustrado na Figura 17f). Na Figura 17b) existem duas chaves envolvendo o objeto primário estas caracterizando a agregação entre os objetos participantes da relação. Cabe notar que a chave que envolve o obejto primário carrega consigo uma carga semântica; em outras palavras, elas indicam que existe uma instância do relacionamento em questão. Na Figura 17c) encontra-se a representação de um objeto como valor de um atributo. Note-se que não há, nesse caso, a representação de um atributo "oposto", e a característica do atributo não é de relacionamento, apenas o "tipo de dado" do atributo é um tipo de objeto. 
Relacionamentos ternários, quaternários, etc. também podem ser representados. Neste caso, em mais do que dois objetos, existem atributos com caracteristicas de relacionamento, que se associam via objeto primário representado pelo círculo central. Na Figura 17d), tem-se a representação de um relacionamento ternário. Nas Figura 17e), Figura 17f), Figura 17h) e Figura 17i) são mostrados alguns exemplos de relacionamentos. Na Figura 17e), é exemplificado um relacionamento binário simples entre dois objetos, onde os objetos Carro e Montadora estão agregados via atributos Montado_em e Monta. Na Figura 17f), está representado um relacionamento entre os objetos Cliente e Carro, os quais estão agregados através dos atributos multivalorados Compra e É_Comprado. A partir do objeto primário relacionamento, é colocado um atributo do relacionamento, que indica o Valor da compra, cujo valor instanciado no exemplo é R\$16.000,00. Note-se que neste caso as chaves indicam quais dentre o conjunto de relacionamentos possiveis são instanciados, pois os atributos com característica de relacionamento são multivalorados. Apenas uma instância do relacionamento está sendo considerada e esta possui um atributo de relacionamento instânciado.

Na Figura 17g), pode-se ver um caso onde o valor de um atributo é um objeto. No exemplo, o atributo Possui do objeto Carro possui, como valor, o objeto Motorista. Na Figura 17h) tem-se um exemplo de relacionamento binário, análogo ao exemplo mostrado na Figura 17e). Neste caso, a instância do relacionamento representada é a única possivel, uma vez que os atributos que participam da relação são monovalorados. Na Figura 17i), está representado um relacionamento ternário, onde os objetos participantes são Carro, Montadora, e Relatório, os quais estão ligados através do objeto primário relacionamento, que é o valor dos atributos: Tem, Confecciona e Associado_a.

Em SIRIUS, define-se um relacionamento particular denominado relacionamento triplo, onde a denominação "triplo" não provém do número de objetos participantes, mas sim por identificar três maneiras de um objeto poder participar do relacionamento [Biajiz-92]. Um relacionamento triplo é um relacionamento que envolve mais de dois objetos, no qual dois dos objetos são capazes de identificar o relacionamento (através de um par de atributos com característica de relacionamento denominado relacionamento identificador) com os demais objetos envolvidos, acessados a partir do relacionamento identificador (aos objetos envolvidos dá-se o nome de relacionamentos de conjuntos). Na Figura 18 , é dado um exemplo, onde o objeto Carro relaciona-se com os objetos: Montadora, Computador. 
Ferramenta e Peça. Note-se que, apesar de cinco tipos de objetos participarem do relacionamento, este relacionamento não é um relacionamento quinário, pois o objeto Carro relaciona-se com o objeto Montadora, constituindo o relacionamento identificador. $\mathrm{O}$ objeto Carro associa-se aos objetos Computador, Ferramenta e Peça, estabelecendo

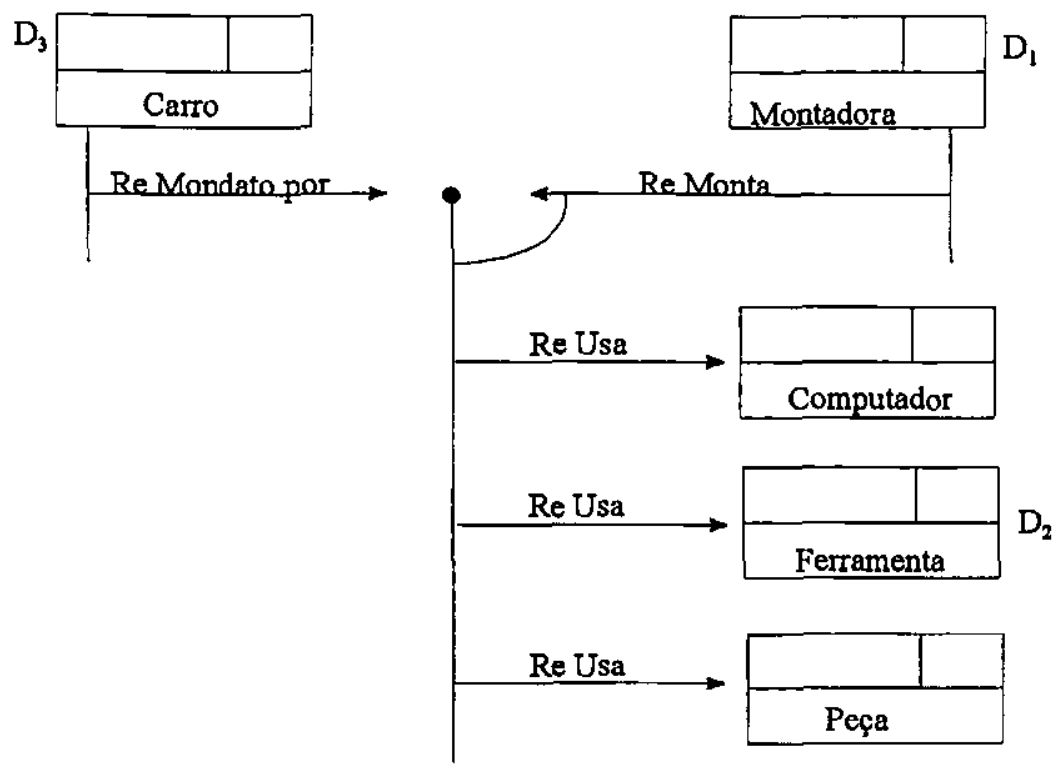
relacionamento de conjunto.

Semanticamente, tem-se que um objeto Carro é montado por uma Montadora, usando os objetos do conjunto $D_{2}$ formado por objetos dos tipos: Computador, Ferramenta e Peça. É importante observar que Carro ser montado por Montadora é identificador, pois Computadores, Ferramentas e Peças usadas são identificadas a partir desse relacionamento. Na Figura 18, observa-se também a existência de três divisões $D_{1}, D_{2} \in D_{3}$, que são estabelecidas para tornar mais clara a definição de relacionamento triplo. No exemplo, o objeto Carro pertence à divisão $D_{3}$ (o que é montado), os objetos Computador, Ferramenta e Peça pertencem à divisão $D_{2}$ (usando o que), e o objeto Montadora pertence à divisão $D_{1}$ (quem monta).

O conceito de multiplicidade também é empregado em SIRIUS. A própria notação utilizada identifica se o atributo é monovalorado ou multivalorado, mas pode-se usar o conceito de multiplicidade, que indica os limites mínimo e máximo de valores instanciados que um determinado atributo pode assumir como complemento, pois este fornece mais informações semânticas a respeito dos atributos.

A multiplicidade é um dado complementar, e como tal, sua indicação é optativa. A representação da multiplicidade se dá através de um par (entre parentêses), onde o limite inferior pode ser 0,1 ou outro inteiro definido, e o limite superior pode ser $1, N$, ou um outro inteiro definido. Quando se utiliza a 
multiplicidade, esta é indicada precedendo $o$ nome do atributo, como mostra $o$ exemplo na Figura 19, bipartida em Figura 19a) onde se tem os atributos não instanciados, e na Figura 19b), onde aparecem os atributos instanciados. Notese que a representação de multiplicidade não é utilizada para representar instância na Figura 19b).

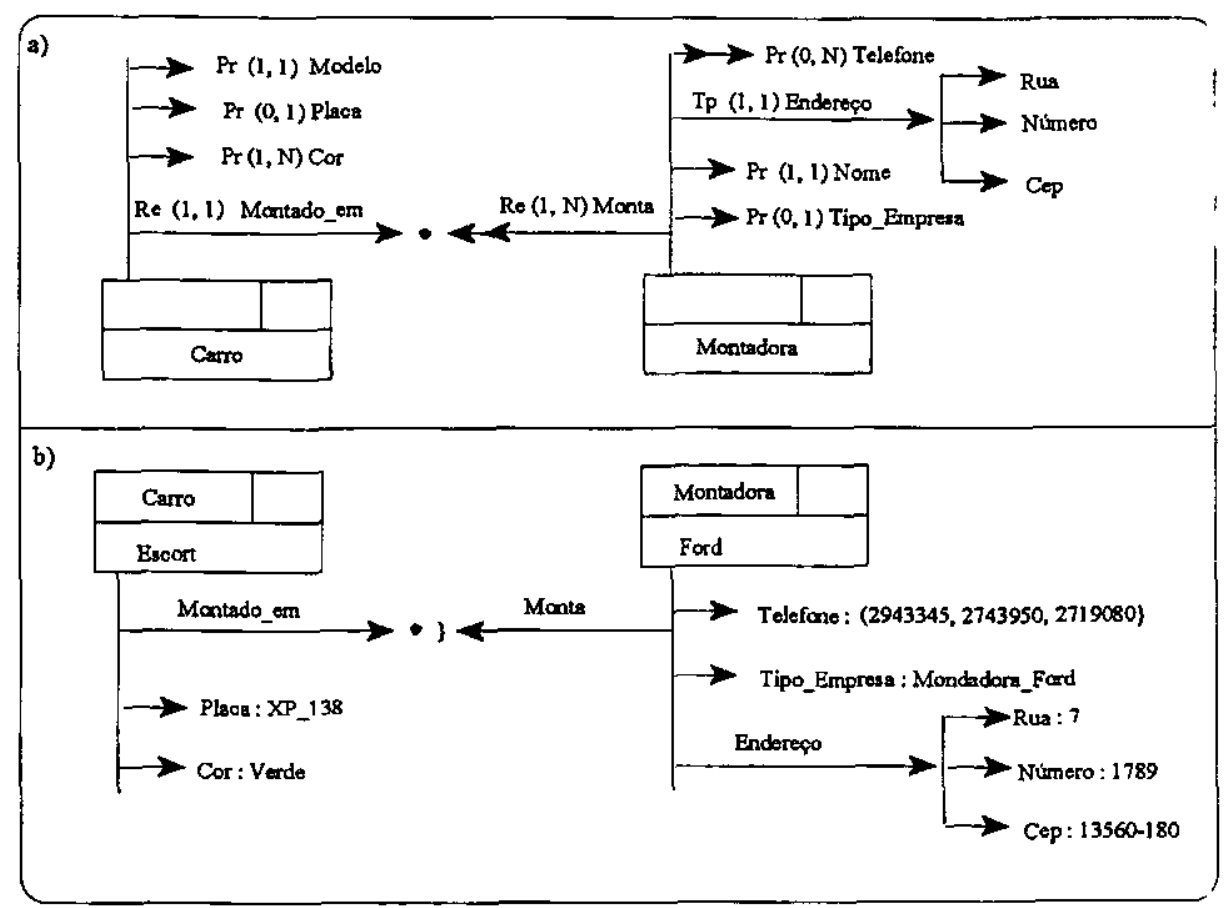

Figura 19) Exemplo de agregação

\subsection{Abstração de Classificação}

A abstração de classificação é obrigatória em qualquer modelo de dados, pois são as particularizações da abstração de classificação que permitem a existência de esquemas de dados, cujos elementos são instanciados nas bases extensionais. O diagrama de abstração de classificação permite estabelecer claramente como se dá o processo de classificação/instanciação nos modelos de dados. Este processo gera uma hieraquia de classificação.

A hierarquia de classificação pode ser vista através de níveis de classificação, que vão do objeto mais "básico" até o objeto máximo da hierarquia (que é denotado em SIRIUS como Objeto Abstração de Classificação). Modelos tradicionais definem o número de niveis como sendo apenas um (por exemplo o ME-R) ou dois (os metamodelos). Entretanto, conceitualmente não existe um número máximo de níveis, sendo esse número determinado pela realidade que está sendo modelada. Em SIRIUS, a capacidade de representação de um tipo de objeto e de suas instâncias constitui um elemento de representação do modelo, ou seja, é um construtor semântico. Quando o tipo de um objeto não é outro 
tipo definido pelo usuário, é porque ele é um tipo inicial, ou seja, metatipo objeto. Representa-se isso num diagrama, deixando-se em branco a parte superior esquerda da representação de objetos.

Notação: Na Figura 20, são ilustradas ocorrências da abstração de classificação. Na Figura 20 a), pode-se ver um objeto instanciável, cujo nome é Veículo. Na Figura 20b) tem-se um objeto instanciavel, Modelo classificado como sendo do tipo Veículo. Na Figura 20c), o objeto XP-138 é representado, e neste caso o seu tipo é Modelo.

Assim, XP-138 é uma instância de Modelo e este é uma instância de Veículo (onde Veículo possui como tipo o metatipo). A seqüência de ocorrência destas instânciações é ilustrada na Figura 20d). Analogamente, Veículo é uma

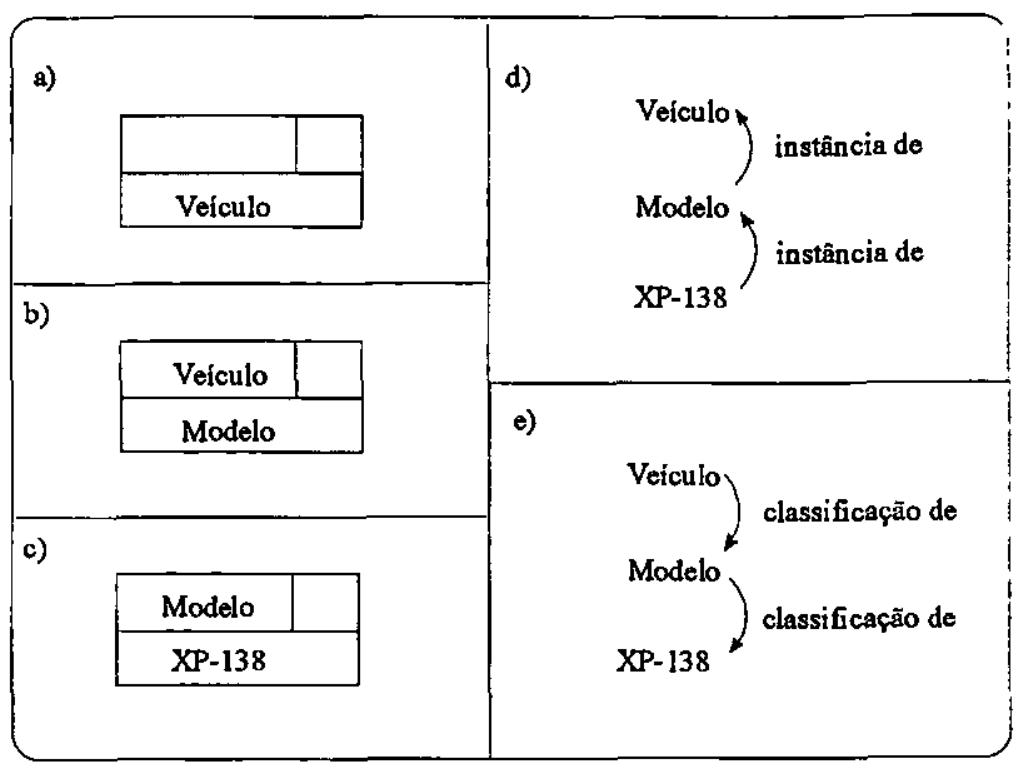

Figura 20) Representação gráfica de objetos e tipos de objetos classificação de Modelo, e Modelo é uma classificação efetuada sobre carros, entre os quais o identificado pela placa XP-138. Este caso é esquematizado na Figura 20e). Observa-se que a ocorrência da abstração de classificação envolve os três objetos juntamente, ou seja, em uma modelagem, os três objetos apareceriam em um mesmo diagrama. Em outras palavras, os diferentes níveis da hierarquia da abstração de classificação aparecem ao mesmo tempo em uma modelagem, sendo representados ao mesmo tempo os objetos e suas instâncias.

A abstração de classificação é representada pela indicação do nome do tipo do objeto (na primeira linha do retângulo à direita), e pela indicação do nome do próprio objeto (na segunda linha do retângulo). A maneira como um objeto é instanciado é estabelecida através de um subconjunto dos atributos de um objeto que é tipo, denominados Atributos de Classificação do Tipo ou, simplesmente, atributos de classificação. A notação proposta para representar os atributos de classificação é colocar-se uma linha vertical com os atributos de classificação acima do retângulo que representa o objeto, cujos atributos 
do próprio objeto, chamados de Atributos de Instância (ou Atributos Instanciados), são representados na linha abaixo do retângulo.

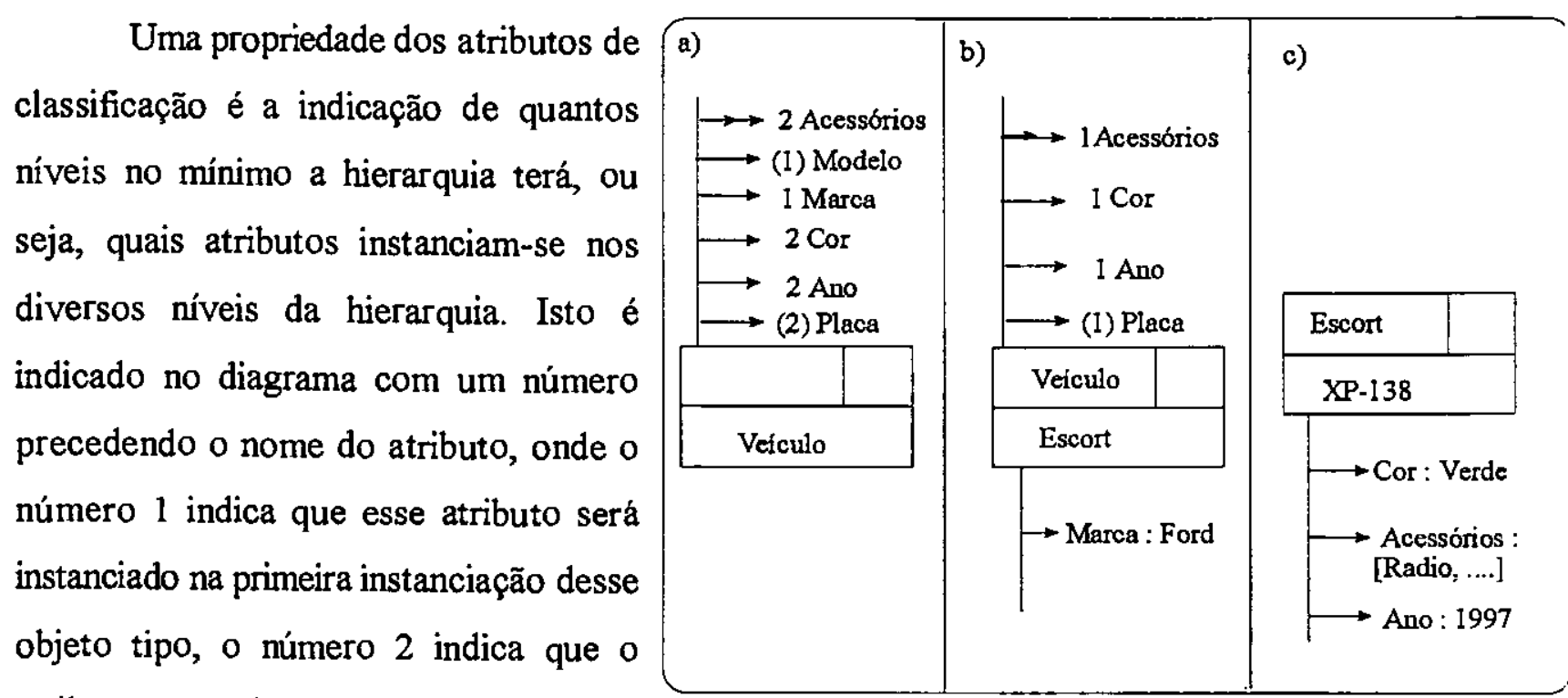
atributo será instanciado na segunda Figura 21) Exemplo de ocorrência de abstração de classificação instanciação desse objeto, etc. 0 raciocínio é análogo para outros números. Outra propriedade que o diagrama de classificação exibe é indicar se o atributo será um identificador (de usuário) do objeto onde ele for instanciado. Isso é representado nos diagramas colocando-se entre parênteses o número do nível onde o atributo será instanciado. A Figura 21 ilustra estes conceitos, onde o atributo Modelo de veiculo é um identificador que classifica o objeto Escort, e o atributo Placa é um identificador que classifica XP-138, ou reversamente, o objeto XP-138 é instância de Escort, e Escort é instância de Veiculo. Na Figura 21a), tem-se a representação de um tipo de objeto (o objeto denominado Veiculo), cujo tipo que está omitido, é o próprio metatipo. Note-se que este objeto não tem atributos de instância, apenas atributos de classificação. Os atributos precedidos pelo número 1 serão instanciados em todas as instâncias de Veículo, ou seja, nos modelos, e os atributos precedidos pelo número 2 serão instanciados nas instâncias das instâncias de Veículos, ou seja, nas instâncias de cada modelo. Na Figura 21b), mostra-se a representação de um objeto denominado Escort, cujo tipo é Veículo. Note-se que este objeto possui um atributo de instância (abaixo do objeto), e atributos de classificação (acima do objeto) que serão instanciados na Figura 21c). Pode-se observar também que na Figura 21a), o número 1, que precede 
o atributo Modelo, indica que ele será um identificador do objeto instanciado, ou seja, não poderão existir 2 Veículos com o mesmo Modelo. Já o número 2, precedendo Placa, indica que (por ser 2) não será instanciado nas instâncias de Escort, mas será instanciado como identificador nas instâncias das instâncias de veículos. Ou seja, não poderão existir 2 objetos com placas iguais do mesmo Modelo. $\dot{E}$ por isso que aparece 1 entre parênteses precedendo Placa no objeto Escort, indicando que, na instância de Escort, O atributo Placa é identificador. O atributo identificador Placa foi instanciado no objeto XP138. Observe-se que o objeto XP-138 não é um objeto instanciável.

Note-se que os
números sem parênteses são
usados para indicar atributos
que serão simplesmente
instanciados em seus valores,
mas sem serem identificadores. É o caso dos atributos Cor e Ano (atributos monovalorados) e Acessórios (atributo multivalorado). A Figura 22) fornece um exemplo de atributos multivalorados. $\mathrm{Na}$

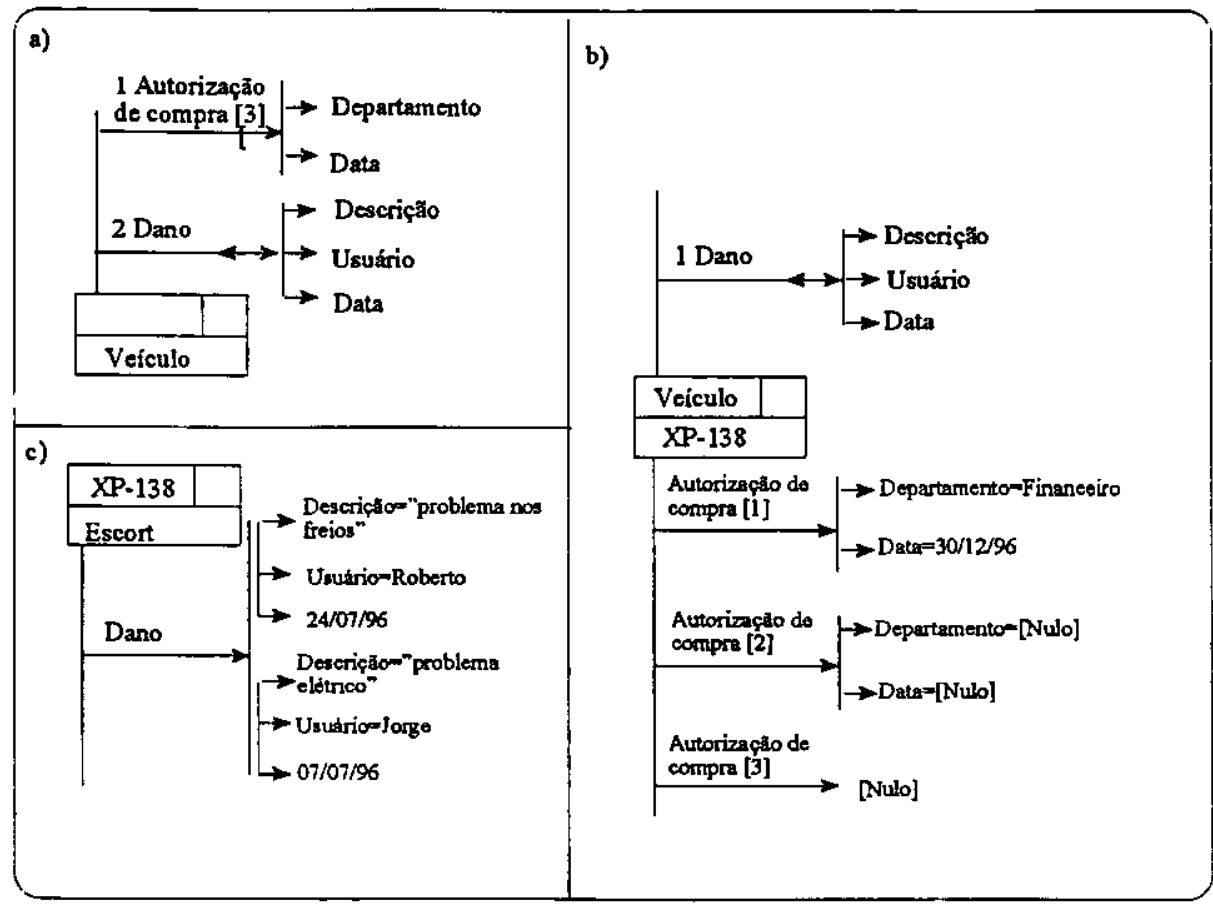

Figura 22) Exemplo de atributos multivalorados

Figura 22a), mostram-se os

atributos multivalorados Autorização de Fabricação (organizado como um vetor de 3 autorizações), e o atributo Dano (organizado como uma lista de valores); e na Figura 22b), uma possível instanciação do atributo Autorização de fabricação, que, neste caso, foi instanciada 3 vezes, das quais a autorização 1 tem valores locais (Departamento e Data), a autorização 2 tem valores nulos para todos os componentes (Departamento e Data), e a autorização 3 não está definida. Na Figura 22c), ilustra-se o fato de que o objeto XP-138 do tipo Escort, cujo atributo Dano representa uma lista com 2 valores (cada valor sendo uma tupla, com todos os atributos elementares definidos). Cabe dizer, que o modelo suporta atributo default e atributo extra. $O$ primeiro indica a possibilidade de se ter um atributo de classificação mais que 
já possui um valor prédefinido, onde tal valor pode ou não ser repassado para as instâncias do objeto que possui este atributo. $\mathrm{O}$ atributo extra por outro lado, é um atributo que não tinha sido previsto quando um objeto e seus atributos foram definidos. No entanto se durante o processo de modelagem houver a necessidade de se definir um atributo que não tinha sido previsto este recebe o nome de atributo extra. É importante observar que um atributo extra pode ser criado em qualquer nivel da hierarquia e pode ser também tanto um atributo de classificação como de instanciação. Note-se que quaisquer objetos podem ter atributos "extras" não previstos em seu tipo, sejam de instância ou de classificação. Isso é fundamental para permitir a construção dos tipos instanciados diretamente do metatipo "Objeto", e sua representação no diagrama de abstração de classificação é análoga à representação dos outros atributos do diagrama. Um exemplo, pode ser visto no Anexo Figura 71, ele contém um atributo que possui valor default, que é o atributo Número_de_Pneus. Um exemplo de atributo extra pode ser o atributo Número_de_Espelho_Retrovisor no objeto Escort (este não ilustrado na figura).

Os símbolos apresentados nas Figura 21 e Figura 22, permitem a construção de um diagrama que admite representar, em uma mesma modelagem, tipos de objetos e suas instâncias. É interessante notar que dessa forma é possível mostrar explicitamente os relacionamentos entre tipos de objetos de niveis de classificação diferentes, assim como entre objetos e tipos de objetos. Também deve-se notar que apenas um nível da abstração de classificação deve obrigatoriamente ser modelada, uma vez que os demais níveis podem gerar uma coleção de conceitos muito dependentes da evolução da base de dados.

\subsection{Abstração de Generalização}

A abstração de generalização é caracterizada pelo fato de um tipo de objeto poder acrescentar mais detalhes (especializar) a um outro tipo já existente. $O$ modelo impõe para uma generalização que sejam definidos: um tipo que será especializado (supertipo); um conjunto de tipos especializados (subtipos); um critério de especialização (critério); restrições para especialização (restrições); e um conjunto de regras de inicialização para cada tipo especializado (regras). 
Notação: A notação utilizada é a encontrada na Figura 23. A abstração é mostrada através de uma rede acíclica, onde cada nó é um tipo de objeto. Os retângulos que representam tipos específicos têm uma terceira linha dividida em duas. Na parte direita dessa terceira linha, são colocados os valores de inicialização d e at r ibutos, relacionamentos e colônias de objetos do supertipo. Quando um tipo é criado segundo seu predicado (é representado pelo conjunto denominado "Inic"). $\mathrm{Na}$ parte esquerda da linha, é colocado o critério para que um objeto de tipo genérico seja desse tipo específico. Um retângulo no centro do diagrama de representação indica as restrições da generalização: quando o critério depende do valor de um atributo cujo domínio é discreto e finito, o nome desse atributo é indicado na metade de baixo do retângulo. Nesse caso, a terceira linha de cada tipo específico tem, na

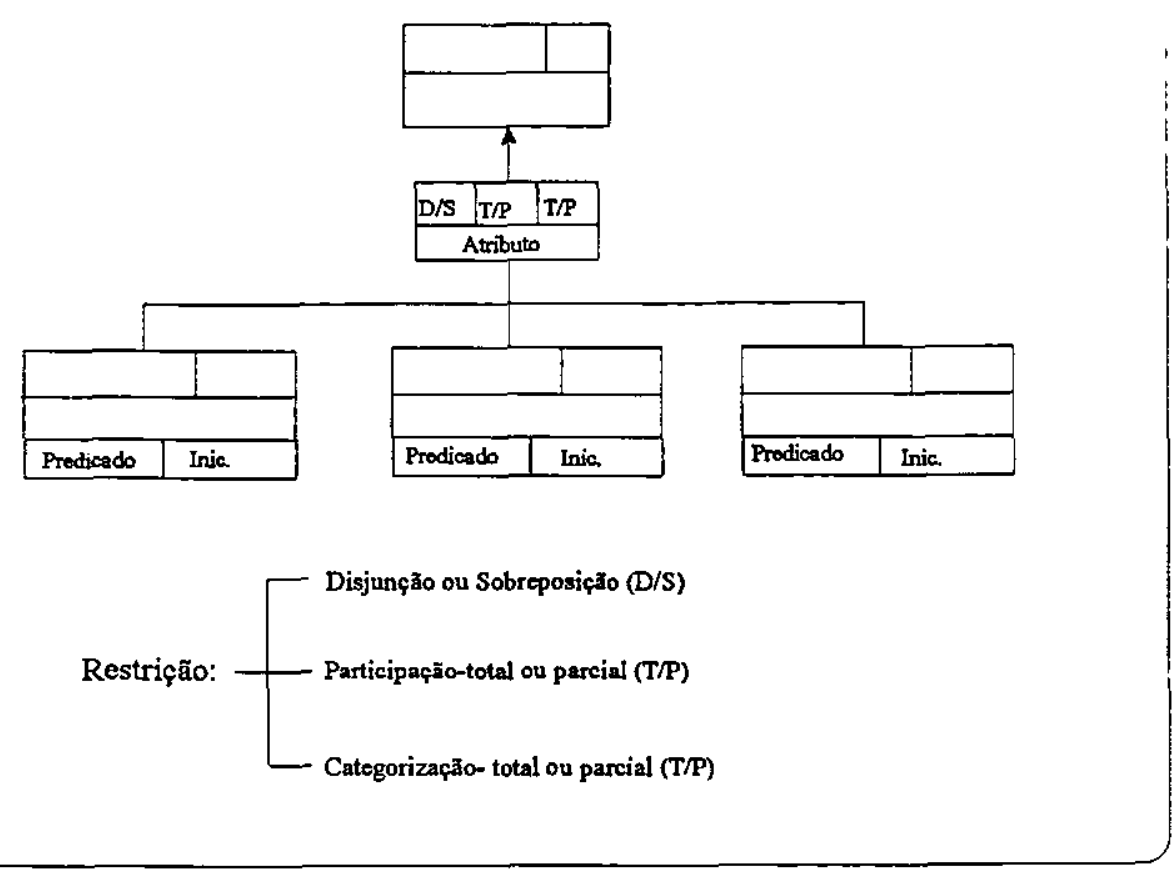

Figura 23) Notação da abstração de generalização

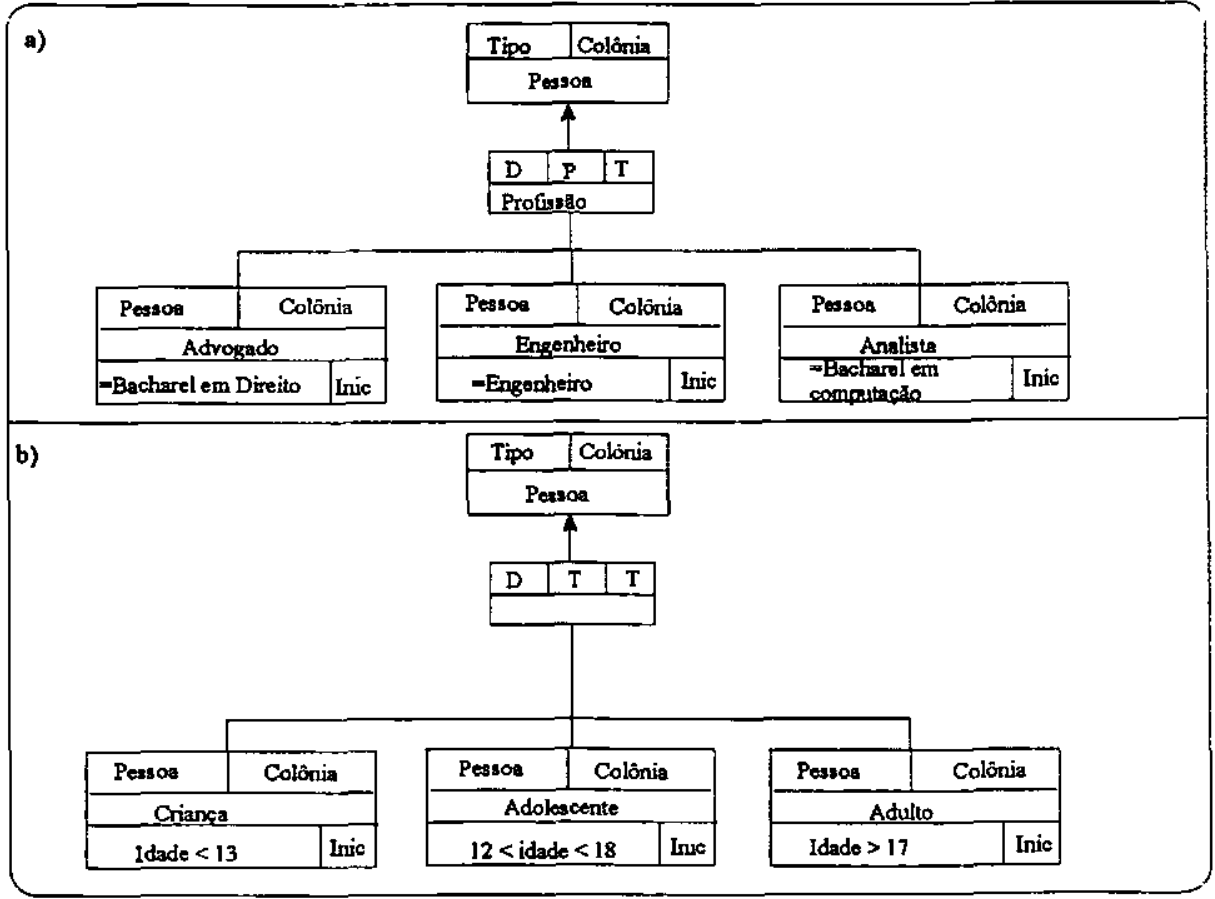

Figura 24) Exemplos de ocorrências da abstração de generalização 
parte do predicado, o valor que o atributo deve assumir; quando o critério depende de mais de um atributo, de uma expressão sobre o atributo, ou de uma coleção de valores de atributos, a parte de abaixo do retângulo é deixada vazia. Nesse caso, a terceira linha do retângulo que representa cada tipo específico tem o seu critério particular indicado. Um exemplo de cada situação descrita acima é mostrado na Figura 24.

\subsection{Abstração de Composição}

O termo composição é utilizado para caracterizar situações em que os objetos são realmente "compostos por" outros, como por exemplo, quando se descreve que um carro é "composto por" motor, lataria, pneus, etc. Note-se que a Abstração de Composição, tal como a Abstração de Agregação, é uma especialização da Abstração de Associação entre objetos, porém representa um significado diferente, mais específico, pois cada instância da Abstração de Composição determina a existência de um objeto composto, como o objeto abstrato, e um conjunto de objetos que são "parte de" esse objeto, como objetos detalhe, onde os objetos que são parte de um objeto composto são objetos de fato, definidos e reconhecidos pelo usuário.

Notação: A Figura 25a) mostra o relacionamento é parte que existe entre um objeto composto e suas partes. É comum que esses objetos formem um conjunto com propriedades distintas. Assim, SIRIUS define o conceito de Colônias, como o Conjunto de Objetos que compõem um Objeto Composto segundo um determinado Aspecto. Na Figura 25b), tem-se os relacionamentos implicitos que ocorrem entre os objetos envolvidos nu-

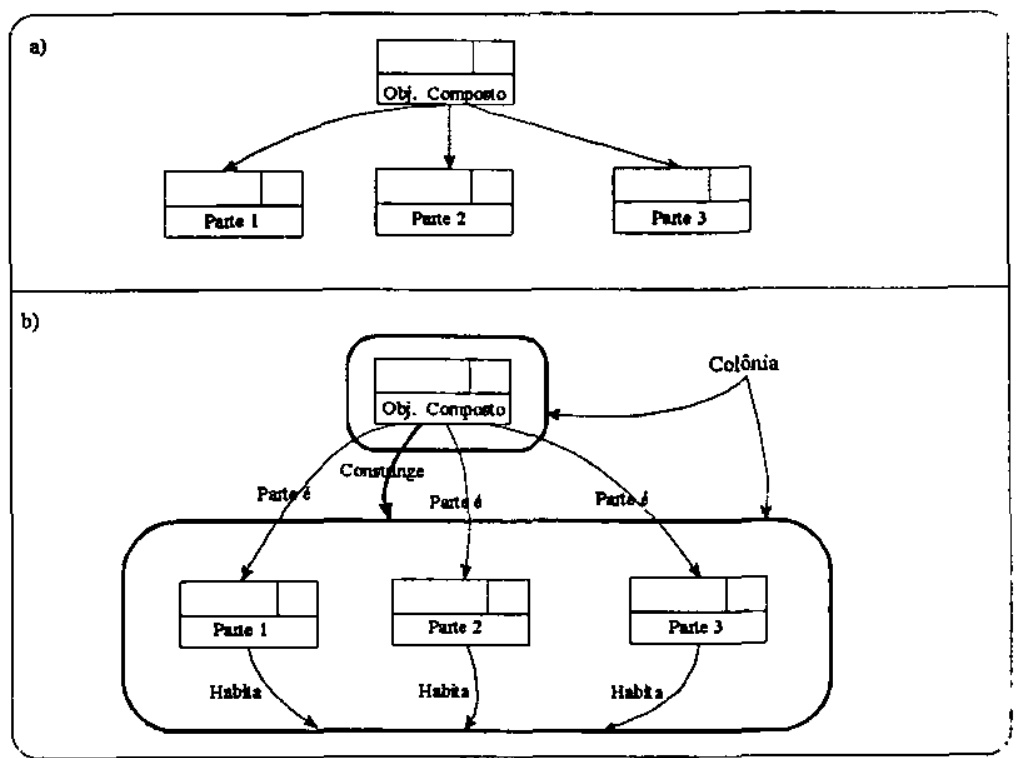
ma ocorrência de uma Abstração de Figura 25) Representação de composição (colônia de objetos) 
Composição: um objeto composto constringe ${ }^{6}$ uma colônia, onde habitam os objetos objetos parte, que são parte daquele objeto composto. Colônias determinam objetos primários, que, como qualquer outro, possuem um tipo. Portanto, toda colônia tem um tipo.

Uma colônia poder representar composição lógica ou fisica de objetos, e o modelo impõe a restrição de que todo objeto deve habitar fisicamente exatamente uma colônia. Por outro lado, um objeto pode habitar logicamente qualquer quantidade de colônias, sem causar nenhum tipo de dependência existencial. Um objeto pode habitar logicamente a mesma colônia mais de uma vez.

A indicação do tipo da colônia que um objeto habita é efetuada nos diagramas através da colocação do nome da colônia na parte direita da linha do retângulo que representa o seu tipo de objeto, e para todo tipo é obrigatória a indicação de exatamente uma colônia que é habitada fisicamente.

Existe uma colônia fisica do tipo denominado "Global", na qual pode haver apenas uma instância. A partir dela, é definida a hierarquia de composição, que estabelece o contexto em que os objetos estão sendo compostos, e representa a própria base de dados.

Um exemplo pode ser visto através do diagrama denominado Diagrama Hierárquico de Colônias (DHC), na Figura 26). O "contorno" que envolve os objetos corresponde às colônias (objetos primários). No exemplo, estão representadas 3 colônias: a colônia Global, a colônia Acessórios e a colônia Peças. As setas que partem do objeto Veículo em direção

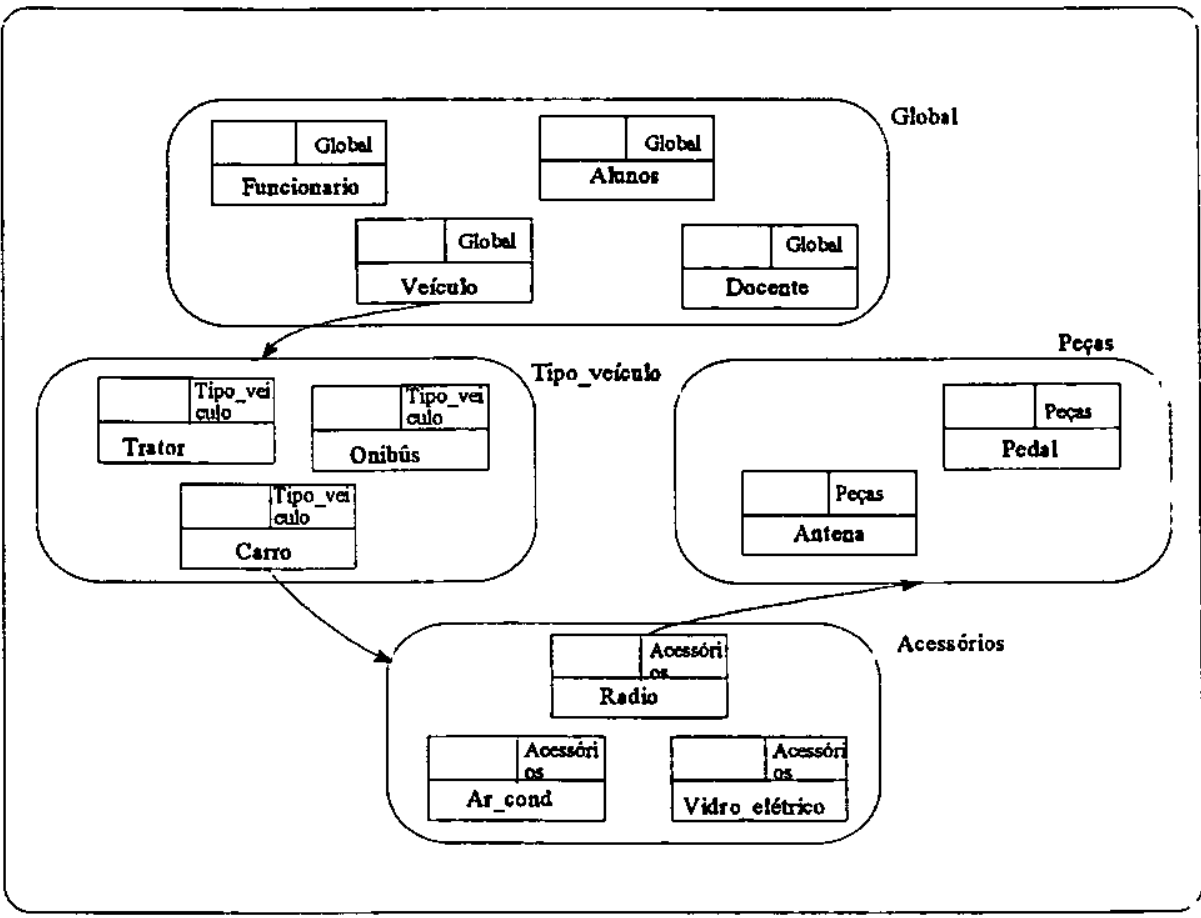

Figura 26) Exemplo de representação de colônias

${ }^{6}$ A palavra constringe é utilizada no sentido de delimitar (abraçar, envolver) um conjunto de elementos sob um determinado aspecto 
à colônia Acessórios, do objeto Rádio em direção à colônia Peças representam o fato de que o objeto Veículo constringe a colônia Acessórios, e o objeto Rádio constringe a colônia Peças.

\subsection{Conclusão}

Este modelo apresenta um rico conjunto de conceitos e de construtores semânticos, portanto sua notação tende a ser dificil de ser entendida, e tende a gerar diagramas densos, dificeis de serem compreendidos por pessoas que não tiveram contato com ele.

A notação original foi concebida para ilustrar o suporte formal do modelo, e não para ser utilizada de fato em processos de modelagem real. Assim, para que SIRIUS seja utilizado efetivamente em modelagens, é necessário que se defina uma notação mais adequada para seu uso prático. 


\section{Capítulo 4}

\section{Comparação entre os Elementos Básicos e Abstrações dos Modelos}

\subsection{Introdução}

Esta seção tem como objetivo efetuar uma comparação dos elementos conceituais básicos e também as abstrações dos modelos apresentados anteriormente [Araujo_98]. Este capítulo inclui cinco tabelas, onde cada uma aborda um tipo de conceito básico, avaliando sua notação em cada modelo. Em cada tabela, tem-se um texto correspondente visando ressaltar os pontos em comum entre os modelos, bem como as distinções e particularidades de cada um.

\subsection{Descrição das Tabelas}

\subsubsection{Entidade/Objeto e Conjunto/Classe}

A Tabela 1 apresenta os elementos que representam "alguma coisa", ou seja, elementos representáveis do mundo real. Estes podem ser representados por entidades (quando se consideram Modelos Semânticos) e/ou objetos (quando se consideram Modelos Orientados a Objetos). Conceitualmente, entidades e objetos são similares. No entanto, a informação sobre uma entidade (como a utilizada no ME-R e ME-RX) é fornecida restritamente a sua estrutura, através dos atributos que estão associados a esta. Já o conceito de objetos dos demais modelos, além de fornecer informações estruturais sobre os objetos através dos atributos, também oferece informações a respeito do comportamento do objeto, por meio das operações (métodos ou serviços) que estão associadas ao objeto. Nos modelos OOA [Coad_96], OMT [Rumbaugh_91] e Fusion [Coleman_94], estas operações são mostradas 
separadamente, o que não ocorre em SIRIUS [Biajiz_96], onde o comportamento está embutido nos atributos, classificados como possudores de comportamento dinâmico (vide capítulo 3 - seção 3.4 Características de Atributos), e é expresso através das características de atributos:

- regras: atributos que possuem uma condição e uma ação. A condição permite que a açāo seja executada sempre que for feita alguma operação do SGBD sobre o objeto, ou quando for recebida alguma mensagem pelo objeto, oriunda da execução de outra ação ou procedimento na base de dados;

- procedimento: são atividades que devem ser exercidas de uma forma predeterminada pelo sistema, solicitadas pelos aplicativos para a execução imediata ou postergada.

Esses atributos apresentam os aspectos dinâmicos do modelo, ou seja, as operações ou métodos, e fornecem informações a respeito do comportamento do objeto modelado.

Na Tabela 1 também é ilustrado o conceito de classe, o qual corresponde a conjuntos de objetos que possuem característica e comportamento comuns. Em OMT, os atributos e as operações são definidas sobre uma classe, sendo portanto válidos para uma instância de objeto. Em OOA, uma classe é representada por um conjunto uniforme de atributos e serviços, nela o serviço é um comportamento específico que um objeto deve exibir, indicando qual comportamento será oferecido por um objeto em uma classe. No modelo Fusion, a representação de uma classe se dá através do nome da classe e os atributos que caracterizam os objetos pertencentes a esta classe. Em SIRIUS, a representação de classe é diferente, pois esta é representada por tipos de objetos, onde o nome do tipo é escrito na parte superior à esquerda, na representação do objeto. 


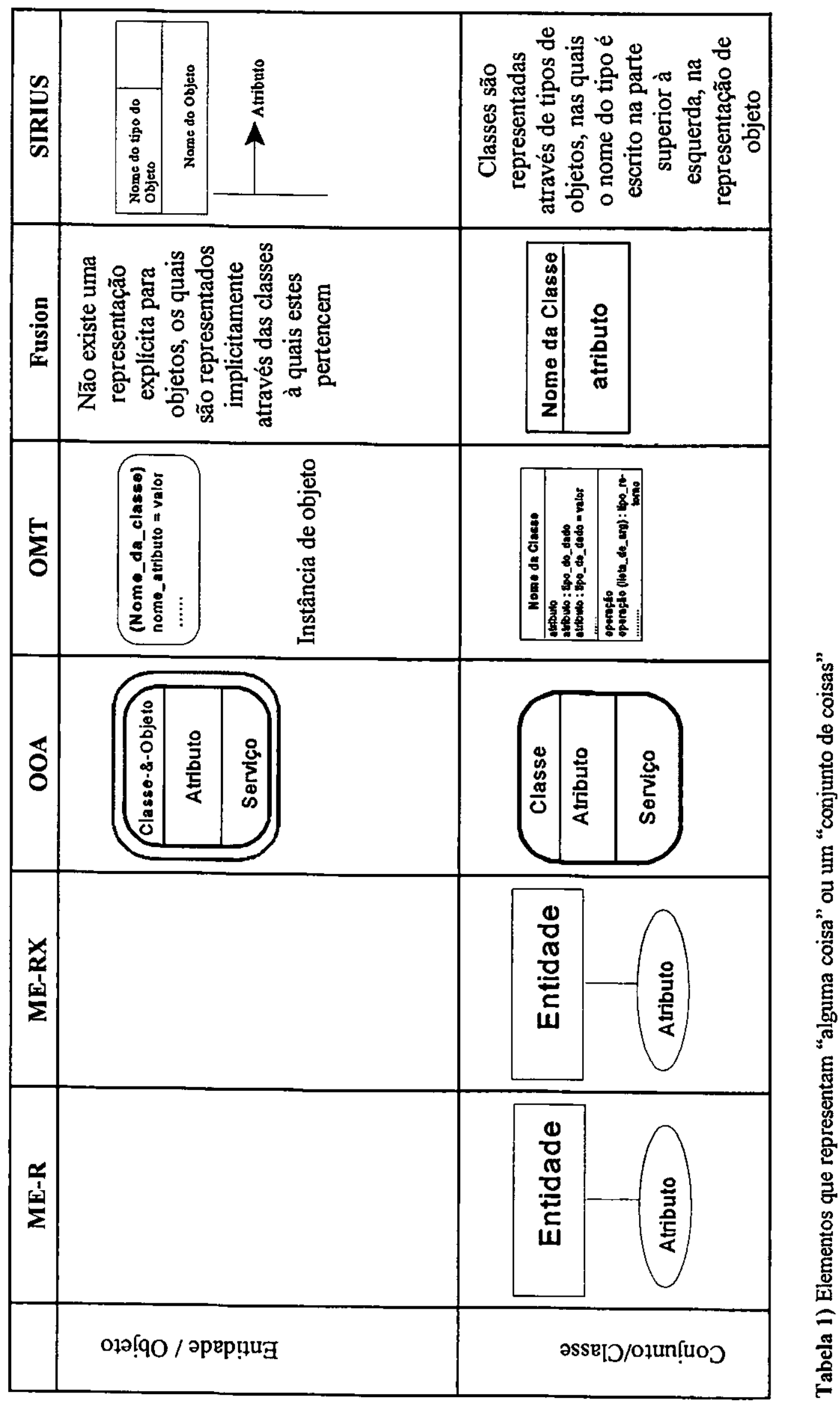




\subsubsection{Associação entre Elementos}

$\mathrm{Na}$ Tabela 2 encontra-se a representação de associação (ou relacionamento) entre os elementos vistos na Tabelal.

Basicamente, os relacionamentos entre os modelos estudados são muito similares, podendo diferenciar-se, eventualmente, quanto ao nome utilizado. Por exemplo, os modelos MER, ME-RX e SIRIUS utilizam o termo relacionamento, já os modelos OOA e OMT empregam o termo associação, mas ambos representam os mesmos conceitos. Podem-se ressaltar também algumas peculiaridades de um modelo. Por exemplo, o método OMT refere-se ao nome ligação para expressar a associação entre instâncias de objetos, e esta ligação é representada, de modo análogo, pela associação entre classes. Já o modelo SIRIUS representa instâncias do conjunto de relacionamentos entre objetos por duas chaves $(\{\}$ ), envolvendo o objeto primário (simbolizado pelo círculo). SIRIUS possui também a particularidade de representar o conceito de relacionamento triplo, um tipo especial de relacionamento onde a palavra "triplo" não provém do número de objetos participantes, mas sim por identificar três maneiras de um objeto poder participar do relacionamento [Biajiz_92].

Os modelos têm em comum o fato de poderem representar relacionamentos ternários, relacionamentos quaternários, etc. (exceto OOA, pois este não suporta esta forma de relacionamento). O método OMT representa estes relacionamentos acrescentando um losango que conecta todas as classes envolvidas no relacionamento. Os demais modelos não lançam mão de notações adicionais para representar esta forma de relacionamento, apenas conectam os elementos que participam do relacionamento ao símbolo de relacionamento. Em SIRIUS, o relacionamento que envolve mais de dois objetos, significa que mais do que dois objetos possuem atributos com características de relacionamento, e que se associam via objeto primário (objeto que representa o relacionamento e que é indicado pelo círculo). Outra característica comum entre os modelos é que todos, com exceção de OOA, podem apresentar atributos de relacionamentos. Geralmente são apresentados de modo análogo à representação de atributos de objetos (ou entidades), porém neste caso, estes atributos representam características do relacionamento. 


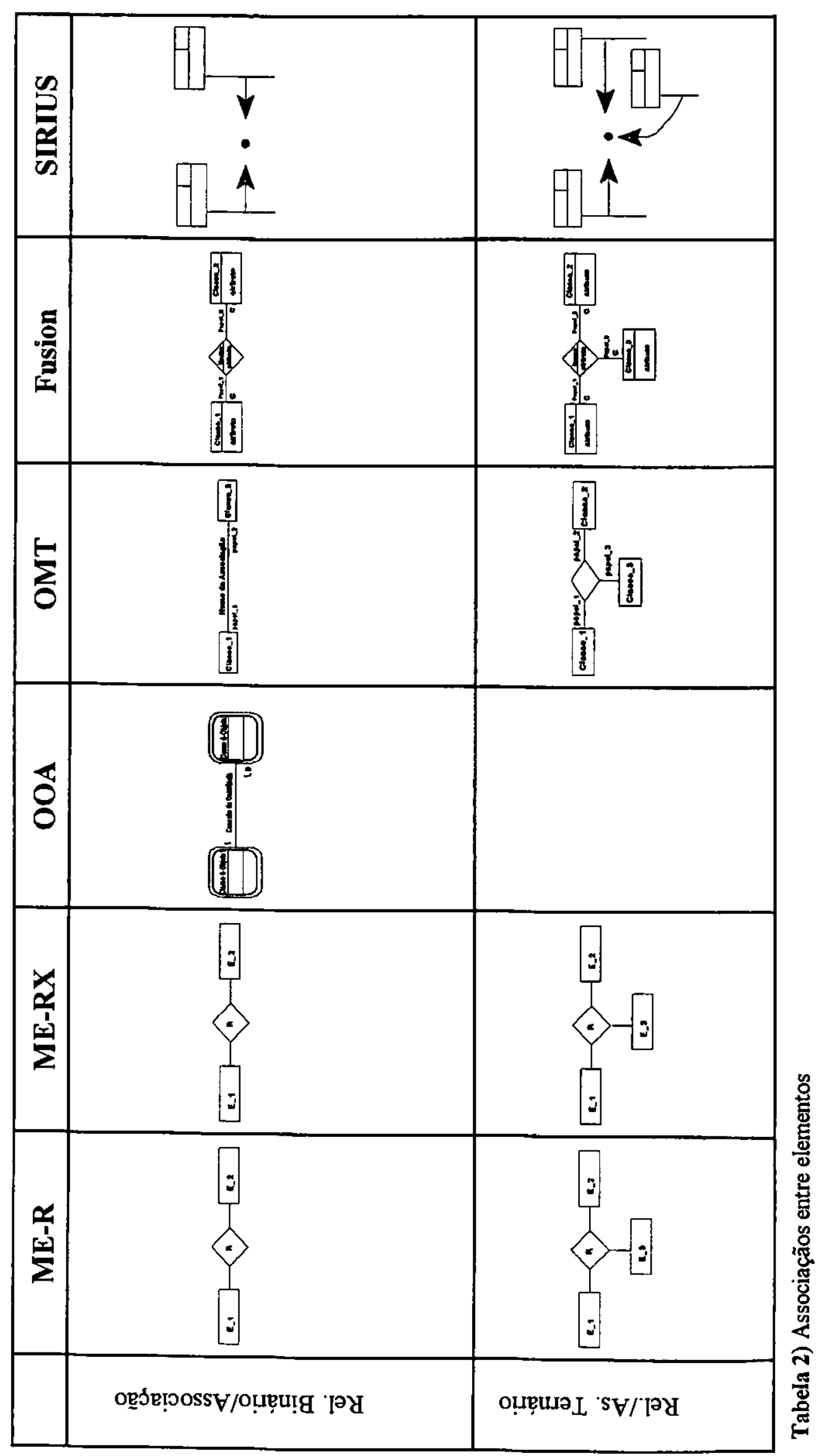




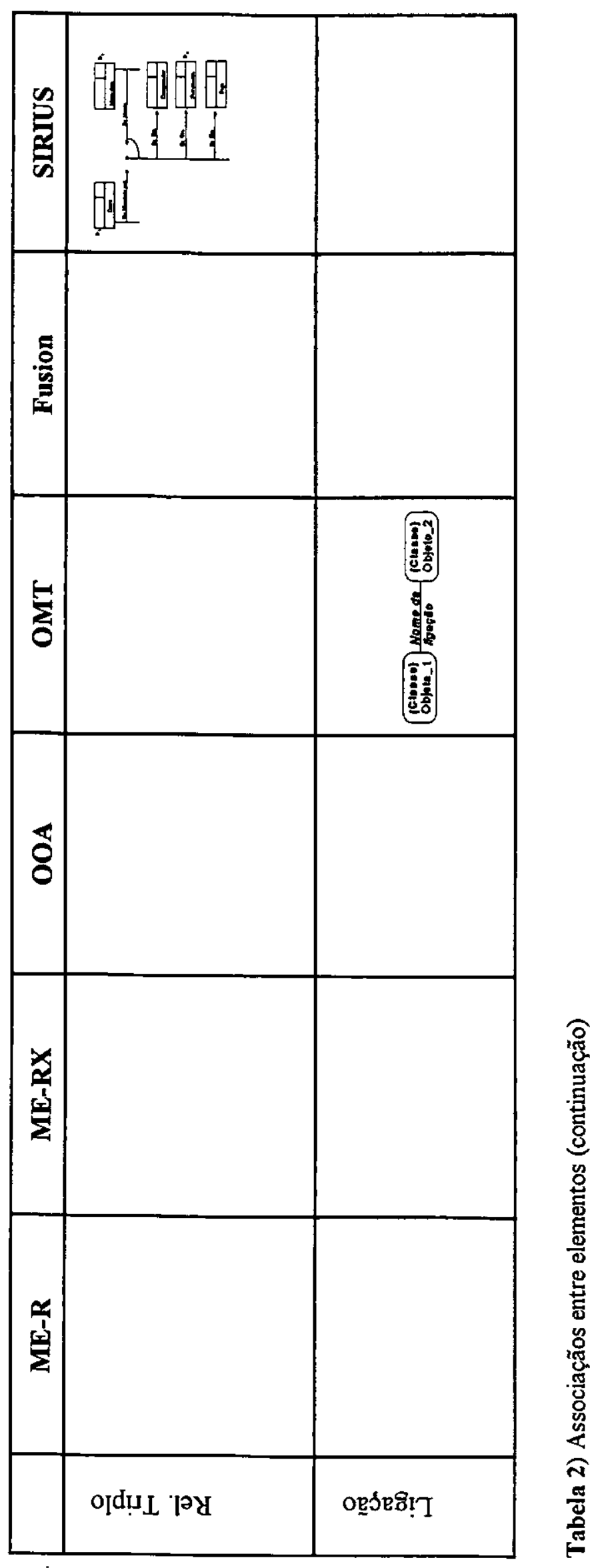




\subsubsection{Tipos de Atributos}

A Tabela 3 contém alguns tipos de atributos encontrados nos modelos, como os atributos monovalorados, que estão presentes em todos os modelos e são representados de modo análogo pela maioria deles; diferindo no ME-R e ME-RX, onde estes atributos são representados por elipses, e em SIRIUS, onde são indicados por setas dispostas ortogonalmente a uma reta vertical que se origina no objeto.

Os atributos multivalorados e compostos são tratados na fase de modelagem apenas pelos modelos ME-R, ME-RX e SIRIUS. Os demais modelos tratam estes atributos nas fases posteriores à análise (geralmente na fase de projeto), pois consideram que a análise deve ser efetuada em um alto nivel de abstração, em que "detalhes" são inseridos só depois que a modelagem for considerada satisfatória.

O ME-R e ME-RX não fazem restrições quanto ao uso de atributos multivalorados e compostos; no entanto, ambos não possuem uma notação padrão, e por isto tais atributos têm sido representados de várias maneiras por diversos autores ${ }^{7}$. É interessante notar que, em um diagrama de Entidade - Relacionamento, nem sempre se indicam os elementos que compõem um atributo composto, e quando estes são indicados explicitamente, podem ser representados por uma das maneiras ilustradas na Tabela 3. Atributos multivalorados são representados nos diagramas por uma elipse dupla ou uma barra após o nome do atributo, ou ainda, por uma linha dupla.

SIRIUS trata atributos multivalorados distintamente e ainda subdivide estes atributos em:

- listas, que correspondem a uma seqüência de elementos (no caso uma seqüência de atributos), onde podem ser definidas operações próprias de conjuntos, tais como união e intersecção ou ordenação e tratamento de repetição de valores;

- conjuntos, onde são definidas operações como união e intersecção, mas não ordenação. Neste caso não se admite repetição de elementos;

- vetores, que representam estruturas de arranjos de dados unidirecionais indexados, que, por sua vez, formam um conjunto finito e ordenado de elementos.

${ }^{7} \mathrm{Na}$ Tabela 3, a notação empregada para representar atributo multivalorado do ME-R é extraida de [Traina_96] [Elmasti_94]. E as notações empregadas para ilustrar atributos multivados de SIRIUS são as novas notaçōes criadas. $O$ uso destas será apresentado no próximo capítulo 
Um atributo composto em SIRIUS é representado por uma tupla, formada pela agregação de mais do que um atributo. Existe também outro tipo especial de atributo formado pela agregação de outros atributos, o chamado atributo de atributo, formado por um atributo "base" e seus subatributos não sendo estes tão relevantes para a modelagem a ponto de serem representados individualmente. A representação de atributos que possuem esta característica também pode ser encontrada na Tabela 3.

Os atributos de relacionamento são tratados de modo análogo aos atributos (de entidades e/ou objetos) pelos modelos, ME-R, ME-RX, Fusion e SIRIUS. Este tipo de atributo não é suportado por OOA. O modelo OMT possui uma categoria de atributo que é o atributo de ligação, onde é tratado de modo análogo ao atributo de objeto e classes. 


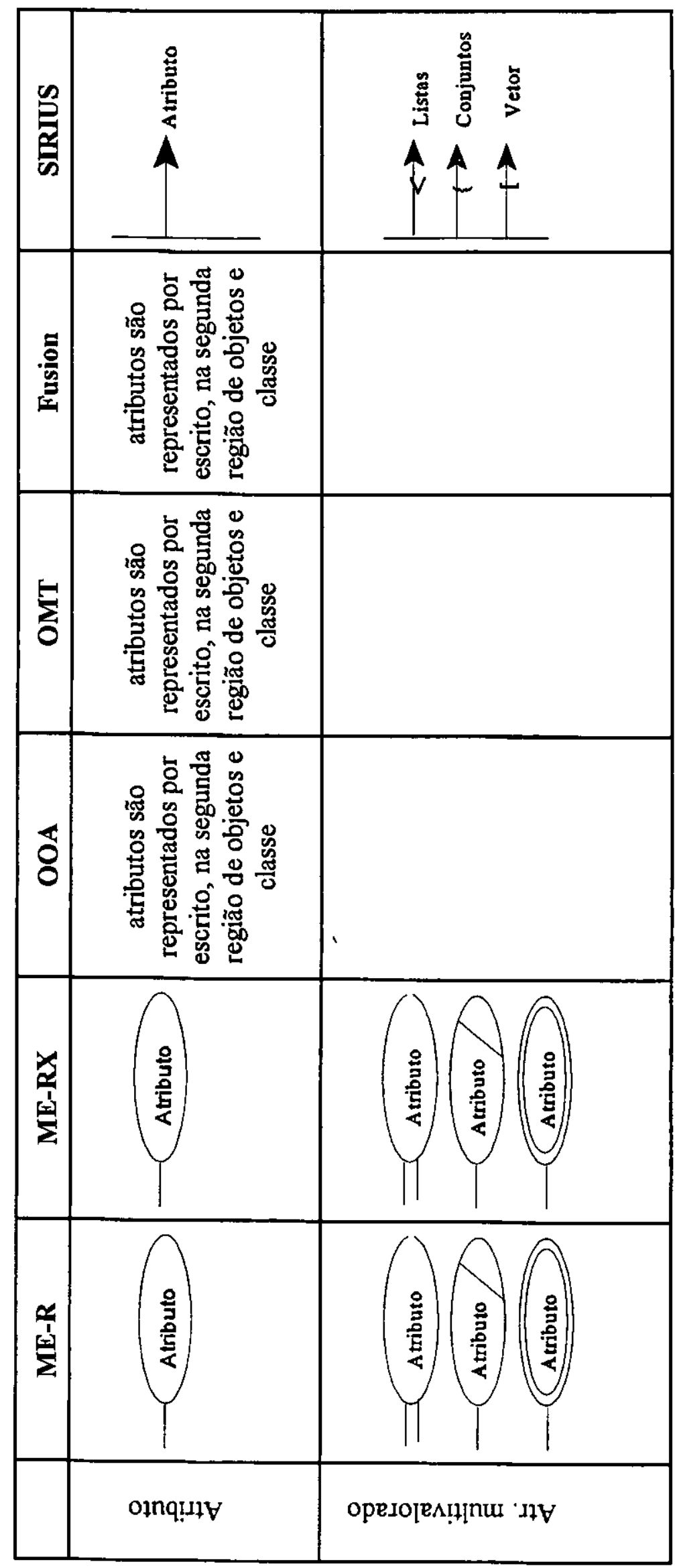

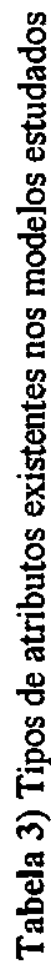




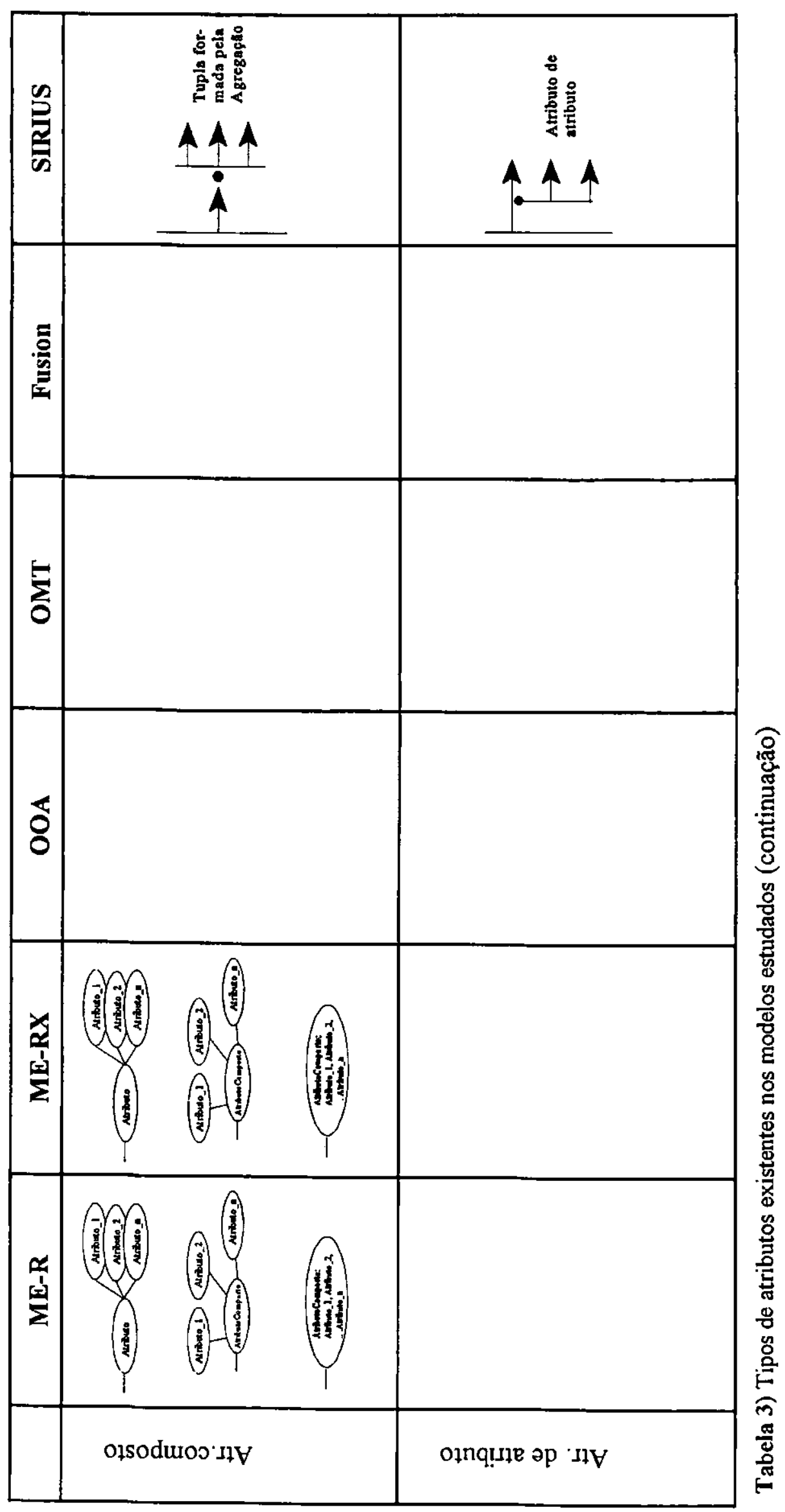




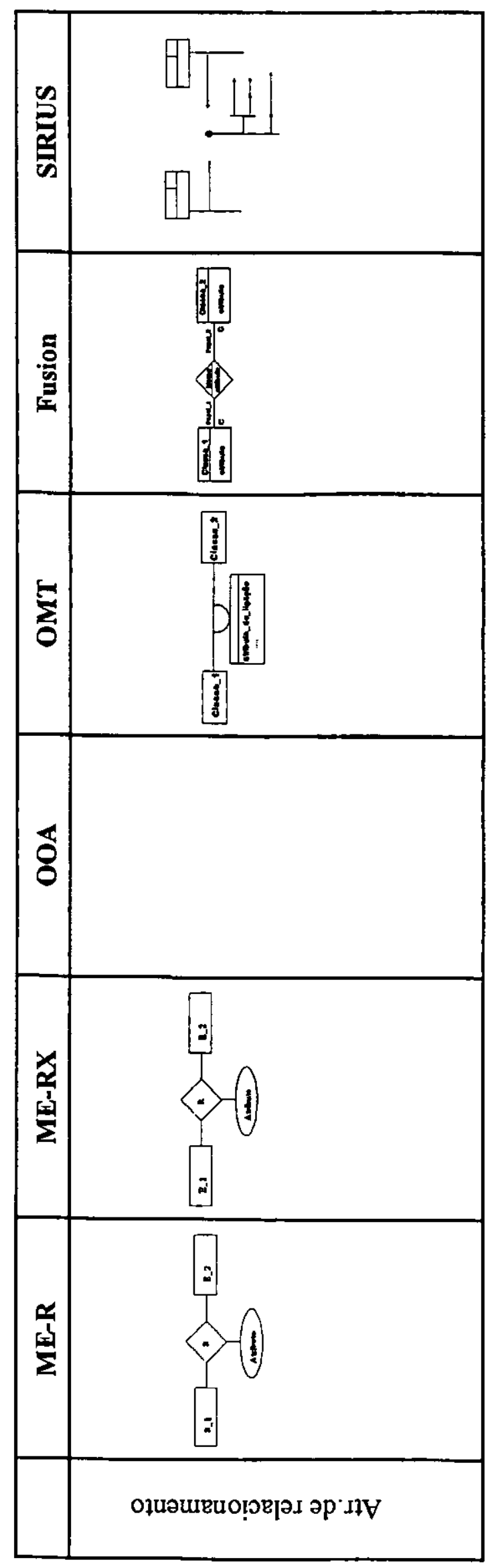

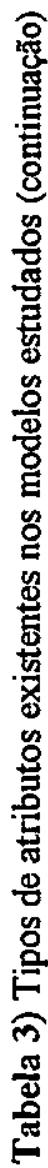




\subsubsection{Cardinalidade/Multiplicidade}

A Tabela 4 ilustra como são utilizados os conceitos cardinalidade (determina quantas vezes no mínimo, uma entidade ou objeto pode ocorrer em um relacionamento), e multiplicidade (ou participação) (determina um intervalo mínimo e máximo de ocorrências de um objeto em um relacionamento). De modo geral, não existe uma distinção precisa de qual conceito um determinado modelo está utilizando, porque alguns modelos misturam tais conceitos.

Os modelos ME-R, ME-RX e Fusion empregam o termo cardinalidade. No entanto analisando-se mais atentamente, nota-se que Fusion considera também intervalos numéricos, e que, a rigor, deveria ser classificado como multiplicidade. Por outro lado, o modelo OMT utiliza o termo multiplicidade, mesmo quando se refere à ocorrência de apenas um objeto em um relacionamento. SIRIUS utiliza o conceito de multiplicidade para indicar os limites mínimo e máximo de valores instanciados que um determinado atributo pode assumir, não se empregando o conceito de cardinalidade.

Observa-se que, apesar de não existir sempre uma coerência formal entre o conceito (cardinalidade/multiplicidade) e o nome utilizado para este, os modelos indicam a(s) quantidade(s) de ocorrência entre os elementos que estão envolvidos em um certo relacionamento, sem causar impacto para a modelagem. 


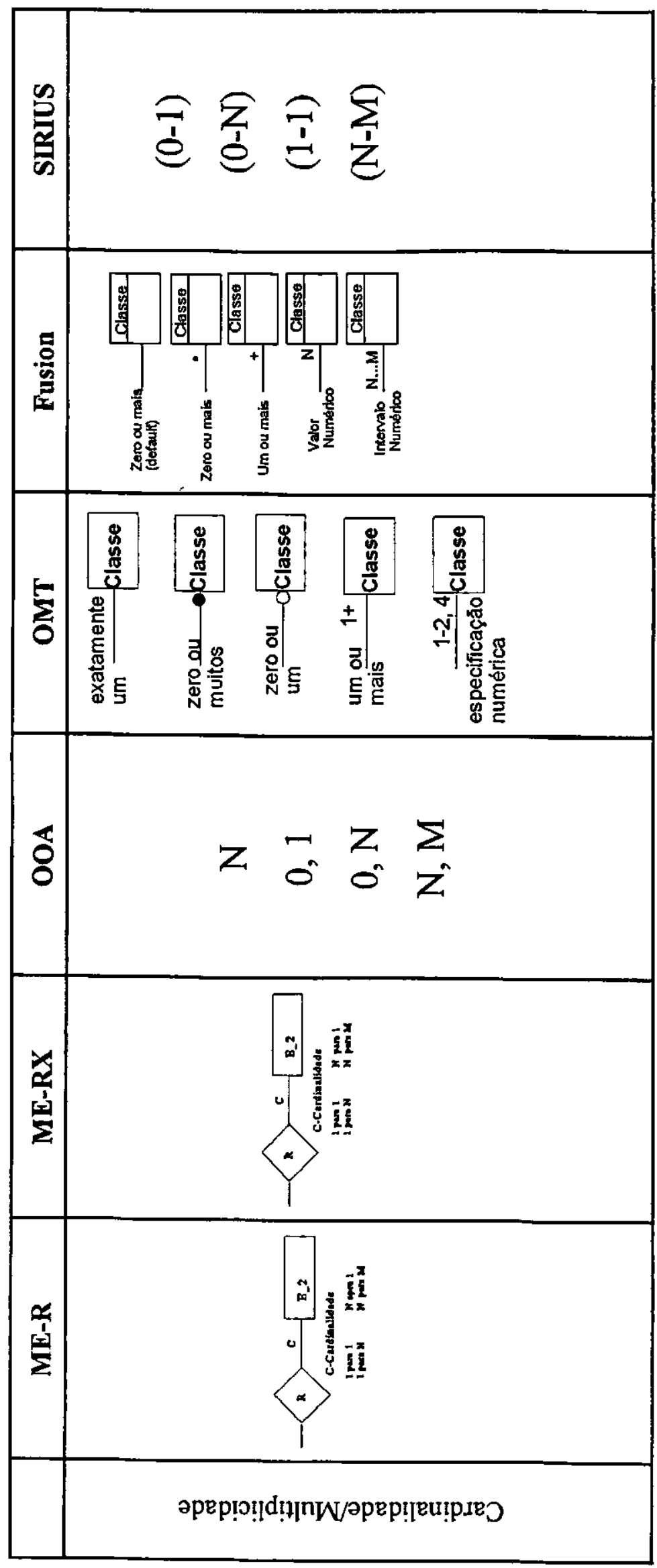

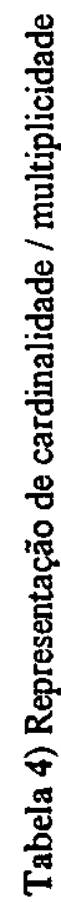




\subsubsection{Abstrações}

A Tabela 5 ilustra os tipos de abstrações que um modelo pode conter. O ME-R suporta implicitamente alguns tipos de abstrações como: abstração de classificação, que pode ocorrer através do conjunto de entidades e de relacionamento, e abstração de agregação, que pode ocorrer através do conjunto de relacionamento. No entanto, não existe uma notação para representar estas abstrações neste modelo.

A Abstração de generalização é análoga conceitualmente para cada modelo, no entanto, sua representação notacional pode diferir de modelo para modelo.

Basicamente, todos os modelos representam esta abstração através de uma classe (ou entidade) genérica, a qual é especializada por um critério de generalização. Este critério indica a forma como irá ocorrer a especialização, unindo a classe genérica às classes (ou entidades) especializadas. Este critério possui uma notação distinta para cada modelo, onde a principal diferença se dá nas restrições colocadas, que dependem da semântica, e do que se pretende representar na modelagem.

Os modelos OOA e OMT não possuem restrições associadas à abstração de generalização. Fusion indica a restrição de sobreposição, ou seja, quando uma superclasse pode ser formada apenas por uma subclasse (disjunta representada pelo triângulo cheio), ou quando uma superclasse pode ser formada por mais de uma subclasse (não disjunta representada por um triângulo vazio). ME-RX possui duas restrições, exclusão mútua/sobreposição e especialização total/parcial. Na exclusão mútua, a intersecção de entidades detalhe é vazia (disjuntas). Esta restrição é indicada por dois arcos que cruzam os segmentos de retas que unem as entidades detalhe ao critério de generalização. $\mathrm{Na}$ sobreposição, a intersecção de entidades detalhe pode não ser vazia (não disjuntas). $\mathrm{Na}$ especialização total, a união das entidades detalhe forma a entidade abstrata, o que é representado por uma seta "grossa", que une o critério de generalização à entidade abstrata. Na especialização parcial, a união de entidades detalhe é diferente da entidade abstrata [Traina_96].

SIRIUS trata a abstração de generalização (generalização ampla) especializando-a na abstração de generalização restrita e categorização. Porém estas duas últimas abstrações "herdam" os conceitos da generalização ampla, e o critério de generalização é representado de maneira distinta para cada abstração. Na generalização restrita (ilustrada na Tabela 3 mas referenciada apenas por 
generalização), o critério é representado por um trapézio ${ }^{8} 9$ dividido ao meio em cuja parte superior têm-se as restrições e, na parte inferior, o nome do critério utilizado na especialização. $\mathrm{Na}$ categorização, o critério de generalização é representado por um trapézio invertido, em cuja parte superior têm-se as restrições e, na parte inferior, o nome do critério.

Tanto a generalização restrita quanto a categorização possuem dois tipos de restrições:

- disjunção (D) ou sobreposição (S), as quais são conceitualmente análogas à restrição de exclusão mútua/sobreposição do ME-RX;

- participação total $(\mathrm{T})$ ou participação parcial $(\mathrm{P})$, análoga à restrição de especialização total/parcial do ME-RX.

As restrições de SIRIUS são indicadas na primeira linha do trapézio (especialização restrita) ou na do trapézio invertido (categorização), no centro do diagrama da abstração de generalização (generalização ampla).

Abstração de agregacão corresponde à idéia de que elementos de modelagem podem associarse, formando outros objetos que representam essa associação. Estes objetos correspondem ao todo e os objetos que formam o "todo" são considerados parte do "todo". Esta abstração pode ser representada por uma entidade agregação, que é formada por entidades componentes, por triângulos que indicam quais Classes-\&-Objetos são parte da Classe-\&-Objeto "toda", por losangos indicando qual classe-parte forma uma classe-todo e por classe agregada, formada por outras classes que estão associadas à classe agregada, para os modelos ME-RX, OOA, OMT e Fusion, respectivamente. A agregação em SIRIUS é diferente dos demais modelos, pois aí uma agregação é representada através de tuplas, relacionamentos e atributos de atributos.

Abstração de Classificação tem como objetivo "classificar" os elementos utilizados em uma modelagem. Isto é feito no ME-R e ME-RX implicitamente, pois um conjunto de entidades "classifica" uma determinada entidade. Analogamente, para o OOA, OMT e Fusion, esta abstração se dá através do conceito de classe de objeto. Em SIRIUS, a abstração de classificação ocorre por classificação/instanciação de objetos.

Abstração de Composição não é suportada pelos modelos OOA, OMT e Fusion. No ME-RX, esta abstração corresponde à idéia de que os elementos de modelagem podem compor outros

${ }^{8}$ Esta notação será apresentada mais detalhadamente no capítulo 5

${ }^{9}$ No documento original de SIRIUS, a categorização é tratada apenas como uma restrição. Porém é importante notar que aqui é considerada uma abstração 
elementos, formando objetos complexos (compostos). Em SIRIUS, a idéia da abstração de composição é análoga, porém, utiliza o conceito de colônia ${ }^{10}$ para ilustrar a abstração de composição

${ }^{10}$ Conceito que carrega uma grande carga semântica, pois não representa apenas o conceito de que elementos são compostos por outros. Mas também estabelece, de certa forma, um "gerenciamento" entre os objetos em uma modelagem, ou seja, objetos especificos habitam colônias especificas 


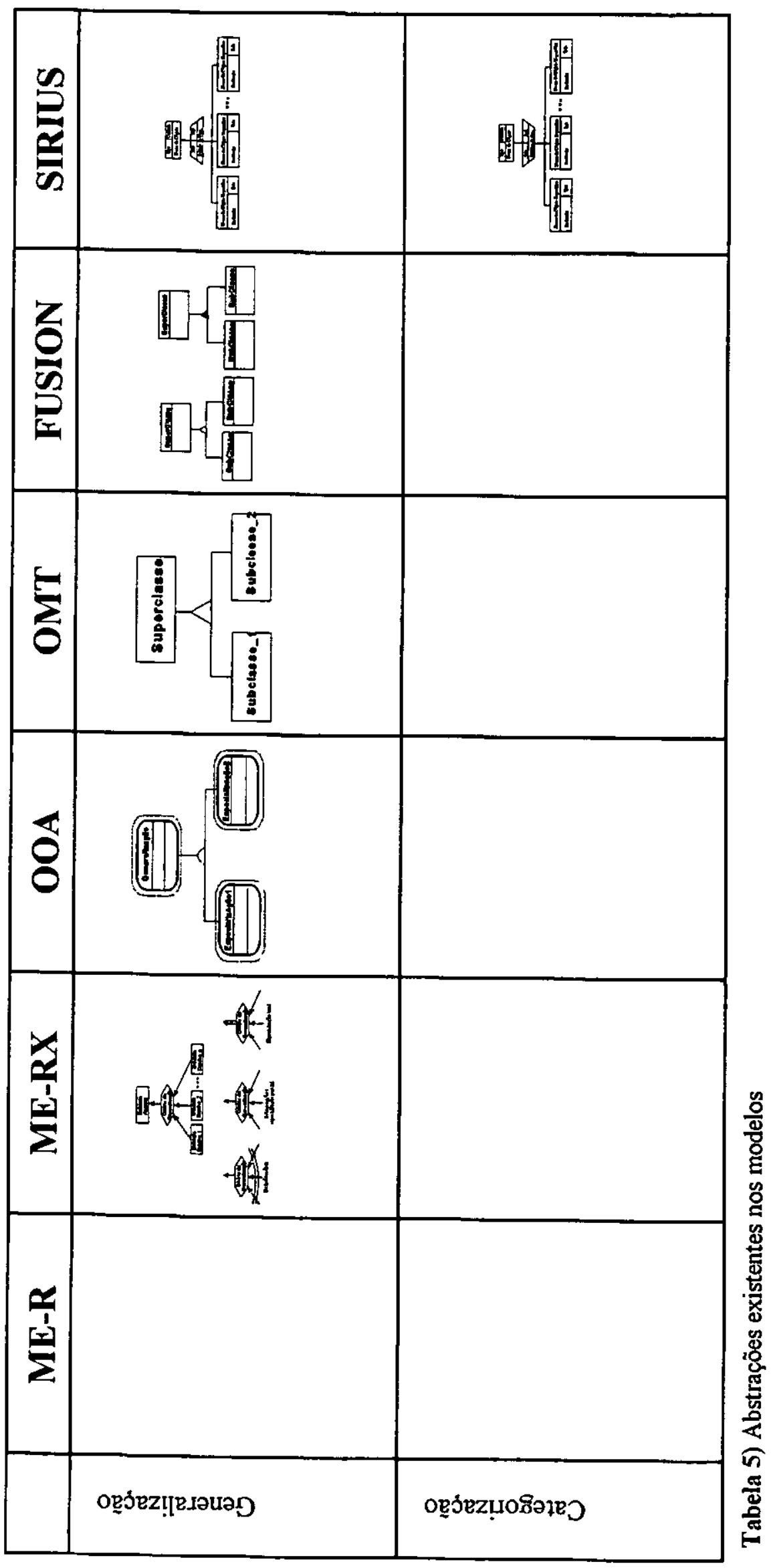




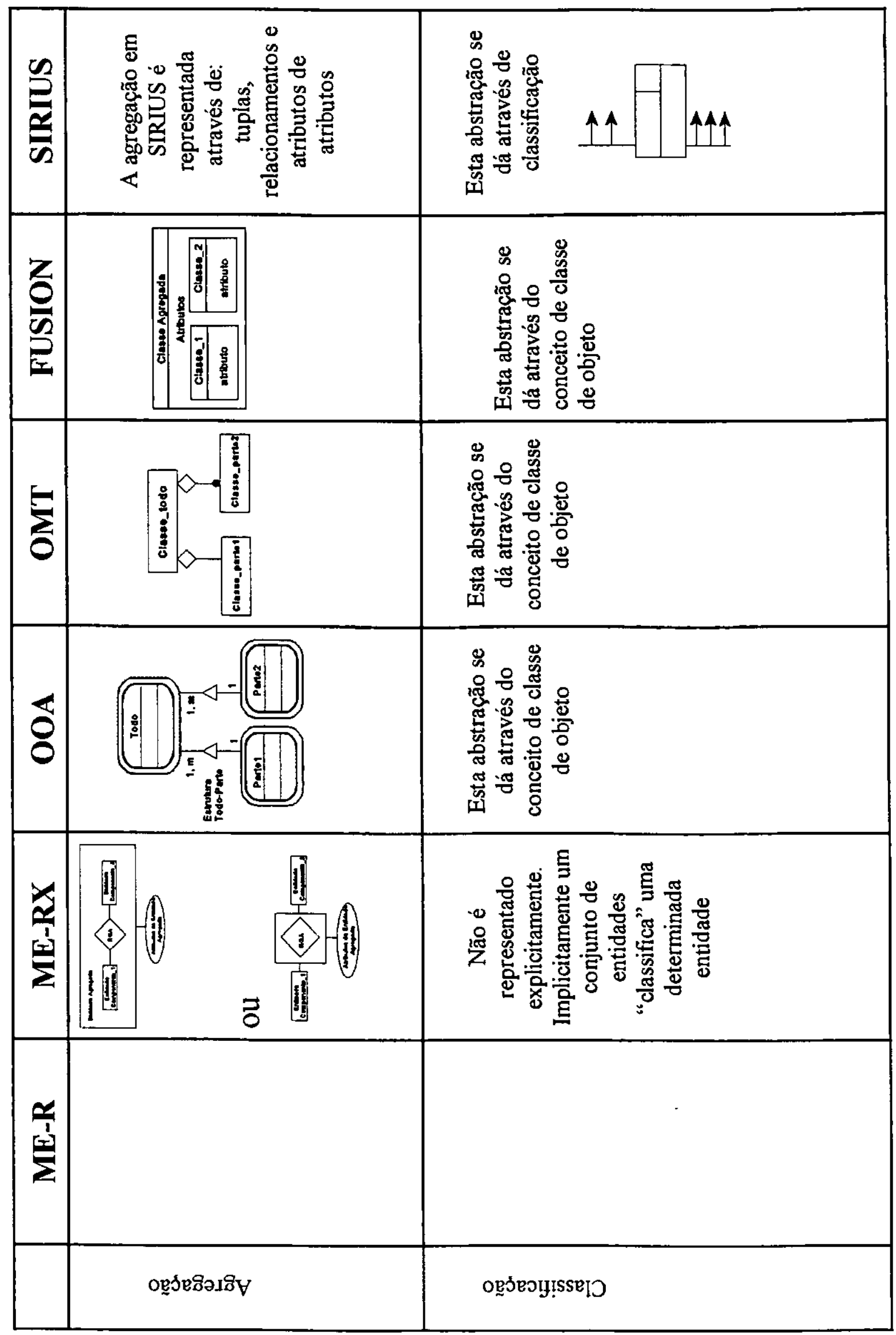

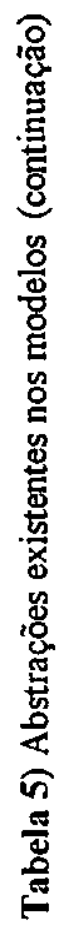




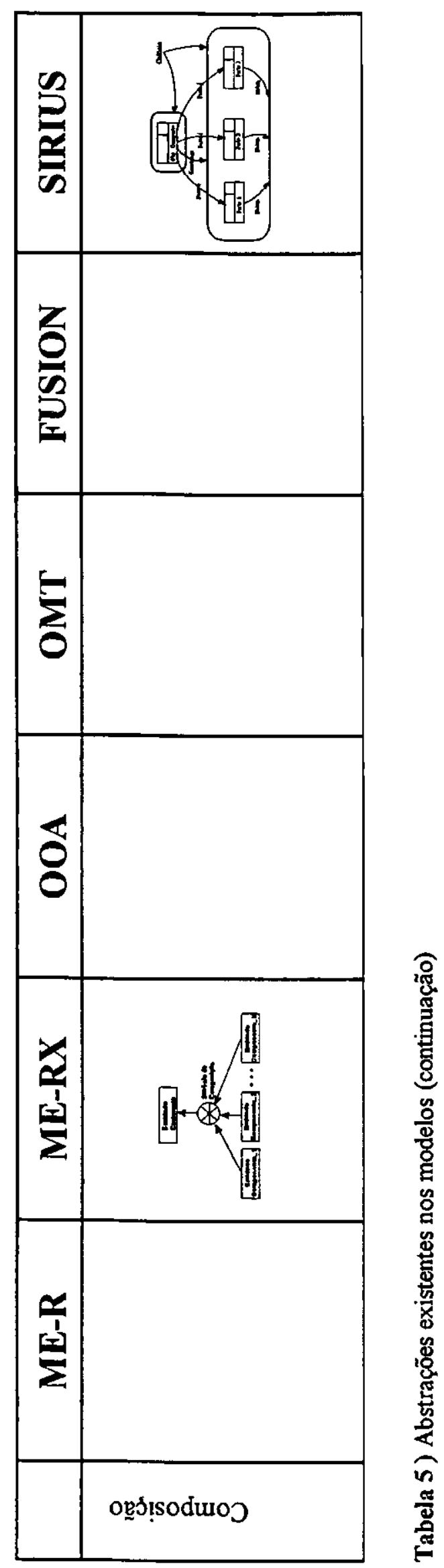




\section{3 Conclusão}

As notações aqui apresentadas não são únicas, pois podem ser ilustradas de maneira distintas por mais de um autor. Um único elemento do modelo e/ou um construtor semântico, bem como as abstrações destes, podem apresentar, algumas vezes, mais de uma variação notacional.

No entanto, sabendo-se claramente qual(is) o(s) conceito(s) que se deseja ilustrar em uma modelagem, a representação notacional pode apresentar algumas pequenas variações, não acarretando grandes problemas no entendimento da modelagem. A comparação notacional feita anteriormente serve também para que o leitor se acostume com as diversas representações, facilitando, deste modo, o emprego correto das mesmas.

O próximo capítulo ilustra as novas notações propostas para o modelo SIRIUS, juntamente com as respectivas justificativas para a aplicação das mesmas no modelo. Estas novas notações foram elaboradas de forma que atendessem os objetivos expostos no capitulo 1. Como, por exemplo, uma notação clara, limpa e concisa. 


\section{Capítulo 5}

Proposta de Notações

Este capítulo tem como principal objetivo mostrar algumas representações gráficas que foram estudadas como alternativas para o modelo SIRIUS, e também as notações que foram elaboradas. Estas últimas são apresentadas juntamente com as respectivas justificativas para seu emprego ou não no modelo. Como conseqüência natural, uma vez que todo modelo foi reavaliado para a elaboração e validação notacional, alguns conceitos foram validados e outros foram propostos. Estes últimos também serão apresentados neste capitulo.

\subsection{Representação de Atributos de Classificação e Atributos}

\section{Instanciados}

É desejável que uma modelagem seja limpa, concisa e clara. Para que tais objetivos sejam atingidos, foram estudadas maneiras alternativas de representar os atributos de classificação (ou atributos não instanciados) e os atributos instanciados (ou atributos de instanciação) associados a um objeto.

É importante notar aqui que o significado de um atributo de classificação é completamente diferente do de um atributo de instanciação: ao passo que um atributo de instanciação representa um atributo do próprio objeto onde ele está ligado, os atributos de classificação definem "tipos de atributos", que de fato apenas existirão ligados a objetos que são instância do objeto ao qual aparecem agora ligados. É importante notar também que esse conceito é distinto do conceito que leva um nome semelhante na área de Linguagens Orientadas a Objetos. Os termos Atributos de Classe e Atributos de Instância. Atribu tos de classe são comuns a todas as instâncias de uma classe, ou seja, sumarizam a classe ou são compartilhados por todas as instâncias da classe. Atributos de 
classificação são instanciados um para cada instância desse objeto; correspondem ao conceito usual de construção da(s) tupla(s) que descreve(m) a construção de um tipo (ou uma classe) em Linguagens de Programação Orientadas a Objetos. Tanto Atributos de Classe quanto Atributos de Instância estão vinculados ao conceito de Atributos de Classificação, pois relacionam-se com o conceito de definição de uma classe ou de um tipo. Já os Atributos de Instanciação não têm uma contrapartida usual em Linguagem de Programação, uma vez que correspondem aos atributos do próprio objeto tipo ao qual estão ligados (que em Linguagens de Programação ocupam memória de fato no programa executável). Em SIRIUS, os objetos que são tipos de objeto são persistentes e possuem $\mathrm{OID}^{11}$, ao contrário do tratamento usual da área de Linguagem de Programação, onde os tipos existem apenas durante a fase de compilação, sendo posteriormente descritos sem que seu OID sobreviva para o tempo de execução do sistema.

$\mathrm{Na}$ proposta original, os atributos de classificação são representados por setas, dispostas ortogonalmente a um segmento de reta acima e perpendicular ao objeto onde tal segmento está situado. A representação de atributos instanciados é análoga, exceto neste caso em que, o segmento de reta situa-se na parte inferior do objeto (vide capítulo 3, Figura 14).

Esta representação pode revelar alguns inconvenientes. Em uma modelagem com um número razoável de objetos, mais do que 10 por exemplo, onde estes possuem atributos de classificação, atributos instanciados e atributos com característica de relacionamento, as informações desta modelagem podem ir se tornando "carregadas"e de dificil representação em uma única "folha". Os segmentos de reta acima e/ou abaixo dos objetos devem possuir um comprimento adequado para acomodar os atributos de classificação e atributos instanciados, e também permitir a representação dos relacionamentos entre os objetos. Em alguns casos, é necessário que este segmento de reta seja "grande", comprometendo a "leitura" da aplicação modelada, bem como a sua representação. Conseqüentemente, em modelagens com maior quantidade de objetos, a localização visual de um objeto pode não ser direta.

Uma sugestão inicial para evitar esse problema é representar os atributos de classificação e os atributos instanciados dentro do próprio retângulo que representa um objeto, ou seja, todas as informações a respeito do objeto estarão contidas neste retângulo.

${ }^{11}$ OlD - Object Identifier 
Esta sugestão pode ser vista na Figura 27, em três alternativas. $\mathrm{Na}$ Figura 27a), a representação original do objeto está situada no topo do retângulo; e logo abaixo do nome do objeto, são listados os atributos de classificação, separados por um segmento tracejado dos atributos instanciados que estão situados na parte inferior do retângulo. Esta representação tem como vantagem o fato de que os objetos são facilmente identifica-

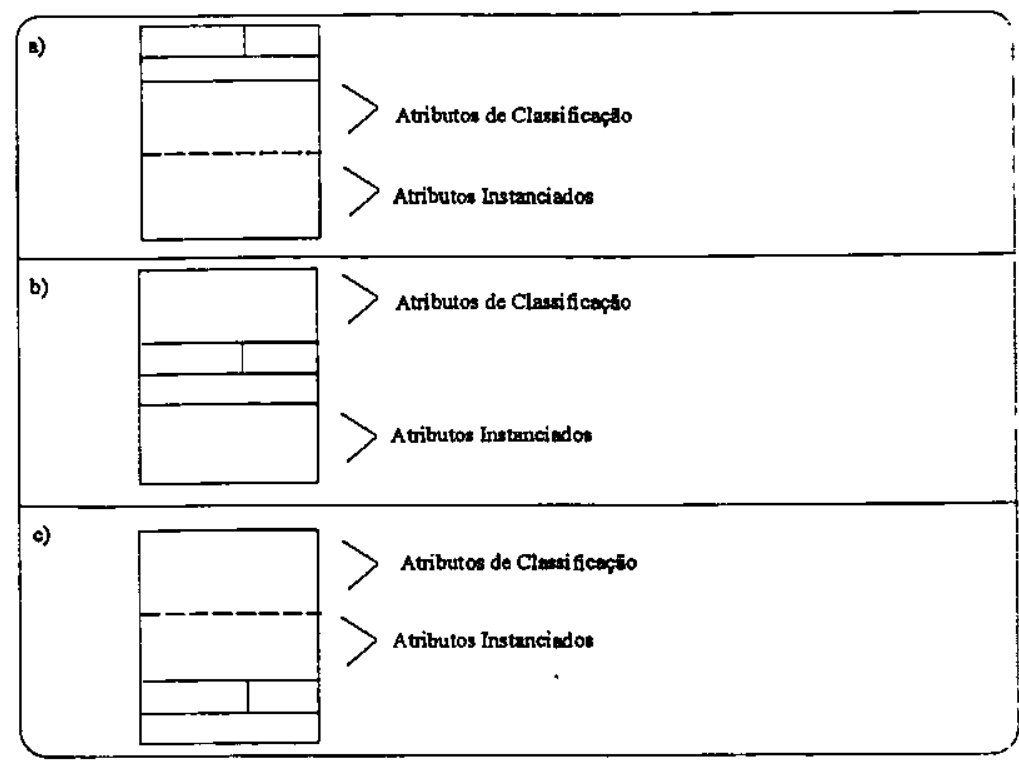

Figura 27) Representação altemativa para atributos dos pois, em uma modelagem, eles são representados em uma "caixa" contendo todas as informą̧ões que os compõem, e além disso, o seu nome é localizado na segunda linha do retângulo, não havendo necessidade, para identifica-los, de "correr os olhos" em uma lista de atributos até que se chegue a eles. Esta notą̧ão tem a vantagem de ser semelhante a notações já bem divulgadas [Coad_96][Rumbaugh_91], porém, por esse mesmo motivo, também é desvantajosa, pela diferença conceitual nos conceitos que estão compartilhando essa notação.

Na Figura 27b) não há a necessidade de acrescentar um segmento de reta tracejado para dividir os atributos de classificação dos atributos instanciados, diminuindo assim os símbolos empregados em uma representação gráfica, que fica mais próxima da notação original. Por outro lado, a localização do objeto não é tão direta quanto na Figura 27a). Esta notação poderia ser interessante se fosse adotado um padrão de cores para a representação dos conceitos do modelo ${ }^{12}$.

$\mathrm{Na}$ Figura 27c) a representação é semelhante à da Figura 27a) mas, neste caso, a representaçăo original do objeto é situada na parte inferior do objeto.

A notação sugerida na Figura 27 é mais limpa em uma modelagem, uma vez que todos os atributos associados a um objeto estão localizados "fisicamente" dentro de um retângulo,

${ }^{12}$ Nota do orientador: embora os recursos tecnológicos permitam hoje a visualização e documentação adotando padrōes de cor, creio que um estudo nesse sentido deveria, por sua novidade, ser parte de um estudo mais abrangente, envolvendo o uso de recursos de cor também em outros aspectos da representação da informação, para a construção de sofiware 
juntamente com o nome do objeto, o nome do tipo do objeto e o tipo da colônia onde as instâncias deste objeto habitam. Outra vantagem é que os relacionamentos são mais facilmente localizados, mesmo quando os objetos participantes do relacionamento não estiverem próximos.

Um exemplo do emprego desta notação
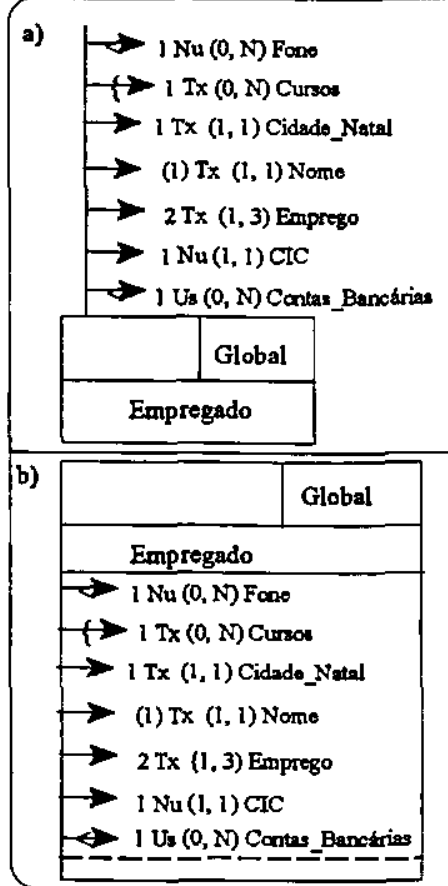

Figura 28) Notação altemativa de objeto alternativa pode ser visto no Anexo (Modelagens 1, 2 e 3). Observa-se que, neste exemplo, optou-se pela notação da Figura 28a), por ser mais fácil a localização do objeto.

Observa-se também que, dependendo do número de atributos associados a um objeto, a representação deste torna-se demasiadamente grande, principalmente quando os atributos possuem muitos valores. Por exemplo valores de uma lista, um conjunto ou um vetor, onde, nestes casos, para poder englobar todas as informações associadas ao objeto, o retângulo que representa este objeto passa a ocupar uma grande porção fisica "no espaço" disponivel. Tal situação pode ser melhor esclarecida pela Figura $28^{13}$. Na Figura 28a) os atributos são colocados fora do retângulo, como a notação original; e na Figura 28b), os atributos são posicionados dentro do retângulo. Na Figura 28b), sugere-se também que, para os atributos de classificação, $a(s)$ seta(s), que representa(m) graficamente qual o tipo do atributo, seja(m) representada(s) à direita do atributo. Note-se que, quando os atributos multivalorados instanciados possuem muitos valores, representá-los dentro do retângụlo faz que este aumente de tamanho, o que não é muito apropriado em uma representação gráfica. Para utilizar a notação proposta, é interessante que os atributos ocupem pouco "espaço".

13 Estas caracteristicas de atributos, como são utilizadas na figura, serão vistas na seção 5.2 , e a notação do atributo multivalorado será vista na seção 5.4 
Para isto, uma alternativa foi representar, por exemplo, os atributos tuplas, de forma textual. A Figura 29 ilustra isto: na Figura 29 a), tem-se a representação original de uma tupla, e na Figura 29 b), a representação é feita utilizando-se os símbolos $<^{14}$ (abre tupla) e $>^{15}$ (fecha tupla). Entretanto, tal sugestão não possibilita que atributos mais complexos sejam representados de forma clara. Por exemplo, uma lista de tuplas teria uma representação muito extensa, não possibilitando uma rápida identificação dos elementos que formam uma tupla. Uma outra sugestão para a representação de atributos cuja característica é uma tupla ou atributo de atributo é utilizar o recurso de identação, ou seja, o uso de outro(s) retângulo(s) dentro do retângulo maior, como ilustrada na Figura 29 c). No entanto, esta sugestão melhora pouco a notação.

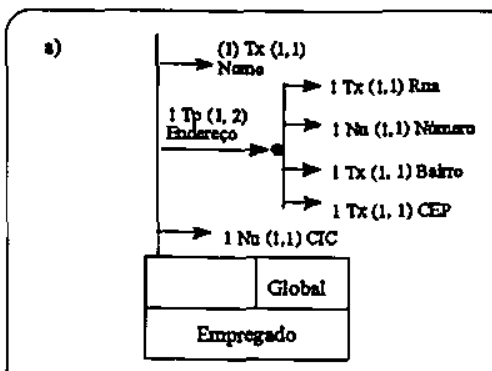

b)

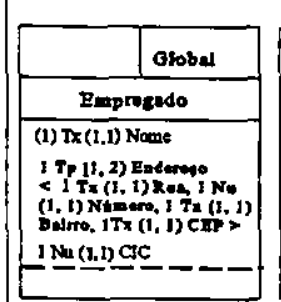

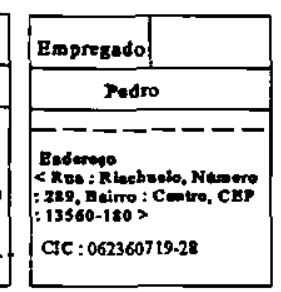

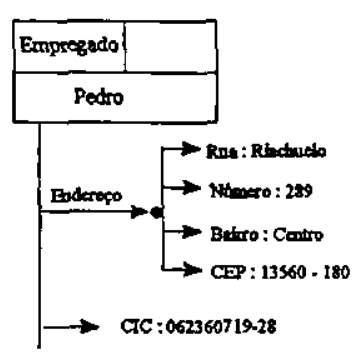

c)

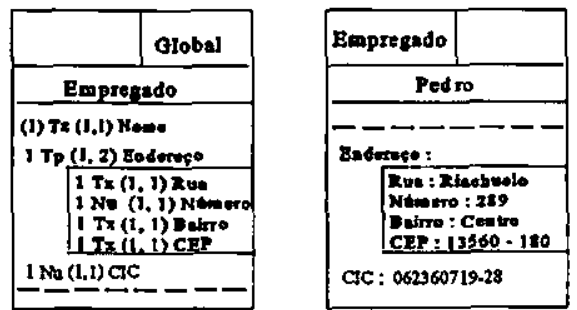

Conseqüentemente, apesar de a modelagem, representando o objeto e

Figura 29) Notação altemativa de atributo com caracteristica tupla seus atributos dentro de um único retângulo, ficar mais "limpa", o ganho é relativo, uma vez que esta representação é interessante quando os atributos associados aos objetos não possuem uma natureza muito complexa, ou seja, quando os atributos monovalorados ou multivalorados têm poucos valores, o que, muitas vezes, não modela uma situação real. Por outro lado, uma modelagem mais simples é representada de maneira mais clara com a notação originalmente proposta.

É intuitivo entretanto, que por mais simples que seja a representação gráfica dos elementos de um modelo, uma aplicação complexa possua uma representação mais carregada, pois neste caso

\footnotetext{
${ }^{14}$ Sinal de menor para abrir tupla

${ }^{15}$ Sinal de maior para fechar tupla
} 
existe a necessidade de representar muitos objetos, atributos, e os relacionamentos entre estes objetos.

De fato, o suporte da abstração de classificação num modelo de dados deve ser integrado a todos os demais conceitos do modelo, e portanto a notação deve harmonizar-se com eles. Um dos conceitos em que essa integração deve ser especialmente harmônica é a representação de atributos, suas caracterísiticas e estruturas. Paradoxalmente, o suporte conceitual que SIRIUS previu para esse aspecto tem ainda muitos pontos que não ficaram completamente estabelecidos, e devem portanto ser avaliados, envolvendo estudos que estão fora do contexto deste trabalho. Assim, decidiu-se adotar por ora a notação original, propondo-se que a mesma seja reavaliada quando um estudo sobre as consequiencias da instanciação de estruturas de dados for efetuado.

Como suporte a essa constatação, a Figura 30 ilustra uma situação em que ocorrem diversas situações de múltiplas instanciações envolvendo estruturas de conjuntos e vetores. A notação aqui utilizada para atributos multivalorados será vista adiante.

Observando-se a Figura 30, nota-se que novos conceitos são apresentados, como o conceito de vetores indexados através de índices literais. Por exemplo, o vetor Atores (atributo de classificação associado ao objeto Romeu e Julieta) é um vetor com característica texto cujo índice é o atributo Personagens (atributo de classificação associado ao objeto Peça, onde tal atributo é um vetor, portanto multivalorado). $\mathrm{O}$ objeto Montagem esboça como seria a instância de um atributo deste tipo, isto é, o atributo Atores (atributo de instância de objeto Montagem) possui os índices Romeu, Julieta, Príncipe e Frei respectivamente.

E para cada índice existem valores associados. Por exemplo, Romeu é o índice do vetor, cujo campo a ele associado é um outro vetor com os elementos Rui e Ari (indicando que o personagem Romeu pode ser interpretado por mais de um ator, no caso, os atores aptos para interpretar tal papel são os atores Rui e Ari); Julieta é o índice do vetor cujo campo a ele associado é um outro vetor que possui os elementos Ana e Lia (indicando que a personagem Julieta pode ser interpretada pelas atrizes Ana e Lia). O raciocínio é análogo para os índices Príncipe e Frei.

Outro conceito não previsto no modelo original é o de vetores indexados por outros vetores. Por exemplo, o atributo Atores_e (ou Atores efetivos), atributo de classificação associado ao objeto Montagem. O objeto Encenação possui uma instância deste atributo. Esta representa semanticamente, por exemplo, que dentre os atores aptos para interpretar o papel de Romeu, o ator 


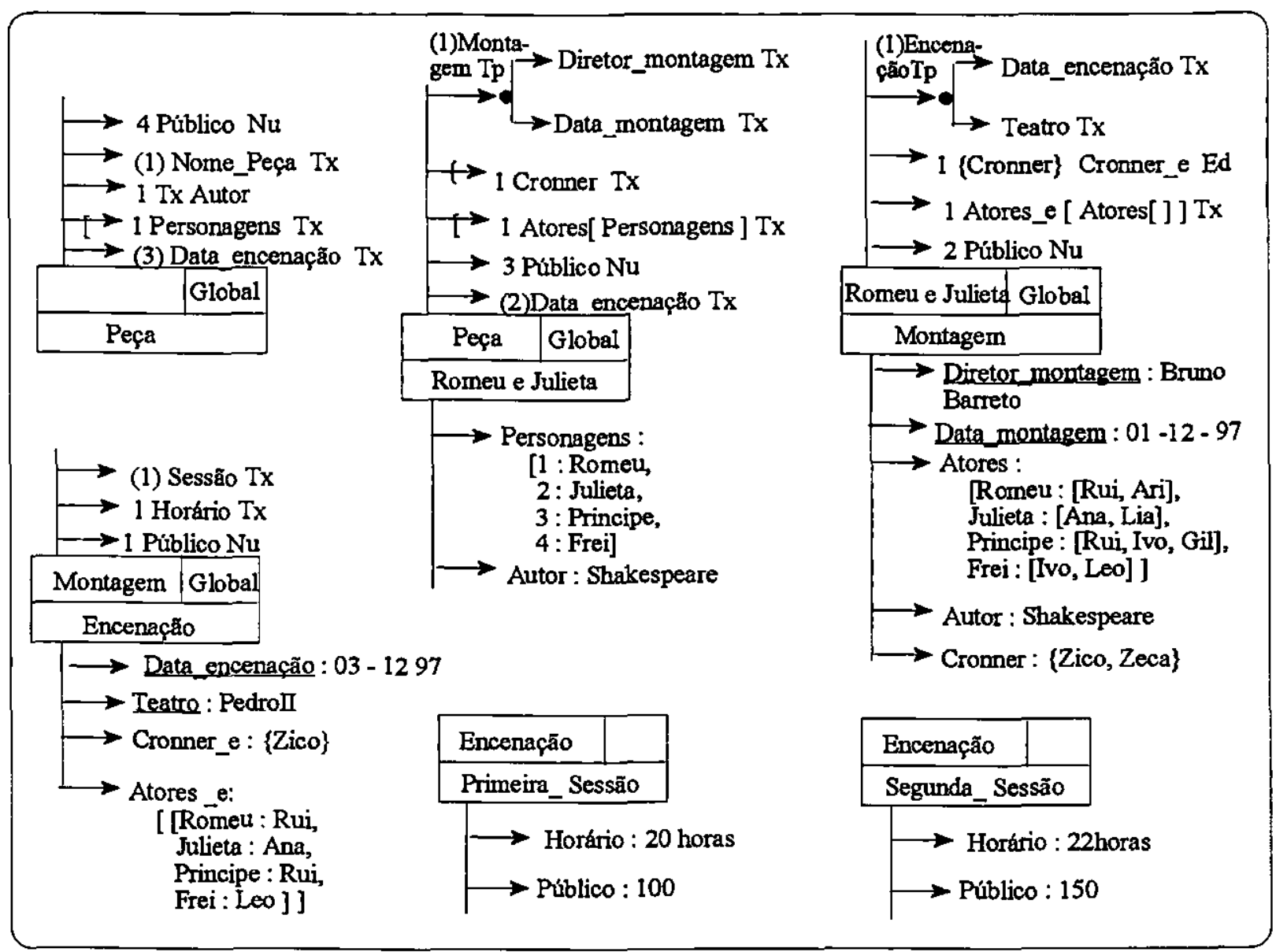

Figura 30) Exemplo de hieraquia de classificação - Peças

efetivo escolhido foi o Rui; dentre as atrizes aptas para interpretar o papel de Julieta, a atriz efetiva Ana foi alocada; analogamente, o papel de Príncipe será interpretado pelo ator Rui, e por fim, o Frei será interpretado pelo ator Leo.

A possibilidade de existir um atributo identificador cuja característica é uma tupla também é outro tópico que precisa ter uma notação gráfica e uma contextualização mais bem elaborada. Esta situação é ilustrada na Figura $30^{16}$.O objeto Romeu e Julieta possui um atributo identificador Montagem, que é uma tupla com os subatributos: Diretor_Montagem e Data_Montagem. Do mesmo modo, o objeto Montagem possui um atributo identificador Encenação, uma tupla com os subatributos: Data_Encenação e Teatro. Quando estes atributos identificadores são instanciados, o objeto instância passa a ter o nome da tupla que na verdade representa os valores associados a ela.

${ }^{16} \mathrm{O}$ simbolo de característica é colocado depois do atributo. Durante as modelagens efetuadas notou-se que esta forma de escrever é mais natural, uma vez que primeiro é "criado" um atributo e depois este é classificado 
Por exemplo, a instância do objeto Romeu e Julieta possui o objeto instanciado "apelidado" como Modelagem, mas que na verdade representa o objeto Bruno Barreto, 01-12-97. Estes valores são indicados juntamente com a indicação explícita do(s) subatributo(s), e este(s) é (são) grifado(s) ${ }^{17}$ para diferenciá-los dos demais atributos.

Outro conceito novo é o de tipo coletivo, ou seja, um tipo que é tipo comum de todas as instâncias de um objeto (assim o tipo coletivo passa a existir quando é considerada uma hieraquia de no mínimo 2 níveis). No exemplo da Figura 31, tem-se que Montagem é o tipo coletivo das instâncias de todas as instâncias do objeto Peça; Encenação é tipo coletivo das instâncias de todas as instâncias das instâncias de Peça; analogamente, Sessão é tipo coletivo das instâncias de todas as

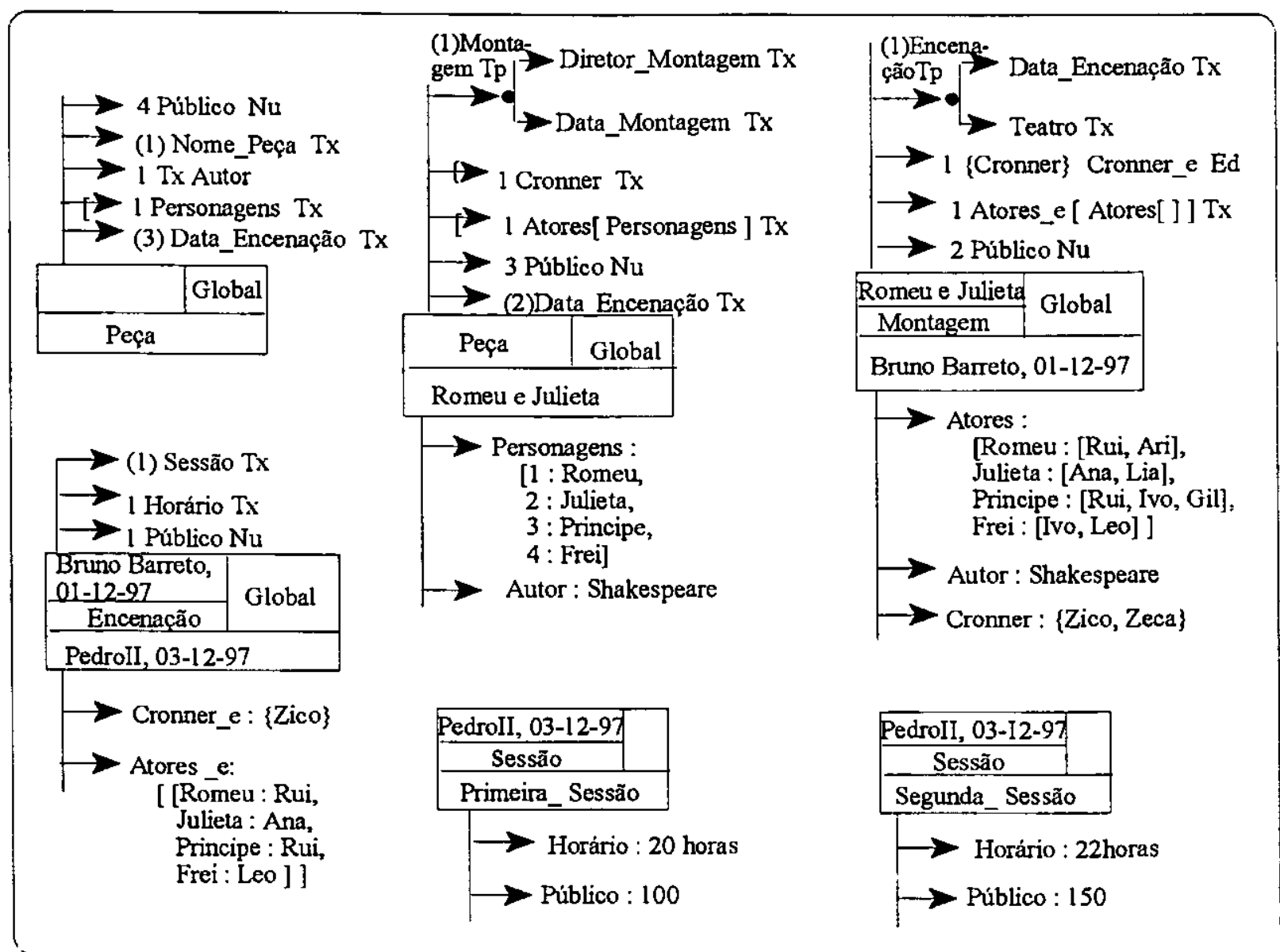

Figura 31) Exemplo de hieraquia de classificação - Peças (utilizando a notação de tipo coletivo)

${ }^{17}$ Cabe observar que o fato de tais atributos estarem grifados não indica que estes serão chaves, uma vez que estes conceito não faz parte do modelo em questão 
instâncias do objeto PedroII, 03- 12- 97 (ou das instâncias de todas as instâncias das instâncias das instâncias de Peça). Este conceito é representado graficamente no objeto, entre o tipo do objeto $\mathrm{e}$ o nome do objeto, ou seja, a parte superior, à esquerda da representação do objeto é dividida em duas outras: na parte superior, indica-se o tipo do objeto, e na parte inferior, o nome do objeto. A Figura 31 esboça esta notação através dos objetos:

- Romeu e Julieta o tipo do objeto é Peça a não indicação do tipo coletivo, indica que este objeto não possui tipo coletivo;

- o objeto Bruno Barreto, 01-12-97 tem tipo Romeu e Julieta e o tipo coletivo Montagem;

- o objeto Pedro II, 03-12-97 possui tipo Bruno Barreto e tipo coletivo Encenação; finalmente

- os objetos Primeira_Sessão e Segunda_Sessão possuem tipo Pedro II, 03-12-97 e o tipo coletivo Sessão.

\subsection{Características de Atributos}

Da mesma forma que outros conceitos do modelo, as caracteristicas dos atributos foram reavaliadas e, como conseqüência, algumas modificações foram efetuaadas. No documento original [Biajiz_96], consideram-se 13 caracteristicas, entre as quais: propriedade e comentário. Estas são substituídas pelas caracteristicas: texto e número; a primeira é apropriada para armazenar dados correspondentes a pequenas cadeias de caracteres (strings) onde o comprimento pode ser prédefinido ou para armazenagem de dados longos em formato texto, como por exemplo, ASCII. Já a caracteristica número engloba cadeias de caractéres numéricos tais como os formatos: inteiro, real entre outros.

Além das modificações acima, novas características são consideradas: a característica booleano e atributo de atributo. A característica booleana é considerada quando se deseja armazenar dados booleanos, permitindo-se, desta forma, que expressões lógicas possam ser consideradas e tratadas pelo SGBD.

A característica atributo de atributo é considerada para armazenar atributos que possuem a estrutura atributo de atributo. Esta estrutura é formada por um atributo que será chamado de atributo "base", que é o atributo que dá nome à estrutura e que possui a característica atributo de atributo. Ao atributo base têm-se associados subatributos que podem possuir características distintas uns dos 
outros, e um deles deve ser escolhido para ser, juntamente com o atributo base, o identificador da estrutura. $O$ subatributo identificador é indicado grifando-se o nome deste. Tal consideração não tinha sido explorada no documento original de SIRIUS. Portanto, a partir de agora consideram-se esta nova característica e as peculiaridades pertinentes à mesma, como um subatributo identificador.

\begin{tabular}{|c|c|c|c|}
\hline $\begin{array}{l}\text { Classe de } \\
\text { característica }\end{array}$ & Característica & Símbolo & Tipo de Dado \\
\hline \multirow[t]{3}{*}{ Estática } & texto & $\mathrm{Tx}$ & string, ASCII, RTF \\
\hline & número & $\mathrm{Nu}$ & inteiro, real \\
\hline & booleano & Bo & binário \\
\hline \multirow[t]{2}{*}{ Dinâmica } & regra & $\operatorname{Rg}$ & trigger \\
\hline & procedimento & $\mathrm{Pc}$ & stored procedure, método \\
\hline \multirow[t]{5}{*}{ Interface } & visualização & Vs & DFM \\
\hline & som & So & WAV, VOC, AIFF \\
\hline & partitura & $\mathrm{Pa}$ & MIDI, MOD, SNG \\
\hline & imagem & Im & BMP, TIFF, J-PEG \\
\hline & gráfico & $\mathrm{Gr}$ & WPG, CDR, WindowsMetaFile \\
\hline \multirow[t]{5}{*}{ Estruturais } & estrutra de dado & Ed & $\begin{array}{l}\text { vetor, lista, conjunto, dependência } \\
\text { funcional }\end{array}$ \\
\hline & tempo & $\operatorname{Tm}$ & absoluto, relativo \\
\hline & tupla & $\mathrm{Tp}$ & \\
\hline & $\begin{array}{l}\text { atributo de } \\
\text { atributo }\end{array}$ & Aa & \\
\hline & relacionamento & $\operatorname{Re}$ & \\
\hline
\end{tabular}

Quadro1) Caractéristicas de atributos

Na Figura 32 (da próxima seção), tem-se um exemplo, onde o atributo com característica atributo de atributo é o atributo Passaporte, que possui os subatributos: Nro_Passaporte (subatributo 
identificador, com característica número); Data_de_Emissão e Orgão_Expedidor, com característica texto.

Características de atributos são representadas em uma modelagem através de símbolos apropriados para indicá-las. O Quadro 1 exibe todas as características de SIRIUS, agrupadas em classes apropriadas; o símbolo associado a cada característica e alguns exemplos de tipo de dado suportado por algumas características.

\subsection{Representação do Objeto Primário}

O termo objeto primário é utilizado para caracterizar os objetos que não são transparentes ao usuário, mas que são por ele identificados somente através de abstrações. Estes objetos são manipulados pelo próprio sistema, pois apresentam uma característica mais voltada à implementação, embora sejam percebidos pelo usuário [Biajiz_96].

Biajiz pretendeu identificar tais objetos claramente na representação de um relacionamento, em que o objeto primário é representado por uma "bolinha", a qual é apontada pelos demais

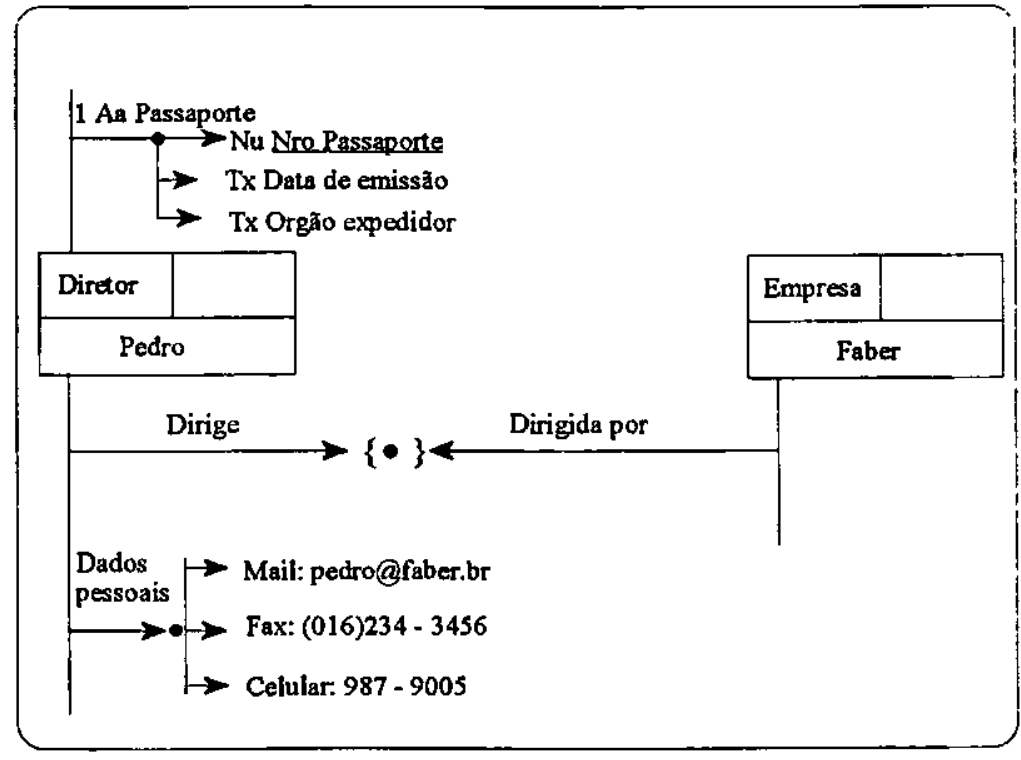

Figura 32) Representação e exemplo de objeto primário objetos que participam da associação (vide capítulo 3 Figura 17). O objeto primário encontra-se presente nas seguintes situações:

- relacionamentos,

- tupla, representando a associação implícita que ocorre entre o atributo formador da tupla e os atributos que compõem uma tupla,

- atributos de atributos, representando a associação implícita entre o atributo que dá nome ao atributo de atributo e os subatributos do atributo de atributo,

- nos critérios de generalização, pois nestes a "bolinha" também não é representada explicitamente, mas o objeto primário é simbolizado pelo trapézio, no caso da 
generalização restrita, e pelo trapézio invertido, na categorização (ambos serão vistos na seção 5.5), e através do conceito de

- colônias, pois nos diagramas não se representam as colônias, mas apenas seus tipos. Assim a "bolinha" não aparece explicitamente. No diagrama DHC, que será visto na secão 5.6, este conceito é representado pelo(s) retângulo(s) com cantos arredondados, que representa(m) colônia(s).

No entanto, no documento original de SIRIUS, estes casos específicos nem sempre continham a representação explícita do objeto primário. Sugere-se agora que tais objetos sejam explicitamente representados sempre que participarem do processo de modelagem. Esta opção é para que se tenha uniformidade na representação deste tipo de objeto. Além disso, aumenta ainda mais a "semântica gráfica" do modelo, uma vez que tal representação não acarreta maiores esforços representativos e não irá sobrecarregar os elementos gráficos do modelo. Durante o trabalho de avaliação destas propostas com outras pessoas, ficou claro que esse aspecto auxilia no entendimento do modelo as pessoas pouco familiarizadas com o mesmo. A Figura 32 ilustra a representação explícita de três objetos primários:

- o objeto primário, que participa do relacionamento;

- o que "liga" um atributo tupla ao seus subatributos e análogamente;

- o objeto primário do atributo de atributo.

\subsection{Representação dos Atributos Multivalorados}

No texto original de SIRIUS, as notações dos atributos multivalorados são feitas como ilustra a Figura 33 a). Uma lista é representada por uma seta com duas pontas opostas, um conjunto por uma seta com duas pontas na mesma direção, e um vetor por uma seta, sobre a qual há um colchete.

No entanto, a representação de lista e conjunto não é muito intuitiva. Fica mais intuitivo utilizar uma notação "composta" com um outro símbolo para representar cada atributo multivalorado. Desta forma, cada atributo tem sua representação particular, não se correndo o "risco" de confusões como: "Qual é o lado da seta que representa o quê?". Na nova notação, o atributo multivalorado "lista" é ilustrado através da composição: sinal menor sobre uma seta. Para representar-se um conjunto, coloca-se sobre a seta uma chave. Esta notação é mais adequada, pois fazendo-se uma analogia com a matemática, verificamos que esta utiliza chaves para ilustrar o conceito de conjunto, que é o mesmo conceito que se deseja representar. A notação do atributo vetor 
é também sugestiva, uma vez que ela é indicada por um colchete sobre uma seta. Neste caso, o colchete é intuitivo, pois também se usa colchetes para representar vetores em linguagens de programação. Dessa forma, o símbolo original utilizado é adequado para re-

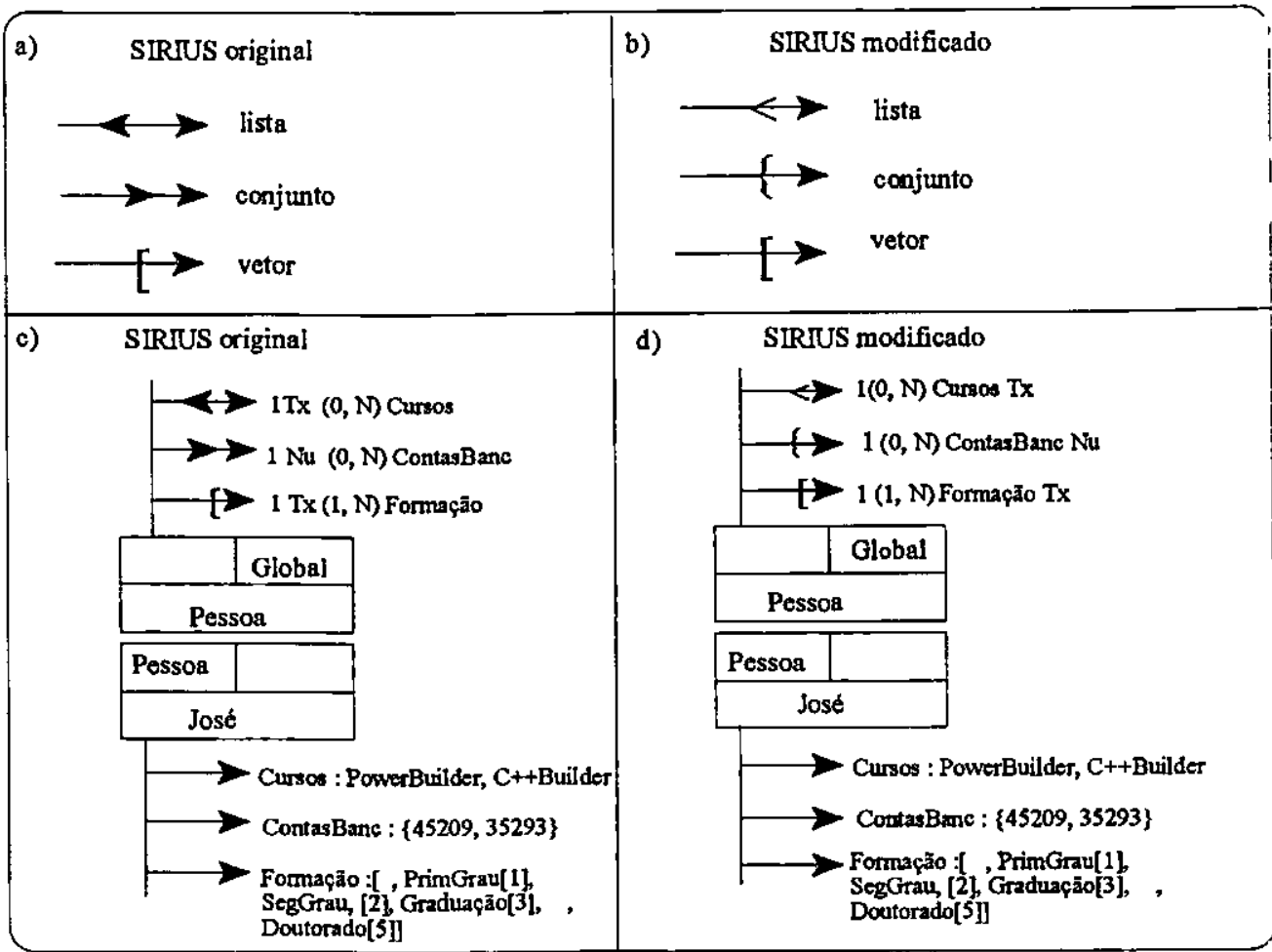
presentar o concei-

Figura 33) Representação de atributos multivalorados e exemplo da utilização destes

to de vetor.

Na Figura 33 b) pode-se ver como são representados os atributos multivalorados no modelo SIRIUS, após essas alterações.

Na Figura 33 c) e Figura 33 d), tem-se exemplos do emprego da notação original e da notação proposta respectivamente. Note-se que, tanto na Figura 33 c) como na Figura 33 d), o atributo de classificação Formação possui multiplicidade que varia de no mínimo 1 (um) a no máximo $\mathrm{N}$, ou seja, o objeto Pessoa pode possuir um único curso de formação escolar no mínimo, ou pode possuir $\mathrm{N}$ cursos no máximo. Neste caso, para o valor máximo do vetor não é atribuido nenhum valor, isto é, o vetor poderá assumir algum tamanho que a priori não se sabe. Quando este atributo é instanciado, o valor de $\mathrm{N}$ passa a assumir o tamanho máximo do vetor. No exemplo, Figura $33 \mathrm{c}$ ) e Figura 33 d), o valor de $\mathrm{N}$ é 6, pois o vetor possui 6 elementos. O primeiro e o quarto elementos, que possuem os índices 0 e 3 respectivamente, têm um valor indeterminado. Isto pode indicar, por exemplo, que José não fez o pré-primário e a pós-graduação. $O$ valor indeterminado de um vetor é indicado por duas virgulas, ou seja, a célula (ou campo) do vetor que corresponde a um valor indeterminado é deixada em branco. O segundo, terceiro, quinto e sexto elementos do vetor foram instanciados respectivamente com o valor PrimGrau[1], SegGrau[2], Graduação[3] e Doutorado[5]. 
O número entre colchetes indica a posição que um determinado elemento ocupa no vetor, mas notese que o vetor começa a ser instanciado a partir do elemento [0], mesmo que este não esteja explicitamente representado.

O parágrafo acima é necessário para esclarecer o emprego do atributo multivalorado vetor, uma vez que, no texto original, não fica claro se o número $\mathrm{N}$, utilizado na multiplicidade máxima de um atributo de classificação, indica o número máximo de elementos que podem ser instanciados, ou o comprimento do vetor. $O$ texto original permite representar o atributo de classificação Formação, do seguinte modo: $1 \mathrm{Tx}$ Formação [6], indicando um vetor com seis elementos. Observe-se que existe uma redundância de representação, pois as duas formas de indicar o atributo vetor, com ou sem o emprego de multiplicidade, é a mesma. Propõe-se aqui que tais notações devam ser usadas separadamente, ou seja, não é conveniente escrever algo do tipo: $1 \mathrm{Tx}(0, \mathrm{~N})$ Formação [6], pois esta notação, além de sobrecarregar a representação do atributo, pode gerar dúvidas quanto ao valor de N.

\subsection{Representação de Relacionamentos Multivalorados}

SIRIUS é um modelo rico por dar suporte a vários conceitos que têm grande significado semântico. Alguns destes conceitos são os que o distinguem de outros modelos como: quinze tipos distintos de caracteristica de atributos, relacionamento triplo, colônia, entre outros. Por outro lado, existem conceitos que, por serem bastantes flexíveis, tornam-se complexos ao serem representados graficamente em uma modelagem. Por exemplo, a representação de várias instâncias de um relacionamento multivalorado, cujos atributos com característica de relacionamento que participam deste relacionamento são multivalorados, relacionamentos entre atributos de classificação com caracteristica de relacionamento e atributos instanciados

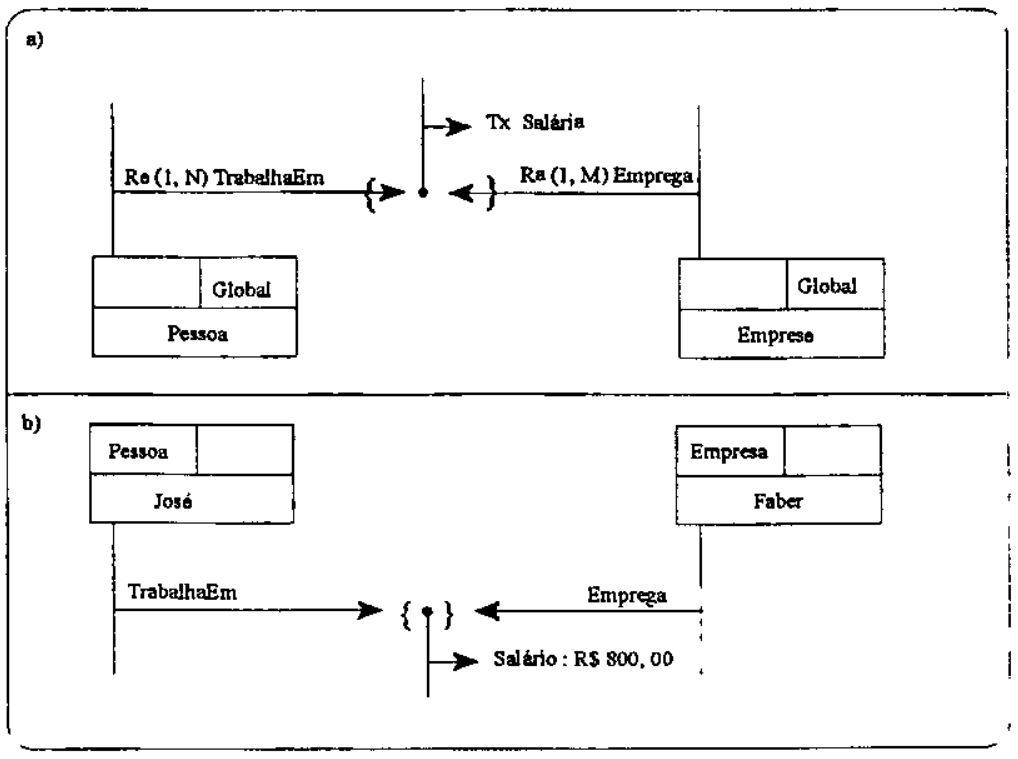

Figura 34) Relacionamento multivalorado e uma instância deste com caracteristica de relacionamento, 
a representação de um atributo quando este for complexo, por exemplo, um vetor de tuplas onde alguns atributos do relacionamento possuem característica de relacionamento e se relacionam com outros objetos. Enfim, as situações possíveis de serem modeladas são intrinsecamente não enumeráveis.

Para que se possa ter uma idèia da complexidade descrita anteriormente, um exemplo simples será mostrado a seguir, bem como possiveis formas de representá-lo. A Figura 34a) ilustra um exemplo, onde o objeto Pessoa possui um atributo com característica de relacionamento TrabalhaEm, e o objeto Empresa possui um atributo com característica de relacionamento Emprega. Ambos atributos que participam do relacionamento são atributos multivalorados, neste caso, conjuntos. E além disso, o relacionamento entre o objeto Pessoa e Empresa possui o atributo de relacionamento Salário com característica texto $(\mathrm{Tx})$. Outro problema de representarem-se várias instâncias deste tipo de relacionamento é que estas podem estar conectadas a vários atributos de relacionamento distintos.

Uma situação simples que pode ocorrer é a da Figura 34b), onde José trabalha na Faber. Neste caso, apenas uma instância do atributo Trabalha_em e Emprega é representada. A chave que envolve o objeto primário indica que está sendo representado apenas um elemento do conjunto de relacionamentos possiveis. Por ser um relacionamento multivalorado, podemos representar tantas instâncias deste relacionamento quantas forem necessárias. Procuraramse modos alternativos para representar este tipo de relacionamento, e alguns deles são ilustrados na Figura 35 .
A Figura 35
a) ilustra duas ins- tâncias distintas de

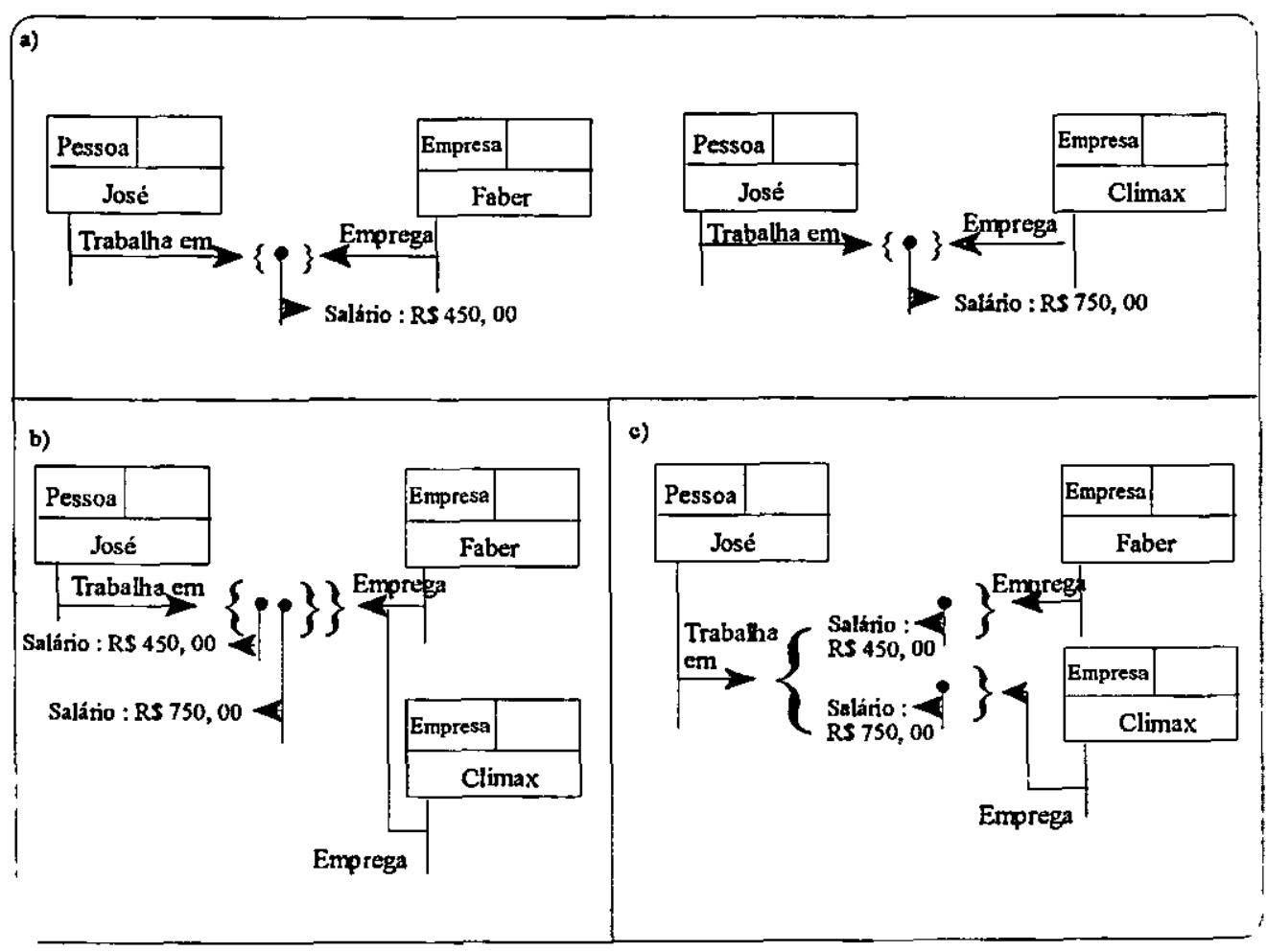

Figura 35) Instâncias de relacionamento multivalorado 
um mesmo relacionamento. Semanticamente, tem-se que José trabalha na Faber e na Climax. A representação destas instâncias é feita em diagramas separados, ou seja, um relacionamento entre José e a Faber, e outro relacionamento entre José e a Clímax, cada qual com seu respectivo atributo de relacionamento, Salário. Outra forma de representar é considerar um único diagrama como na Figura 35 b) e Figura 35 c). Na Figura 35 b), tem-se o atributo Emprega apontando para os objetos primários envolvidos por chaves, um representando o relacionamento entre José e Faber, e outro representando o relacionamento entre José e Clímax. Observe-se que o atributo Emprega tem como origem os objetos Faber e Clímax, e que os objetos primários são envolvidos por uma chave à esquerda, o que significa que apenas uma instância do conjunto de atributos Trabalha_em foi instanciada; e por duas chaves à direita, indicando que duas instâncias do conjunto de atributos Emprega foram instanciadas. Existe a necessidade de representar os dois objetos primários, pois é a estes que estão associados os atributos de relacionamento.

$\mathrm{Na}$ Figura $35 \mathrm{c}$ ), existem setas distintas para o atributo Emprega. Neste caso, as chaves à direita são posicionadas uma sobre a outra.

A representação utilizada na Figura 35 a) é mais simples de ser entendida, uma vez que as instâncias do relacionamento múltiplo são "quebradas" em várias instâncias de relacionamentos monovalorados, tornando mais fácil a compreensão do relacionamento multivalorado. No entanto, a desvantagem desta representação é que há a necessidade de se traçar novamente um objeto várias vezes. Sendo assim, a modelagem torna-se muito repetitiva, extensa e dispersa, e nela um mesmo relacionamento pode ter instâncias separadas em locais distintos (não pode ser visto como um único diagrama, onde todas as informações do relacionamento estão agrupadas).

A notação empregada na Figura 35 b) e Figura 35 c) tem todas as informações representas em um único diagrama. Entretanto, esta representação é mais densa, pois existe um maior acúmulo de informações no centro do diagrama. É necessário que existam dois objetos primários próximos, e se estes tiverem muitos atributos, a representação pode ser extensa $e$ as chaves que contêm estes objetos primários podem ser, algumas vezes, muito grandes, sobrecarregando uma modelagem.

A notação utilizada na Figura 35 c) é semelhante à utilizada na Figura 35 b). A vantagem desta representação é que, como as chaves à direita são colocadas uma sobre as outras, tornam mais direta a associação entre o objeto primário e o relacionamento que este representa. Note-se que na Figura 35 b) e Figura 35 c) uma chave à esquerda indica uma instância do atributo Trabalha_em. 
Duas chaves e dois objetos primários indicam que se têm duas instâncias do atributo Empresa. De qualquer forma o diagrama da Figura 35 b) é tão denso quanto o da Figura 35 c).

Outra situação de modelagem pode ocorrer quando duas pessoas trabalham em duas empresas. Por exemplo, tanto José como Maria trabalham na Faber e na Clímax. Esta situação é ilustrada na Figura 36. Na Figura 36 a), tem-se a representação utilizando-se diagramas separados, e na Figura 36 b,) utilizando-se um único diagrama.

Os exemplos expostos neste tópico foram suficientes para maior entendimento do problema da representação de relacionamentos multivalorados, e principalmente para a representação das instâncias destes relacionamentos. Contudo, não foi possível obter uma representação gráfica simples, clara e concisa, que des-

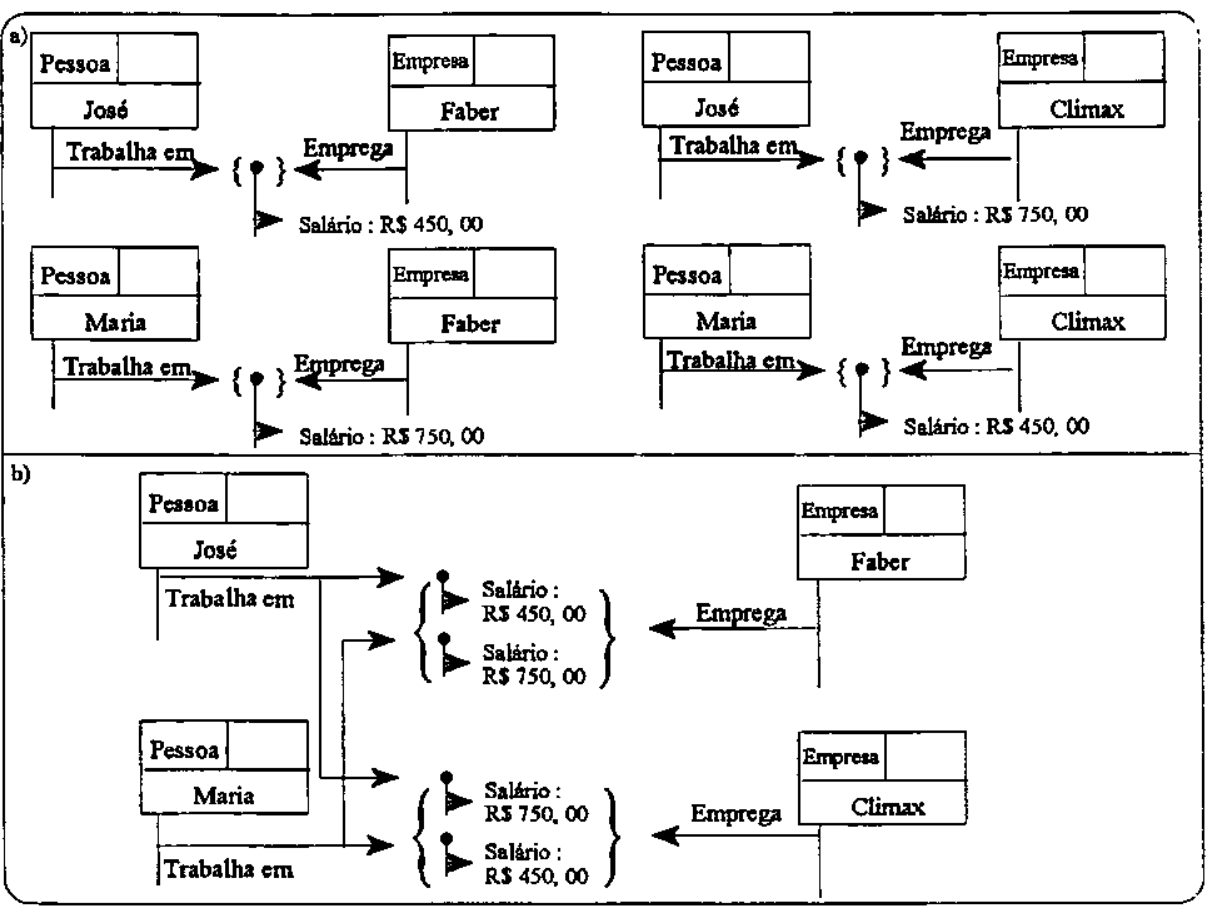

Figura 36) Instâncias de relacionamento multivalorado se suporte para represen-

tar satisfatoriamente todo o embasamento semântico que este conceito abrange. $O$ exemplo utilizou a modelagem de uma situação muito simples, que evidentemente não precisa ser representada, mas foi utilizada por ser também facilmente compreendida (no Anexo na Modelagem 4, mostram-se situações onde ocorrem relacionamentos multivalorados). No entanto, a necessidade de representarse instâncias de relacionamentos, quando o modelo permite a representação da abstração de classificação, é muito importante e precisa ser suportada.

Dentre as notações apresentadas, a representação em diagramas separados não contém muitas informações concentradas em um único local, o que sobrecarrega demasiadamente a modelagem. Tal representação é adequada quando não existe a necessidade de representar explicitamente muitas instâncias de um mesmo relacionamento, o que tende a ser um caso comum. 
Em uma modelagem real, é possível representar instâncias de um relacionamento multivalorado tanto em diagramas separados como em um único diagrama. Porém a representação empregada deve ser a que melhor se ajusta à modelagem em questão.

\subsection{Representação da Abstração de Generalização}

A Figura 37 ilustra a notação da abstração de generalização utilizada em [Biajiz_96]. Essa abstração é representada através de uma rede acíclica, onde cada nó é um tipo de objeto. Na Figura 37 a) e Figura $37 \mathrm{~b}$ ) tem-se:

\section{o objeto generalização ${ }^{18}$ no topo da Figura 37;}

o critério de generalização, ilustrado pelo retângulo entre o objeto generalização e $o(s)$ objeto(s) específico(s). Na linha superior, deste retângulo, são indicadas as restrições para a especialização (vide capítulo 3 - seção 3.7). Na linha inferior, tem-se a representação do critério pelo qual o objeto generalização foi especializado. Consideram-se também duas formas distintas para a representação deste critério. Uma forma é quando o critério depende do valor de um único atributo cujo domínio é discreto e finito. O nome do atributo (utilizado para especializar o objeto generalização) é indicado explicitamente na linha inferior do critério de generalização, como na Figura 37 a). Outra forma é quando o critério depende de mais de um atributo, de uma expressão sobre o atributo, ou de uma coleção de valores de atributos, neste caso a parte de baixo do retângulo é deixada em branco, como na Figura 37 b);

- o(s) objeto(s) específico(s) é(são) representado(s)pela indicação do nome do objeto generalização e o nome da colônia na primeira linha. Indica-se o nome do objeto específico na segunda linha. $\mathrm{O}$ predicado utilizado no processo de especialização e o conjunto de inicialização, na terceira linha. Na Figura 37 a) como o critério depende de um único atributo cujo o domínio é discreto e finito, então o predicado

${ }^{18}$ Biajiz utiliza o termo objeto genérico. Este termo também é empregado para expressar o objeto abstrato do versionamento, quando se trabalha com a Abstração de Versionamento [Camolesi_96]. Porém, para evitar conflito entre os termos empregados, utilizaremos, daqui em diante, o termo generalizaçāo para referenciar-se ao objeto mais abstrato de uma hieraquia de generalização/especialização 
é o próprio valor de atributo. Na Figura 37 b), como o critério não possui um domínio discreto e finito, então o predicado é representado por uma expressão ou um conjunto de valores.

SIRIUS trata a abstração de generalização (generalização ampla) especializando-a na abstração de generalização restrita e categorização ${ }^{19}$. Tais abtrações "herdam" os conceitos da generalização ampla. O critério de generalização é representado de maneira distinta para cada abstração. $\mathrm{Na}$ generalização restrita,

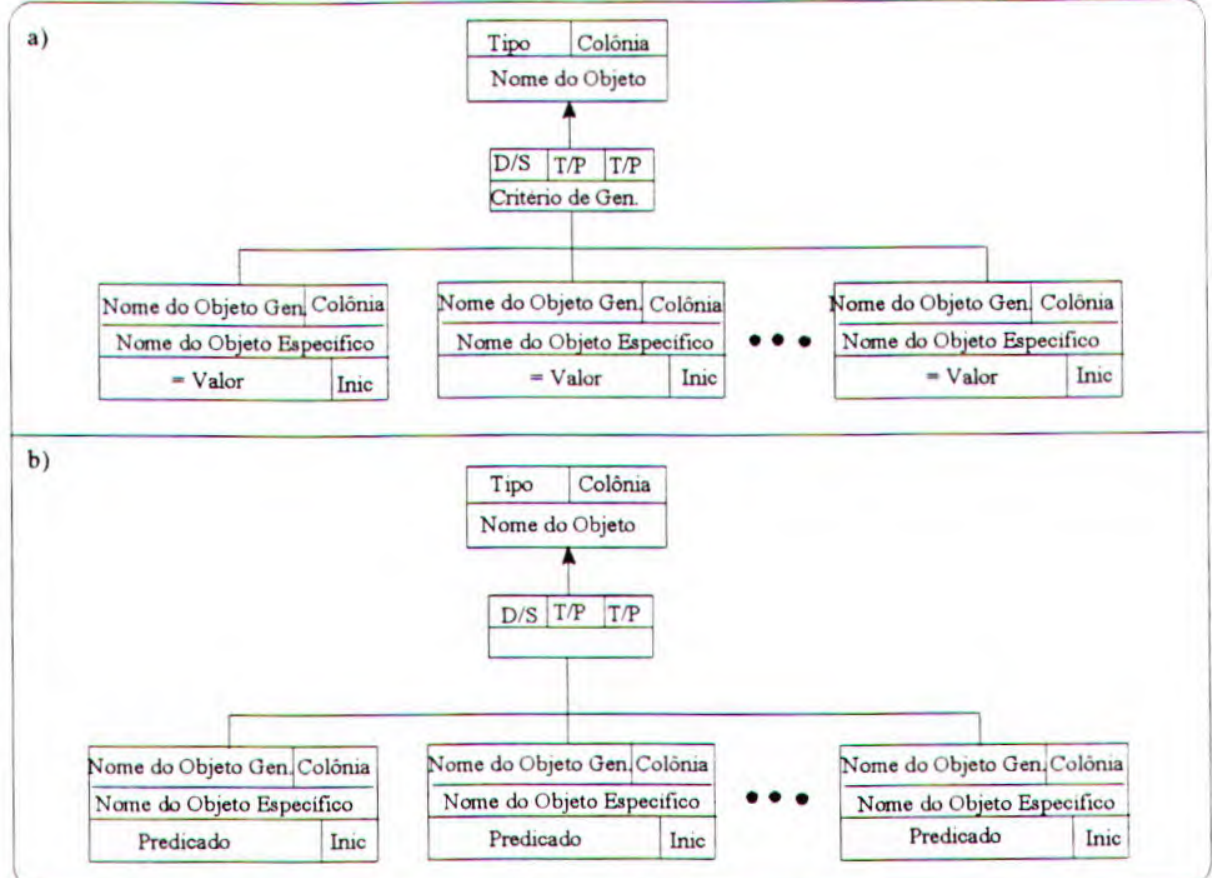

Figura 38 a), o critério é Figura 37) Hieraquia de generalização - notação original representado através de um trapézio dividido em duas partes: na parte superior, têm-se as restrições, e na parte inferior o nome do critério utilizado na especialização. Na categorização Figura 38 b) o critério de generalização é representado por um trapézio invertido com as restrições na parte superior, e na parte inferior, o nome do critério.

Tanto a generalização restrita quanto a categorização possuem dois tipos de restrições:

- disjunção (D) ou sobreposição (S), a qual é conceitualmente análoga à restrição de exclusão mútua/sobreposição do ME-RX.

- participação total $(T)$ ou participação parcial $(P)$, análoga à restrição de especialização total/parcial do ME-RX

${ }^{19}$ Esta era considerada apenas como uma restrição. Neste tópico considera-se a abstração de categorização 
As restrições de SIRIUS são indicadas na primeira linha do trapézio (generalização restrita) ou trapézio invertido (categorização) no centro do diagrama da abstração de generalização (generalização ampla).

Propõe-se que o(s) objeto(s) específico(s) se$\mathrm{ja}(\mathrm{m})$ representado(s) apenas pelo nome do objeto específico (na primeira linha), e pelo predicado e o conjunto de inicialização (na segunda linha). Neste caso o predicado indica a forma pelo qual o objeto

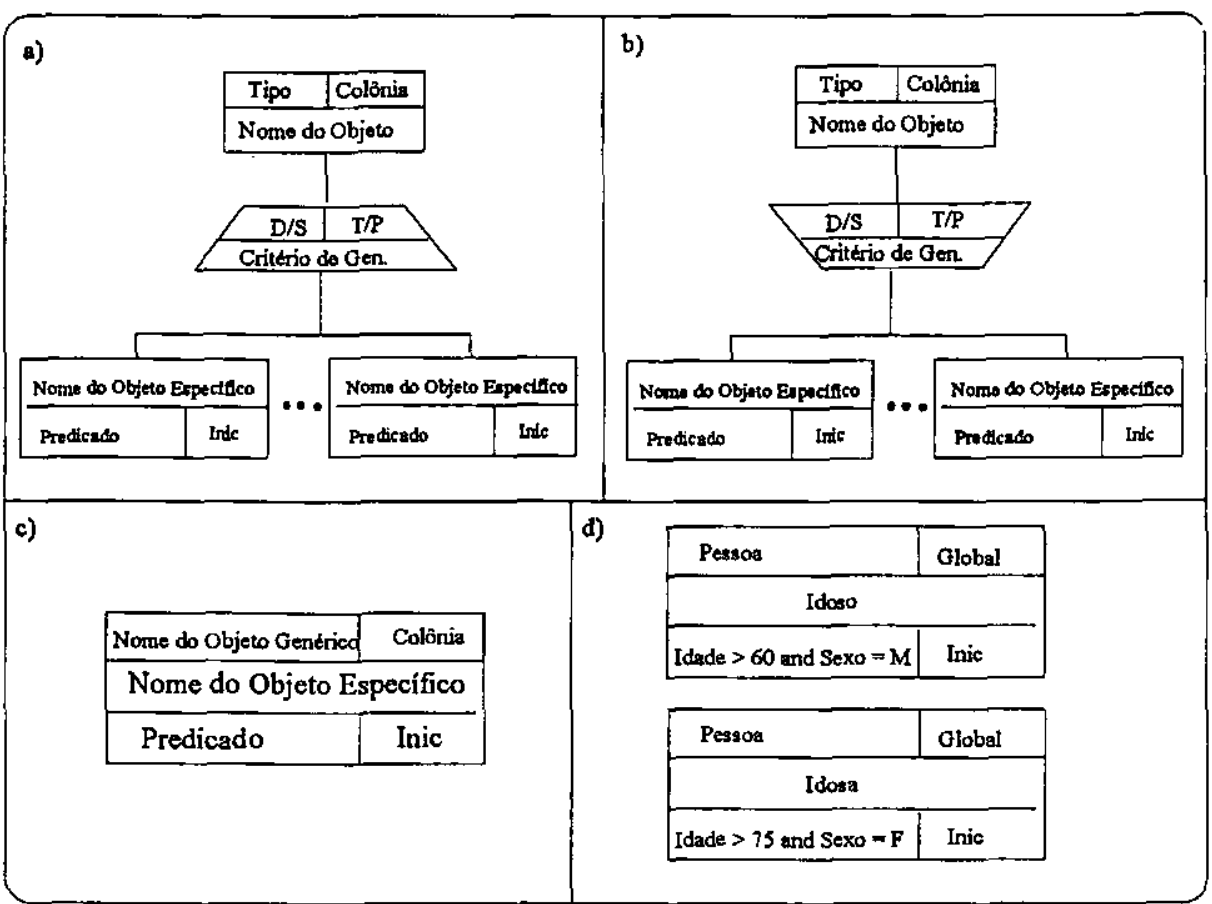
Figura 38) Representação da hierarquia de generalização e exemplos de objetos específicos que não estão vínculados diretamente na hierarquia de generalização generalização está sendo especializado, sem fazer distinção entre o domínio do(s) atributo(s) utilizado(s) para especializar um objeto generalização.

Está é uma forma de deixar a notação menos carregada, uma vez que fica redundante a repetição do nome do objeto generalização e do tipo da colônia, pois os objetos específicos herdam tais características do objeto generalização, não havendo a necessidade de repeti-las na representação.

Sempre que o objeto generalização estiver explicitamente representado em uma modelagem, como na Figura 38a), a representação $\operatorname{do}(s)$ objeto(s) especifico(s) pode conter apenas as características próprias de cada objeto especifico. Por outro lado, em uma modelagem pode acontecer ser preciso utilizar apenas um objeto específico, sem que a representação de toda hierarquia da generalização seja necessária. Neste caso, é interessante manter a representação do nome do objeto generalização e o nome da colônia, como na Figura $38 \mathrm{c}$ ), pois, fazendo-se uma referência ao objeto generalização, podem-se obter as características herdadas do objeto generalização. Na Figura 38 d), tem-se um exemplo de um objeto específico, o objeto Idoso, o qual é herdado do objeto generalização (o tipo de objeto cujo nome é Pessoa e cujas instãncias pertencem à colônia Global). 
Note-se também que o critério para esta especialização depende de mais de um atributo, no caso, os atributos Idade e Sexo, indicados pela expressão que forma o predicado.

A Figura 39 ilustra as modificações, através de um exemplo. $\mathrm{Na}$ Figura 39 a) e Figura 39 b) tem-se a notação proposta em [Biajz_96]. $\mathrm{Na}$ Figura 39 c) e

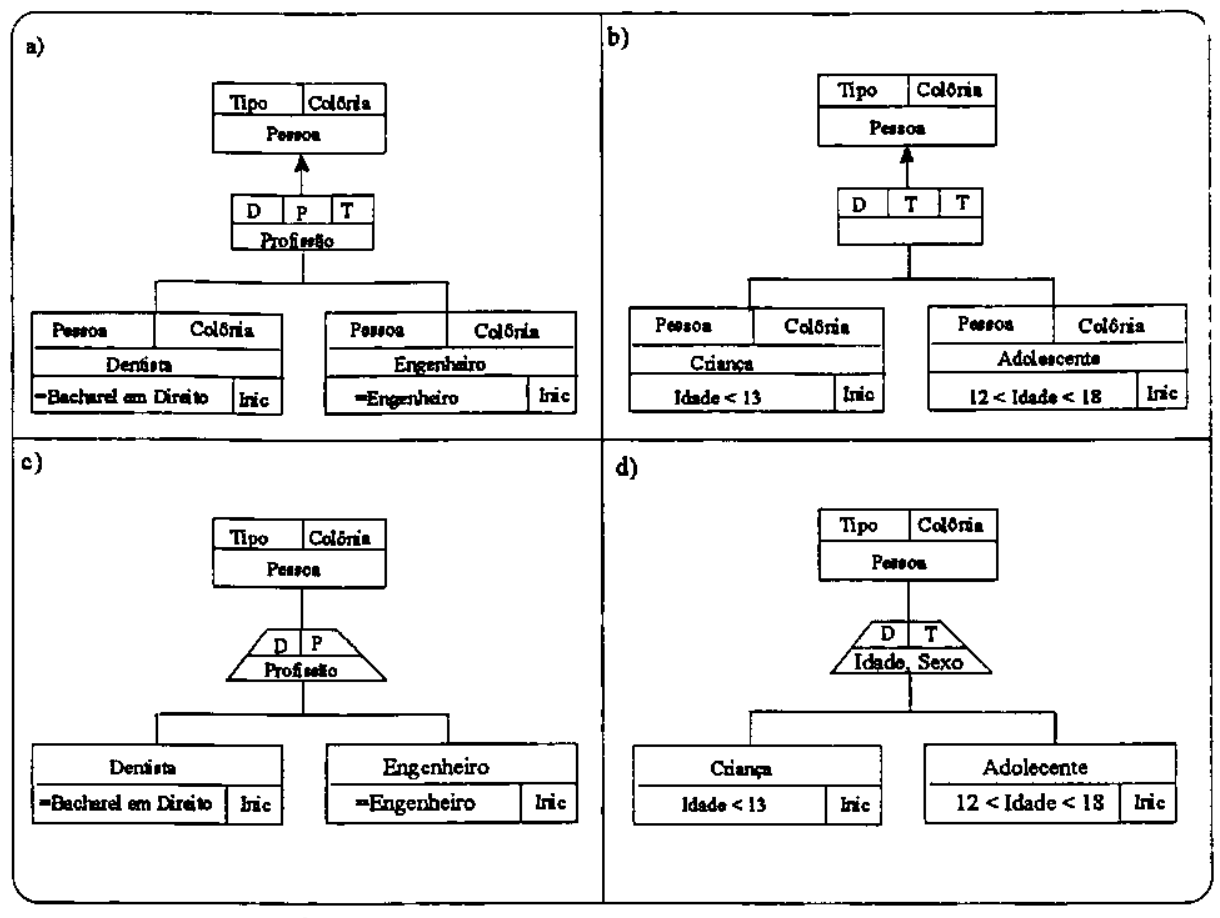

Figura 39) Exemplos de hieraquias de generalização

Figura 39 d) tem-se o mesmo exemplo, representado pela notação aqui proposta. Outro exemplo da hierarquia de generalização pode ser visto no Anexo - Figura 72.

\subsection{Representação da Abstração de Composição}

O termo composição em SIRUS é utilizado para caracterizar que objetos são compostos por outros, ou seja, existe um objeto denominado objeto composto, que é formado por objetos componentes ou objetos parte, formando assim a hierarquia de composição. No entanto, um objeto é composto por objeto(s) componentes, segundo um determinado aspecto. Desta forma, define-se uma colônia como sendo o conjunto de todos os objetos que compõem diretamente um determinado objeto, segundo um certo aspecto.

Todos os objetos habitam fisicamente exatamente uma colônia e toda colônia é constrita por um único objeto composto. Toda colônia tem um tipo, que determina o aspecto do objeto que a constringe, detalhado pelos objetos que a habitam.

Implicitamente, o conceito de composição abrange duas formas de relacionamento existentes entre um objeto e uma colônia: 
- relacionamento constringir, que indica que um objeto pode constringir várias colônias, desde que seja uma de cada tipo, e o inverso, uma colônia é constrita por um único objeto,

- relacionamento habitar, que indica que um objeto habita (fisicamente) uma única colônia e uma colônia é habitada por vários objetos.

Tem-se também o relacionamento entre colônia e tipo de colônia, derivado da abstração de classificação, que diz o seguinte:

uma colônia é de um único tipo mas um tipo pode ser de várias colônias.

A indicação de um objeto é feita universalmente pelo seu código, porém o identificador definido pelo usuário é único apenas no contexto de uma única colônia. Assim, o identificador definido pelo usuário somente identifica univocamente um objeto quando concatenado à hierarquia de colônias onde o objeto habita.

Para representar graficamente os conceitos que envolvem a Abstração de Composição foi necessária a criação de dois diagramas:

- o DHC (Diagrama Hierárquico de Colônia) e

- o DRI (Diagrama de Representação de Instância).

O DHC indica a composição por tipo; em outras palavras, mostra como os tipos de colônias são criados e quais são os tipos de objetos que as habitam e constringem, indicando graficamente como as informações da base estão logicamente agrupadas. Neste diagrama, o objeto máximo da Abstração de Composição é um (ou mais de um) objeto cujo tipo da colônia é Global, indicando assim que as instâncias do objeto habitam a colônia Global. Cada objeto, por outro lado, pode constringir um (ou mais de um) objeto que possui um certo tipo de colonia, por exemplo, o tipo X, mostrando que as intâncias deste objeto irão habitar uma colônia cujo tipo é X. Criam-se, portanto, mais niveis na hieraquia de composição, formando tantos níveis quantos forem necessários. O DHC é representado por objetos em que para cada um a informação de qual o tipo da colônia as instâncias deste objeto irão habitar fisicamente é colocada no canto superior direito do objeto. Os tipos que habitam colônias de um mesmo tipo estarão representados dentro de "nuvens", que representam os tipos de colônias. A informação de que um objeto constringe colônias de um certo tipo é ilustrada através de setas entre os objetos. Na Figura 40, tem-se um exemplo deste diagrama. Nela os tipos de objetos Planeta e Estrela possuem, como tipo de colônia, a colônia Global. O objeto tipo de objeto Planeta, por sua vez, constringe a colônia do tipo Oc.\&Cont. (Oceano e Continentes). O tipo 
de objeto Continente constinge a colônia do tipo Países. Por outro lado, esta constringe dois outros tipos de colônias: o tipo de colônia Regiões e DivGeog. (Divisão Geográfica). A colônia Regiões constringe a colônia Est (Estados), que constringe a colônia Cidades.

Note-se que este diagrama não ilustra quais objetos irão habitar uma colônia. Para isto, um outro diagrama dever ser considerado, que é o DHC

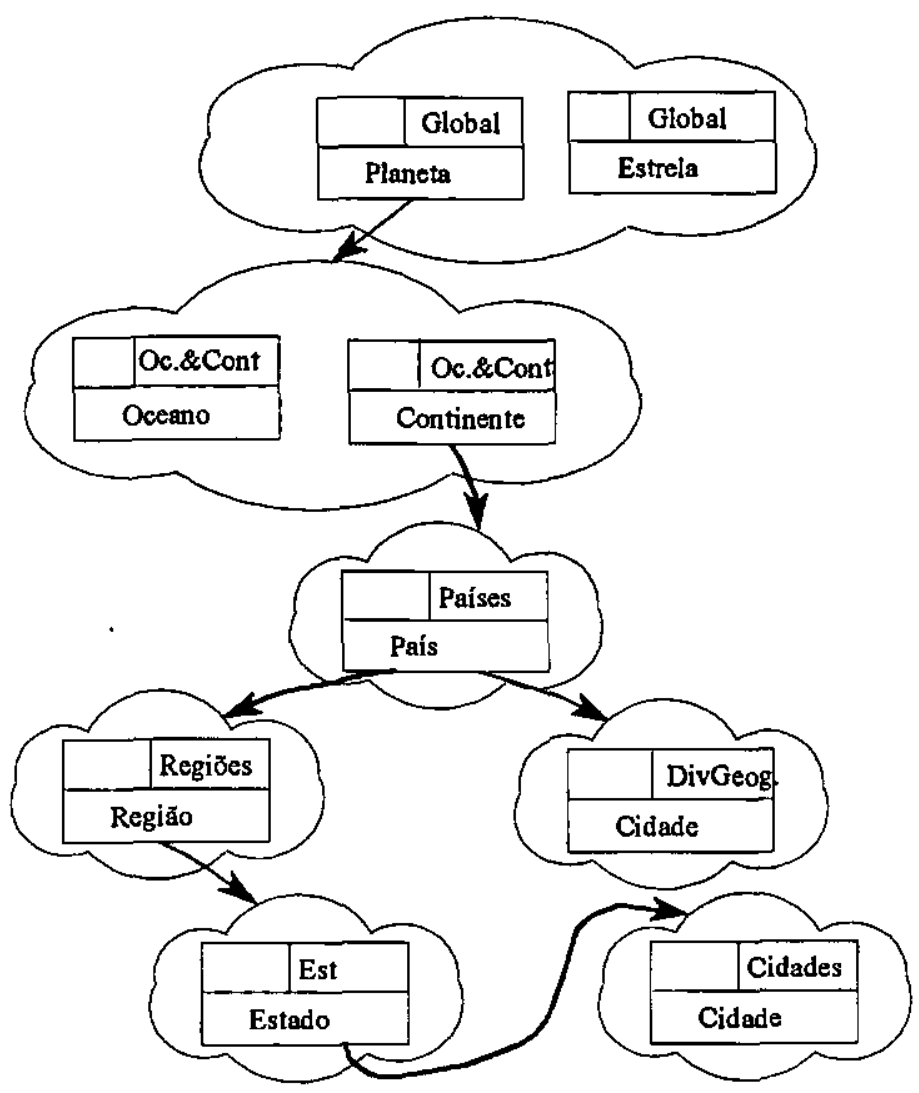

Figura 40) DHC - Diagrama Hierarquico de Colônia

DRI (Diagrama de Representação de Instância). Neste diagrama, representam-se as colônias, dentro das quais têm-se os objetos que a habitam, partindo-se da colônia Global (que é o topo da hieraquia). Assim, a colônia Global é desenhada e dentro dela são representados os objetos que a habitam. Se existir um ou mais objetos que constringem uma ou mais colônias, elas também são representadas, indicando-se para cada uma qual é o objeto que a constringe e qual(is) objeto(s) a(s) habita(m).

A notação empregada é um retângulo com cantos arredondados. Do lado externo deste retângulo, indica-se o tipo da colônia, e no interior, o(s) objeto(s) que a habitam. Quando existir um objeto que constringe uma colônia, esta informação é representada por uma seta, partindo-se do objeto que constringe até a colônia que será constrita por este objeto. Observe-se que, no DRI, geralmente não existe a necessidade de escrever no canto superior direito do objeto qual é o tipo da colônia da qual normalmente esses objetos não são tipos. Um exemplo do DRI pode ser visto na Figura 41, na qual colônias são ilustradas: a colônia Global, onde habitam os objetos Saturno e Terra (do tipo Planeta) e o objeto Sol (do tipo Estrela). O objeto Terra constringe a colônia do tipo 
Oc.\&Cont. Nesta colônia habitam objetos que são continentes ou oceanos, como: Europa, Ásia, Américas, África e Oceania do tipo Continente e os objetos Atlântico, Pacífico e Índico do tipo Oceano. Por outro lado, o objeto Américas constringe a colônia Paises (onde habitam dois objetos: México e Brasil, ambos do tipo País). Brasil constringe duas colônias: a colônia do tipo Regiōes e a do tipo Div. Geog. (Divisão Geográfica). Na colônia Div. Geog. habitam os objetos: Cerrados, Caatingas, Mata Atlântica e Campos do tipo Vegetação. Na colônia Regiōes habitam os objetos Norte, Nordeste, CentroOeste, Sul e Sudeste, todos do tipo Região. O objetos Sul e Sudeste constringem colônias que têm o mesmo tipo, ou seja, as colônias do tipo Est., porém estas são colônias distintas. $\mathrm{O}$ objeto Sul constringe a colônia Est; onde habitam os Estados da região sul. Na Figura 41, apenas o Estado do Paraná esta ilustrado. O objeto Sudeste constringe a colônia Est; onde habitam os estados da região sudeste como: Rio de Janeiro, Minas Gerais e São Paulo. Este

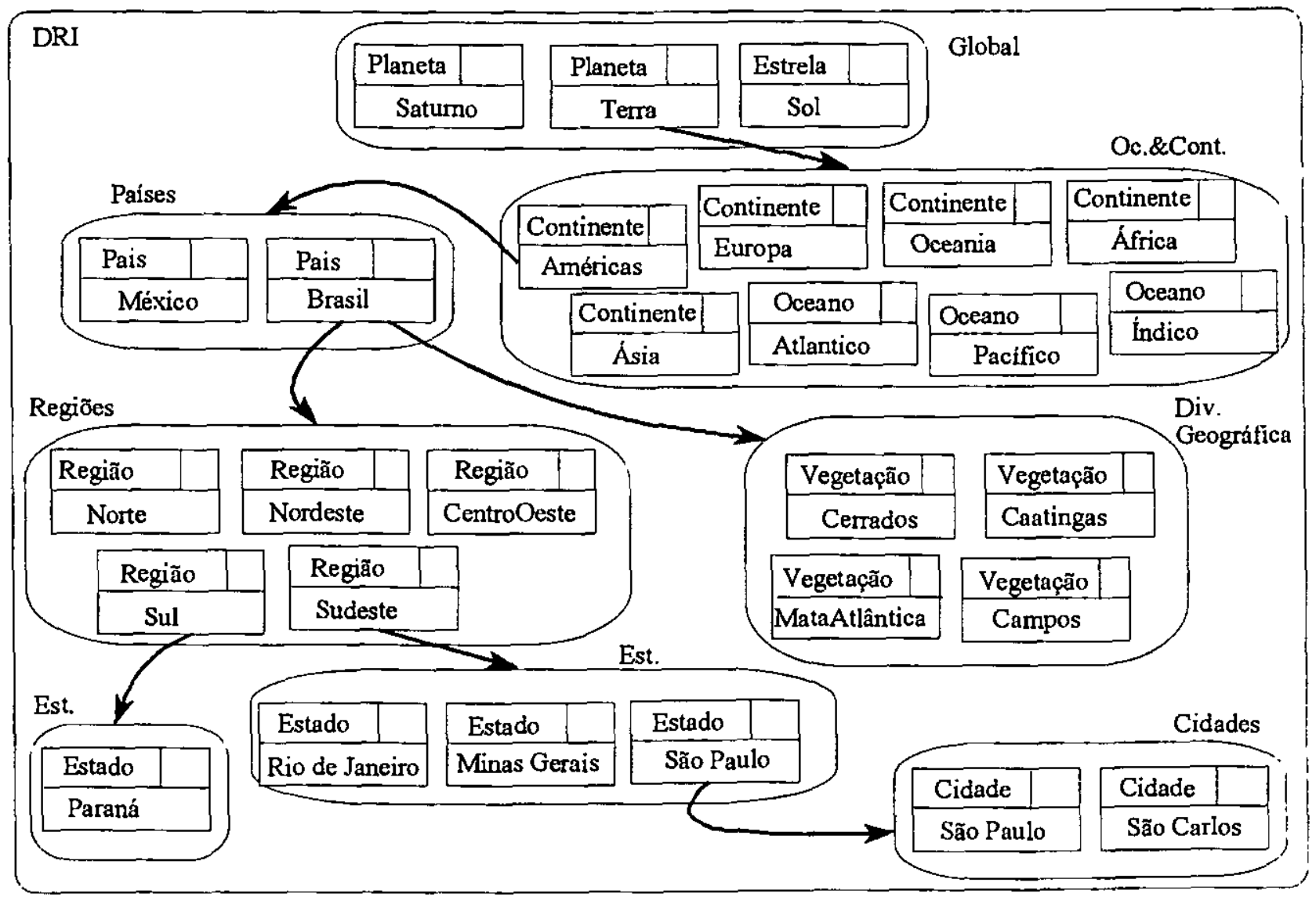

Figura 41) DRI - Diagrama de Representação de Instâncias

último constringe a colônia Cidades, onde habitam cidades do Estado de São Paulo, como a capital 
do Estado, São Paulo e uma cidade do interior, por exemplo, São Carlos (ambas do tipo Cidade). Outro exemplo da abstração de composição pode ser visto no Anexo - Figura $\mathbf{7 3}^{20}$.

\subsection{Conclusão}

Neste capítulo foram apresentadas novas notações elaboradas com a finalidade de melhorar a representação gráfica dos elementos construtivos de SIRIUS, visando expressar tais elementos e conceitos por uma simbologia gráfica mais clara, limpa, concisa e efetiva.

Como conseqüencia da reavaliação feita no modelo, alguns conceitos foram mais bem elaborados e conceitos novos também foram propostos, objetivando-se melhorar o modelo, uma vez que tais conceitos propiciam mais flexibilidade, por aumentar ainda mais a capacidade de representação semântica do mesmo, sem acarretar aumento da complexidade. Porém, os novos conceitos precisam ter um maior embasamento teórico.

O próximo capítulo ilustra uma solução encontrada para permitir a edição de modelagens reais de SIRIUS auxiliando também o treinamento nos conceitos do mesmo. A solução encontrada foi a utilização da representação dos elementos em uma modelagem via formulários. Para isto, um Editor de Esquemas foi construido e será mostrado detalhadamente a seguir.

\footnotetext{
${ }^{20}$ Nesta figura o DHC esta sẹndo representado de uma maneira simplificada
} 


\section{Capítulo 6}

\section{Editor de Esquemas - E²SIRIUS}

Este capítulo apresenta um Editor de Esquemas [Araujo_98a], construído neste projeto, chamado $E^{2}$ SIRIUS. Esse Editor tem como objetivo a edição de modelagens no Gerenciador de Objetos SIRIUS/GO [Traina_96a] e também auxiliar no treinamento de projetistas nos conceitos do modelo. $E^{2}$ SIRIUS explora todas as abstrações suportadas pelo modelo SIRIUS, representando também todos os seus elementos uniformemente, ou seja, tanto objetos que são tipos como objetos que não são tipos podem ser armazenados e acessados, tanto em tempo de compilação como em tempo de execução. Assim $E^{2}$ SIRIUS armazena tanto os tipos de objetos quanto os próprios objetos de maneira homogênea.

Durante a construção do Editor, houve a preocupação de que sua interface fosse o mais próxima possivel da notação, vista nos capítulos anteriores, utilizada para representar os elementos do modelo graficamente, existindo assim, uma maior "sincronia" entre os símbolos gráficos de SIRTUS e seu Editor.

O Editor poderá ser utilizado para alimentar uma base SIRIUS, quando o Gerenciador estiver disponivel. Atualmente, foi utilizado um gerenciador relacional para armazenar os dados editados.

\subsection{Descrição dos Principais Formulários}

Neste tópico, os principais formulários de $E^{2}$ SIRIUS serão descritos, bem como a funcionalidade de alguns componentes e/ou formulários necessários para facilitar o entendimento do Editor. Todos os componentes presentes nos formulários são chamados de interadores. Em particular, nesta descrição, os interadores, que são botões, estão escritos entre parênteses apenas para ressaltar este tipo específico. 


\subsubsection{Formulário Objeto}

O formulário objeto, ilustrado na Figura 42, destaca-se por ser o mais importante e também o mais complexo. Este formulário mostra sempre um objeto, chamado objeto corrente. Ele é indicado pelo seu nome, tipo e o tipo da colônia onde as sua instâncias habitam.

Os atributos de classificação de um objeto corrente situarm-se na parte superior do objeto. O interador Atributos de Classificação exibe para cada atributo de classificação informações como: nome, característica e organização do atributo, bem como o nivel de classificação do atributo, o valor default (quando existir) e por fim, indica quando um atributo é identificador ou não. $\mathrm{O}$ botão à direita dessa tabela (Edita Valor) chama outros formulários, permitindo que o usuário defina um valor para o atributo que tiver um valor default.

Os atributos de instanciação situam-se na parte inferior do objeto. $\mathbf{O}$ interador que exibe tais atributos é formado por quatro colunas: nome e característica do atributo, nome do subatributo (quando o atributo possuir característica tupla ou atributo de atributo) e valor do atributo ou subatributo. Os botð̃es à direita do interador Atributos de Instanciação, exceto o botão (Fechar), permitem que o usuário defina e/ou modifique $\mathrm{o}(\mathrm{s})$ valor(es) de um atributo. $\mathrm{O}$ botão (Def.Valor) define e/ou modifica o(s) valor(es) do(s) atributo(s) do objeto que está um nivel acima na hierarquia de classificação em relação ao objeto corrente. O botão (Edita Valor) define e/ou modifica o(s) valor(es) do(s) atributo(s) associado(s) ao objeto corrente. O botão (Def.Atr.Extra) define um atributo extra.

Existem ainda dois outros botões, situados entre os interadores Atributos de Classificação e Atributos de Instanciação, que se referem aos atributos. $O$ botão (+ Atributo) permite que o usuário entre em uma tela onde ele deve optar por adicionar um novo atributo ou fazer um vínculo entre um atributo que já existe na base e o objeto corrente. $O$ botão (-Atributo) permite que o usuário remova um atributo da base ou simplesmente remova o vínculo deste atributo com o objeto corrente.

Associados diretamente ao objeto corrente estão os botões: ( + objeto), que insere na base um objeto definido pelo usuário, e o botão (- objeto), que remove da base o objeto corrente. 


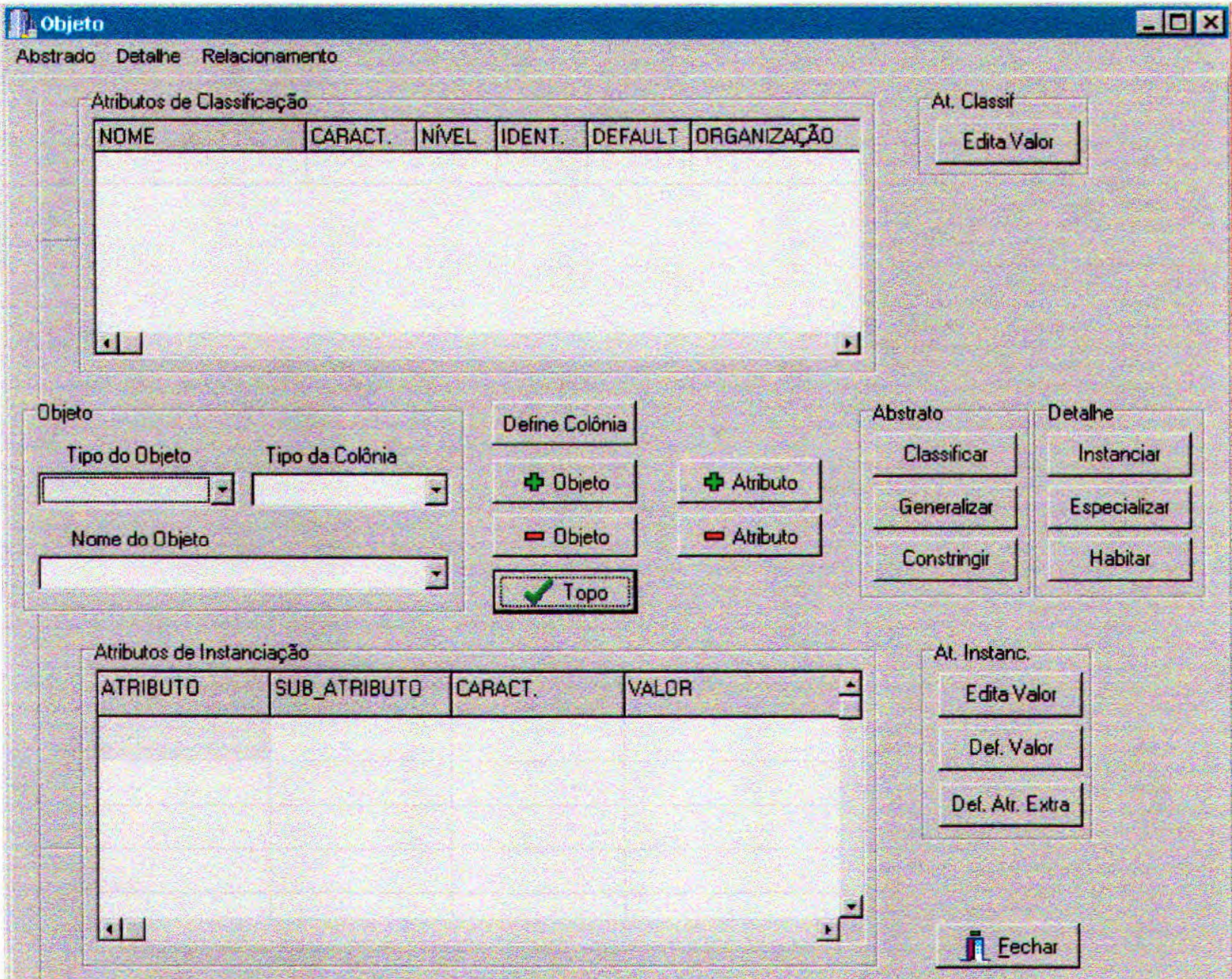

Figura 42) Formulário Objeto

O botão (Topo) retorna ao nível mais alto da hierarquia de classificação.

O formulário objeto é importante no Editor de Esquemas pois, além das funções descritas acima, é este formulário que permite que o usuário represente, em uma modelagem, as abstrações que o modelo suporta, tanto em nível abstrato, através dos botões: (Classificar), (Generalizar) e (Constringir), quanto em nível de detalhe, através dos botões (Instanciar), (Especializar) e (Habitar). A associação de atributos a objetos, junto com a representação de relacionamentos, é a maneira de implementar a abstração de agregação. Desta forma, os construtores semânticos do modelo estão centralizados no objeto corrente. Quando uma base de dados é criada, ela é inicializada automaticamente com todos os objetos padrão definidos pelo modelo SIRIUS, como por exemplo, a colônia Global e o objeto Tipo de objeto Metatipo. A Figura 42 mostra todos os objetos controlados pelo sistema, inicializados automaticamente quando uma 
base é criada, que pode ser um objeto tipo ou não, pois o Editor de Esquemas trata ambos de maneira uniforme.

Como o Tipo de Objeto Metatipo já existe em uma base, qualquer objeto pode ser incluído na base como o formulário Objeto.

\subsubsection{Formulário Define/Vincula Atributos}

O formulário Define/Vinculaatributos mostrado na Figura 43 possui quatro interadores. O interador Atributos da Base exibe todos os atributos armazenados na base juntamente com suas respectivas características, possibilitando assim que o usuário efetue uma consulta aos atributos que já foram criados e que se encontram disponíveis na base. Estes podem ser vinculados a objetos, e/ou a outros atributos formando novos atributos, que possuem característica tupla ou atributo de atributo. $\mathrm{O}$ botão (Define atributo) permite que um novo

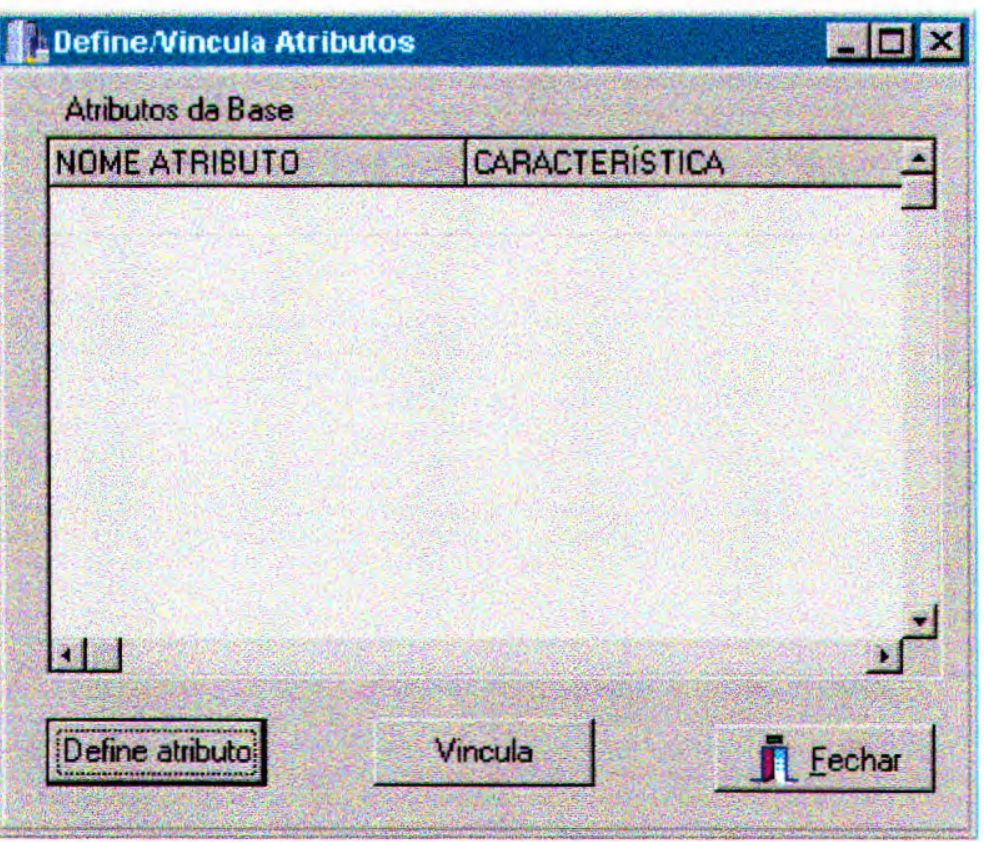

Figura 43) Formulário Define/Vincula Atributos atributo seja criado na base, caso ele não exista. Para isto, este botão faz uma chamada a um formulário específico, que permite a definição de atributos. Por outro lado, o botão (Vincula) permite que um atributo na base seja vinculado ao objeto corrente. Isto será feito no formulário Vínculo, descrito adiante. Finalmente, o botão Eechar sai deste formulário e retorna para o formulário que o chamou.

\subsubsection{Remove Atributo}

Uma das operações que pode ser efetuada sobre um atributo é a de remoção. O editor permite que a remoção de um atributo seja feita simplesmente removendo o vínculo entre o atributo e o objeto corrente, (deste modo o atributo permanece na base) ou removendo o atributo da base. Um atributo 
só poderá ser removido da base caso não exista vínculo dele com nenhum objeto ou com nenhum outro atributo.

No formulário Remover Atributo mostrado na Figura 44, o usuário poderá optar por como ele deseja remover um atributo. Caso opte por retirar apenas o vínculo com o objeto corrente, todos os atributos vinculados ao objeto corrente são listados no interador Nome do atributo, para que o usuário escolha qual deles ele deseja remover. Analogamente, se o usuário optar por remover o atributo da base, todos os atributos são listados no interador Nome do atributo, para que o usuário escolha qual será

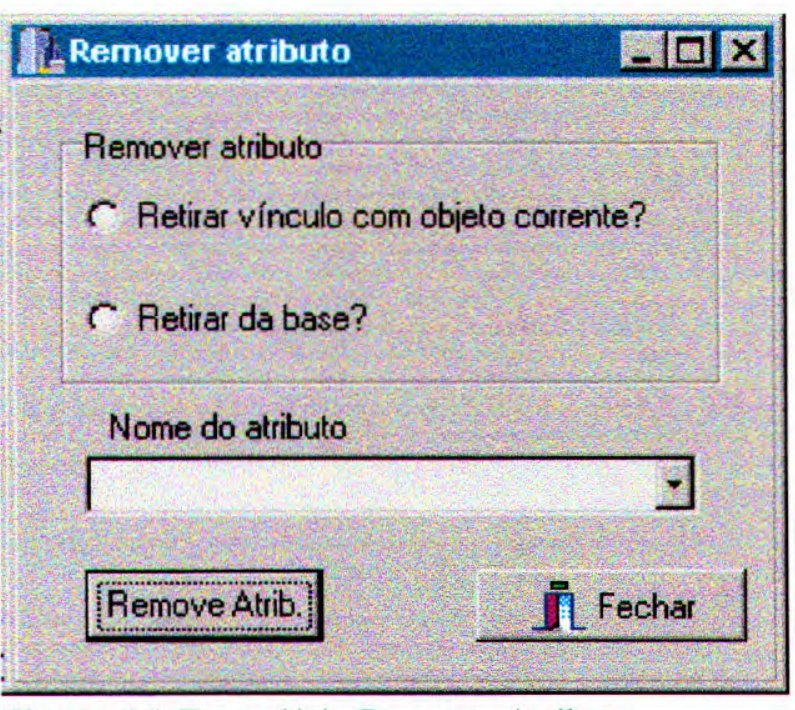

Figura 44) Formulário Remover Atributo retirado. Sabendo-se qual atributo será removido, a operação pode ser executada pressionando-se o botão (Remove Atributo) .

\subsubsection{Formulário Atributo}

O formulário Atributo exibido na Figura $\mathbf{4 5}^{21}$ é composto por várias "fichas" sobrepostas, duas das quais são mostradas nas Figura 45 e Figura 46. Cada "ficha" representa uma característica de atributo que o modelo suporta. O nome da característica do atributo é situada na "lingueta" de cada ficha e é através desta que se escolhe a característica do atributo a ser criado. Como as características possuem particularidades específicas, estas também são representadas no formulário, ou seja, as "fichas" são

${ }^{21} \mathrm{Na}$ verdade a Figura 45 e Figura 46, referem-se ao mesmo formulário, ilustrando apenas atributos com caracteríticas distintas. 


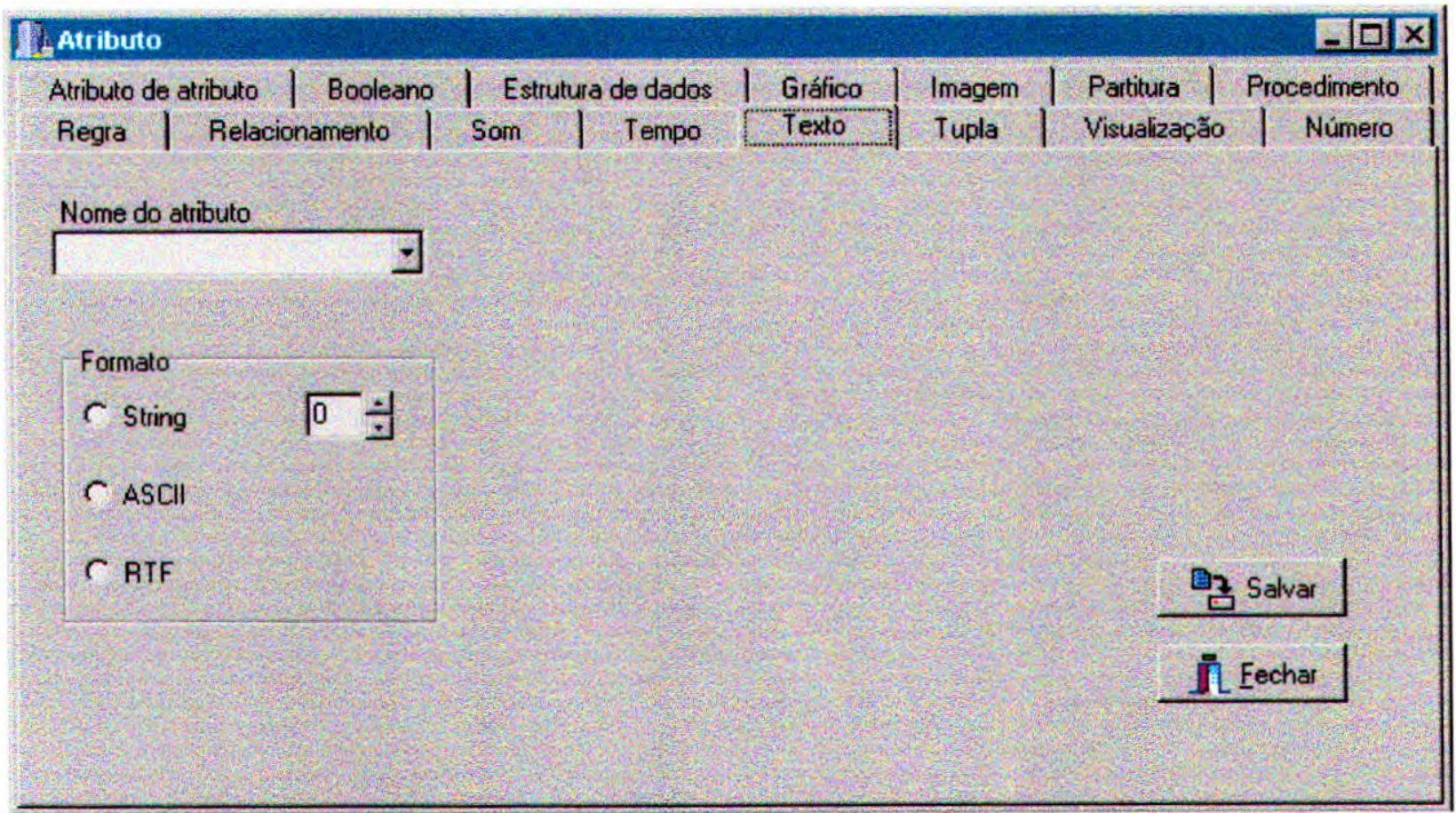

Figura 45) Formulário Atributo (Característica Texto)

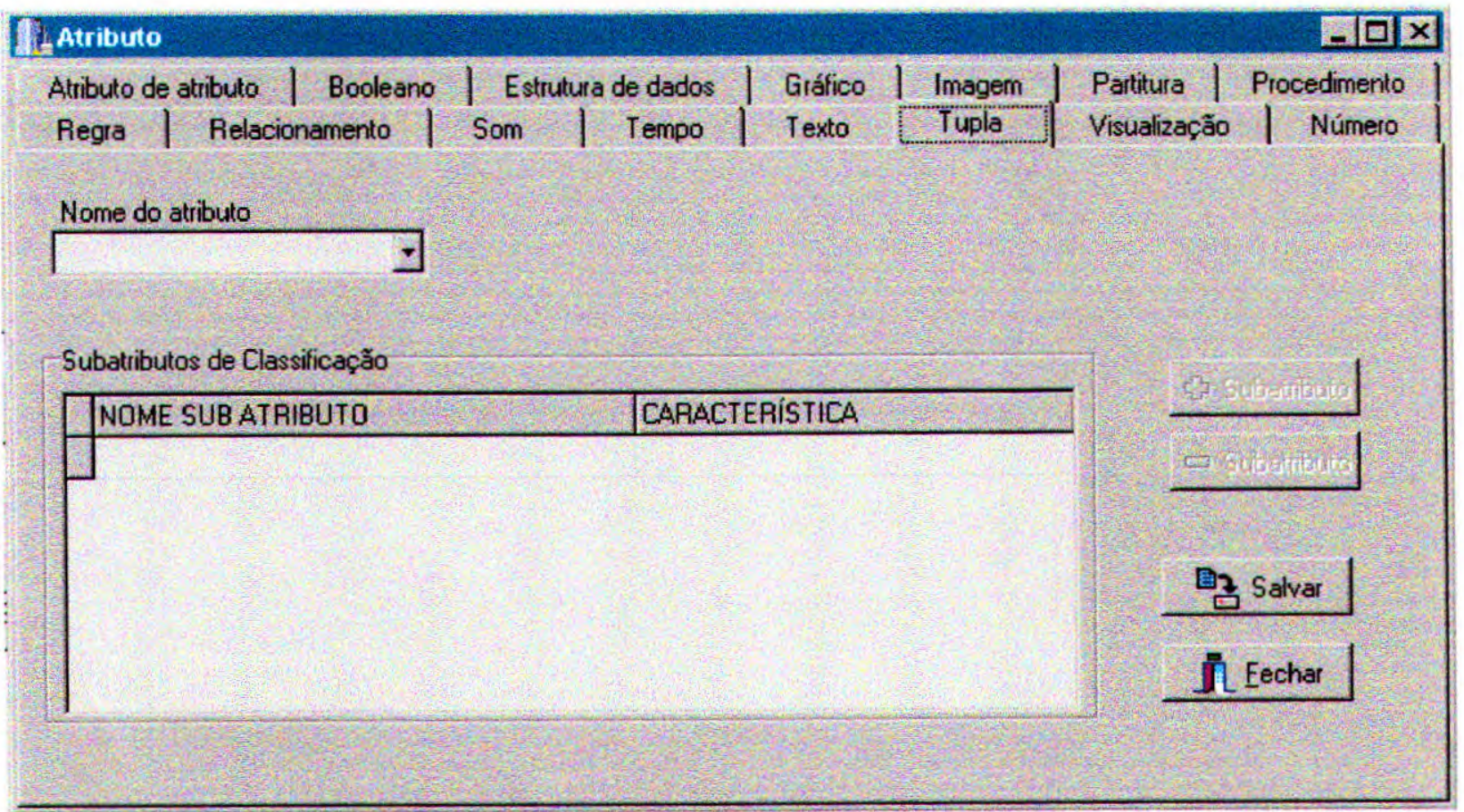

Figura 46) Formulário Atributo (Característica Tupla)

distintas umas das outras, possibilitando que o usuário armazene informações apropriadas para cada característica. Por exemplo, para criar-se um atributo com característica texto Figura 45, o usuário 
deve editar o nome do atributo no interador Nome atributo e escolher também, no interador Eorma to, um formato para o atributo. Já para um atributo com característica tupla Figura 46, é necessário definir o nome do atributo e os subatributos que irão compor esta tupla. Para isto, quando o nome da tupla estiver definido, o botão (+Subatributo) é então habilitado, permitindo que os subatributos sejam criados. Cabe observar que os subatributos são criados através de um formulário próprio, o formulário subatributo. Por ser muito parecido com o formulário Atributo ele não será representado. A diferença básica entre o formulário Atributo e o formulário subatributo é que o último indica não só o nome do subatributo mas também o nome do atributo ao qual os subatributos estarão associados. Visualmente, um interador chamado Nome do subatributo é colocado à direita do interador Nome do atributo no formulário subatributo. O formulário Subatributo é utilizado para criar-se subatributos de atributos cujas características sejam tupla ou atributo de atributo. Para atributos que possuem tais características, o formulário Atributo possui o interador Subatributo de classificação, que exibe o nome e a característica do subatributo associado ao atributo de atributo ou a uma tupla, cujo nome é mostrado no interador Nome atributo. O interador Nome atributo também lista os atributos que possuem as mesmas características. Por exemplo, quando a característica texto é selecionada, os atributos que possuem esta característica serão listados. Deste modo, quando o usuário criar um atributo de uma determinada característica, ele poderá ver se já existe um atributo com o mesmo nome do atributo que ele deseja criar. Caso exista, o aplicativo não permite que um novo atributo seja criado. Em outras palavras, o usuário só irá visualizar os atributos da característica corrente.

Finalmente, o atributo criado será armazenado na base quando o usuário salvar as informações do formulário, através do botão (Salvar). O botão (Fechar) retorna para o formulário que o chamou.

\subsubsection{Formulário Vínculo}

É o formulário vínculo, mostrado na Figura 47, que irá promover a agregação entre o objeto corrente e um atributo da base. $O$ atributo que será vinculado ao objeto deve ser escolhido no intera 
dor Nome do atribu

to, que irá listar os atri-

butos da base. Uma vez

escolhido o atributo, este

pode ser vinculado ao

objeto, podendo ser um

atributo de classificação

ou atributo de instancia-

ção. O usuário deve fazer

uma escolha através do in-

I Vinculo

$-\square$

t e r a d or

Clas -

Nome do atributo

$\longrightarrow$

Classit. Instanc.

ᄃ Classificação

$\Gamma$ Identificador $\Gamma$ Atrib. indefinido

C Instanciação

$\Gamma$ Fixo

$\Gamma$ Valor nulo

$\sqrt{0}$ ivivel

$\Gamma$ Default

Organização

C Monovalorado Misinc $[0]$

$C$ Lista

C Conjunto

$C$ Vetor

界 Salvat

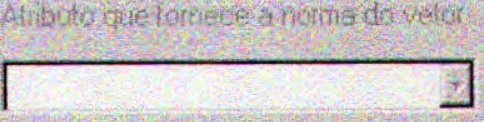

Eechar

Figura 47) Formulário Vínculo

sif./Instanc. Con-

forme a opção escolhida, outros interadores serão ativados pelo aplicativo, de maneira adequada, de acordo com os conceitos teóricos do modelo. Por exemplo, se o usuário desejar vincular um atributo como sendo de classificação, ele deve indicar, no interador Classif./Instanc., a primeira opção. Feito isso, o sistema pré-inicializa o interador Nível para 1 (um). Se esse atributo for um identificador, $E^{2}$ SIRIUS desabilita os interadores Fixo, Default, Atrib. Indefinido e Valor Nulo; apenas o interador Nível fica habilitado para que o usuário forneça qual é o nível de classificação do atributo que está sendo vinculado. Se o atributo for indefinido, então ele não pode ser um identificador e também não pode ter um valor nulo. Neste caso, os interadores Identificador e Valor Nulo são desabilitados. Se o atributo tiver valor nulo, o interador Identificador é desabilitado.

Considerando-se um atributo vinculado como sendo atributo de instanciação, então os interadores Identificador e Nível são desabilitados, pois não faz sentido para o modelo ter um atributo instanciado que seja um identificador e/ou que possua nível. Se o atributo for indefinido significa que não será atribuído nenhum valor para ele, portanto, o interador valor Nulo é desabilitado, para que o atributo não tenha nenhum valor, nem mesmo o valor nulo. $\mathrm{O}$ fato de existirem interadores que, ora estão habilitados, ora não, permite impedir, via aplicativo, que o usuário execute operações ilegais. Este recurso foi utilizado também em outros formulários do Editor. 
Ao escolher a forma como um atributo será vinculado, o usuário deve escolher também a organização do atributo. Um atributo pode ser monovalorado ou multivalorado. Quando for indicada a organização monovalorado, a norma (ou comprimento) não precisa ser dada, neste caso, foi considerado 1 (um). No caso de atributos multivalorados, que podem possuir como organização lista, conjunto ou vetor, a norma deve ser setada pelo usuário. Para lista e conjunto, o interador Norma é habilitado. Quando a organização for um vetor, além do interador Norma, o interador Atributo que fornece uma Norma também é habilitado. Este interador permite que a norma de um vetor seja escolhida por um atributo com característica número que possui um valor inteiro. Finalmente, o vínculo é armazenado na base através do interador (Salvar).

\subsubsection{Formulários Editar e Definir Valor de Atributo}

$E^{2}$ SIRIUS possui três formulários que permitem editar e/ou definir o valor de um atributo. No entanto, cada formulário é empregado em uma determinada situação.

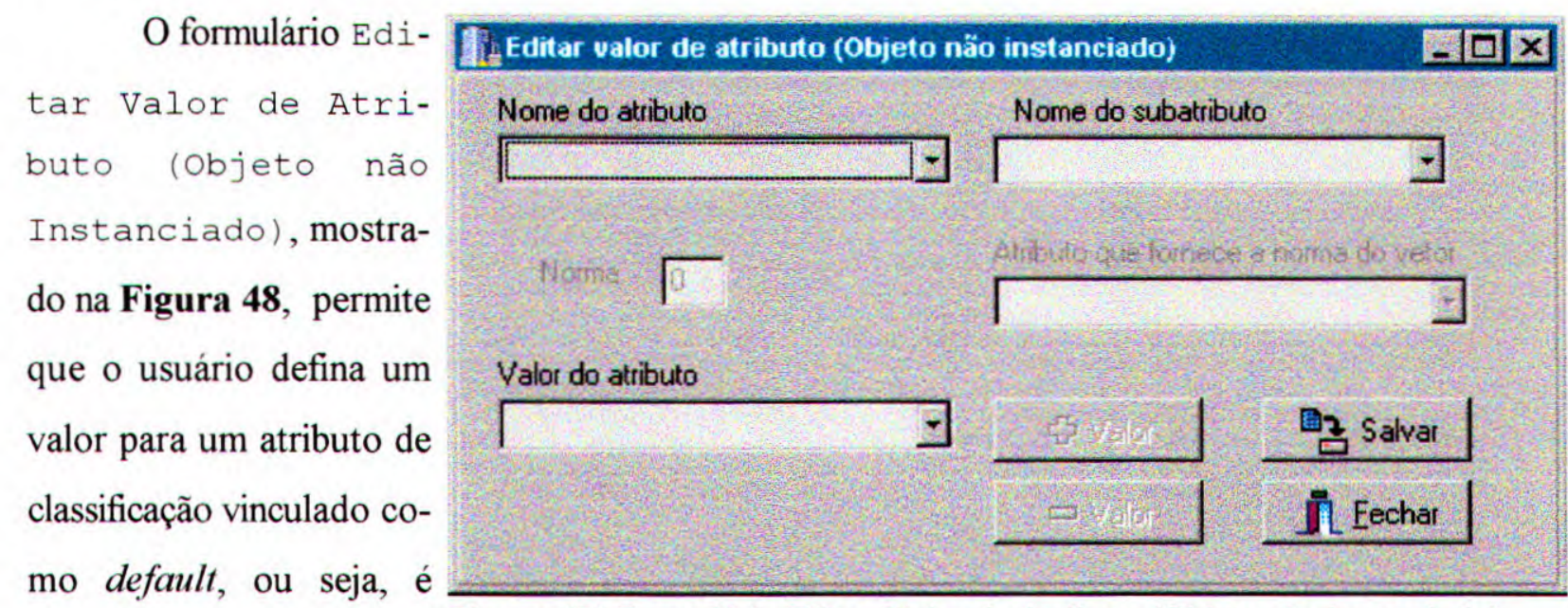
através deste formulário

Figura 48) Formulário Editar Valor de Atributo (Objeto não instanciado) que atributos default têm seus valores definidos e/ou alterados caso já existam. Editar Valor de Atributo (objeto Instanciado) Figura 49 possibilita que o valor de um atributo de instanciação seja definido e/ou modificado, caso exista.

Os formulários Figura 48 e Figura 49 são parecidos. Ambos possuem nove interadores. $\mathrm{O}$ interador Nome do atributo é o único que difere de um formulário para outro, pois ele irá listar o nome do atributo de acordo com a funcionalidade do formulário, isto é, no formulário Editar 
Valor de Atributo (objeto não Instan ciado), os atributos listados são os atributos de classificação, que sejam também default. Já no formulário Editar Valor de Atributo (objeto Instanciado) são listados todos os atributos de instanciação Editar valor de atributo (Objeto instanciado) -

\section{Nome do atributo}

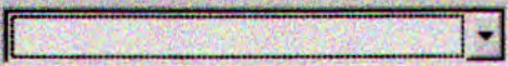

Nome do subatributo

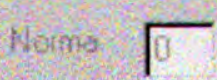

Valor do atributo
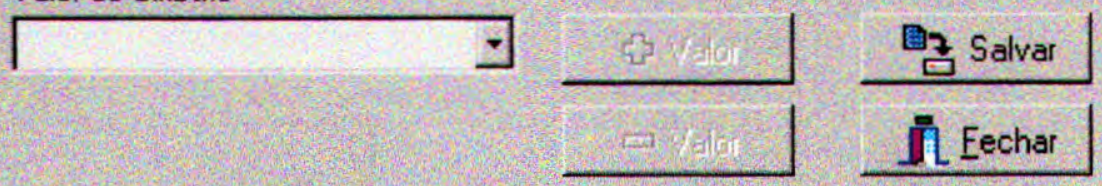

Figura 49) Formulário Editar Valor de Atributo (Objeto instanciado) associados ao objeto corrente instanciado.

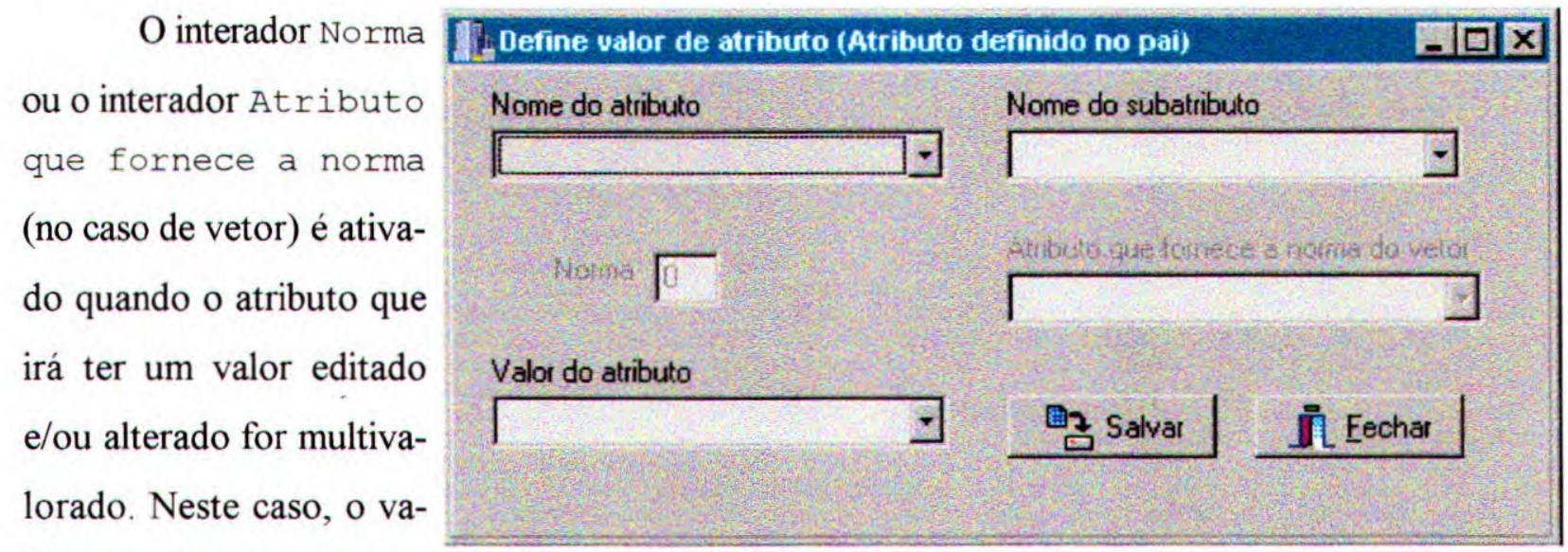
lor que foi setado para Figura 50) Formulário Define Valor de Atributo este atributo, quando o vínculo foi feito, será exibido para que o usuário saiba quantos valores ele deverá armazenar, no máximo, para um atributo multivalorado.

Para atributos com característica de tupla ou atributo de atributo, o interador Nome do sub atributo lista os subatributos que podem ter seus valores editados e/ou listados.

É no interador Valor de Atributo que o usuário irá definir e/ou alterar um valor. No caso de atributos multivalorados podem-se adicionar ou remover (caso já exista) os seus valores com o auxílio do botão (+Valor) e do botão (-Valor), respectivamente. Quando o valor já estiver editado e/ou modificado, o interador (Salvar) salva as informações necessárias na base.

O formulário Define Valor de Atributo Figura 50 possui interadores iguais aos formulários descritos acima, exceto os interadores (+Valor) e (-Valor), que neste caso não 
existem. É este formulário que irá definir e/ou alterar valor de atributos (fixos, monovalorados e de nível um) que estão vinculados no objeto que está um nível acima na hieraquia de classificação, ou seja, no objeto "pai".

O interador Nome do atributo, no entanto, lista os atributos vinculados ao "pai" do objeto corrente, de forma que o vínculo seja feito de acordo com a necessidade de adicionar um valor para um atributo que será vinculado no objeto corrente, quando o seu atributo receber um valor.

\subsubsection{Formulário Generalização Ampla}

Em SIRIUS,

a abstração de

generalização

é considerada

de uma forma

Generalização Ampla

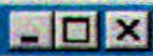

abrangente

generalizaçã

o ampla, que

é especializa-

da em gene-

raliza ção

restrita e

categoriza-

ção. Em

E $^{2}$ SIRIUS o

formulário

\section{Opção de Especialização}

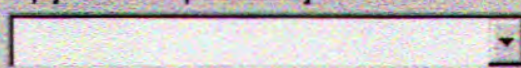

Objetos Específicos

OBJETO ESPECÍFICO

Participação

$C$ Total

5 Parcial

\section{Tipo da Colônia}
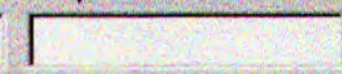

Sobreposição

C Disiunção

C Sobreposição

Generalização

Ampla Figura

51 é um for-

Figura 51) Formulário Generalização Ampla

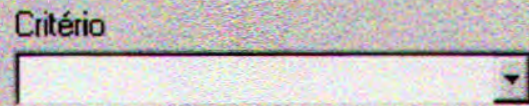

mulário de consulta. Nele o usuário poderá obter informações de como um tipo de objeto generalização foi especializado. Para isto, tem-se o tipo de objeto generalização representado no topo do formulário. Neste caso, o tipo do objeto generalização coincide com o objeto corrente. Sabendo-se qual é o tipo do objeto generalização, as informações de sua especialização são 
recuperadas da base e estas são ilustradas em interadores apropriados. Se o tipo do obejto foi especializado, então as restrições utilizadas para que esta especialização fosse possivel são mostradas no interador Restrições (estas podem ser de Sobreposição ou Participação). O interador opção de Especialização indica como o tipo objeto foi especializado, se através da especialização restrita ou da categorização. Da mesma forma o interador Cri tério irá ilustrar qual foi o critério utilizado para que a especialização fosse possivel.

Finalmente, as informações particulares para cada tipo de objeto especifico são mostradas no interador objetos Especificos. Este representa o nome do objeto, predicado e, se existir, a inicialização, considerados em sua especialização. Cada linha deste interador representa um tipo de objeto específico. Note-se que os interadores Restrições, opção de Especialização e Critério possuem as mesmas informações para um certo conjunto de tipos de objetos específicos ilustrado no interador Objetos Específicos.

\subsubsection{Formulário Especialização Restrita}

O formulário Especialização Restrita, mostrado na Figura 52, é um formulário editável que o usuário irá utilizar para criar tipos de objetos específicos. O tipo de objeto generalização é ilustrado no topo do formulário. Para especializar um tipo objeto, o usuário deve indicar no interador Restrição quais as restrições para a especialização. O interador Critério é editável e nele o usuário ira digitar o nome do atributo que será o critério da especialização. Este interador também lista os critérios vinculados ao tipo do objeto generalização. Este formulário foi implementado de forma que apenas um atributo seja escolhido como critério para cada especialização. O botão (-Critério) deixa o usuário remover um critério, caso não exista o tipo objeto específico vinculado a este critério. Uma 


vez indicadas as restrições e o
critério, o próximo passo é
definir qual(is) é (são) o(s) tipo(s)
objeto(s) especifico(s) derivado(s) do tipo objeto generalização. Para isto, o nome do tipo objeto específico deve ser editado no interador objeto Específico, bem como o predicado utilizado nesta especialização, e a inicialização, caso exista. Durante a criação dos tipos objetos específicos, o usuário tem a liberdade de mudar as restrições e/ou o critério de especialização, caso seja necessário. O botão (Salvar) irá armazenar na base todas as informações editadas neste formulário, criando-se, desta forma, os tipos objetos específicos.

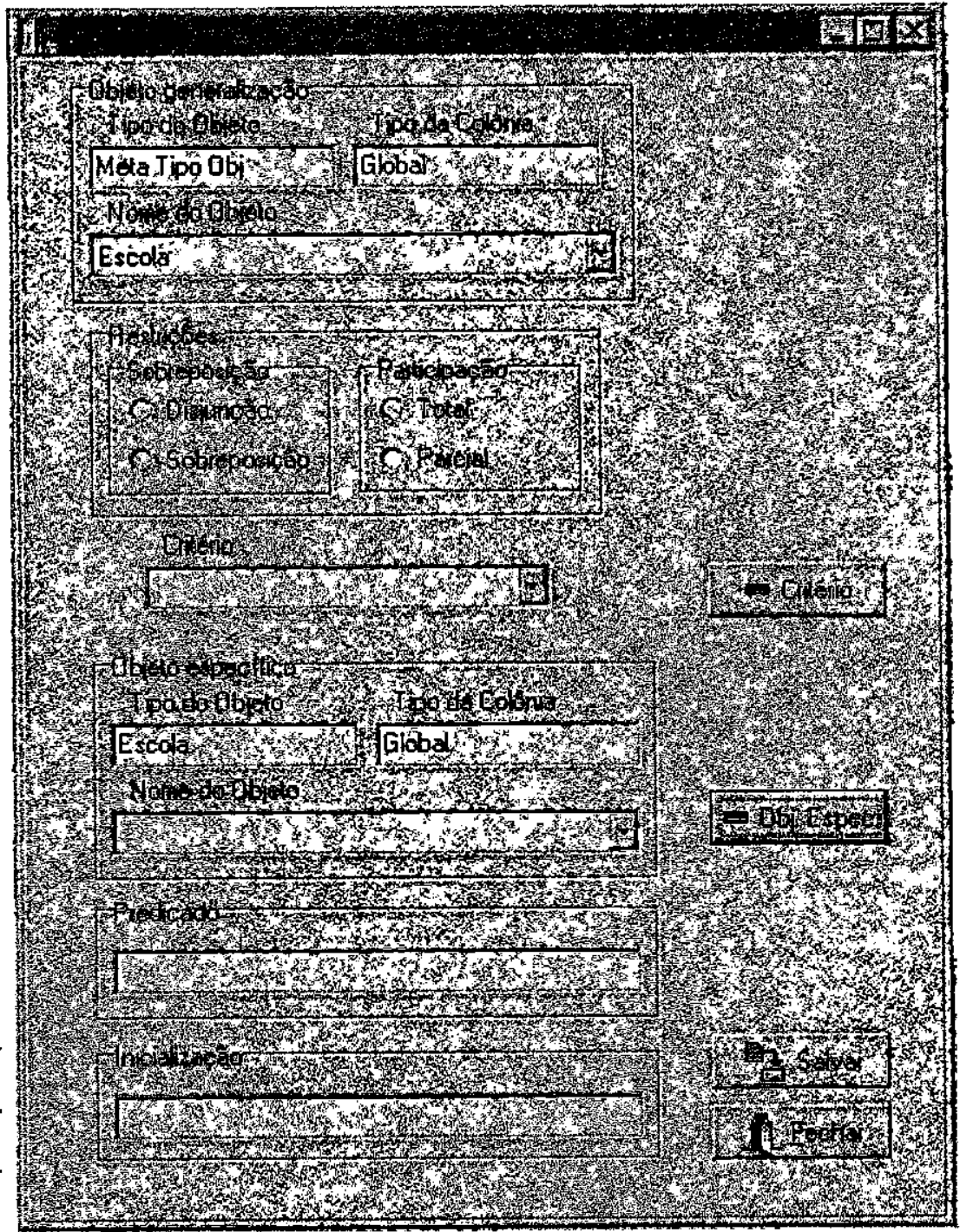

Figura 52) Formulário Especialização Restrita

Note-se que existe ainda o botão (- obj .Espec. ), que elimina o vínculo do tipo objeto específico com o tipo objeto generalização, ou seja, o tipo objeto específico deixa de ser derivado do tipo objeto generalização. No entanto, o tipo objeto especifico continua armazenado na base.

\subsubsection{Formulário Colônias Abertas}

O modelo impõe que os objetos devem ser criados em colônias que estejam abertas. Sendo assim, o usuário necessita saber quais colônias estão abertas, antes de criar um objeto. Esta é a finalidade do formulário Colônias Abertas, Figura 53, um formulário de consulta que está sempre disponivel em tempo de execução. Ele contém apenas um interador, que lista o tipo da colônia e o 
objeto que constringe uma colônia aberta. Por default, a colônia do tipo Global sempre estará aberta. Observe-se que o objeto que constringe esta colônia não é ilustrado, pois neste caso este objeto pertence ao metaesquema e não precisa aqui ser explicitamente representado.

É o botão (Constringir) do formulário objeto que irá criar uma colônia, caso ela ainda não exista, e abri-la. Desta forma, sempre que uma colônia for aberta, ela é listada no formulário Colônias Abertas. É importante observar que este formulário não armazena informações na base, trata de informações que ficam presentes apenas

em tempo de execução em $E^{2}$ SIRIUS. Quando Figura 53) Formulário Colônias Abertas este não estiver rodando, as informações são perdidas, pois não existem colônias abertas. Estas estarão abertas só em tempo de execução.

\subsubsection{Define Tipo Colônia}

Uma colônia não tem nome. Ela possui apenas um tipo, pois objetos habitam colônias de um certo tipo, e objetos também constringem colônias de um certo tipo. Uma colônia é identificada por seu tipo e pelo nome do objeto que a constringe, uma vez que cada objeto constringe no máximo uma colônia de um dado tipo. O tipo de uma colônia é criado através do formulário, Define Tipo de Colônia Figura 54. Este formulário possui o interador editável Nome do Tipo da Colônia, onde o usuário define o tipo de uma colônia. Os

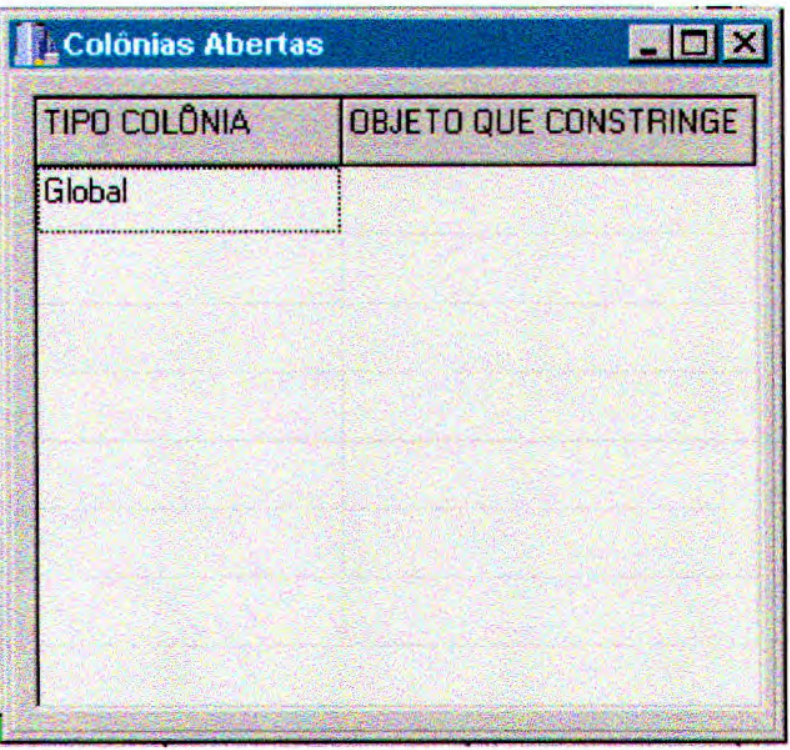




\subsubsection{Habita}

O formulário Habita, Figura 55, é um formulário de consulta, cuja finalidade é informar ao usuário em quais colônias os objetos habitam. Estas informações são transmitidas por um interador que possui três colunas: o nome do objeto e o tipo colônia que ele habita juntamente com o objeto que constringe a colônia.

Desta forma, para cada objeto, o usuário pode saber qual é o tipo da colônia que este objeto habita e também qual é o objeto que esta constringindo a colônia desse tipo, identificando assim a colônia. A
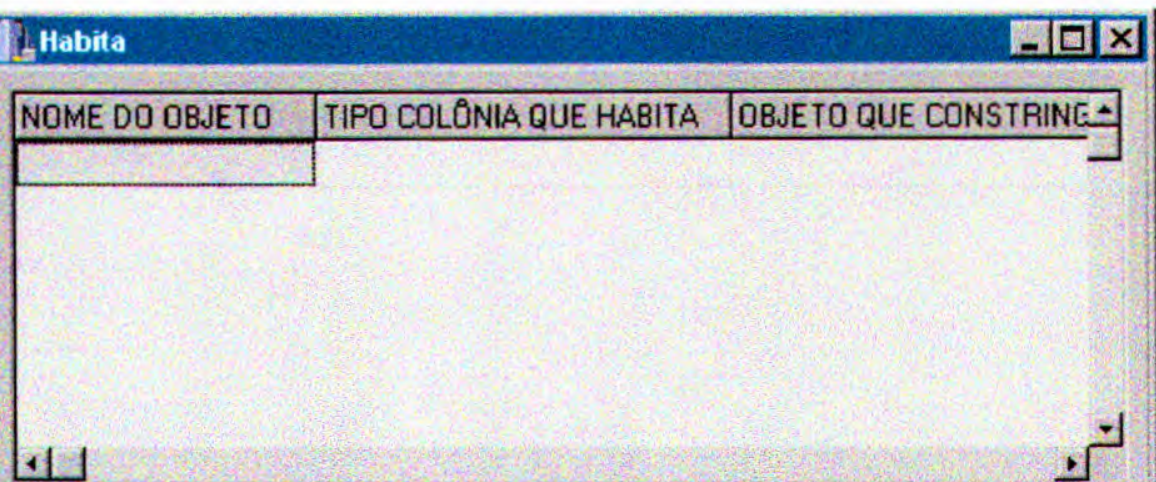
Fechar informação de qual objeto Figura 55) Formulário Habita constringe é muito importante, uma vez que o modelo permite que exista mais de uma colônia com o mesmo tipo, que é constrita por objetos distintos. Então, sabendo-se também qual é o objeto que constringe uma colônia é que de fato se pode localizar em qual colônia o objeto habita. $\mathrm{O}$ interador (Fechar) retorna para o formulário objeto.

\subsection{Navegação nas Abstrações Utilizando-se E² SIRIUS}

Para a criação de $E^{2}$ SIRIUS, as abstrações do modelo foram agrupadas em subconjuntos de formulários que abrangem apenas uma das abstrações de cada vez. Desta forma, os subconjuntos de formulários foram agrupados de modo a obter-se uma coleção mínima de formulários, tratando de maneira independente cada abstração, pois os formulários estão agrupados de acordo com uma abstração específica.

É importante observar que os formulários e/ou subconjuntos de formulários estão interligados, pois existe uma conexão entre as abstrações. Desta forma, $E^{2}$ SIRIUS engloba todas as abstrações do modelo.

O ponto de partida para navegar nas abstrações do modelo é o formulário objeto, que permite que o usuário navegue tanto na direção do abstrato, por meio dos botões (Classificar). 
(Generalizar) e (Constringir), quanto na direção do detalhe por meio dos botões (Instanciar), (Especializar) e (Habitar).

A abstração de agregação é suportada diretamente pela representação dos atributos associados diretamente ou indiretamente ao objeto corrente.

A abstração de classificação/instanciação é ilustrada em $E^{2}$ SIRIUS por meio do formulário objeto. A Figura 56 a) ilustra como ocorre a navegação nesta abstração. Nela e nas outras figuras deste tópico o(s) retângulo(s) tracejados representa(m) o(s) formulário(s) e o retângulo pontilhado indica telas de mensagens. Dentro do(s) retângulo(s) tem-se o nome do formulário que este representa e as setas que partem de um formulário para outro indicando ações dos botões. $O$ nome escrito entre parênteses, do lado de cada seta, é o nome de um botão que pertence ao formulário de onde parte a seta. De modo genérico, um formulário $X$ possui um botão $(Y)$ que, quando acionado, executa uma ação, por exemplo, a chamada de um formulário $Z$. Na Figura 56 a), o formulário objeto e as três setas que partem e chegam ao formulário objeto representam os botões (Topo), (Classificar) e (Instanciar). $O$ botão (Classificar) permite que o usuário navegue em direção do elemento mais alto da hierarquia, que no Editor será um objeto cujo tipo é o Metatipo. Supondo que o objeto corrente seja o objeto objeto 3 Figura 56 b), cujo tipo é o objeto 2. Quando o usuário clicar o botão (Classificar), objeto corrente passa a ser objeto objeto 2 , cujo tipo é o objeto objeto 1 justamente o objeto tipo do objeto 3. Classificando-se novamente, tem-se o objeto 1, cujo tipo é o Metati-

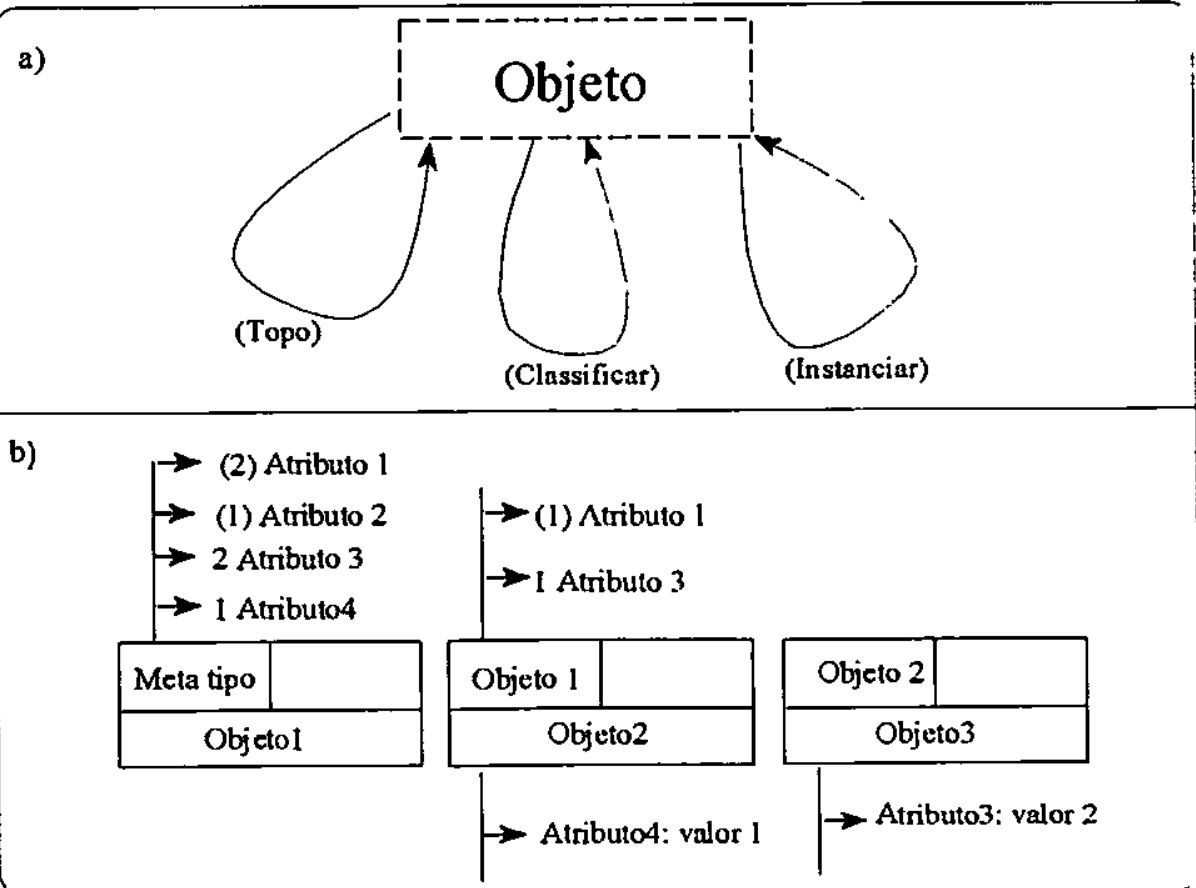

Figura 56) Navegação na abstração de classificação/instânciação po. Este objeto não pode ser mais classificado. Analogamente, pode-se descer na hierarquia indo em direção a um objeto não instanciável, o que significa que partindo-se do objeto 1 , chegando -se 
ao objeto 3 após duas instanciações. O botão (Topo) é apenas um botão de "atalho" para se chegar ao objeto cujo tipo é o metatipo. Desta forma, quando o objeto corrente não for do tipo metatipo, clicando-se o botão (Topo) sabe-se qual é o objeto mais alto na hierarquia de classificação em que o objeto corrente se encontra. Note-se que na abstração de classificação/instanciação, o formulário objeto é o único utilizado. Os interadores objeto, Atributos de classificação e Atributos de instanciação são mostrados durante a navegação na hierarquia. Observe-se também que esta navegação ocorre sempre em dois sentidos: do abstrato para o detalhe ou vice-versa.

A abstração de agregação/separação é representada em $E^{2}$ SIRIUS através da visualização dos atributos de classificação e atributos de instanciação que são agregados ao objeto corrente, ou através de

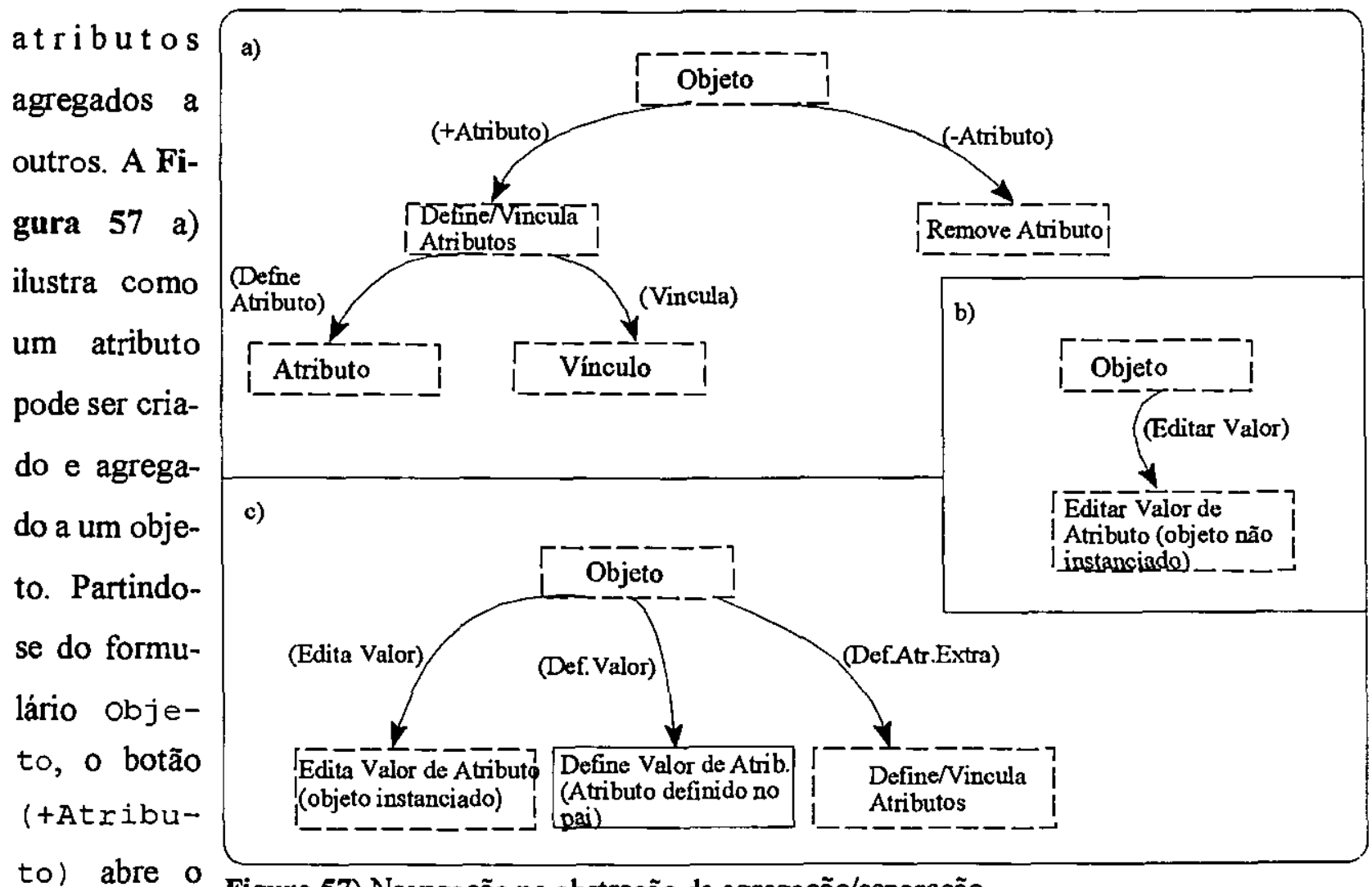

to) abre o

Figura 57) Navegação na abstração de agregação/separação

formulário

Define/Vincula Atributos. Este formulário pode, como o próprio nome diz, definir um atributo caso ele não exista. Isto é feito por meio do botão (Define Atributo) do formulário Define/Vincula Atributos, que irá chamar o formulário Atributo, para que um novo atributo seja criado. Para agregar um atributo já existente ao objeto corrente, utiliza-se o botão (Vincula), que irá levar ao formulário Vínculo, para que um vínculo de classificação ou 
instanciação seja estabelecido entre o atributo e o objeto. Atributos agregados a objeto ou entre si podem também ter valor. Em $E^{2}$ SIRIUS, existem botões específicos para atribuírem-se valores a atributos. Por exemplo, um atributo de classificação (associado ao objeto corrente) pode ter um valor, que no caso será o valor default. Este valor é definido através do botão (Edita Valor), que irá abrir o formulário Editar valor de Atributo (objeto não instanciado), como indica a Figura 57 b). Este formulário permite que valores default sejam definidos. O botão (Edita Valor) define e/ou modifica o(s) valor(es) do(s) atributo(s) de instanciação associado(s) ao objeto corrente através do formulário Edita valor de Atributo (objeto instanciado). O botão (Def.Valor) define e/ou modifica o(s) valor(es) do(s) atributo(s) de classificação do objeto que esta um nível acima na hieraquia de classificação em relação ao objeto corrente. $O$ botão (Def. Atrib.Extra) define um atributo extra. Isto é feito chamando-se o formulário Define/Vincula Atributos para que primeiramente um novo atributo seja definido e em seguida vinculado ao objeto corrente. Este atributo, que não tinha sido previsto, recebe o nome de atributo extra.

Cabe dizer aqui que a remoção ocorre quando um atributo não mais estiver vinculado ao objeto corrente, o que é possível ser feito via aplicativo, como ilustra a Figura 57, partindo-se do formulário objeto e utilizando-se o botão (-Atributo) . Este botão abre o formulário Remove Atributo, onde o usuário deve optar por remover apenas o vínculo do atributo com o objeto corrente ou remover o atributo da

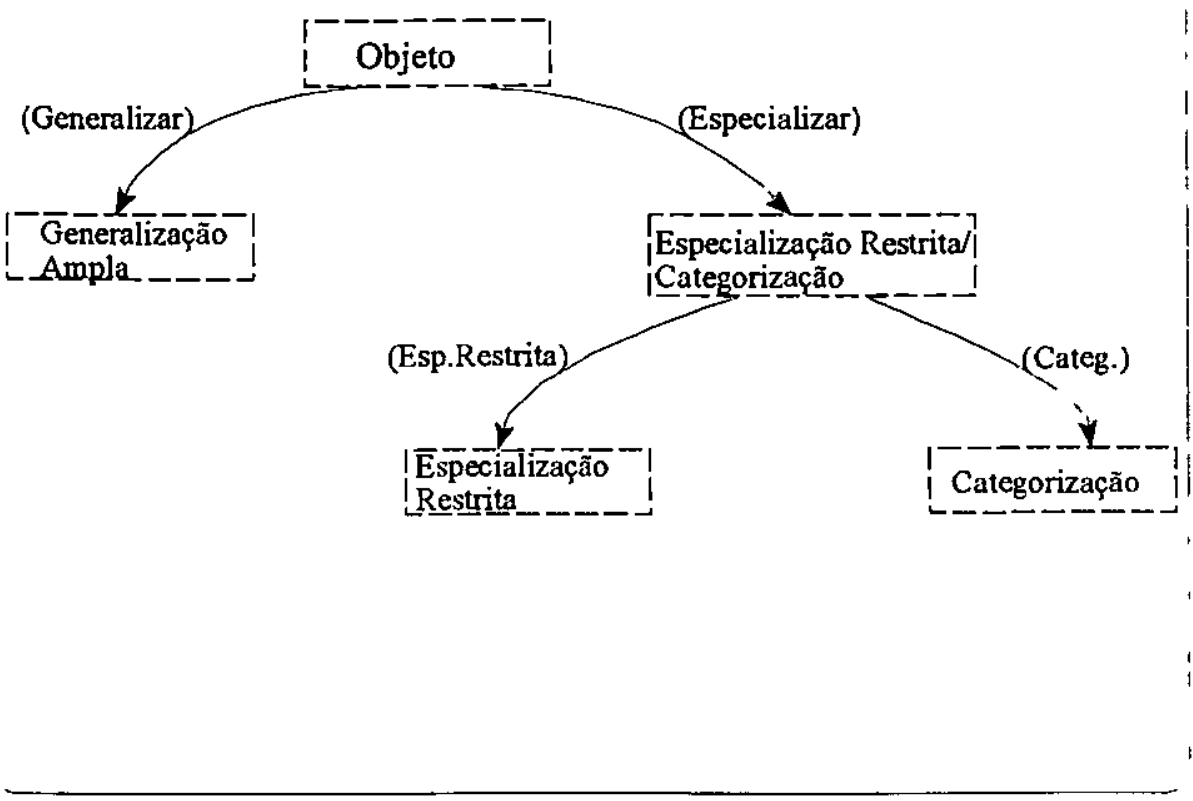

Figura 58) Navegação na abstração de generalização/especialização base. Toda vez que um atributo se agrega ou se separa de um objeto e/ou um atributo, (no caso do 
subatributo), o interador Atributos de Classificação e o interador Atributos de Instanciação são automaticamente atualizados.

A Figura 58 ilustra como é feita a navegação na abstração de generalização/especialização. Partindo-se do formulário objeto, o usuário pode apenas efetuar consultas e/ou criar objeto(s) específicos. Através do botão (Generalizar), o formulário Generalização Ampla é chamado e, neste formulário, consultas a respeito do objeto generalização podem ser efetuadas. Quando o usuário quiser especializar um objeto, ele utiliza o botão (Especializar), que irá chamar o formulário Especialização Restrita /Categorização, onde o usuário deve decidir de que forma o objeto generalização deve ser especializado. Os objetos específicos são criados tanto no formulário Especialização Restrita quanto no formulário Categorização, dependendo apenas de qual foi a opção do usuário. Como ilustra a Figura 58, a navegação ocorre partindo-se do objeto. Tem-se informações a respeito de objeto(s) específico(s) quando o botão (Especializar) é escolhido e tem-se informações a respeito de objeto(s) generalização quando o botão (Generalizar) é escolhido.

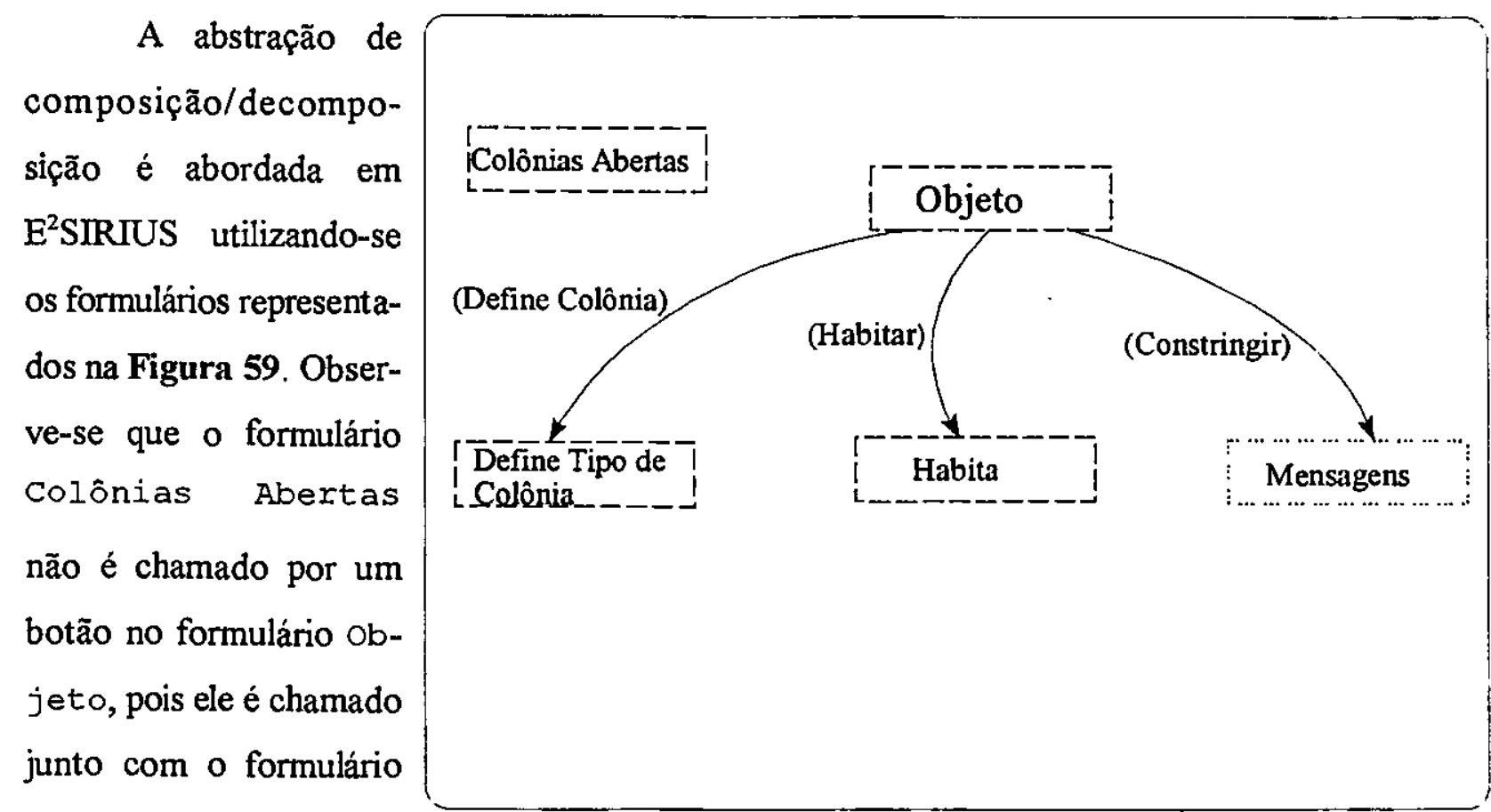

objeto e permanece dis- Figura 59) Navegação na abstração de composição ponivel o tempo todo pa-

ra que usuário saiba quais são as colônias que estão abertas durante a execução do aplicativo. Um tipo de colônia pode ser definido ou removido em $E^{2}$ SIRIUS pelo botão (Define Colônia), chamando o formulário Define Tipo de Colônia. Objetos habitam colônias de tipos definidos, 
e esta informação é dada no editor utilizando-se o botão (Habitar), que abre o formulário Habita contendo informações de como os objetos habitam colônias de certos tipos e, através da informação objeto que constringe, pode-se visualizar como os objetos são compostos. O botão (Constringir) cria uma colônia, caso esta não exista, ou apenas abre uma colônia que já existe. Se já existe uma colônia de um certo tipo aberta, para que outra do mesmo tipo seja aberta, primeiro se fecha a anterior, e em seguida, abre-se a outra. Todas as operações que são conseqüências do botão (Constringir) não abrem um formulário específico. Neste caso, apenas mensagens de confirmação ou erro são enviadas ao usuário para que este possa saber se ele está sendo bem sucedido ou não.

O usuário irá navegar nos subconjuntos de hierarquias das abstrações suportadas pelo modelo e, como cada subconjunto refere-se a uma abstração específica, o usuário saberá em qual contexto ele estará navegando. $O$ usuário poderá também navegar em todas as abstrações ou não; neste caso, ele irá navegar apenas nas abstrações que forem necessárias. Em outras palavras, não é obrigatório que se navegue sempre em todas as abstrações. E como as abstrações são organizadas numa estrutura multidimensional, o usuário só poderá navegar em uma direção (detalhe para abstrato ou vice-versa). Além de o movimento de navegação ser sempre em uma única direção, o usuário dificilmente terá muitos niveis dentro de uma abstração. Como não existe composição de abstrações entre si, é mais dificil que o usuário se perca durante a navegação em $E^{2}$ SIRIUS.

\subsection{Mapeamento para o Modelo Relacional}

Nos tópicos anteriores descreveram-se o Editor e suas principais funcionalidades. Aqui se pretende abordar como foi formulada a armazenagem das informações que são compostas pelos formulários.

$E^{2}$ SIRIUS foi elaborado para atender as necessidades de um modelo orientado a objetos, considerando que é importante ter a disponibilidade de objetos tipo ao mesmo tempo que se têm objetos que não são tipos. O modelo orientado a objetos SIRIUS foi mapeado para o modelo relacional, uma vez que o Gerenciador SIRIUS não está disponivel para armazenar as informaçōes de um esquema.

Devido ao conjunto de representação formal existente em SIRIUS, o mapeamento para o modelo relacional foi feito diretamente, uma vez que os construtores semânticos do modelo já estavam previstos no formalismo, possibilitando, deste modo, que o mapeamento para o modelo relacional fosse feito de maneira consistente. Levaram-se também em consideração algumas regras de 
controle de consistência durante a elaboração do Editor, fundamentais para a criação de uma base de dados que irá armazenar informações das modelagens feitas utilizando-se o SIRIUS. Isto foi possível devido à precisão e ao rigor de expressões algébricas utilizadas na representação formal do modelo SIRIUS.

Enfim, o mapeamento para o modelo relacional foi feito por meio de criação de tabelas relacionais que cobrissem todo o embasamento teórico do modelo. O modelo SIRIUS foi criado apoiando-se em um forte formalismo, o que facilitou a criação das tabelas relacioniais empregadas em $E^{2}$ SIRIUS. Foram criadas várias tabelas a partir de uma principal, a tabela de objeto. Esta agrega parte de todas as abstrações que formam o modelo. Como ilustrado na Figura 60 a), tem-se a tabela de objeto, formada por cinco colunas das quais: a primeira coluna (CodObj - código do objeto)

está inclusa a)

naturalmente

em todas as

abstrações.

As duas pri-

meiras colunas (CodObj e CodTObj código tipo objeto) formam uma base para representar a abstração de a) Tabela: objeto

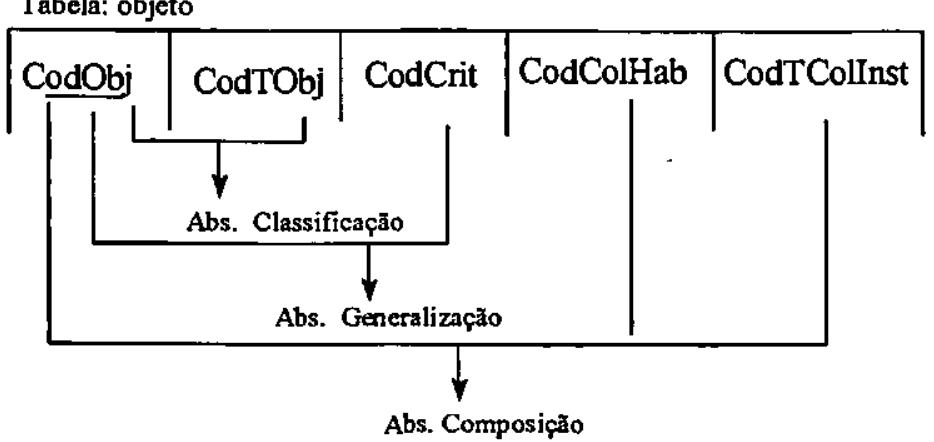

Abs.Agregạäo: se dá pela tabela: vincula atributo_objeto que é referenciada pelo CodObj da tabela objeto e pelo CodTAt da tabela atributo

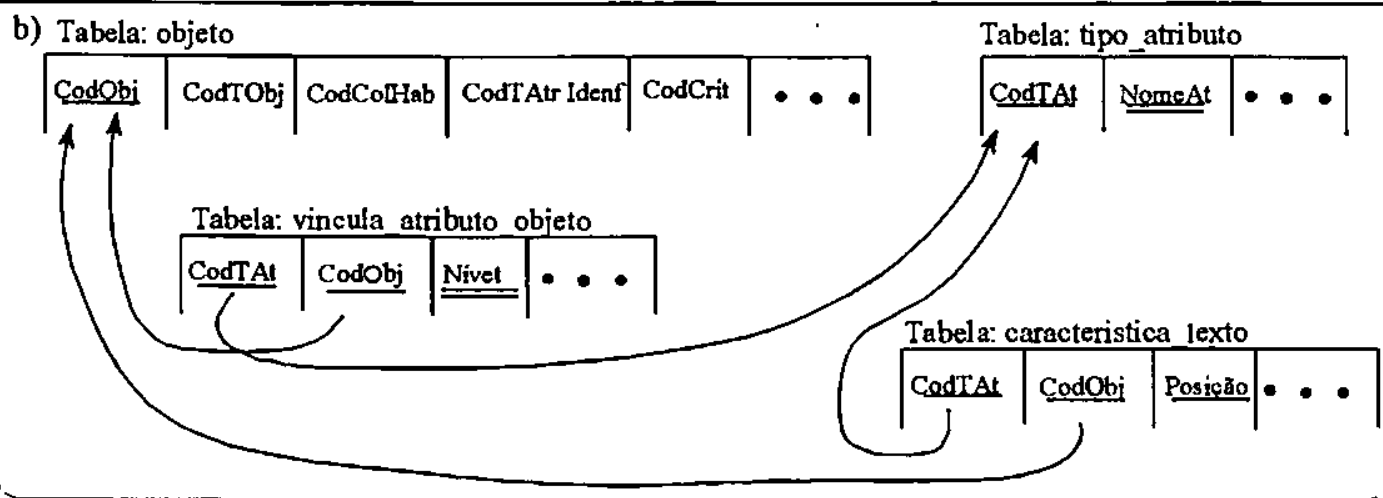

classificação. Figura 60) Tabelas relacionais para SIRIUS

A terceira coluna (CodCrit - código critério), juntamente com a coluna CodObj, formam uma base referencial para a abstração de generalização. As duas últimas colunas (CodColHab - código colônia habita, CodTColInst - código do tipo da colônia onde habitam as instâncias do objeto corrente) juntamente com o CodObj, formam uma base para a abstração de composição. A abstração de 


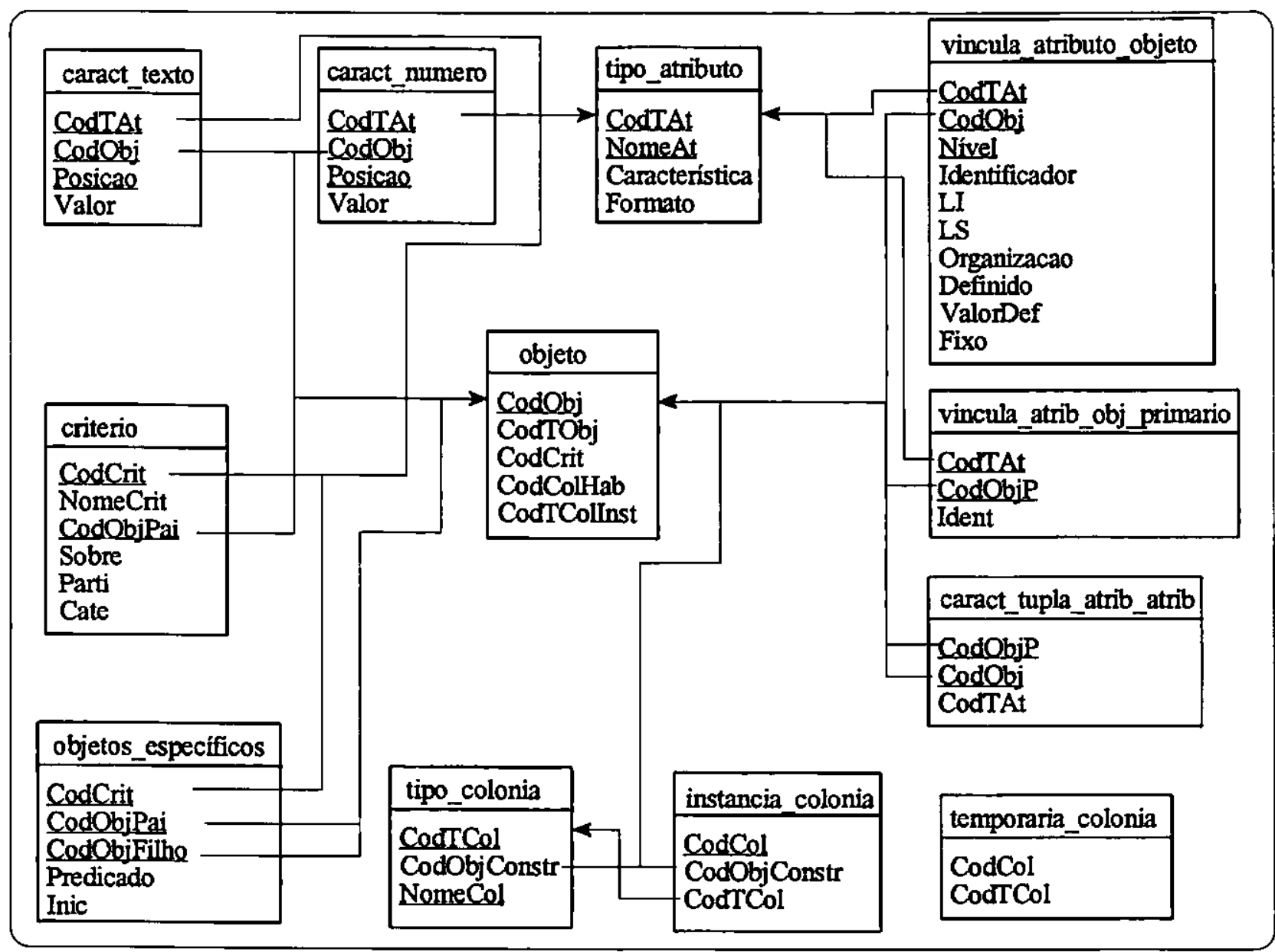

Figura 61) Diagrama das tabelas relacionais

agregação é mapeada por várias tabelas, em particular pela coluna CodObj, que é referenciada pela tabela de atributo, sendo as duas últimas referenciadas pela tabela vincula atributo objeto. Desta forma, todos os construtores semânticos do modelo são mapeados para o modelo relacional através da tabela de objeto, e as demais tabelas são derivadas dessa. A Figura 60 b) mostra algumas tabelas derivadas. A Figura 61 ilustra o conjunto de todas as tabelas relacionais utilizadas na implementação do Editor de Esquemas, bem como suas chaves primárias (sublinhadas) e as referências de chaves estrangeiras (indicadas por setas).

\subsection{Implementação}

$E^{2}$ SIRJUS foi elaborado, na sua versão de desenvolvimento, utilizando-se o gerenciador INTERBASE [Interbase_98], para que fosse criada uma base que armazenasse os dados de um esquema feito para um modelo orientado a objetos altamente complexo. Na verdade, a base de $E^{2}$ SIRIUS foi criada a partir de um conjunto de três scripts constituídos pelos arquivos: 
tabelas.sql, inicializações.sql e código.sql. É o script tabelas que contém a criação de todas as tabelas. O sistema foi construído de maneira portátil, utilizando-se os recursos básicos da linguagem SQL, de maneira que o aplicativo possa ser conectado em outro servidor, monousuário ou multiusuário, que utilize o padrão SQL. Como SIRUUS é também um metamodelo, houve a necessidade de uma pré-inicialização para que as informações a respeito do metamodelo fossem armazenadas na base. Isto foi feito através do script inicializações, utilizando-se o comando INSERT INTO. É a partir destas que os dados do usuário são armazenados na base. Desta forma, tais dados pré-inicializados sempre estarão contidos na base, mesmo quando esta não tiver dados de modelagens de usuários. A base irá armazenar também os OID's (identificadores de objetos, tipos de objetos, atributos, tipos de colônia etc.). Estes são representados na implementação pelos códigos de objeto, tipo de objeto, atributos, tipo de colônia, entre outros. Os códigos são gerados automaticamente pelo sistema toda vez que o usuário criar qualquer objeto ou qualquer tipo de objeto. Estes são gerados no script código por meio de uma stored procedure. Esta função gera os códigos automaticamente. Ela possui dois parâmetros de entrada: o primeiro é uma variável e o segundo é um incremento inteiro. Esta função, sempre que chamada, incrementa a variável com o incremento de entrada da função, retornando o valor da variável somada ao incremento.

Assim, a base é construída de maneira que somente comandos básicos de SQL são utilizados, de maneira que o aplicativo possa ser conectado em outro servidor, monousuário ou multiusuário, que utilize o padrão SQL.

Tendo-se uma base criada, o passo seguinte foi a elaboração de uma interface que, como a base, engloba todos os construtores semânticos do modelo. Na implementação da interface, a ferramenta de desenvolvimento utilizada foi o C++Builder [Borland_97][Inprise_98].

$E^{2}$ SIRIUS foi implementado de forma que os dados sejam digitados em campos especificos de certos formulários. Por exemplo, no interador objeto, do formulário objeto, o usuário digita qual o nome do objeto corrente no campo apropriado. Uma vez fornecido o nome de um objeto, o sistema gera o código para ele e $\mathrm{O}$ armazena, juntamente com seu nome, nas tabelas apropriadas. $\mathrm{O}$ código de um objeto não aparece em nenhum formulário do Editor, assim, o código permanece interno ao Editor, e o usuário navega utilizando apenas os nomes e valores que ele mesmo definiu. O próprio aplicativo efetua alguns controles de restriçðes de integridade, evitando-se, desse modo, entre outras coisas, que o usuário armazene dados inválidos e/ou duplicados na base, ou seja, para cada formulário que o usuário irá utilizar para armazenar informações existe um controle na base. 
Com isso, implementam-se os construtores semânticos do modelo SIRIUS. A mesma técnica pode ser aplicada para a modelagem de sistemas que possuem características similares.

\subsection{Conclusão}

O Editor de Esquemas descrito anteriormente é adequado à representação dos conceitos, propiciando a aprendizagem do modelo por ele suportado. $E^{2}$ SIRIUS pode ser usado como editor de esquemas de um futuro gerenciador SIRIUS removendo-se o acesso à Base de Dados Relacional, e navegando as informações diretamente na Base de Dados SIRIUS. Por efetuar operação em nivel elementar, o Editor facilita o aprendizado dos conceitos de SIRIUS, mas por outro lado, é complexa para utilização como ferramenta real de entrada de esquemas. Para evitar que isto ocorra, o sistema precisaria possuir características wizard. Por outro lado, um sistema com características wizard pode impedir que o usuário utilize todos os recursos que o sistema oferece, optando sempre pelas alternativas default oferecidas pelo sistema. Deste modo, o aprendizado e a utilização do sistema se tornariam deficitários. 


\section{Capítulo 7}

Conclusão

\subsection{Decisões de Projeto}

\subsubsection{Por que Utilizar uma Base de Dados Relacional e não o GEO?}

A origem dos trabalhos em bases de dados desenvolvidos pelo GBdI - Grupo de Base de Dados e Imagens do ICMC remonta ao desenvolvimento de um modelo de dados, denominado MRO Modelo de Representação de Objetos [Trania_92], sobre o qual foi implementado um Sistema de Gerenciamento de Banco de Dados denominado GEO - GErenciador de Objetos. Desde sua concep̧ão, o objetivo do MRO foi o de suportar aplicações "não convencionais" de sistemas de Bases de Dados, em especial os Ambientes de Projeto/Desenvolvimento - incluindo os de Software (CASE) e Projeto e Fabricação Auxiliados por Computador (CAD/CAM). Os recursos para a modelagem conceitual de dados do MRO incluem Tratamento Individual de Objetos, Controle de Versões e Alternativas, Herança de Dados, Regras de Tratamento, manuseio de informações incompletas e/ou contraditórias e representação de informações gráficas. O MRO teve sua primeira definição realizada de maneira informal [Traina_86]. Posteriormente foram formalizados seus aspectos estáticos [Biajiz_92], utilizando-se tanto conceitos da Álgebra Relacional nos aspectos que cuidam de conjuntos de objetos, quanto da Teoria dos Grafos, em aspectos que cuidam da representação individual de cada objeto.

O GEO foi implementado a partir de 1989 em linguagem C, incorporando atualmente muitos dos conceitos do MRO e de Orientação a Objetos em geral. O sistema conta atualmente com aproximandamente 12MBytes de código fonte (incluindo a documentação inserida no código fonte), e existem versões para Sun-OS e para MS-DOS.

O objetivo dessa implementação foi o de servir como uma "Bancada de Experimentação" para o desenvolvimento de algoritmos e técnicas que contribuíssem para a criação de Gerenciadores de 
Dados Orientados a Objetos de nível industrial eficientes e confiáveis, sem contudo pretender-se que essa implementação resultasse em si num produto. Assim, modularidade, expansibilidade e portabilidade do sistema sempre foram propriedades consideradas essenciais. Diversos módulos têm de fato diversas implementações, que podem ser conectadas individualmente para compor uma versão do gerenciador

O grupo GBdI trabalhou no desenvolvimento do GEO, por um bom tempo. No entanto, este não se encontra completamente terminado, no sentido em que nem todos os conceitos do SIRIUS são suportados na atual implementação. Existem ainda alguns pontos para serem elaborados e implementados. Por outro lado, muitas das suas estruturas internas não são adequadas para o suporte a muitos dos conceitos que foram sendo incorporados ao MRO ao longo do tempo. Alguns desses conceitos seriam interessantes para justificar seu uso. A utilização do modelo relacional justifica-se também pela forma como o modelo SLRIUS foi desenvolvido. Como este se apóia em um forte formalismo, facilita o emprego de tabelas que modelam, sem muita perda semântica, o modelo SIRUUS para o modelo relacional Além disso, o GEO não oferece o mesmo suporte que o relacional, no sentido que por existirem versões comerciais de gerenciadores relacionais, há um grande número de pessoas já familiarizadas com ele, além de suporte técnico, se necessário. $\mathrm{O}$ mesmo não ocorre com o GEO, justificando-se desde modo a opção feita em empregar o modelo relacional.

\subsubsection{Por que o C++Builder?}

O grupo vem desenvolvendo projetos ao longo dos anos utilizando como linguagens de desenvolvimento a linguagem $\mathrm{C}$ ou a linguagem $\mathrm{C}+\mathrm{H}$. Portanto, houve a preocupação de escolher-se uma linguagem compativel com os trabalhos já existentes. Conseqüentemente, linguagens como Visual Basic e Delphi foram descartadas de imediato; Power Builder também foi descartada, pois não havia a necessidade nem de gerenciador para bases de grande porte, nem, portanto, de um software muito poderoso. Mas por outro lado, que pudesse ser eficiente em gerar programas que não dependessem de um gerenciador relacional. Foi necessário também escolher uma linguagem que permitisse acesso a um banco de dados para que informações fossem armazenadas na base. Além disso, era preciso um software que desse apoio visual para a criação do editor. Considerou-se que - Ambiente de Desenvolvimento mais adequado para as condições acima descritas é o C+Builder. Este software padrão, SQL, permite acesso a bancos de dados como Informix, Sybase, Oracle, Paradox e o geraneciador nativo INTERBASE. É uma ferramenta RAD (Rapid Application 
Development - Desenvolvimento Rápido de Aplicativos), o que facilita a construção das telas de edição do editor de esquemas. $\mathrm{E}$, além do mais, utiliza como linguagem de programação a linguagem $\mathrm{C}++\mathrm{e}$ todos os recursos que a mesma oferece, sendo compativel com o compilador Borland $\mathrm{C}++$, utilizado nos demais projetos do grupo. Logo, tal software mostrou-se ser o que melhor se adaptava às exigências citadas acima.

\subsubsection{Por que a Criação de um Editor de Esquemas e não um Editor Gráfico?}

A elaboração de um editor gráfico é muito mais dificil e completa do que a elaboração de um editor de esquemas. Além disso, o tempo estipulado para o encerramento do mestrado não seria suficiente para a confecção de tal editor, levando-se em consideração a complexidade para a criação do editor gráfico, e a grande quantidade de símbolos gráficos necessários para representar os construtores semânticos de SIRIUS, uma vez que tal modelo também é muito complexo e possui uma grande densidade de informações a serem representadas. Por outro lado, considerou-se que se a notação gráfica do modelo não pode ser considerada capaz de atender a todos os requisitos de clareza, completude e consistência, tão pouco tais propriedades poderiam ser atendidas por um editor que representasse a mesma simbologia no computador.

Diante deste panorama, optou-se por criar uma interface, que por um lado é razoavelmente intuitiva, e por outro, capaz de aproveitar livremente os paradigmas de interface próprios do meio digital, permitindo explorar praticamente todas as facetas do SIRIUS sem se preocupar com detalhes desnecessários, tais como, por exemplo, como ficaria a diagramação de situações que graficamente são muito complexas. Na verdade, para representar os elementos do modelo de maneira esquemática, e ao mesmo tempo, de maneira semelhante ao de uma modelagem feita em papel, seria preciso considerar-se apenas a noção espacial dos elementos do modelo para saber, por exemplo, como um elemento é representado. Assim, podemos constatar que existe um grande apelo espacial nos conceitos de SIRIUS, mas que não são necessariamente gráficos. Esta notacão espacial foi conseguida pela uniåo dos componentes que pertencem a um determinado formulário. Tais componentes, muitas vezes, simulam uma modelagem, estando também muito próximos de uma modelagem em papel. Além disso, com a confeç̧ão do Editor de Esquemas, conseguiu-se a exploração de muitas coisas, que seguramente seriam impossiveis de terem sido feitas se estivessemos presos a construção de um editor gráfico que, por mais bem construido que fosse, nāo 
teria viabilidade de implementação completa em um projeto de mestrado, uma vez que sua complexidade seria demasiada para o tempo disponível.

\subsection{Contribuições}

Ao longo do desenvolvimento deste trabalho, foram validados os conceitos e as notações empregadas no modelo SIRIUS propostas inicialmente em [Biajiz_96]. Em alguns casos, houve a necessidade de efetuarem-se reformulações.

Uma das modificações que podem ser observadas é em relação às características de atributo. No documento original, consideravam-se 13 características: comentário, propriedade, tempo, estrutura de dados, procedimento, regra, visualização, imagem, gráfico, som, partitura, tupla e relacionamento. Atualmente são consideradas 15. As caracteristicas comentário e propriedades [Biajiz_96] foram substituídas pelas características texto e número. Além disso, acrescentaram-se mais duas características no conjunto das já existentes: atributo de atributo e booleano. Assim, as características definidas agora são: texto, número, regra, procedimento, visualização, som, partitura, imagem, gráfico, estrutura de dados, tempo, tupla, atributo de atributo, relacionamento $\mathrm{e}$ booleano. (vide capítulo 5, seção 5.2). Quando um atributo possui a caracteristica atributo de atributo, um subatributo deve ser escolhido, para que este, juntamente com o atributo cuja característica é atributo de atributo, seja identificador do atributo. (vide capitulo 5 , seção 5.2).

Outra modificação em relação ao texto original pode ser vista na abstração de generalização. No texto original de SIRIUS [Biajiz_96], o autor considera que a abstração de generalização pode ser especializada na abstração de generalização restrita e na abstração de categorização. Entretanto, o mesmo não considera estas duas últimas abstrações separadamente. Elas são tratadas através das restrições de generalização. No capitulo 5 , seção 5.6 deste trabalho, foram consideradas separadamente as abstrações de generalização restrita e a abstração de categorização permitindo deste modo a existência de um maior número de construtores semânticos, que podem ser considerados quando se efetua uma modelagem em SIRIUS.

Outra reformulação que cabe dizer aqui, refere-se à representação da abstração de composição. A abstração de composição é representada, no capítulo 5 seção 5.7, por dois diagramas complementares: o DHC (Diagrama Hierárquico de Colônia), que indica a composição por tipo; e o do DRI (Diagrama de Representação de Instâncias), onde se representam as colônias e, dentro delas os objetos que a habitam. 
Além de validar os conceitos já existentes, novos conceitos que ainda precisam ser mais bem formulados foram propostos, como por exemplo, os conceitos de identificador composto e tipo coletivo (visto no capítulo 5 seção 5.1). A idéia de ter-se também um vetor cujo índice seja literal precisa ainda ser mais bem trabalhada, para estabelecer-se, por exemplo, a ordem dos elementos de um vetor que possui este tipo de índice. Outro conceito que precisa ser mais bem elaborado é o conceito de vetor de vetor.

Finalmente, com a criação e elaboração de $E^{2}$ SIRIUS, outras contribuições foram dadas, como por exemplo: uma implementação que suporta o conceito de tipos persistentes [Araujo_98a], ou seja, a implementação do Editor foi feita de forma que tanto os objetos tipo como os objetos que não são tipo são armazenados na base.

Além disso, E2SIRIUS também é um meio de facilitar a construção de modelagens feitas com um modelo altamente complexo, auxiliando o treinamento de projetistas nos conceitos do modelo. Portanto, como ferramenta de auxílio à aprendizagem do modelo, o editor apresenta recursos para permitir a manipulação e visualização de conceitos próprios de SIRIUS.

Por outro lado, E'SIRIUS constitui-se em uma ferramenta de suporte ao desenvolvimento do próprio gerenciador SIRIUS/GO, pois ele fornece suporte para a especificação detalhada de todos os conceitos do modelo, bem como recursos para a alimentação de dados de teste em pequenos volumes, com uma interface que procura facilitar o trabalho de concepção e digitação de esquemas.

\subsection{Sugestões para Futuras Pesquisas}

Este trabalho é parte de um projeto bem maior, que é a construção do sistema SIRIUS, o qual compõem-se basicamente de três módulos:

- o Modelo SIRIUS;

- o Gerenciador SIRIUS e

- as Técnicas SIRIUS de Desenvolvimento de Sistemas.

Existe muito campo para pesquisa em cada uma das frentes que levarão ao desenvolvimento de cada uma dessas componentes. Assim, as sugestões feitas aqui focam-se nas atividades ligadas diretamente à continuação imediata dos trabalhos efetuados.

No que diz respeito ao desenvolvimento do Modelo SIRIUS, pode-se considerar que este trabalho validou e completou a maior parte dos conceitos. Alguns pontos ainda deixados em aberto referem-se basicamente à necessidade de estudar mais detalhadamente o impacto que os quatro 
conceitos seguintes, surgidos a partir deste trabalho, têm em sua integração com o restante do modelo: Atributos Identificadores Compostos, Tipos Coletivos, Vetores com Índices Literais e Vetores de Vetores. Esse estudo deveria buscar exemplos de situações em que ocorrem tais conceitos, e criar (ou validar) a semântica e a sintaxe que lhes foram propostas. Deve-se tambem avaliar o impacto que sua inclusão ao modelo traz para o formalismo desenvolvido em [Biajiz_96a].

Nessa mesma linha de atividade, é necessário rever o formalismo desenvolvido, para atender às modificações feitas ao modelo. Em particular, deve-se avaliar o impacto que as seguintes alterações feitas causam: tratamento explícito das abstrações de Generalização Restrita e de Categorização e suporte de Atributo de Atributo como Característica de Atributo.

$\mathrm{Na}$ linha de desenvolvimento do Gerenciador SIRIUS, existem algumas atividades de grande porte a serem consideradas. Uma delas corresponde à disponibilização do gerenciador SIRIUS em duas versões: uma "nativa", com todo o suporte ao modelo, a partir de estruturas desenvolvidas especificamente para ele, que incorpora todo o controle de concorrência, gerenciamento de memória e disco, identificação de objetos, etc., e uma baseada em um gerenciador relacional, tal como feito neste projeto, porém com uma - IPA - Interface de Programação de Aplicativos compativel com a da versão nativa.

Outras atividades consistem em completar-se o atual Editor, para generalizar determinadas construções, que, nesta versão, foram implementadas de maneira restrita. Como exemplo dessas restrições, está o número de niveis permitidos para o aninhamento de tuplas, e o tratamento do critério, da inicialização e do predicado nas ocorrências das abstrações de generalização.

Outra atividade de desenvolvimento do Gerenciador SIRIUS é a criação de recursos que aumentem a produtividade de sua utilização, como o Editor de Esquemas do Gerenciador. Essa atividade deve-se ao fato de que os recursos de interface com o usuário atuais preocuparam-se em representar diretamente cada um dos conceitos do Modelo. Isso é adequado para atender a um dos objetivos do editor, qual seja, o auxilio ao treinamento de projetistas nos conceitos do Modelo SIRIUS. Não foram consideradas opções para automatizar procedimentos que ocorrem freqüentemente, os quais poderiam ter interfaces especiais, por exemplo, do tipo wizards, que facilitariam essas atividades (embora possam "esconder" conceitos importantes), mas poderiam estar disponiveis em uma versão cujo objetivo principal seja a produtividade do desenvolvimento e edição de esquemas. 
No módulo de Técnicas SIRIUS para Desenvolvimento de Sistemas, considera-se importante que se definam linhas que delimitem as atividades a serem efetuadas em cada fase de um projeto, $\mathrm{e}$ assim, que se determinem quais informações devem passar a integrar um esquema em cada fase de projeto. A existência dessas técnicas pode definir uma interface alternativa com o usuário. Atualmente cada construtor semântico do editor procura cobrir todos os vínculos de cada elemento de modelagem. Numa interface voltada a atender uma determinada técnica de projeto, os elementos poderiam ser projetados para atender a determinados objetivos que são perseguidos em cada fase.

Também é importante definir-se adequadamente o sistema de Ajuda do Editor, o que deve ser feito levando-se em conta qual o objetivo de cada operação/elemento da interface, em função de cada fase do projeto em andamento, para procurar prever qual poderia ser a ajuda que um usuário poderia necessitar em cada interador do Editor. 


\section{Anexo}

A finalidade deste anexo é ilustrar alguns exemplo de modelagem em SIRIUS. Facilitando desta forma o entendimento do modelo bem como o emprego notacional do mesmo. As modelagens ilustradas são:

- Modelagem 1: Parte de um sistema de gerenciamento bancário. As informações textuais desta modelagem encontra-se no capítulo2. A Figura 62 ilustra o emprego notacional de SIRIUS. Ela expressa a representação de relacionamentos multivalorados, hierarquia de generalização entre outros. A Figura 63 esboça a mesma modelagem empregando-se a notação alternativa proposta no capítulo 5 .

- Modelagem 2: Parte de um sistema de gerenciamento de depósito de cargas. Uma descrição desta modelagem pode ser vista no capitulo 2. A Figura 64 mostra uma modelagem em SIRIUS utilizando os recursos que este oferece. Na Figura 65 a mesma modelagem é representada, com auxilio da notação alternativa sugerida no capítulo 5 .

- Modelagem 3: Parte de um sistema de gerenciamento de fitas em uma locadora. Na Figura 66 o sistema é modelado por meio de conceitos como: relacionamentos monovalorados; multivalorados; hierarquia de especialização, em particular, categorização; agregação de atributos a objetos etc. Na Figura 67 este sistema é expresso por meio da notação alternativa.

- Modelagem 4: Parte de um sistema de empresas de aluguel. $O$ objetivo desta modelagem é ilustrar parte da complexidade que envolve a representação de relacionamentos multivalorados, bem como suas instanciações. Esta modelagem é representada em três níveis na hierarquia de classificação. Primeiramente são representados os objetos: Motorista, Tipo de Corrida e Veículo, Figura 68, associados a seus respectivos atributos entre eles, os atributos com caracteristica relacionamento, gerando os relacionamentos: Motorista - Tipo de Corrida e Tipo de Corrida - Veículo. Em um outro nível, Figura 69, os objetos Carro Luxo, Figueira, Corrida Normal e Diária Fechada são criados a partir da instanciação dos objetos 
Veículo, Motorista e Tipo de Corrida respectivamente. Observe que a partir da instanciação do objeto Tipo de Corrida dois novos objetos foram criados, o objeto Corrida Normal que possui um relacionamento entre os objetos: Carro Luxo Figueira e o objeto Diária Fechada, este último é o objeto generalização, da hierarquia de generalização criada a partir deste objeto. E por fim o último nível da hierarquia de classificação é ilustrando na Figura 70, a partir dos relacionamentos entre as instâncias dos objetos Carro Luxo, Diária Fechada e Figueira. Por meio do objetos Xp - 138, Plano A e Zé. As instâncias dos relacionamentos entre os objetos que possuem o tipo Corrida Normal, Carro Luxo e Santos também é ilustrado na Figura 70, por meio dos objetos Corrida -1, Xp - 138 e Carlos.

\section{Modelagem 1: Parte de um sistema de gerenciamento bancário}

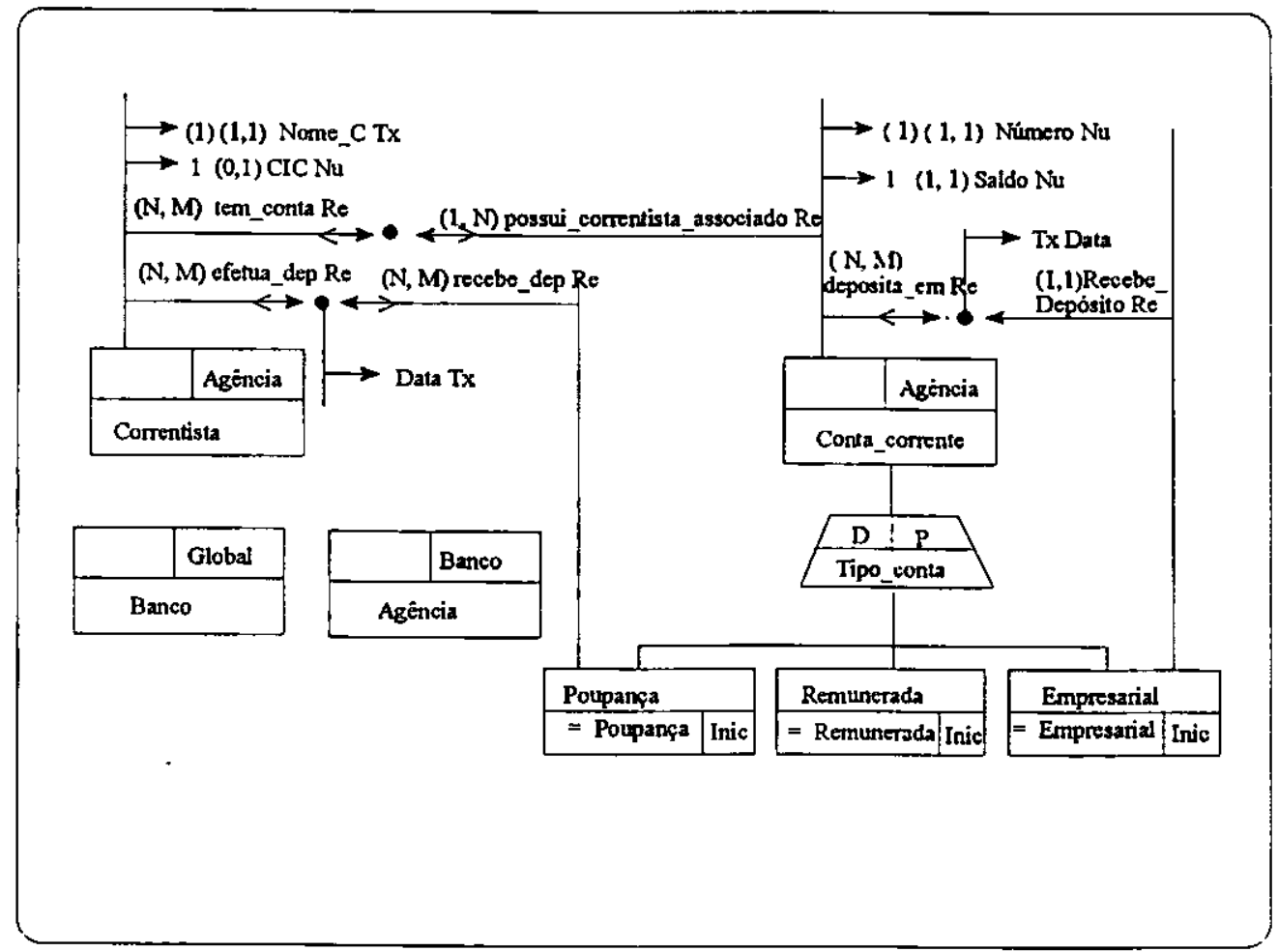

Figura 62) Sistema bancário (notação - SIRIUS) 


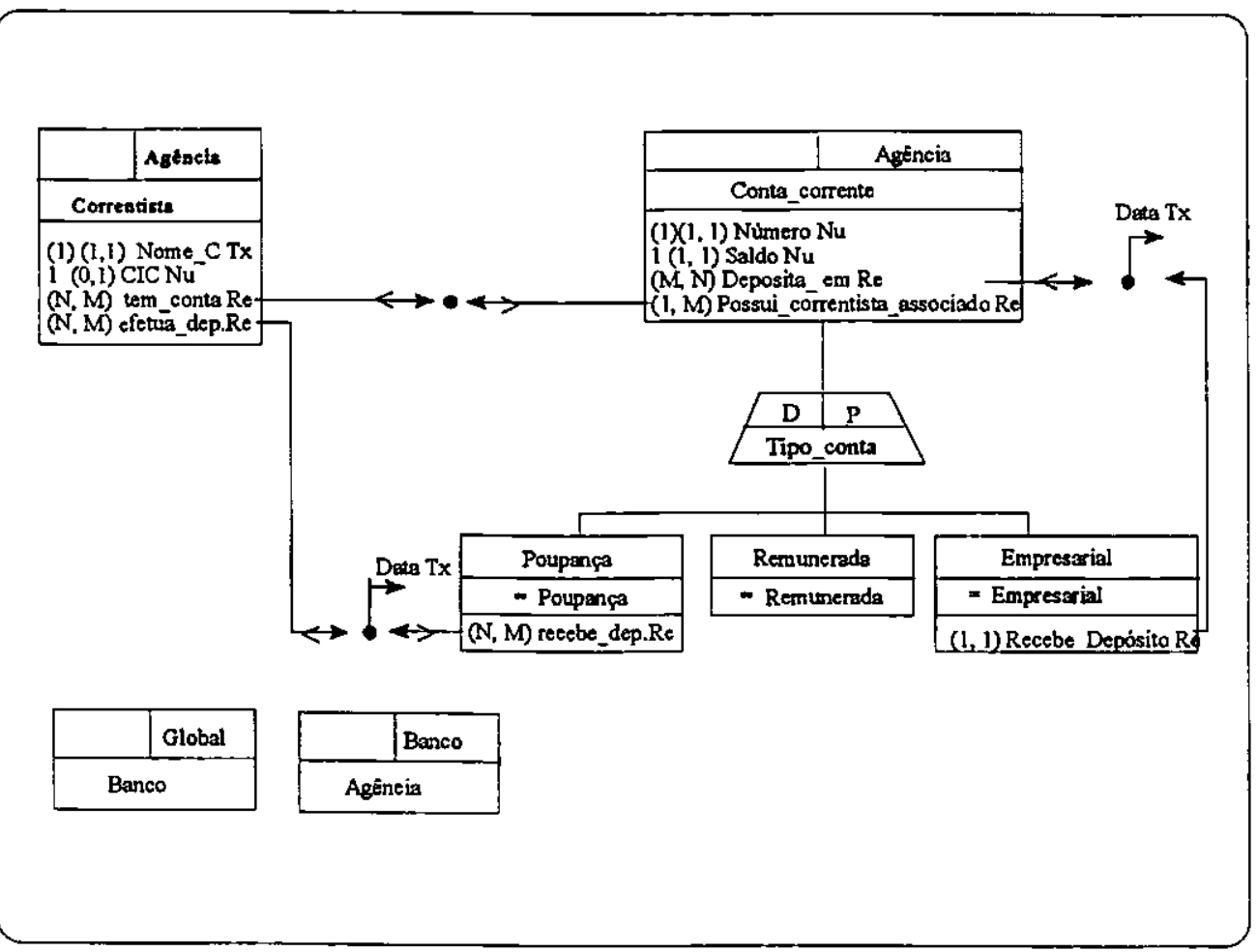

Figura 63) Sistema bancário (notação alternativa - SIRIUS)

\section{Modelagem 2: Parte de um sistema de gerenciamento de depósito de cargas}

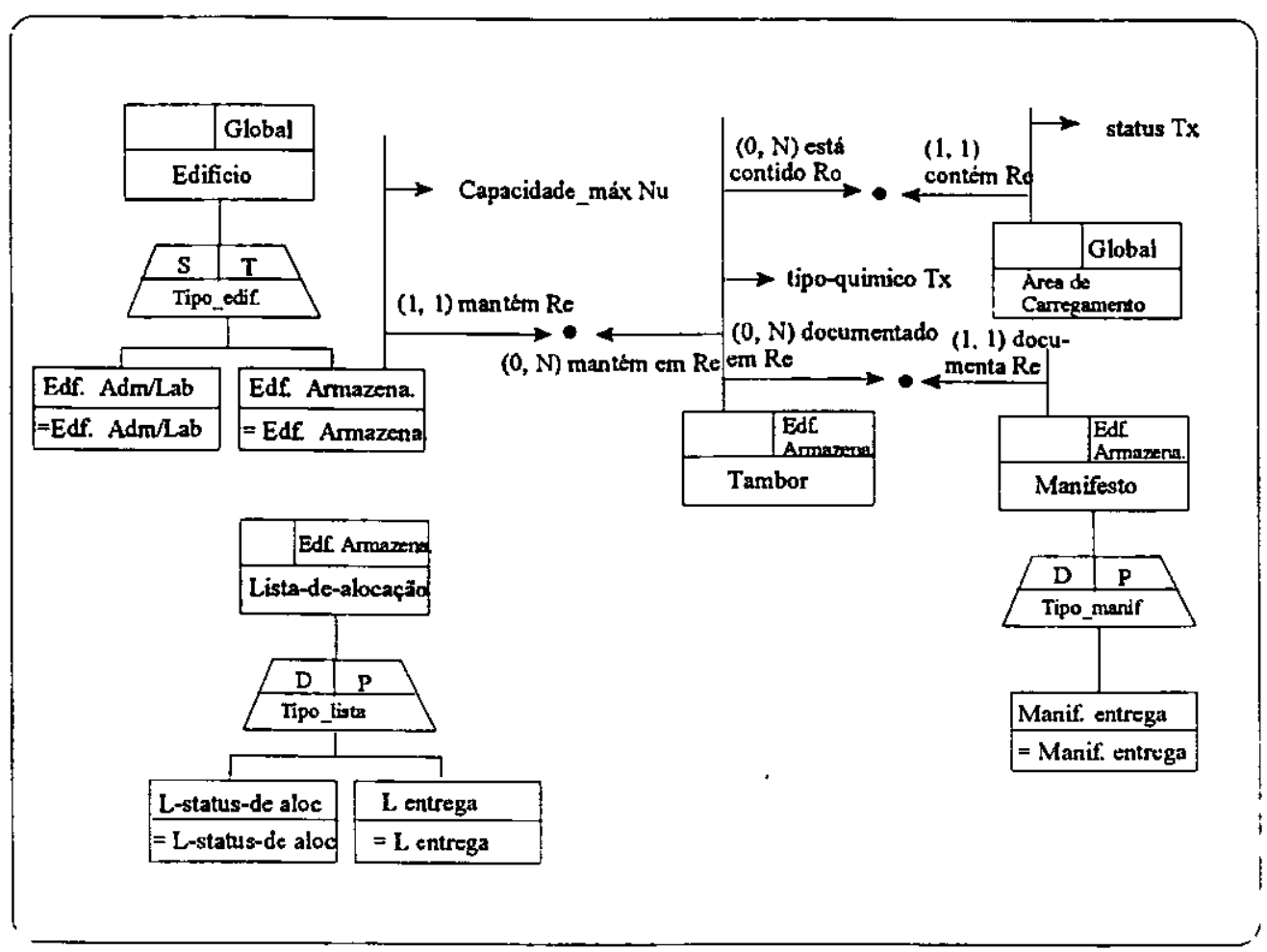

Figura 64) Sistema de gerenciamento de depósito de cargas (notação - SIRIUS) 


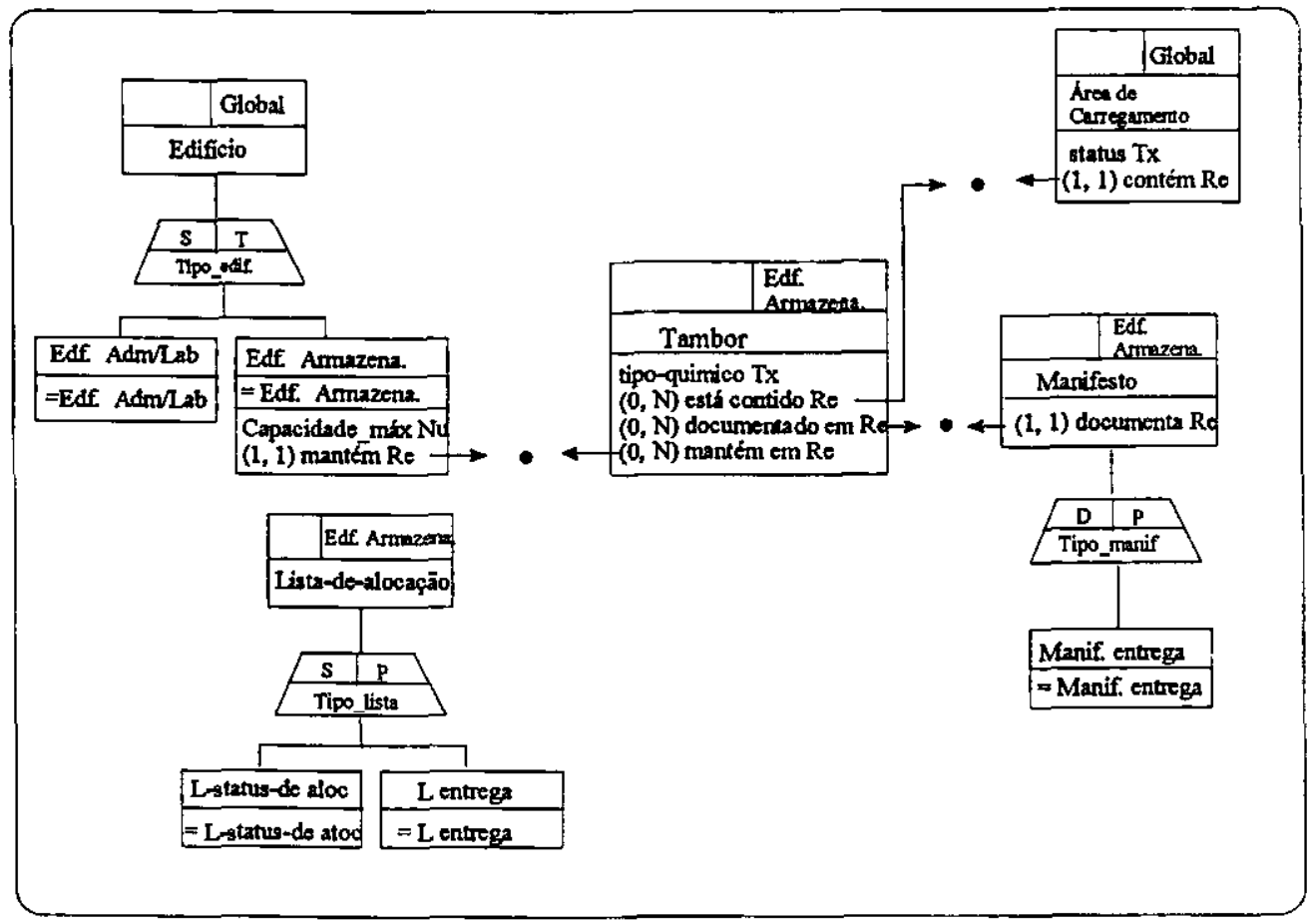

Figura 65) Sisterna de gerenciamento de depósito de cargas (notação alternativa SIRIUS)

\section{Modelagem 3: Parte de um sistema de gerenciamento de fitas em uma locadora}

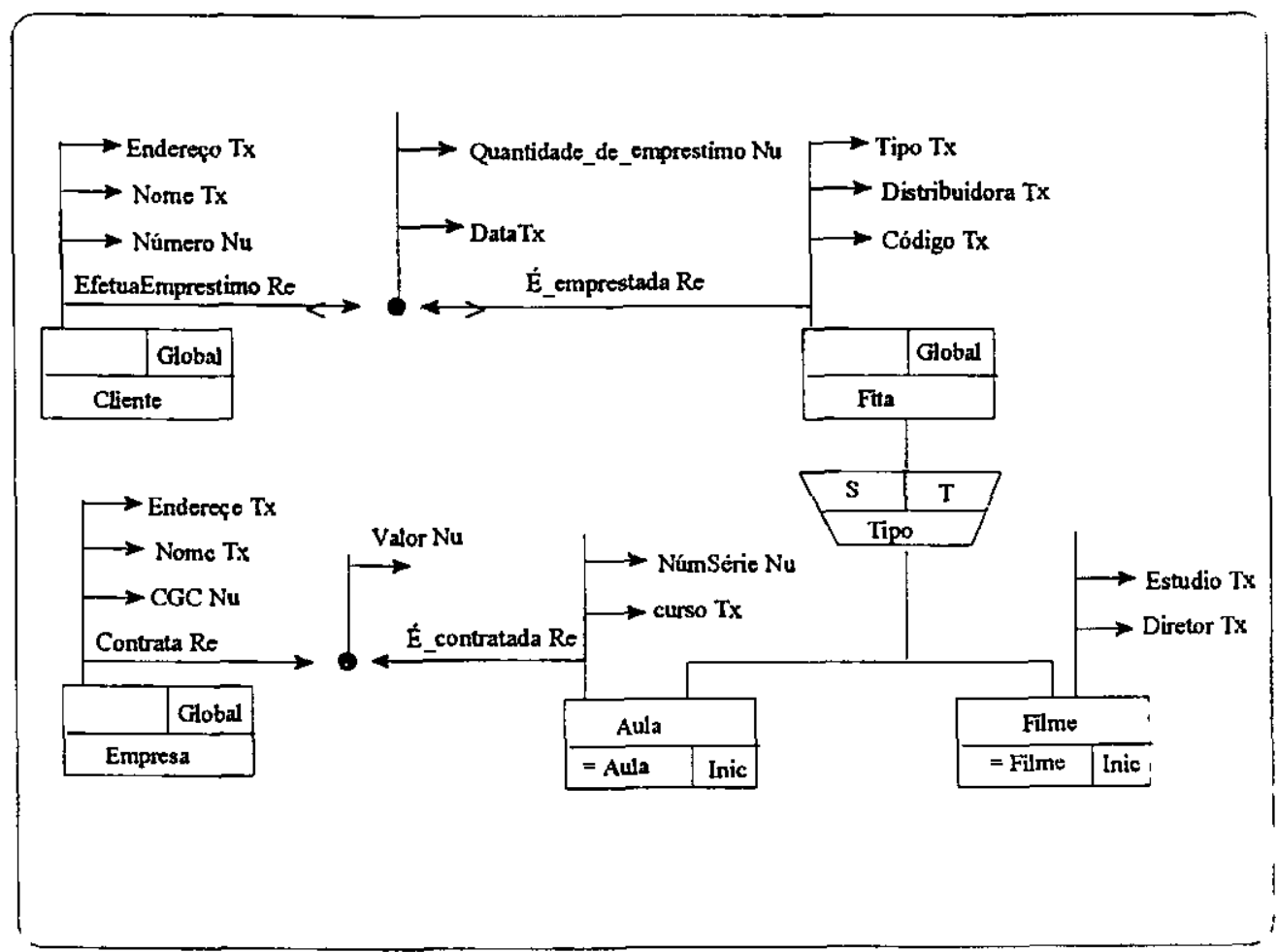

Figura 66) Sistema de gerenciamento de fitas em uma locadora (notação - SIRIUS) 


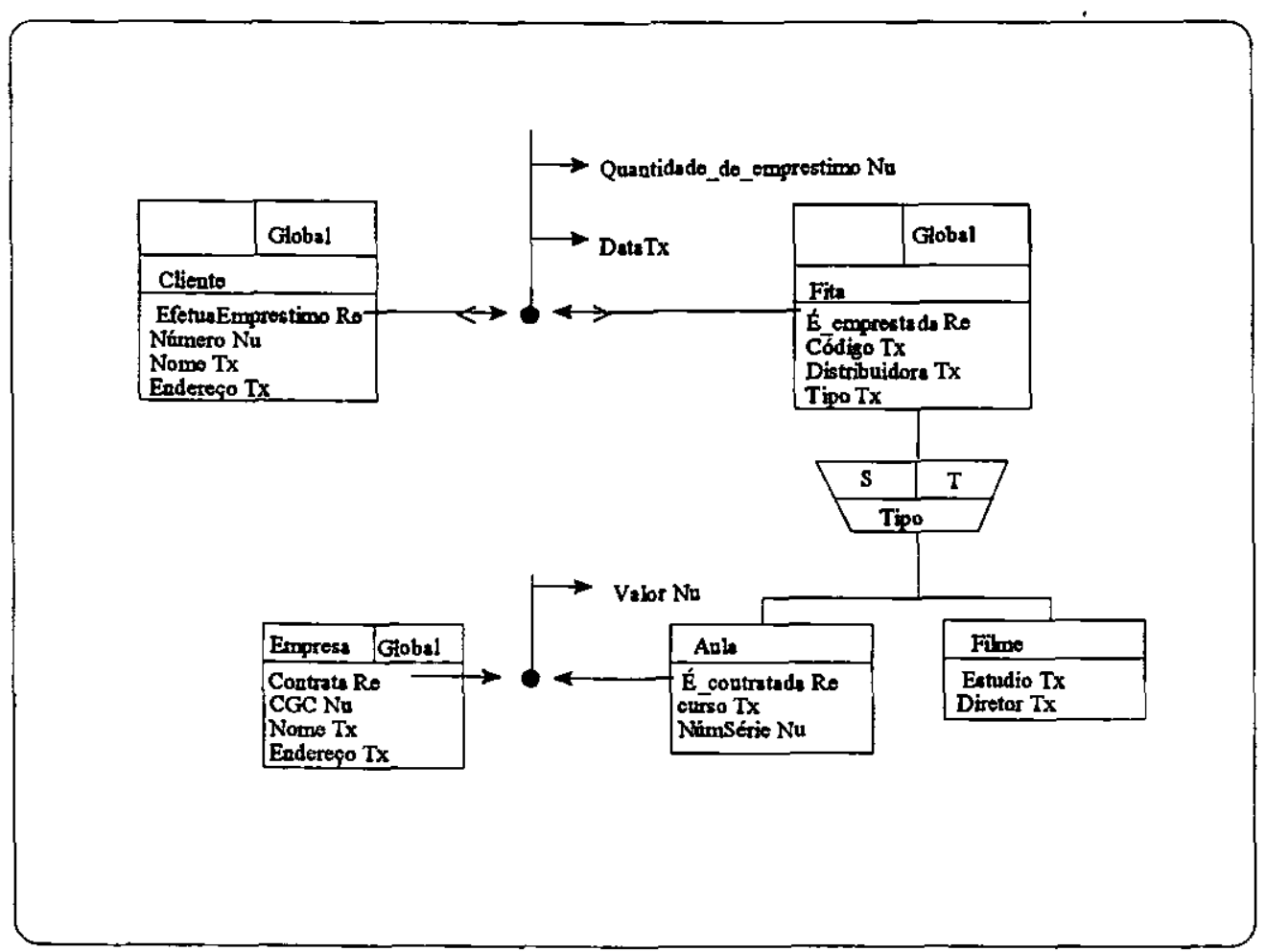

Figura 67) Sistema de gerenciamento de fitas em uma locadora (notação alternativa - SIRIUS)

\section{Modelagem 4: Parte de um sistema de empresas de aluguel}

O Sindicato de Empresas de Alugel da cidade determina que uma empresa pode definir diversos planos, tais como corrida de taxi normal, ou aluguel do veículo ern diária fechada, ou outros planos que toda empresa pode criar livrernente. Toda corrida deve sermpe corresponder a somente urn veiculo, e sempre deve ser feito por motorista da empresa. Toda corrida deve ter um custo e urna kilometragem total, que é repassada ao sindicato para coleta de tributos. Cada tipo de corrida oferecida por uma empresa deve ter também um índice de custo por kilomento para tributo, acordado entre o sindicado e a empresa. 


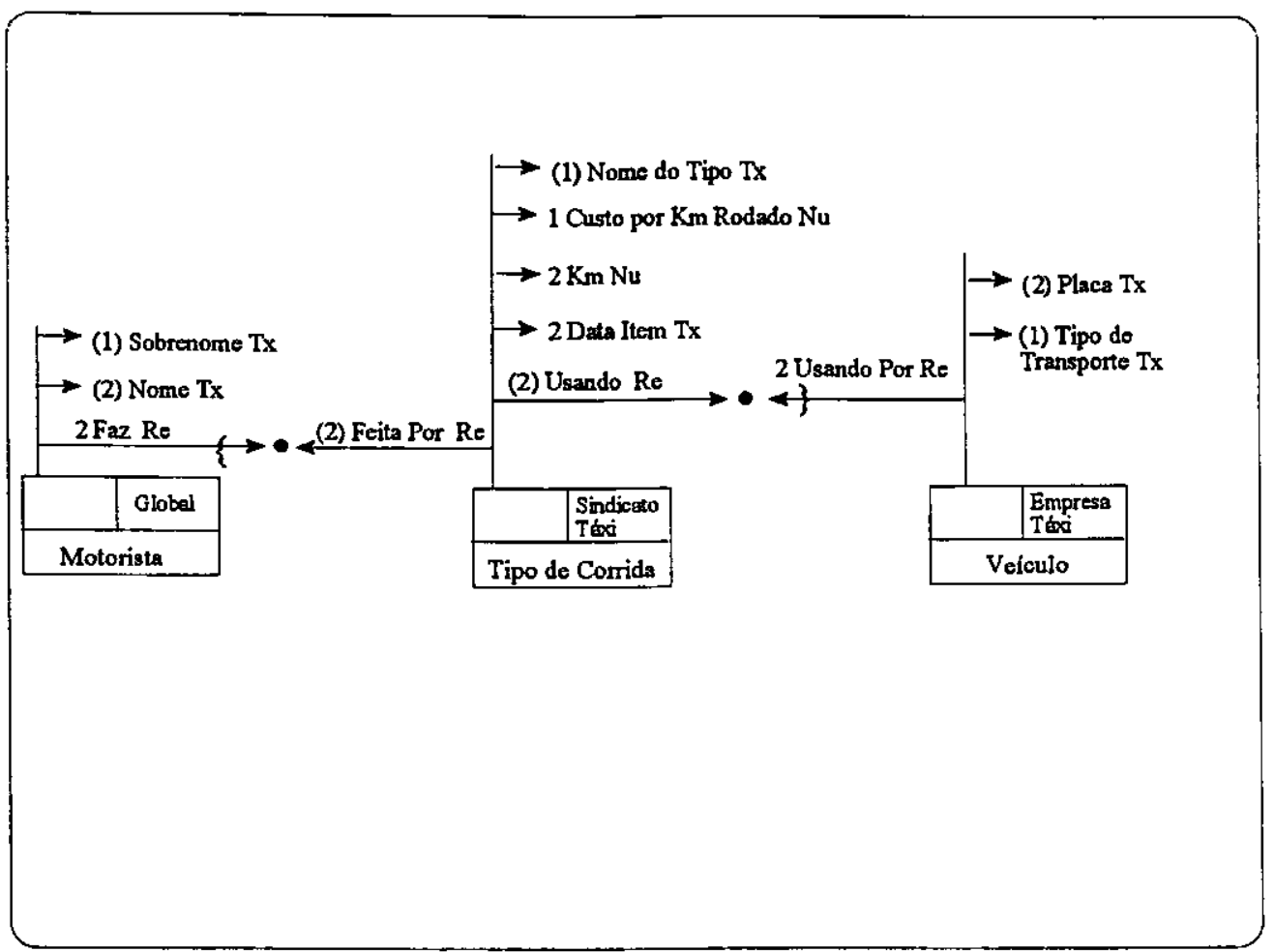

Figura 68) Sistema empresas de aluguel (notação - SIRIUS)

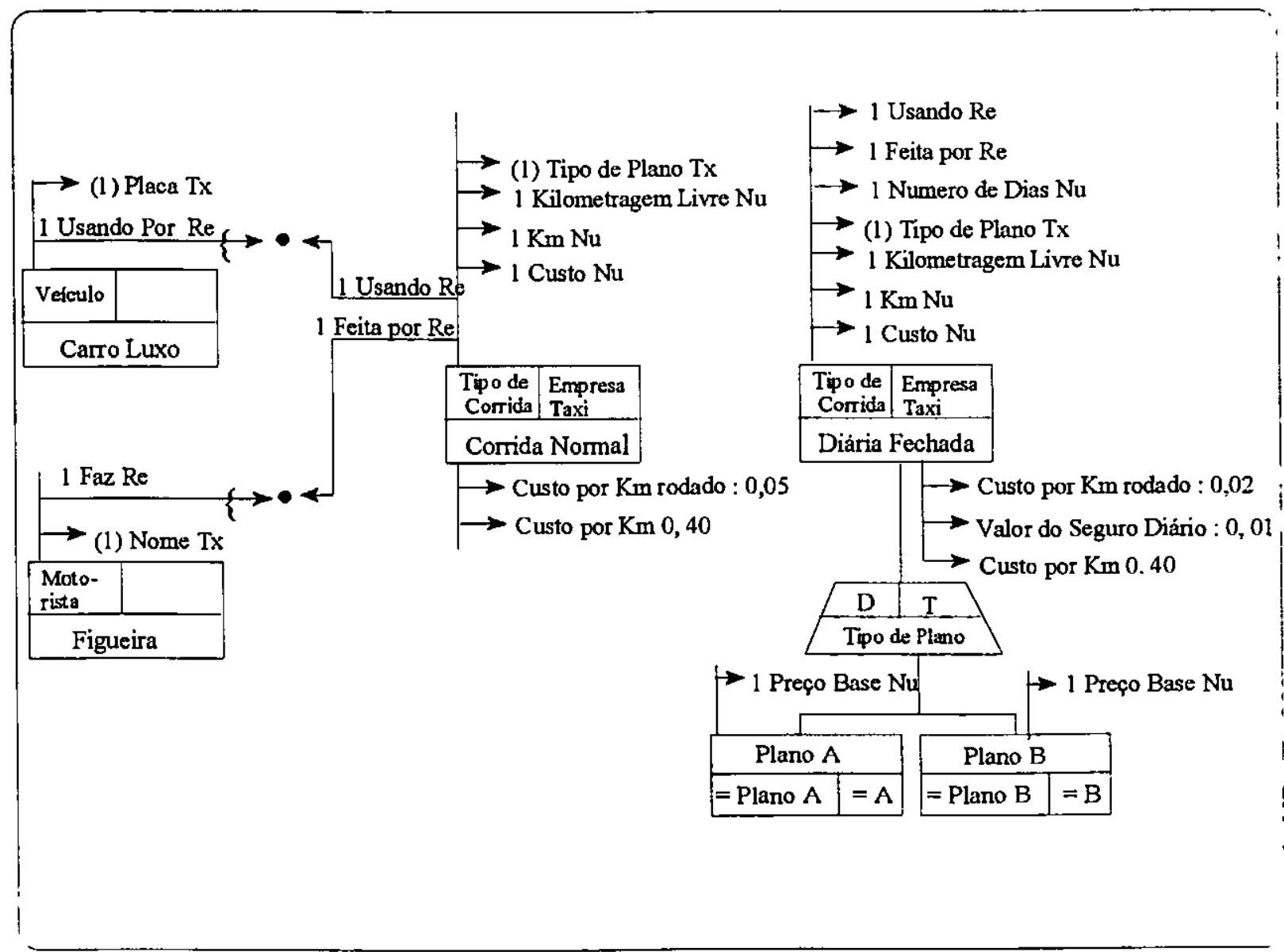

Figura 69) Sistema empresas de aluguel, primeiro nivel de instanciação (notação - SIRIUS) 

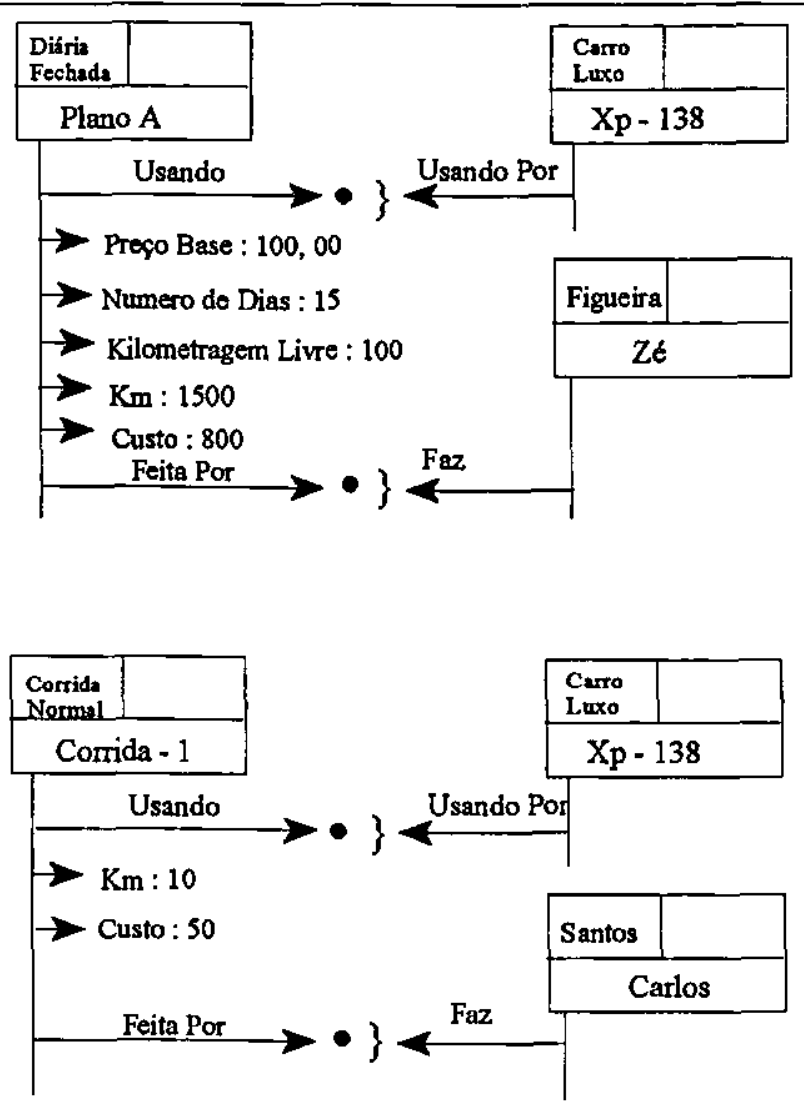

Figura 70) Sistema empresas de aluguel, segundo nivel de instanciação (notação - SIRIUS)

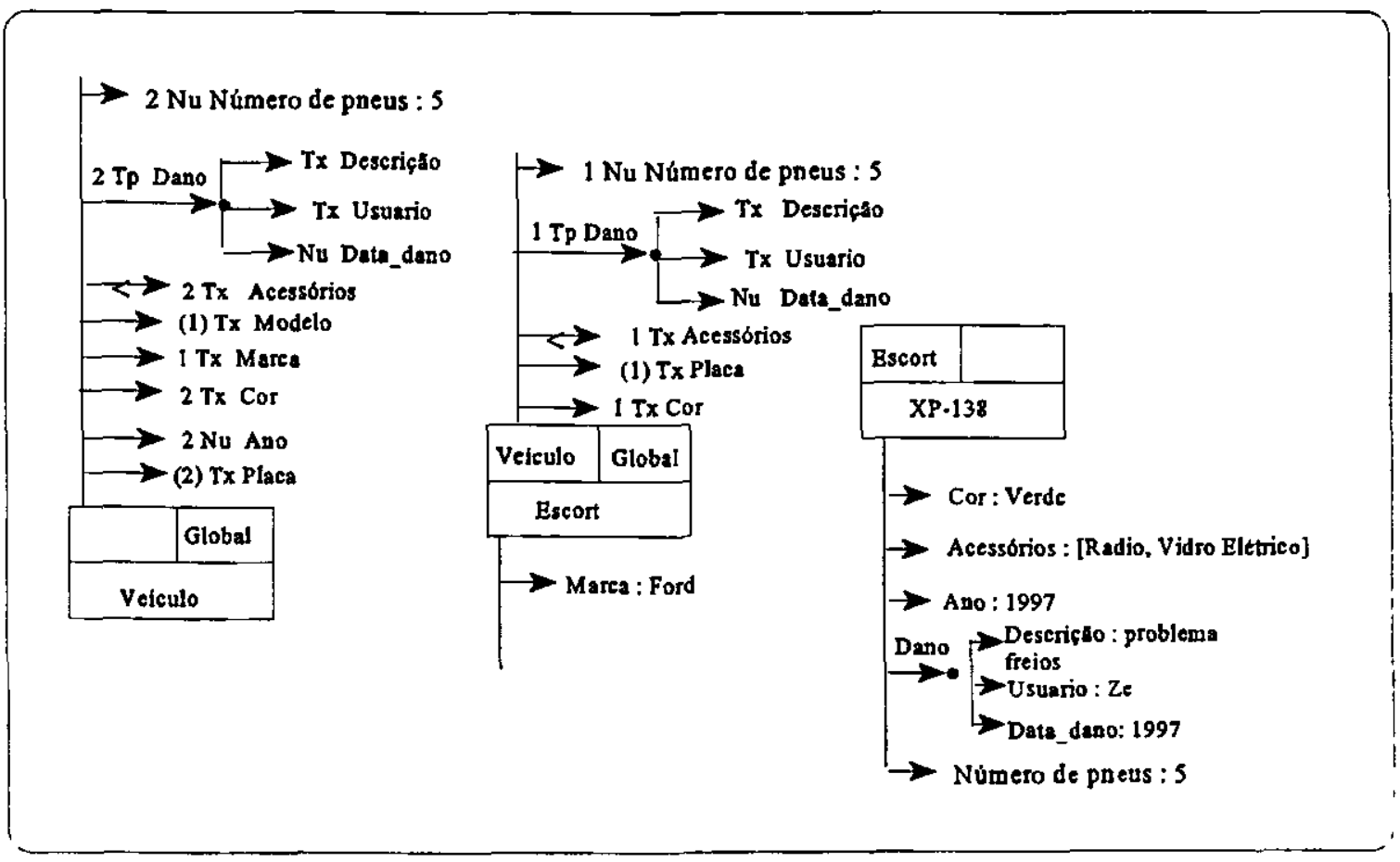

Figura 71) Abstrações de Classificação e Agregação 


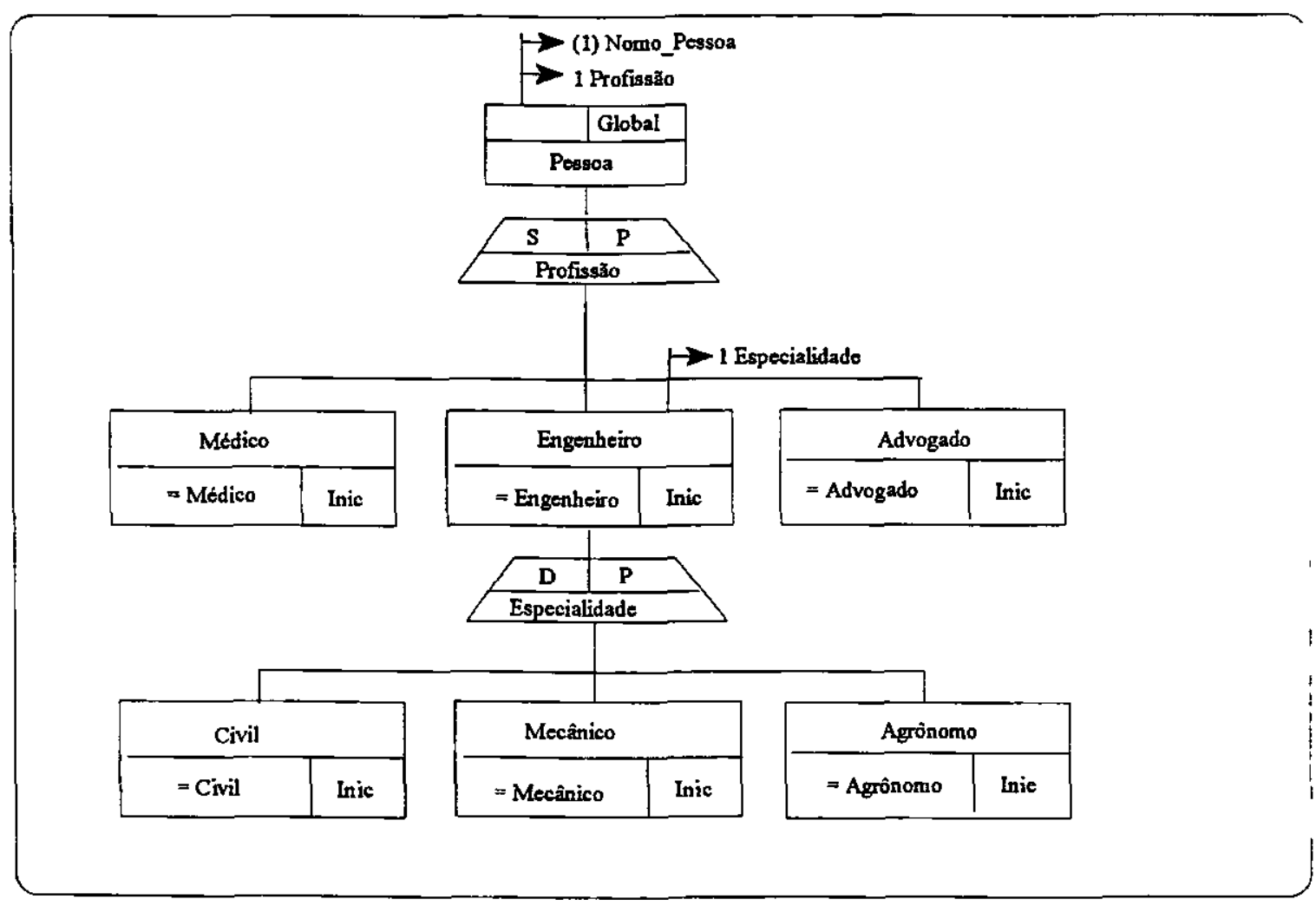

Figura 72) Abstração de Generalização

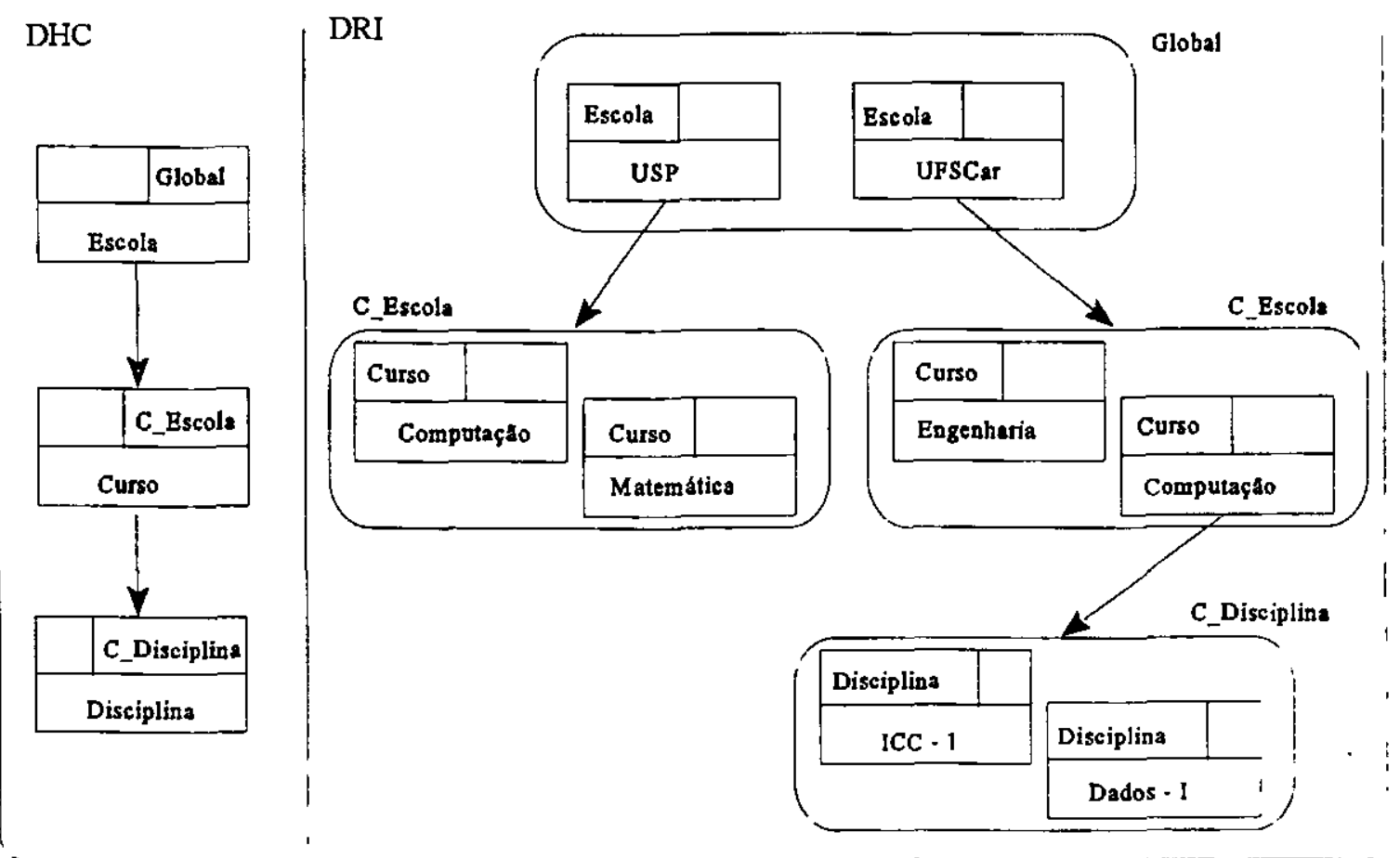

Figura 73) Abstração de Composição 


\section{Referências Bibliográficas}

[Abiteboul_87] Abiteboul, S.; Hull R. - "IFO: A Formal Semantic Database Model". ACM Transations on Database Systems, vol2.18, n우, pp. 525 - 565, December 1987.

[Araujo_98] Araujo, M. R. B; Traina, C. Jr - "Estudo Comparativo entre as Notações Adotadas em Diferentes Modelos de Dados para Representação de Abstrações e Construtores Semânticos”, Relatório Tecnico do ICMC, maio 1998.

[Araujo_98a] Araujo, M. R. B; Traina, C. Jr - "Editor de Esquemas com Suporte para Hierarquia de Classificação", enviado para XIII Simpósio Brasileiro de Banco de Dados, a ser realizado em Maringá, de 12 a 14 de outubro de 1998.

[Biajiz_92] Biajiz, M.; Traina, C. Jr - "MRO - Uma Atualização do Modelo de Representação de Objetos e Uma Abordagem Formal", Dissertação de Mestrado em Ciências da Computação ICMSC - USP, São Carlos julho 1992.

[Biajiz_96a] Biajiz, M.; Traina, C. Jr - "Representação de Modelos de Dados Orientados a Objetos através de Parametrização de Abstrações", Tese de Doutorado, apresentada ao IFSC - USP, São Carlos, setembro de 1996.

[Biajiz_96b] Biajiz, M.; Traina, C. Jr;; Vieira, M. T. P. - "SIRIUS - Modelo de Dados Orientado a Objetos e Baseado em Abstrações de Dados", $11^{\circ}$ Simpósio Brasileiro de Banco de Dados, São Carlos, 14 a 16 de outubro 1996.

[Booch_94] Booch, G. - "Object-Oriented Analysis and Design with Applications", The 
[Camolesi_96] Camolesi Jr, L.; Traina Jr, C. - "Um Modelo de Versões Apoiado em Objetos Compostos para Utilização em Instâncias e Esquemas de Bases de Dados Orientadas a Objetos", Tese de Doutorado arpesentada ao IFSC-USP, São Carlos, outubro 1996.

[Chen_76] Chen, Peter P. S. "The Entity-Relationship Model - Toward a Unified View of Data", ACM Transations no Database Systems, vol.1, $n^{\circledR} 1$, pp. 9 - 36, March 1976.

[Coad_93] Coad, P.; Yourdon, E. - "Projeto baseado em objetos", Editora Campus, 1993.

[Coad_96] Coad, P.; Yourdon, E. - “Análise baseada em objetos”, Editora Campus, 1996.

[Coleman_94] Coleman, D.; Arnold, P.; Bodof, S.; et al. - "Object-Oriented Development The Fusion method", Prentice Hall Object-Oriented Series, 1994.

[Elmasri_94] Elmasri, R.; Navathe, S. B. - "Fundamentals of Database Systems", Addison-Wesley Publishing Company, 1994.

[FigueiredoLR_97] Figueiredo, L. R.; Traina, Jr., C.; - "Uma Metodologia para Representação do Tempo em Modelos de Dados", Dissertação de Mestrado apresentada ao ICMSC-USP, São Carlos, novembro 1997.

[FigueiredoMB_97] Figueiredo, M. B.; Traina, Jr., C. - "Representação de Áudio em Banco de Dados", Dissertação de Mestrado apresentada ao ICMSC-USP, São Carlos, setembro 1997.

[Gazeta_97] Gazeta, W.; Traina, Jr., C. - "Estudo sobre a Representação de Estruturas de Atributos em uma Base de Dados Orientada a Objetos", Dissertação de Mestrado apresentada ao ICMSCUSP, São Carlos, outubro 1997.

[Gogolla_91] Gogolla, M; Hohenstein, U. - "Towards a Semantic View of an Extended EntityRelationship Model", TODS, 16:3, September 1991. 
[Gupta_91] Gupta, R.; Horowitz, E. - "Object-Oriented Databases with Applications to CASE", Networks, and VLSI CAD, Prentice-Hall, 1991.

[Hsu_93] Hsu, C. et al.. - "Metadatabase Solutions for Enterprise Information Integration Problems", Data Base, pp. 23 - 35, Winter 1993.

[Ishikawa_93] Ishikawa, H. et al. - "The Model, Language, and Implementation of an ObjectOriented Multimedia Knowledge Base Management System", ACM Transactions on Database Systems, vol.18, nํ1, pp. 1 - 50, March 1995.

[Kempe_95] Kempe J. et al. - "Benchmarking Object-Oriented Database Systems for CAD"”, Lectures Notes Computer Science, n²978, September 1995.

[Kim_89] Kim, W. et al. - "Feature of the Orion Object-Oriented Database System" in ObjectOriented Concepts, Databases, and Applications, Addison-Wesley, Reading, Massachusetts, 1989.

[Loucopoulos_94] Loucopoulos, P. (Ed.) - "Entity-relationship Approach - ER'94", Springer-Verlag Lecture Notes in Computer Science, 1994.

[Naja_95] Naja, H.; Mouaddib, N. - "The multiple representation in an architectural application", Lectures Notes Computer Science, nำ978, September 1995.

[Ruiz_94] Ruiz, D. D. A. - "Um Modelo para Representação de Atividades em Aplicações de Escritório", In 9 Simpósio Brasileiro de Banco de Dados, pp. 95 - 109, setembro 1994.

[Ruiz_95] Ruiz, D. D. A - "Generalização e Agregação de Atividades Conceitos Clássicos aplicados à Representação Dinâmica de Aplicações de Escritório", $\ln 10$ Simpósio Brasileiro de Banco de Dados, pp 229 - 224, outubro 1995.

[Rumbaugh_91] Rumbaugh, J.; et al. - “Object-Oriented Modeling and Design”, PrenticeHall. 1991 
[Smith_97] Smith, J.; Smith, D. - "Database Abstractions: Aggregation and Generalization", TODS, 2:2, June 1977.

[Santos_97] Santos, R. R.; Traina Jr, C. - "Incorporação do Tipo de Dado Imagem em um Banco de Dados Orientado a Objetos", Tese de Doutorado apresentada ao IFSC-USP, São Carlos, novembro 1997.

[Teorey_90] Teorey, T. - "Database Modeling and Design: The Entity-Relationship Approach", Morgan Kaufmann, 1990.

[Traina_86] Traina Jr., C. - "Máquina de Modelo de Dados Dedicados para Aplicações em Engenharia", Tese de Doutorado apresentada ao IFQSC-USP, São Carlos, dezembro 1986.

[Traina_91] Traina Jr., C.- 'GEO-Um Sistema de Gerenciamento de Bases de Dados Orientado a Objetos-Estado Atual de Desenvolvimento e Implementação", Anais do 60 Simpósio Brasileiro de Banco de Dados, Manaus, Am., 1991.

[Traina_92] Traina Jr., C.; Slaets, J. F. W. - "Um Modelo de Representação de Objetos", Notas do ICMSC-USP nํ104, São Carlos, fevereiro de 1992.

[Traina_96] Traina Jr. - "Sistemas de Banco de Dados Conceitos Gerais e Motivação", Notas de aula do curso de banco de dados, 1996.

[Traina_96a] Traina Jr, C.; Traina A - “Algoritmo para Criação e Gerenciamento de Identificadores de Objetos em um Gerenciador de Objetos", JAIO - 25으 Jornadas Argentinas de Informática e Investigacion Operativa, pp. $2.41-2.52$, Septiembre 1996.

[Weiser_89] Weiser, S. P.; Lochovsky, F. H. - "OZ+: An Object-Oriented Database Systems" in Object-Oriented Concepts, Databases, and Applications, Addison-Wesley, Reading, Massachusetts. 1989. 


\section{Referências via Rede}

[Borland_97] <http://www.borland.com > acessado em 15/1 1/97

[Inprise_98] $<\mathrm{http}: / / \mathrm{www}$.inprise.com/bcppbuilder $>$ acessado em 29/05/98

[Interbase_98] $<$ http://www.interbase.comr $>$ acessado em 30/03/98 


\section{Referências Auxiliares}

[ANSI_74] American National Standard Programming Language COBOL (ANS X3.23-1974). New York: American Nationa Standards Institute, 1974.

[ANSI_78] American National Standard Programming Language FORTRAN (ANS X3.9-1978). New York: American Nationa Standards Institute, 1978.

[Batini_92] Batini, C.; Ceri, S.; Navathe, S. B. - "Conceptual Database Design: An EntityRelationship Approach", The Benjamin/Cummings Publishing Company, Inc. 1992.

[Bertino_93] Bertino, E.; Lorenzo, M. - "Object Oriented Database Systems", International Computer Science Series, Addison-Wesley, 1993.

[Cattell_94] Cattell, R. G. G. - “Object Data Management”, Addison-Wesley Publishing Company, 1994.

[Cattell_95] Cattell, R. G. G. - "Object Databases and Standards", Lectures Notes in Computer Science, $\mathrm{n}^{\mathrm{Q} 940}$, pp. 1-11, 1995.

[Dahl_70] Dahl, O. J. ; Myhrhaug, B. et al. - "SIMULA 67 Common Base Language" Publication N. S - 22, Oslo: Norwegian Computing Center, Out., 1970.

[Darwen_95] Darwen, H.; Date, C. J. - "The Third Manifesto", SIGMOD RECORD, vol.24, nº̂1, March 1995. 
[Gupta_90] Gupta, U.; Gietz, W. - "Guia do Programador em SQL" - Rio de Janeiro Editora Campus, Fevereiro 1990.

[Hudson_89] Hudson, E. S.; King, R. - "CACTIS: A Self Adaptive, Concurrente Implementation of an Object-Oriented Database Management System", ACM Transaction on Database Systems, vol.14, $\mathrm{n}^{\ell} 3$, pp. 291 - 321, September 1989.

[Ingalls_78] Ingalls, D. H. "The Smaltalk-76 Programming System Design and Implementation" Conference Record of the $5^{\text {th }}$ Annual ACM Symp. on Principles of Programming Languages, pp. 9 - 16, January 1978.

[Jaeschke_95] Jaeschke, P.; Oberweis A.; Stucky, W. - "Deriving Complex Strutured Object Types for Business Process Modelling", Lectures Notes in Computer Science, n²81. Ed. Loucopoulos. ER'94 Entity Relationship Approach, pp. 28 - 45, 1995.

[Kernighan_78] Kernighan, B. W.; Ritchie, D. M. - "The C Programming Language" Englewood Cliffs, N. J., Prentice-Hall, 1978.

[Navathe_92] Navathe, S.B.- "Evolution of Data Modeling for Databases", Communications of The ACM, vol.35, n²9, pp. 112-123, September 1992.

[Papazoglou_95] Papazoglou, M. P. (Ed.) - “OOER'95: Object-Oriented and Entity-Relationship Modeling", Springer-Verlag, Lecture Notes in Computer Science, 1995.

[Preece_94] Preece, J.; Rogers, Y. - "Human-Computer Interaction", Addison-Wesley, 1994.

[Pressman_95] Pressman, R. S. - "Engenharia de Software", Makron Books, São Paulo 1995.

[Rosen_67] Rosen, S. - "Programming Systems and Languages", New York, McGraw-Hill, 1967.

[Sammet_69] Sammet, J. E. - "Programming Languages: History and Fundamentals" Englewood Cliffs, N.J., Prentice-Hall, 1969.

[Stonebraker_94] Stonebraker, M. - "Readins in Database Systems" second edition, Morgan Kaufmann Publishers, San Francisco, California, 1994. 
[Su_86] Su, S.Y.W. - "Modeling Integrated Manufacturing Data with SAM*", IEEE Computer, vol. 19, nํ1, pp. 34-39, January 1986.

[Traina_88] Traina Jr.; C. E Slaets, J.F.W.- "Um modelo de Representação de Objetos". In Anais do $3^{\circ}$ Simpósio Brasileiro de Banco de Dados, Recife, pp. 227-242, março de 1988.

[Vieira_91] Vieira, M.T.P.- "Um Modelo de Objetos para um Sistema de Gerência de Objetos em Ambientes de Desenvolvimento de sistemas Interativos", Tese de doutorado apresentada no Departamento de Informática, PUC - RJ, 1991.

[Wegner_80] Wegner, P. - "Programming with Ada: An Introduction by Means of Graduated Examples", Englewood Cliffs, N. J.: Prentice-Hall, 1980.

[Zand_95] Zand, M. Et ali - "A Survey of Current Object-Oriented DataBases" - DataBase Advances. vol. 26, nํ1, pp. 14-29, February 1995. 


\section{Errata da Dissertação}

Representação de Construtores

Semânticos em SIRIUS e

Suporte através de um

Editor de Esquemas

Myrian Renata Barros Araujo

Orientador

Prof. Dr. Caetano Traina Júnior

USP - São Carlos

Julho de 1998 
1. No texto da dissertação a referência [Biajiz_96] dever ser entendida por [Biajiz_96a].

2. Capítulo 2, final do último parágrafo na página 23, a sentença: 'significa que as classes subtipos são disjuntas, caso contrário’, deve ser desconsiderada.

3. Capítulo 3, página 38, a figura 22 deve ser substituida pela figura abaixo:

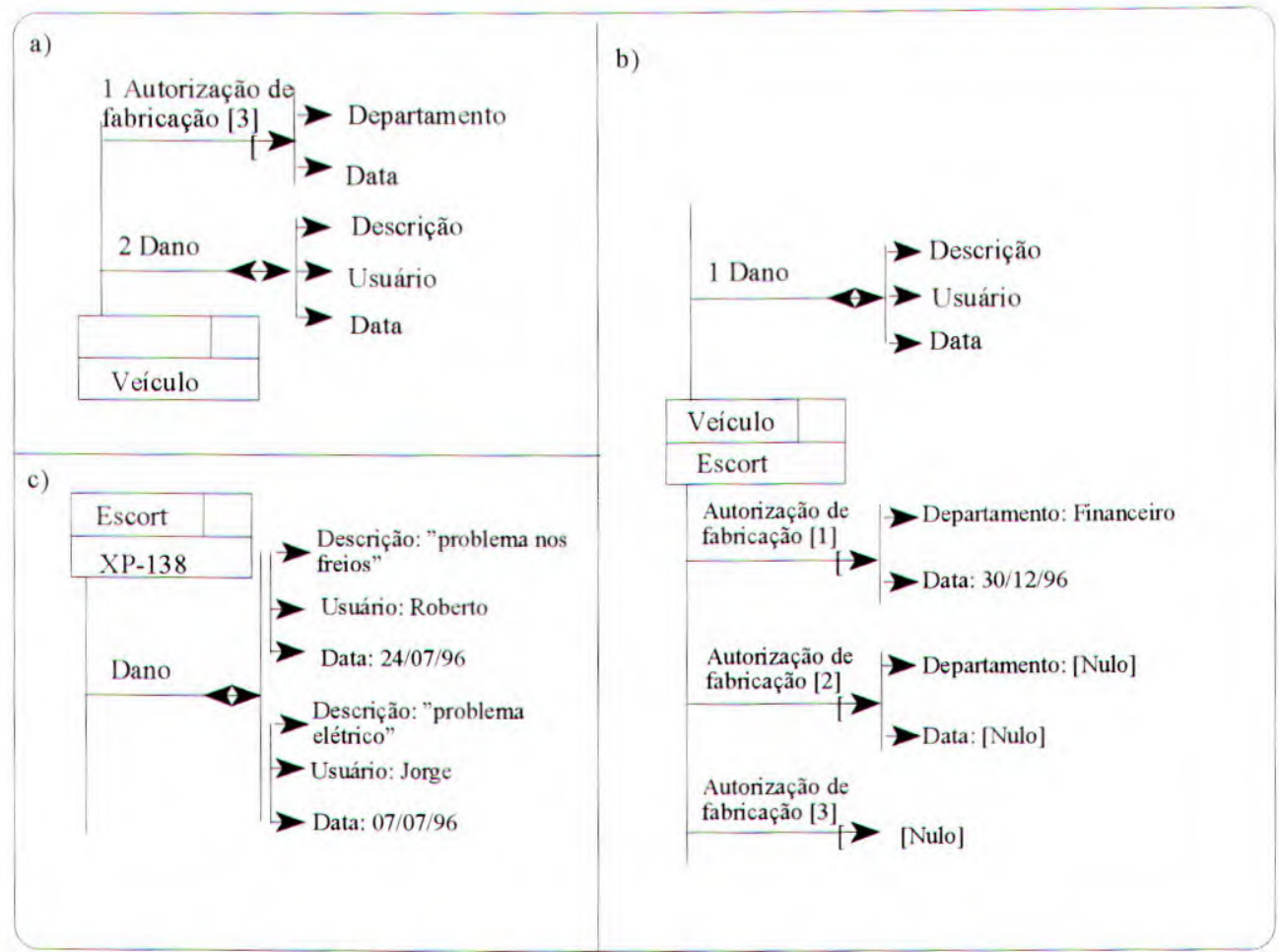

Figura 22) Exemplo de atributos multivalorados

4. Capítulo 3, página 40, a sentença: Na parte esquerda da linha, é colocado o critério para..... Substituir a palavra, critério pela palavra predicado.

5. Capítulo 3, final do último parágrafo na página 42 e início da página 43 , a sentença original deve ser substibuida pela sentença: No exemplo, estão representadas 4 colônias: a colônia Global, a colônia Tipo_veículo, a colônia Acessórios e a colônia Peças. As setas que partem do objeto Veículo em direção à colônia Tipo_veículo, do objeto Carro em direção à colônia Acessórios, do objeto Rádio em direção à colônia peças, representam o fato de que o objeto Veículo constringe a colônia Tipo_veículo, o objeto Carro constringe a colônia Acessórios e o objeto Rádio constringe a colônia Peças. 
6. Capítulo 5, figuras 30 e 32. Nestas figuras os atributos que são identificadores devem ser representados entre parênteses e não grifados. Em particular a figura 30, no objeto Montagem, deve ter os atributos Diretor_montagem e Data_montagem entre parênteses. Do mesmo modo a figura 32, no objeto Pedro, deve ter o subatributo, Nro Passaporte escrito entre parênteses. Em ambos os casos o emprego do parênteses é para diferenciar do conceito de chave (do relacional)

7. Capítulo 5, segundo parágrafo da página 71, a frase ${ }^{\prime}$...ou seja, um tipo que é tipo comum de todas as instâncias de um objeto...' , deve ser substituida pela frase '...ou seja, um tipo que é tipo comum de todas as instâncias das instâncias de um objeto.

Primeiro parágrafo, segundo item da página 72, 'objeto PedroII, 03-12-97 possui tipo Bruno Barreto, 01-12-97', e não simplesmente Bruno Barreto.

8. Capítulo 6, final do segundo parágrafo, página 104, na sentença: 'Quando o usuário clicar o botão (classificar), o objeto corrente.... . Esta sentença deve terminar na palavra Objetol. Deve-se ignorar o resto da sentença 'justamente o objeto tipo do objeto3'.

9. Capitulo 6, a figura 60 b) será melhor compreendida se o primeiro parágrafo página 110 , abaixo da figura 61 for substituido pelo parágrafo abaixo:

‘...mapeada por várias tabelas, entre elas as tabelas: objeto, Tipo Atributo, Vincula Atributo objeto e a tabela Característica Texto. Em particular pela coluna CodObj (da tabela objeto), que é referênciada pelas tabelas: Vincula Atributo objeto e Caracterítica Texto, sendo as duas últimas referênciadas pela tabela: Tipo Atributo (vide figura $60 \mathrm{~b}$ ).' 